Esther Breith off

CONFLICL,

HERIIAGEAND

WORLD-MAKINE

IN THE CHACO F

War at the End of the Worlds? 
Conflict, Heritage and World-Making in the Chaco 



\section{Conflict, Heritage and World-Making in the Chaco}

War at the End of the Worlds?

Esther Breithoff 
First published in 2020 by

UCL Press

University College London

Gower Street

London WC1E 6BT

Available to download free: www.uclpress.co.uk

Text (C) Esther Breithoff, 2020

Images (C) Author and copyright holders named in captions, 2020

Esther Breithoff has asserted her right under the Copyright, Designs and Patents Act 1988 to be identified as author of this work.

A CIP catalogue record for this book is available from The British Library.

This book is published under a Creative Commons 4.0 International licence (CC BY 4.0). This licence allows you to share, copy, distribute and transmit the work; to adapt the work and to make commercial use of the work providing attribution is made to the authors (but not in any way that suggests that they endorse you or your use of the work). Attribution should include the following information:

Breithoff, E. 2020. Conflict, Heritage and World-Making in the Chaco: War at the End of the Worlds? London, UCL Press. https://doi.org/10.14324/111.9781787358065

Further details about Creative Commons licences are available at http://creativecommons.org/licenses/

Any third-party material in this book is published under the book's Creative Commons licence unless indicated otherwise in the credit line to the material. If you would like to re-use any third-party material not covered by the book's Creative Commons licence, you will need to obtain permission directly from the copyright holder.

ISBN: 978-1-78735-808-9 (Hbk)

ISBN: 978-1-78735-807-2 (Pbk)

ISBN: 978-1-78735-806-5 (PDF)

ISBN: 978-1-78735-809-6 (epub)

ISBN: 978-1-78735-810-2 (mobi)

DOI: https://doi.org/10.14324/111.9781787358065 
To my parents Ly and Che 



\section{Contents}

List of figures viii

Acknowledgements xiii

Preface xvi

1. Introduction: War at the end of the worlds?

2. 'Sin vencedores ni vencidos': The Chaco and its forgotten war 28

3. Dwelling place, promised land and green hell? The many worlds of the Chaco 58

4. Trade, trash, treasure: Recycling conflict, making worlds

5. Ruins of modernity: Archaeology and heritage in the Chaco

6. Anthropocene hyperobjects: Persistent heritages beyond the Chaco War

References

Index 


\section{List of figures}

Figure 1.1 Map showing Paraguay and Bolivia and the disputed Chaco region. Major sites discussed in the text are also shown (Source: author).

Figure 1.2 The Trans-Chaco Highway connecting the Chaco with Asunción and the wider world (Source: author).

Figure 2.1 Bush landscapes typical of the Central Chaco (Source: author).

Figure 2.2 Military-indigenous encounters during the war (Courtesy of AIHMM).

Figure 2.3 Chaco Mennonites in the 1930s (Courtesy of GAKM). 39

Figure 2.4 Bolivian soldiers receiving instructions from their superiors (Courtesy of AIHMM).

Figure 2.5 Barefoot Paraguayan soldiers with mules carrying arms and equipment (Courtesy of AIHMM). 46

Figure 2.6 A Paraguayan soldier (Courtesy of AIHMM). 46

Figure 2.7 'Algarrobo Chaco Peace' mural under an Algarrobo tree in Villamontes, Bolivia, depicting Bolivian and Paraguayan military officials shaking hands over the truce made in 1935 under the very same tree (Source: author).

Figure 3.1 Sentry box made out of the hollowed-out trunk of a bottle tree at Fortín Isla Po'í (Courtesy of AIHMM).

Figure 3.2a Reconstruction of a hollowed-out bottle tree and 3.2b used as a sniper's hideout at Fortín Boquerón (Source: author).

Figure 3.3 Inscribed tin plate made by a lieutenant as a souvenir for his 'dear [female] friend' in the Museo Militar Asunción (Source: author). 
Figure 3.4 Tin mug with engravings of a rifle and possible fortín on its base at the Museo Mitológico Ramón Elias (Source: author).

Figure 3.5 Paraguayan official on the left holding a tin mug (Courtesy of AIHMM).

Figure 3.6 Oxen water carrier (Courtesy of AIHMM).

Figure 3.7 Original Ford Cuatro water carrier outside Museo Boquerón inside Fortín Boquerón (Source: author).

Figure 3.8 Paraguayan soldiers posing with a freshly excavated yvy'á (Courtesy of AIHMM).

Figure 3.9 Paraguayan soldier posing next to a well (Courtesy of AIHMM).

Figure 3.10 United by their struggle to survive. Paraguayan soldiers giving water to dying Bolivian troops on what came to be known as the picada de la dessperación (path of desperation) - a waterless stretch of land so dry that it is said to have claimed the lives of thousands of men (Courtesy of AIHMM).

Figure 3.11 Paraguayan soldier on the left enjoying some tereré with his comrades (Courtesy of AIHMM).

Figure 4.1 Bolivian soldier engraving a shell case (Courtesy of AIHMM).

Figure 4.2 Engraved shell case depicting soldiers operating a field gun (Source: author).

Figure 4.3 Detail of engraved shell case showing butterfly design (Source: author).

Figure 4.4 Engraved shell case showing solidarity between the two nations at war, as well as the fusion of the Paraguayan and Bolivian crests (Source: author).

Figure 4.5 Detail of engraved shell case depicting a machine gun and the name and date of the battle at Fortín Herrera (Source: author).

Figure 4.6 Detail of engraved shell case showing a Paraguayan sentinel with a tree in the background (Source: author).

Figure 4.7a Mennonite cowbells made from empty shell and 4.7b cases on display in Koloniehaus museum in Filadelfia, Colonia Fernheim (Source: author). 
Figure 4.8 Mennonite seeders made from metal debris and oil canisters from the Chaco War in Colonia Menno (Source: author).

Figure 4.9 Bell made from the wheel rim of a Chaco War military vehicle in a Mennonite village (Source: author).

Figure 4.10 Ayoreo pumpkin rattle with bullet attached to a string of natural fibre (Source: author).

Figure 4.11 Ayoreo belt with rattles made of recycled war metal (Source: author).

Figure 4.12 Ayoreo chisel made from Chaco War metal and telephone wire (Source: author).

Figure 5.1 La Chaqueña in the town centre of Puerto Casado (Source: author).

Figure 5.2 Bent railway track serving as decoration above a window (Source: author).

Figure 5.3 Skeletal frame of a railway carriage at the old Puerto Casado tannin factory (Source: author).

Figure 5.4 A los defensores del Chaco (To the defenders of the Chaco) war memorial in Puerto Casado (Source: author).

Figure 5.5 Paraguayan soldiers waiting on the railway tracks in Puerto Casado to start their journey into the heart of the Chaco (Courtesy of AIHMM).

Figure 5.6 Restored Mennonite well with the railway station house adapted for reuse in the background at Km 145 (Source: author).

Figure 5.7 Remains of train tracks and red-brick coal oven at Km 145 (Source: author).

Figure 5.8a Fortín Isla Po'í during the war (Courtesy of AIHMM).

Figure 5.8b A partly restored Fortín Isla Po'í in June 2013 (Source: author).

Figure 5.9 Rodeo Isla Po'í signboard depicting military officials shaking hands (Source: author).

Figure 5.10 Members of the Paraguayan military next to Marshal Estigarribia's bust and the bomb case memorial with the restored military mess in the background during the inauguration of the partially restored site in June 2013 (Source: author). 
Figure 5.11 Brick wall and wooden post remains of the field hospital at Fortín Isla Po’í (Source: author). 138

Figure 5.12a Overgrown cemetery in Fortín Isla Po'í in April 2013 (Source: author). 138

Figure 5.12b Cleared cemetery in June 2013 (Source: author). 139

Figure 5.13 Photograph of a bunker and trench taken during the war, location unknown (Courtesy of AIHMM).

Figure 5.14a Remains of a collapsed bunker at Fortín Toledo (Source: author).

Figure 5.14b Reconstructed bunker at the same site (Source: author).

Figure 5.15 Simple tombstone marking the shared grave of a Bolivian and a Paraguayan soldier, who had requested to be buried together (Source: author).

Figure 5.16 Close-up of a cross decorated with a ribbon in the colours of the Bolivian flag in the Bolivian cemetery (Source: author).

Figure 5.17 Reconstruction of command hut in Fortín Boquerón (Source: author).

Figure 5.18 Overgrown trenches surrounding Fortín Boquerón (Source: author).

Figure 5.19 Wooden cross outside the Museo Fortín Boquerón with the Ford Cuatro water truck in the background (Source: author).

Figure 5.20 Memorial in honour of the Paraguayan soldier (Source: author).

Figure 5.21 Trench being excavated at Fortín Nanawa (Source: author).

Figure 5.22 Eyelets from the excavation at Fortín Nanawa (Source: author).

Figure 5.23 Neglected monolito inside Fortín Nanawa (Source: author).

Figure 5.24 Remains of Bolivian tank inside Fortín Nanawa (Source: author).

Figure 5.25 Remnants of modernity inside Fortín Nanawa (Source: author).

Figure 5.26 Spent bullet cases and mortar fragments on the surface marking one of the riflemen's firing positions (Source: author). 
Figure 5.27 Metal splinter inside tree trunk (Source: author). 159

Figure 6.1 Detail from one of the walls in the Salón de

Bronce (Source: author).

Figure 6.2 Children re-enacting scenes from the Chaco

War during the Chaco Armistice Day parade

in Filadelfia, Colonia Fernheim, on 12 June

2011 (Source: author).

165

Figure 6.3 Military cemetery during the war. Location unknown (Courtesy of AIHMM).

Figure 6.4 Trébol cemetery (Source: author).

Figure 6.5 Remains of an original cross with a candle placed at its base, hidden in the bush at Fortín Gondra (Source: author).

Figure 6.6a Suspected mass grave with remains of wooden cross and metal debris in Fortín Gondra (Source: author).

Figure 6.6b Cardboard cross found at the base of the wooden cross remains in 2011 (Source: author).

Figure 6.7 Mennonite house with sheet-metal roof made of flattened oil canisters from the war (Source: author).

Figure 6.8 Butter churn with shell emblem on display in the Koloniehaus museum in Filadelfia (Source: author).

Figure 6.9 Baking tray with Shell emblem in the Geschichtliches Archiv Kolonie Menno in Loma Plata (Source: author). 


\section{Acknowledgements}

This book has been many years in the making, and drafts of it have travelled with me to London, where I was a Postdoctoral Research Associate at the UCL Institute of Archaeology (2016-18), followed by Troms $\varnothing$, where I was a Postdoctoral Fellow at UiT The Arctic University of Norway (201819), and finally back to London again where in May 2019 I accepted my current position as UKRI Future Leaders Fellow/Lecturer in Contemporary Archaeology and Heritage at Birkbeck, University of London. The book, and the dissertation on which it draws, would not have been possible without the help of many people. First and foremost, I would like to thank my $\mathrm{PhD}$ supervisors at the University of Bristol, Nicholas Saunders and Volker Heyd, for their continuous support and advice. Nick, and his innovative approach to the material culture and landscapes of conflict, has been a constant source of inspiration since my days as an MA student at the University of Bristol. Special thanks also go to Alfredo González-Ruibal, whose influential work on the archaeologies of conflict has had a major impact on my own research, for being a generous $\mathrm{PhD}$ examiner and offering invaluable advice on how to improve the thesis. I am also grateful to the Fonds National de la Recherche Luxembourg for kindly funding my research (2012-15) and to Banco Santander for awarding me the Santander Travel Grant for Research in Latin America in 2011 and again in 2013.

In Paraguay I would like to say a very special thanks to Ruth Alison Benítez de Casanova, who not only went out of her way to make things happen for me but has also become a valued friend in the process. Your passion for archaeology is contagious! I would also like to thank the Secretaría Nacional de Cultura, the Fuerzas Armadas de Paraguay, the Archivo del Instituto de Historia y Museo Militar del Ministerio de Defensa Nacional and all the people who contributed in one way or another to my research. I am particularly indebted to my many new Paraguayan friends, with whom I had great conversations over countless rounds of tereré.

In the Chaco I extend my sincere gratitude to the indigenous communities, war veterans and the Mennonite colonies of Fernheim, Menno and Neuland for their warm welcome and for sharing their memories 
with me. I am especially thankful for the continuous support of Hans Fast, Heinz Wiebe, Gundolf Niehbur, Uwe Friesen and Hans Boschmann over the years. Hans F.'s and Heinz's knowledge of the Chaco is inexhaustible, and it was both a great privilege and an adventure to learn from them. I would furthermore like to thank Verena Regehr for giving me access to her private collection of indigenous objects and Peter Toews for granting me access to his private museum and property. Thank you also to the RC1 Valois Rivarola military division in Pozo Colorado for putting soldiers and transport at my disposal during my fieldwork in Nanawa, as well as the landowners for letting me conduct research on their property. For their friendship and hospitality, I would like to thank Mary Esther Sawatzky, Elisabeth Niehbur and Erika Dück.

Further north on the map, my warmest thanks go to Jane Kimball for inviting me into her home in New Mexico to study the Chaco War shells from her incredible trench art collection. Regrettably Jane has since passed away and I dedicate Chapter 4 to her memory.

Even further north I would like to extend my gratitude to my Unruly Heritage team at UiT The Arctic University of Norway, especially Bjørnar Olsen and Torgeir Bangstad for commenting on a draft of the introduction. Thank you also to Póra Pétursdóttir, Geneviève Godin, Anatolijs Venovcevs and Stein Farstadvoll for inspiring team discussions during my time as Postdoctoral Fellow in Troms $\varnothing$. Many thanks also to Tina Paphitis for travelling all the way to the Arctic and giving up her time to make insightful comments on the introductory chapter.

In Denmark and the UK, I would furthermore like to thank Laura McAtackney and James Dixon for taking the time to read through the historical background chapter in my $\mathrm{PhD}$ and for all their helpful suggestions - many of which have made it into Chapter 2 in this book. I am also grateful to Sue Grice for lending me her map drawing skills in Chapter 1. I would like to thank the postdoctoral researchers of Room 613 at the UCL Institute of Archaeology, especially Chiara Bonacchi, Peter Schauer and Colin Sterling, for exciting discussions on heritage-related issues during my time there as Postdoctoral Research Associate. Here I would also like to extend my thanks to my Heritage Futures team. Having been part of this ambitious project has undoubtedly informed and inspired the framework of this book. I would also like to thank Gabriel Moshenska, Matthew Leonard, Emily Glass, John Winterburn, Phil Rowe and Neil Faulkner for numerous stimulating conflict archaeology-related discussions both over pints in Bristol and London, and inside trenches and tent rings in the Jordanian desert. 
I am grateful for my colleagues at my new institutional home in the Department of History, Classics and Archaeology at Birkbeck, University of London, whose warm welcome and supportive environment have allowed me to finish this book. Special thanks go to Kat Hill for her helpful comments on Chapters 2 and 3, and Jennifer Baird for insightful suggestions that helped me improve the text.

At UCL Press I would like to thank Chris Penfold and Robert Davies for guiding me through the publication process and for all the work they have put in to get this book published. I would also like to express my gratitude to the two anonymous reviewers for their encouraging feedback and helpful comments on the manuscript.

As always, I would like to say a heartfelt thank you to my parents and sisters for all their unwavering support and love. I would also like to give a huge thanks to Liam McKervey for having the patience of a saint during the years of my $\mathrm{PhD}$. Thank you for listening, reading and talking things through with me, and for flying out to Paraguay to experience the Chaco together.

Last but not least, a special thanks goes to Rodney Harrison for the many thought-provoking conversations and discussions, and for reading over and commenting on multiple drafts of this monograph. Thank you for not only being an inspiration but above all a wonderful friend. 


\section{Preface}

The Chaco War (1932-5), fought between Paraguay and Bolivia in the heart of South America, has left numerous physical and emotional traces. Academic research, however, has thus far primarily concentrated on the war's military (Farcau 1996; Zook 1960) and social and political histories (Chesterton 2013, 2014). Within this body of literature, the various ethnic minorities affected by the conflict are rarely mentioned (except see Nobbs-Thiessen 2018; Langer 2016; Capdevila et al. 2010; Harder Horst 2010; Richard 2008a) and the material cultures and landscapes generated by the conflict and its aftermath are largely ignored (except see Breithoff 2012, 2013, 2015, 2016, 2017). This book represents the first archaeological-anthropological study of the Chaco War and as such looks at the conflict and the people involved through the material culture of war, defined broadly as encompassing a range of sources including objects, battlefields, buildings, memorials, archival material and landscapes. I draw on approaches from archaeology, anthropology, material culture studies, critical heritage studies and environmental humanities to explore the complex entanglements between people, objects, nature and time during and after the Chaco War in Paraguay, focusing on the material culture and landscapes created by armed conflict and its aftermath. In their struggle to survive in the inhospitable Chaco bush, various groups of indigenous people, soldiers and Mennonites were forced to innovate with limited resources as they confronted each other in bitter conflict between 1932 and 1935. The aim of this book is to describe and analyse the complex and entangled relationships that developed between humans, things, landscapes and time during the conflict and its aftermath, and to explore the ways in which these hybrid assemblages have acted and continue to act together to produce conflicting and coexistent worlds. In doing so, I argue that the Chaco War and its physical remains are not static relics of the past, but are firmly embedded within the present, and continue to act in formulating and reformulating current and future worlds. In light of this, I treat Chaco War sites and 
material cultures as living, fluid entities that have not become but are always becoming through the collaborative processes in which they are engaged with and by other human and non-human actors. Today these physical remains of the war, together with contemporary commemoration practices, constitute an integral and persistent component in the formation of Paraguayan national identity.

The book draws on research undertaken for my doctoral dissertation on 'Conflict Landscapes of the Chaco War', for which I was based in the Department of Archaeology and Anthropology at the University of Bristol and for which I received the University's 'Best Doctoral Research Thesis' award for the Faculty of Arts in 2016, and the 'Outstanding PhD Thesis' award for Excellence in Science and Research by the Fonds National de la Recherche Luxembourg (Luxembourg National Research Fund) in 2017. The empirical material it presents derives from several years' challenging fieldwork carried out in the Paraguayan (and to a lesser extent Bolivian) Chaco, and in Santa Fe, New Mexico, between 2011 and 2013. Fieldwork in Paraguay was undertaken over two five-week and one threemonth periods. I divided my time between Asunción, Paraguarí and the Mennonite colonies in the Chaco, with most of my overall time spent in the Chaco. One week was spent in Villamontes, Bolivia. I also travelled to Santa Fe, New Mexico, where I spent ten days studying a private collection of Chaco War trench art. To the best of my knowledge, this is the only large collection of Chaco War trench art in existence and my work provides the first ever scholarly examination of these objects (see also Breithoff 2016).

This fieldwork aimed to explore a number of related research questions. How did the indigenous people, Mennonites and soldiers engage with the Chaco landscape and its natural resources and how did the Chaco in turn shape their personal and collective understandings of the place? What impact did the recycling of war matériel have on people? How does an ontological approach to objects provide new insights into twentiethcentury industrialised war? What traces of this past persist in the present, and how do they interact with human and non-human actors today?

This study represents the first ever attempt to examine the Chaco War from an archaeological-anthropological perspective. I immediately encountered an overwhelming volume of previously unstudied materials and sources - including written sources, photography, artefacts, landscape settings, battlefields, buildings and memorials. This forced me to be selective both in the materials I would investigate and the questions I would ask of them. Additionally, although the Chaco landscape is dotted with historical sites that date to the period of the war, accessing them is difficult and potentially hazardous. The Chaco region remains 
underdeveloped and isolated as there are no paved roads past the town of Mariscal Estigarribia in Paraguay to the Bolivian border. The various indigenous and Mennonite villages are linked by dirt roads that run a high risk of flooding, and often become impassable during the rainy season. The lack of proper roads, the difficulty of the terrain and minimal signage thus mean that access to sites is a challenge and generally impossible without the knowledge of a local guide. Because of this, and financial, logistical and time restrictions, I decided to limit my investigations to Paraguay and, apart from a short trip to the town of Villamontes across the border, did not explore any site in the Bolivian part of the Chaco. Thus, all sites investigated and discussed in Chapter 5 are situated in the modern-day Paraguayan Chaco. Most of these sites are located on private property, and others are placed within Kolonieland (land owned by one of the Mennonite cooperatives) or military-owned land. This frequently made access to sites impossible and restricted both the choice and number of potential case studies. Furthermore, the lack of infrastructure in the whole of the Chaco, coupled with the fact that a large number of historical sites are situated on private estancias (ranches) to which access is often prohibited, makes a complete recording of every site virtually impossible. The impenetrable character of the Chaco bush adds to the difficulty of recording whole sites. Official permission to carry out my investigation was granted by the Ministry of Culture in Asunción. All case study sites in Chapter 5 were selected based on questions of historical relevance, accessibility, distance of travel, state of preservation and safe access.

In addition to accessing sites, I encountered a number of other challenges in undertaking this research. The underdevelopment of the archaeological field in Paraguay and the general indifference towards archaeological heritage meant that the work required significant selfmotivation and persistence, as logistical and intellectual support from governmental institutions was limited. I also experienced some difficulties with accessing archival sources. Militarised sites are contested spaces with 'secretive qualities' attached to them, which makes assessing information about them a challenge and frequently difficult if not impossible (Woodward 2005, 730; Pearson 2012b, 118). During my fieldwork in Paraguay I was given restricted access to the Archivo del Instituto de Historia y Museo Militar del Ministerio de Defensa Nacional (Institute of History and Ministry of Defence Military Museum Archive, AIHMM) in Asunción. Unfortunately, due to the lack of a reference system and archive structure, storage details on specific documents cannot be provided. The military archives' chaotic state made it furthermore impossible to establish the richness or evaluate the extent of its collection on the Chaco War. 
Extreme climatic and geological conditions make the Chaco a potentially hazardous place to do fieldwork. During my research in Fortín Nanawa, Ruth Alison Benítez de Casanova, my colleague from the Secretaría Nacional de Cultura (National Ministry of Culture), and I were accompanied by two armed soldiers of the Paraguayan army for our protection from the Chaco wildlife - pumas, jaguars, caymans and wild boars are all native to the area. The Chaco is also a narcotics smuggling route from Bolivia and home to drug lords and their armed guards. Trespassing onto unknown property is therefore strictly advised against. There are also significant cultural, religious and practical constraints for solo female researchers working in the region, which needed to be carefully negotiated and evaluated during my periods of embedded fieldwork.

Paraguay is the only country in Latin America that classifies both Spanish and an indigenous tongue - in this case Guaraní - as its official languages. In the Mennonite colonies German is considered the official language, followed by Spanish and the Mennonite Plautdietsch (Low German) dialect. The multi-ethnic composition of Paraguay's various communities is matched by the plurilingual nature of the written documents, which are generally in Spanish, German and French. My fluency in German, Spanish and French has allowed me to access and read most sources in their original language. Any translated quotes and citations are my own personal translations, unless indicated otherwise. All interactions with members of the Latino community, official institutions and the military were carried out in Spanish, while communication with members of the Mennonite colonies was carried out in German. Many older Mennonites only speak Plautdietsch but due to the strong similarities between the Low German and Luxembourgish languages, translators were seldom needed when dealing with the occasional written source in the Mennonite dialect. On the rare occasions Guaraní was required, I used the help of a local Guaraní speaker or online dictionaries.

Studies of modern conflict sites come with a particular set of ethical, moral and political challenges as they may involve the excavation of human remains (Steele 2008) and/or the recording of oral histories and the contested personal and communal memories attached to them (Moshenska 2008a, 2009; González-Ruibal and Moshenska 2015; Harrison and Breithoff 2017). The research drawn on in this book was evaluated by the University of Bristol Faculty of Arts Research Ethics Committee and adhered to the university's policies on governance and research ethics. This work was also undertaken in accordance with local regulations, customs and approvals in Paraguay. All participants gave informed consent for their contributions to the study and were given 
access to check the use of quotes and opinions attributed to them. Where participants are named, consent was obtained to do so. Research permission and access to carry out a small-scale excavation at the site of Fortín Nanawa in collaboration with Ruth Alison Benítez de Casanova from the Departamento de Arquelogía y Paleontología within the Secretaría Nacional de Cultura and the RC1 Valois Rivarola military division in Pozo Colorado was sought from the Secretaría Nacional de Cultura, military authorities and the landowners.

Where people in the author's personal photographs are named, permission was granted for their reproduction. Authorisation was also given to reproduce images from the Archivo del Instituto de Historia y Museo Militar del Ministerio de Defensa Nacional (National Institute of History and the Military Museum of the Ministry of Defence Archive, AIHMM) and the Geschichtliches Archiv Kolonie Menno (Colony Menno Historical Archive, GAKM).

\section{Structure of the book}

Chapter 1 introduces the book and its conceptual framings. It explores the idea of conflict as world-making, unmaking and remaking, and shows how a focus on conflict material culture and heritage particularly reveals such processes and their entanglements. It argues that the material and discursive legacies of modern industrialised conflict constitute a form of Anthropocene hyperobject - a massively distributed viscous material assemblage which persists in time and space and which continues to remake worlds in the present. It argues the relevance of ontological and sensorial approaches to conflict material cultures, landscapes and heritages, and outlines the methodological approaches taken to the empirical research which is presented in the book.

Chapter 2 examines the historical background to the Chaco landscape, the people involved in the war and the conflict itself. It begins with a brief overview of the flora and fauna and climate of the Chaco region before turning its focus to the potential reasons behind Paraguay and Bolivia's decision to go to war over a seemingly empty stretch of land. The chapter then proceeds to the introduction of the various human actors involved in the conflict, starting with the indigenous groups that have lived in the Chaco for centuries before turning to the newly arrived Mennonite communities, followed by a description of the Bolivian and Paraguayan soldiers. In a last section the chapter provides an overview of the war and outlines its major battles and outcomes, before considering 
the historiography of the war and the ways it has been remembered by historians to the present.

Chapter 3 investigates the different lifeworlds that collided in the Chaco War. While the indigenous people might be said to have shared an intimate and collaborative relationship with the Chaco, the Mennonites and soldiers saw it as a threatening 'wilderness' that needed to be tamed and appropriated by the use of a plough and rifle, respectively. In this chapter I focus on how the indigenous people, the Mennonites and the soldiers each perceived and engaged with the Chaco in different ways and how the bush and people's understanding of it shaped their personal and collective experiences. I then discuss the soldiers' struggle to survive in relation to hunger and thirst and the natural resources available to them. Focusing on their physical and sensorial experience of thirst, I analyse how the lack of water heightened and reconfigured the soldiers' sensorial realities as an example of the alternative worlding practices which each different assemblage of people, places and objects enacted during the war.

Chapter 4 explores objects and their interactions with people and the Chaco landscape. In the first part of the chapter I consider the ways in which objects mediated wartime relationships, focusing primarily on the trade that flourished between Mennonites and soldiers. In the second part, I focus on the material excess or rubbish generated by the industrial war in the Chaco by examining examples of military, Mennonite and indigenous recycling practices in the context of 'trench art'. I first examine the decoration of artillery shell cases during the war as the embodiment of particular kinds of wartime material and social relations. I then explore Mennonite trench art to demonstrate the recycled object's potential to transcend its original purpose. In the final part of the chapter I discuss objects recycled from war debris by Ayoreo indigenous people. I argue that an engagement with Ayoreo ontologies in relation to such objects challenges modern definitions of time, objects and 'the human', and provides a means by which to helpfully trouble the concept of trench art in so far as it has been deployed in archaeology, anthropology, heritage and material culture studies.

Chapter 5 presents an account of the archaeology and heritage of the militarised landscapes of the Chaco War. In the first part of the chapter I consider the armies' militarisation efforts and their dependence on natural resources, focusing on the role of the conflict in making, unmaking and remaking the landscape of the Chaco. I then introduce and discuss three main types of conflict sites found within the Chaco: war-related sites, fortines and cemeteries. Puerto Casado and Km 145 act as examples of war-related sites, showing how the transformation of the 
Chaco was not limited to the sites of battlefields in the landscape. The fortines Isla Po'í, Toledo, Boquerón and Nanawa (and associated cemeteries) are subsequently described and discussed as examples of forts or military outposts that have undergone various degrees of restoration and heritagisation.

Chapter 6 considers the contemporary afterlives of the Chaco's conflict landscapes and material culture as 'heritage' and how the war's material and discursive legacies continue to remake worlds in the present. I then return to this book's contention that an archaeological approach to the Chaco War matériel, its making and unmaking of alternative worlds, and its afterlives as archaeology and heritage helps us to understand global industrialised conflict as an Anthropocene hyperobject. I conclude with some comments on the future research directions opened up by this work, which aims to connect current discussions of global anthropogenic change with the study of conflict archaeology and heritage more generally. 


\section{1 \\ Introduction: War at the end of the worlds?}

The Chaco War between Paraguay and Bolivia (1932-5) has been called the bloodiest armed conflict of twentieth-century South America and is known as the continent's first 'modern' war (De Quesada with Jowett 2011, 3). This book draws on approaches from archaeology, anthropology, material culture studies, critical heritage studies and environmental humanities to document and interpret the physical remains of the conflict and its afterlives. Adopting Bjørnar Olsen et al.'s definition of archaeology as 'the discipline of things' (Olsen et al. 2012), it focuses not on archaeological remains as conventionally understood, but on heterogeneous assemblages of objects and landscapes shaped by industrial war and people's past and present engagements with them. Such objects could be understood to constitute a 'dark heritage', the debris of a failed modernity (González-Ruibal 2006a), which in some cases have been discarded and then recollected and recycled, and in other cases abandoned and left to decay - perhaps because such things are too painful to hold onto, but more often simply because they have lost their original function and are thus deemed redundant (e.g. Pétursdóttir and Olsen 2014). And yet it is clear that such objects are not simply dead memorials to this bloody war, but have been, and continue to be active in making, unmaking and remaking worlds - both for the participants of the war itself, and for those who continue to occupy and live amongst the war matériel which persists in the present.

Archaeological and anthropological approaches to material culture are helpful in engaging with the distribution of different forms of agency across these vibrant and often unruly heterogeneous assemblages, which include both human and other-than-human actors, and in recognising the ways in which their pasts are contained within, and continually remade in their presents (Olivier 2004). To study such assemblages in the present 
thus acknowledges the dynamic and manifold relationships between humans, non-humans and the collectives they form, as well as their agency in assembling new pasts and futures in the present (Harrison 2011).

\section{Worlds and world-making in the Chaco}

I use the plural term 'worlds' in the title of the book intentionally. I do so not only to signal an exploration of modern industrialised conflict, and its material and discursive legacies, as both world-making and unmaking, but also to acknowledge the ways in which its worldings are multiple, co-existent, contrasting and often conflicting. Taking an ontological approach to the conflict, its material culture and its material and discursive legacies as 'archaeology' and 'heritage', I draw on current discussions in anthropology, science and technology studies and the social sciences more generally, which suggest that worlds (in the plural) are generated and held together by the inter- and intra-actions of human and non-human assemblages (e.g. Barad 2007; Escobar 2010, 2012; Conway and Singh 2011; de la Cadena and Blaser 2018; Omura et al. 2019; Querejazu 2016). In doing so, I aim to show how the conflicts that catalyse around the material culture of war do not simply represent differences between worldviews, but rather conflicts between and across very different lifeworlds. I proceed from the assumption that we do not live in what the sociologist John Law $(2015,126-7)$ refers to as a dominant 'one-world world', a 'single container universe' or 'space-time box' with 'a single all-encompassing reality'. Law argues that instead of dealing 'with matters of belief - different people believing different things about one hegemonic reality or world - we are dealing with 'matters of reals'- different realities as 'process', not stories, that are performed and enacted through different practices (Law 2015, 126-8, original emphasis). I am also influenced by the anthropologist Eduardo Viveiros de Castro's $(1998,2004 a, 2004 b)$ concept of multinaturalism or ontological perspectivism, which posits the existence not only of different representations of the world, but different worlds and, by extension, different truths and realities that operate simultaneously and independently of one another but that often overlap and interrelate. Acknowledging and taking seriously these conflicting and often contrasting modes of worlding that make up the 'pluriverse' (Escobar 2012; Blaser and de la Cadena 2018 ) is a critical step towards the decolonisation of the single universal truth of the 'one-world world', which Blaser and de la Cadena argue is 'a world that has granted itself the right to assimilate all other worlds 
and, by presenting itself as exclusive, cancels possibilities for what lies beyond its limits' $(2018,3)$.

Within the context of the Chaco and its war, these different and often contrasting worlds cannot be simply divided into indigenous versus western realities. In fact, there was no clear cut between western and indigenous cosmologies as Bolivian and Paraguayan lifeworlds were already hybrid. The Aymara and Quechua soldiers from the Bolivian Altiplano - and to a lesser extent the Paraguayan Guaraní mestizo - were firmly embedded within a Christianised society but retained many of their indigenous beliefs and practices. Some of the indigenous groups inhabiting the Chaco had already had significant contact with outsiders, forming syncretic and hybrid belief systems and practices (Harder Horst 2006, 2010). Each also differed in their beliefs and practices from one another (see for example Miller 2001 and Blaser 2010). Nevertheless, there are enough similarities in the lifeworlds which indigenous groups in the region occupied and created, and such strong contrasts with those of the Mennonites and military groups, that it is helpful to consider them here collectively. Worlds, like those of the different indigenous groups, Mennonites and soldiers, are continuously made and remade through the interactions of human and non-human entities. People, animals, plants, rocks, streams, theories and practices all constitute integral and entangled parts of the unceasing processes of assembling, disassembling and reassembling multiple co-existent realities in which human, animal and spiritual worlds are each entwined, and the concept of linear time is challenged and often erased (e.g. Escobar 2010, 2012). By focusing on conflicts between and across worlds, I argue that conflict landscapes and material culture form particularly important empirical materials through which to engage in a more general project of an ontologically informed anthropology of the otherwise (Povinelli 2012). By this I mean to engage with these different conflicting worlds as arrangements or assemblages of people, places and things which are made and unmade continually and actively by both their actualities and possibilities, and in which past, presents and futures are imminent and integrally bound together.

\section{Modern industrialised conflict as Anthropocene hyperobject}

I frame the study more generally as an exploration of modern, industrialised warfare as Anthropocene 'hyperobject'. I borrow this term from the philosopher Timothy Morton (2013), who defines hyperobjects as 
massively globally distributed material phenomena and their component parts - such as climate change, or plastic wastes. Throughout the book, I aim to show some of the ways in which the archaeology, material culture and heritage of modern conflict point to precisely this kind of planetary ubiquity in their distribution across the surface of the earth, and beneath its surface, fusing together objects and people and connecting them physically and conceptually across vast, almost unimaginable distances and multiple time periods. If the time of the hyperobject can be defined as the 'Anthropocene' - the proposed contemporary geological epoch in which humans became the primary force of planetary climatological, ecological and geological change - the emergence of modern industrialised conflict must be understood as integral to defining, and comprehending, the Anthropocene and its 'Great Acceleration' (McNeill and Engelke 2014) in which the rate of impact of human activity on planetary systems can be demonstrated to have dramatically increased. But I aim to do so in a way that does not simply emphasise human actions in these changes, but instead draws on the approaches of Karen Barad (2007) in looking to the intra- and interactions of heterogeneous assemblages of humans and non-humans in investigating these phenomena. Here I also aim to take up Donna Haraway's $(2015,2016)$ challenge to decentre the human in our understanding of the Anthropocene, drawing attention to the ways in which all species, including humans, are themselves functioning assemblages of multiple species. The book thus offers a unique perspective on understanding 'natural' environments, practices of recycling and concepts of time through the material legacies of war - practices, places and objects that encompass and co-create pasts and futures, but which remain firmly and stubbornly embedded in their present(s).

While much of the current discussion of the Anthropocene has focused on late modern hyperobjects as artefacts of universal human worlding practices - waste, climate, radionuclides - I argue that the artefacts of globalised industrial war, and indeed the materialisations of co-existent and conflicting worlding practices which are embedded within these materials, are also central to understanding the Anthropocene (or perhaps more accurately, Anthropocenes). Here I contend that the concept of the Anthropocene poses three challenges which my discussion of conflict heritage as (plural) Anthropocene hyperobject aims to address:

1. The Anthropocene assumes a universal experience - like climate change, it is often said that the collective human 'we' are 'all in it together' (see e.g. Adeney Thomas 2016). But power is distributed unequally; people (and things) have different capacities to act 
and have been involved in the production of the 'human' planet in different ways (contra Chakrabarty 2009; see Boscov-Ellen 2020; González-Ruibal 2018a, 2018b; Moore 2015).

2. If we are to acknowledge the existence of multiple worlds, then we may also need to acknowledge multiple Anthropocenes, and the possible existence of alternative worlds in which different sets of ecological relations are more or less important (Haraway 2015, 2016). The idea of multiple realities disrupts the universalism of the concept of the Anthropocene in a range of ways that bear further consideration.

3. The notion of the Anthropocene is itself inherently anthropocentric and contains within it a series of truth claims about human exceptionalism - precisely the same as those it purports to critique - about the separation of humans and nature/things, by firmly establishing humans as the primary force of ecological, geological and climatological change on the planet, whilst also setting up a false nostalgia (e.g. Dibley 2012, 142) for a time when humans were somehow separate from nature and did not impact the environment, a time which never really existed (see e.g. Lewis and Maslin 2018).

Given that the Anthropocene is a stratigraphic designation, there is ongoing debate about when this epoch 'began', and how the 'golden spike' which is said to define and designate the end of one epoch and the beginning of another geologically can be defined in relation to it (see Ellis 2018). While there is significant discussion, particularly amongst archaeologists (see Ellis et al. 2013; Edgeworth et al. 2015, 2019; and a range of views in Edgeworth et al. 2014), of the need to think of much longer trajectories leading towards the contemporary conditions which are seen to define the Anthropocene, especially the development of agriculture and its impact on climate, many commentators suggest that the Anthropocene and its accompanying ecological and geopolitical effects should be seen as beginning around 1945 (e.g. Steffen at al. 2016; but see contrasting views in Lewis and Maslin 2018). This is partially to emphasise the role of nuclear testing and the infiltration of radionuclides into the earth's geology, but it also obviously represents the date of the end of the Second World War and the establishment of a series of global organisations which have had an impact on monitoring and influencing global policy relating to the environment. However, the correlation of the beginning of the Anthropocene era with the two world wars, and the relationship between global conflict and the development of their 
associated industrialised technologies (particularly nuclear technologies) which are seen to characterise the origins of the Anthropocene, has strangely been largely ignored by Anthropocene scholars.

Bonneuil and Fressoz's The Shock of the Anthropocene (2016) is one of the few works to engage with the twentieth century's global conflicts as part of an overall narrative of changes in environmentalhuman-technological relations over the twentieth century which they see as prefiguring the Anthropocene, arguing that the Anthropocene must also be seen as a 'Thanatocene' $(2016,122)$. They point in particular to the ways in which the global conflicts of the first half of the twentieth century strategically deployed 'scorched earth' policies and other forms of targeted environmental destruction. These in turn required the development of new, energy-exploitative systems and production chains that heralded the establishment of contemporary global economies based on the industrialised exploitation of natural resources, which have produced the significant environmental impacts that scholars now see as defining the Anthropocene epoch. In particular, they see the development of western petrocultures in the 1950s and 1960s and their subsequent global spread as having emerged out of specific social, political, technological and ecological relations established during the First and Second World Wars, pointing to the significant role of these wars in heralding the acceleration in socio-economic and earth systems trends (including population growth, accelerated rates of production and consumption, and global warming) which are seen to characterise the Anthropocene (Bonneuil and Fressoz 2016, 144-7; see also Scranton 2015).

Timothy Morton's (2013) work on hyperobjects provides an important conceptual framework with which to make sense of this connection between conflict and the distinctive set of material-ecological-human relations that characterises the Anthropocene. Morton famously defines hyperobjects as 'viscous' (attached to humans and difficult to extract oneself from), 'nonlocal' (massively distributed in time and space, sensed but not always able to be 'seen'), 'interobjective' (held together and formed out of relations between complex assemblages of objects, places and people), 'molten' and 'phased' (challenging conventional understandings of the relations between space and time). Morton uses global warming as the exemplar of the hyperobject, but discusses others, including Styrofoam and plutonium. But perhaps less often commented on are the ways in which the concept of the hyperobject stands for Morton as a way of defining the Anthropocene itself; it is through our encounters with 
hyperobjects that we come to confront the Anthropocene as a material, social, ecological and political reality.

The heritage of modern conflict - a term I use here to mean not only heritage understood in its strict sense as those 'things' from the past that are actively preserved, but in a broader sense of material and discursive legacies, including waste products (see Harrison et al. 2020) constitutes precisely this form of massively distributed, viscous material assemblage, which persists in time and space and continues to make and unmake worlds in the present. Such elements of modern conflict heritage point to the violent and extractive nature of human-ecological relations which characterise the Anthropocene, which prefigured the development of the extensive petrocultures of the second half of the twentieth century. I argue that archaeology, material culture and heritage studies thus have a significant role to play in uncovering and documenting the global spread of these assemblages and their material affordances. Like the First World War (and indeed all industrial wars), the Chaco War was a Materialschlacht - 'a war of matériel of the most gigantic proportions' (Jünger 2004, 69) - which left its material mark everywhere. Nicholas Saunders thus argues that 'War is the transformation of matter through the agency of destruction, and industrialized conflict creates and destroys on a larger scale than at any time in human history' (Saunders 2002a, 175). At the end of the war, the Chaco landscape was riddled with bomb craters and scattered with human remains and material debris. Although the military and social histories as well as the ethnographies that have been published on the Chaco War undoubtedly contribute to our understanding of the conflict, their narrow approach and scope does not allow them to address the material realities of the war and the manifold material and discursive legacies that they have created. Exploring conflict as a hyperobject through the multidisciplinary lens of archaeology, material culture and heritage studies allows an insight into the emergence of the Anthropocene's unruly (Olsen and Pétursdóttir 2016), complex, conflicting and violent social, material and ecological worlds, and the inter-relations between them. The empirical material presented in this volume provides a series of vignettes through which to reflect on these questions of the relationship between conflict, heritage (which we might more expansively understand as constituting the whole range of material and discursive legacies, whether positively, negatively or ambiguously valued) and the extractive and often violent nature of human-ecological relations and the multiple Anthropocenes which these have generated. 


\section{The Chaco War and the Chaco region}

The Gran Chaco remains one of the last frontiers of South America. It is a hot and semi-arid lowland plain that stretches over four countries - Paraguay, Bolivia, Argentina and Brazil. As this study is focusing on the Paraguayan Chaco, the term Chaco will henceforth refer to the part of the Gran Chaco that lies within modern-day Paraguay (see Chapter 2). Hot and hostile, and difficult to farm, the Chaco is rich and diverse in flora, fauna and history. It is a haven for animals and plants, many of them

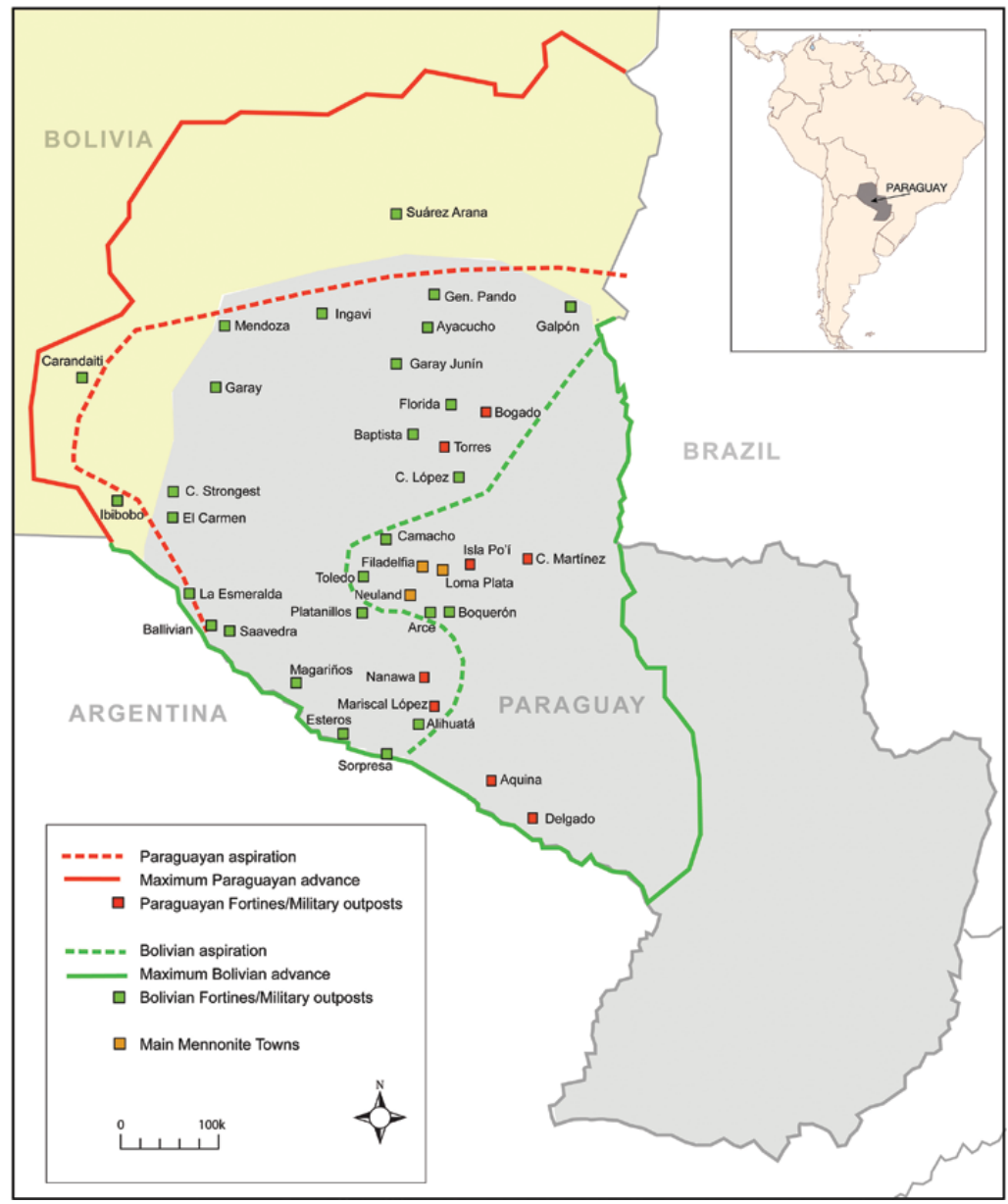

Figure 1.1 Map showing Paraguay and Bolivia and the disputed Chaco region. Major sites discussed in the text are also shown (Source: author). 
unique to the area. It is characterised by parched savannah grasslands, a large variety of cacti, islands of impenetrable thorny forest and palm groves. Although it had been inhabited by various indigenous groups for centuries, by the early twentieth century the Chaco was perceived as an empty and 'wild' stretch of land that was up for grabs and in need of civilising through military and agricultural intervention (Richard 2008b, 9).

In 1932-5, the Chaco became the setting of South America's first industrial war and the continent's first conflict to employ tanks and planes (De Quesada with Jowett 2011). Throughout the 1920s, Bolivia and Paraguay both claimed ownership over the territory under dispute and, unable to come to an agreement, started to build military outposts that slowly moved deeper into the Chaco scrubland. Around the same time, in an effort to populate the region, Paraguay invited Canadian and later Russian Mennonites - members of an evangelical free church - to settle and farm the Chaco (Friesen 1997).

With armies largely made up of Aymara and Quechua miners and Guaraní mestizo farmhands respectively, the Chaco War claimed more than 80,000 lives. While the exact number of casualties suffered by the Chaco's indigenous populations is unknown, some communities are believed to have lost 70 per cent of their members during the war years (Capdevila et al. 2010, 11). The majority of military deaths were however not caused by enemy gunshots but by poor sanitary conditions, diseases and most importantly thirst, making the struggle for survival in the Chaco bush a soldier's biggest challenge.

Due to both Paraguay's and Bolivia's precarious financial situation before the war, their respective armies were equipped with often faulty leftover weaponry from the First World War (Pendle 1967, 27). With trench warfare and European-trained military officials conjuring up memories of the so-called Great War, the Chaco War shared many of its tragic characteristics. Just as the agricultural fields of Belgium and France were turned into muddy battlefields by insect-infested trenches, the din of artillery bombardment, lack of water, the cries of the wounded and the smell of rotting bodies in the Chaco offered a 1930s South American parallel to the Western Front between 1914 and 1918. After four years of people struggling to survive enemy fire and the Chaco environment, the war finally came to a halt at the foothills of the Andes. Although neither side had been officially declared a winner, Paraguay was awarded three-quarters of the region under dispute at a peace conference in Buenos Aires in 1938 (De Quesada with Jowett 2011, 22).

Today, almost a century later, the population and agricultural production of the Chaco is mainly concentrated around the three Mennonite 
colonies of Fernheim, Menno and Neuland, which are made up of around 20,000 Mennonite, indigenous and Latino inhabitants. Until the introduction of mechanised agricultural methods in the 1950s, the Mennonites were largely self-sufficient (Renshaw 2002, 41). As infrastructure was limited to a small number of unreliable dirt roads, the Mennonites' only link to the outside world was a train line that ran from the port town of Puerto Casado in the east $145 \mathrm{~km}$ into the Chaco where it came to an end at Fred Engen Station, locally known as Km 145. It was not until the building of the Ruta Transchaco or the Trans-Chaco Highway, the region's first and to this day only major paved road, in the 1960s that the Mennonites started to engage with the rest of Paraguay (Ratzlaff 1998). Since then, the Mennonite colonies have turned into the agricultural centre of the country and the booming economy attracts outsiders looking for work. Although religion and traditional values are still fundamental to Mennonite life, the Trans-Chaco Highway, industrial prosperity and more recently access to the internet have opened up the Mennonite communities to become part of the wider globalised world.

Nonetheless, the Chaco remains an isolated and inaccessible place where, according to many Paraguayans, 'there is nothing to see'. Those who do visit usually do not go past the modern comforts of the Mennonite

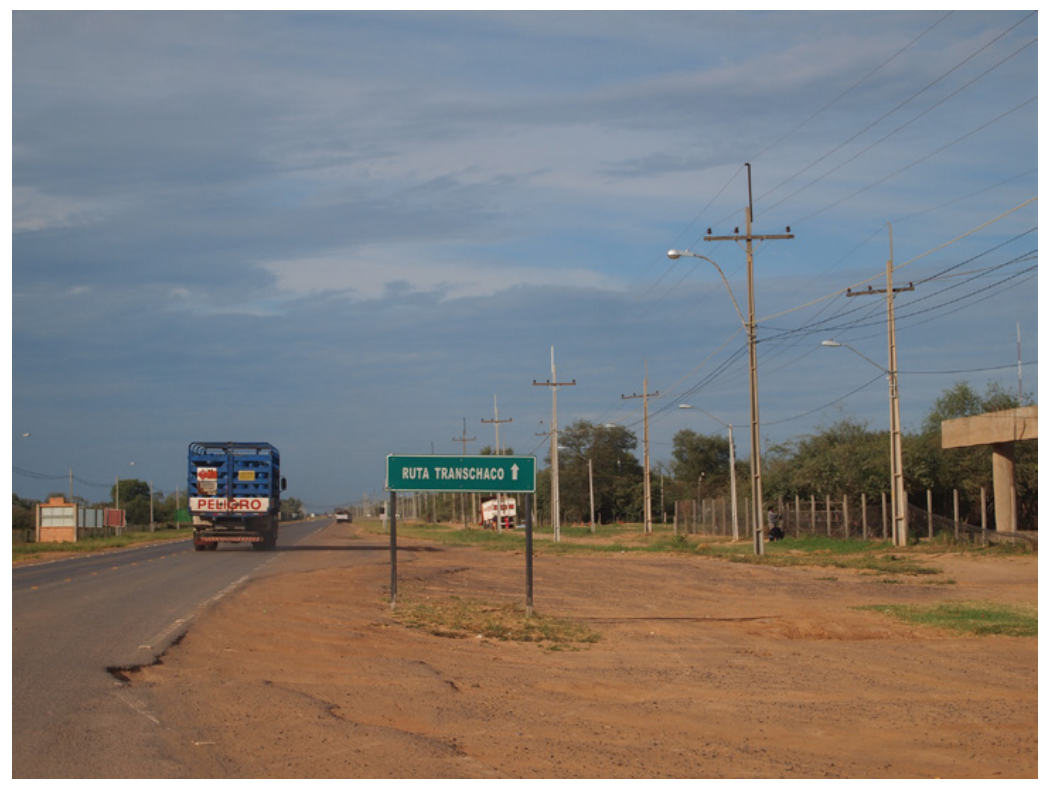

Figure 1.2 The Trans-Chaco Highway connecting the Chaco with Asunción and the wider world (Source: author). 
colonies or the sleepy town of Mariscal Estigarribia, which marks the end of the asphalted part of the Ruta Transchaco. Many Paraguayans have never been to the Chaco and only know it as that part of the patria (fatherland/homeland) that their fathers and grandfathers heroically defended against the invading Bolivian. Thus, for many, the Chaco and its war remain imagined landscapes, conjured up by the oral histories and written sources of those who fought in it.

\section{Archaeology and heritage in Paraguay}

The development of archaeology as a discipline has been said to be connected to the economic situation of a country and the powers of its institutions (Funari 2014, 93), while the development of a broader infrastructure for heritage management and presentation has conventionally been linked to nation-building initiatives and tourist industries (e.g. Harrison 2013a). In Paraguay, both of these fields remain significantly underdeveloped. This is especially the case in relation to the archaeology and heritage of the Chaco War. At the time I conducted fieldwork for this project, the Secretaría Nacional de Cultura (National Ministry of Culture) housed the Gabinete de Arqueología y Paleontología (Office of Archaeology and Palaeontology) within the Dirección de Investigación de Arqueología y Antropología (Directorate of Archaeological and Anthropological Investigation) and employed a passionate and knowledgeable técnico (specialist) in charge of predominantly rescue excavations in the country. Unfortunately, the enthusiasm of the técnico and her institutions, and their genuine efforts to safeguard Paraguay's national heritage, were not matched by any professional archaeological training or the provision of adequate fieldwork equipment. Despite the country's rich indigenous and colonial history, none of the national universities offer degrees or courses in archaeology or heritage studies and only a handful of articles on the archaeology of Paraguay's Guaraní indigenous people and Jesuit ruins have been published (e.g. Vera 1930, 1941; Schmidt 1932, 1934; Gómez-Perasso 1978; McNaspy 1987; Noelli 2004). As a result, the country often relies on foreign specialists (with their own financial resources) to carry out research on Paraguayan territory.

Nonetheless, there have been some grassroots public initiatives concerned with the production of collective historical consciousness in the country. Determined to get the general public interested in Paraguay's history and traditions, a group of mainly history and geography students and graduates formed the Asociación Cultural Mandu'ara 
(Mandu'ara Cultural Association - mandu'ara is Guaraní for 'what is worth remembering' or 'what is memorable'; now known as Asociación Cultural Arandú - a 'wise community or a community that attends to and understands the language of mother nature'). The association's main aim is to teach people about the nation's history and folklore by organising talks and educational fieldtrips. Conveying national pride in a shared and glorious past and celebrating acts of national heroism are also part of the group's mission. The members are, however, selective in their choice of historical events and cultural practices that they believe should be disseminated and honoured in Paraguay. As a result, Mandu'ara focuses on the memory of brave compatriots who fought and lost their lives for the homeland. The fact that the country underwent the longest military dictatorship in twentieth-century South America (1954-89) which saw the torture, forced disappearance and murder of thousands of people (see Domínguez et al. 1998; Almada 2010) does not seem to form part of the association's agenda.

In contrast, the Dirección de Reparación y Memoria Histórica del Ministerio de Justicia (Directorate for Reparations and Historical Memory of the Ministry of Justice), brought into being by the Viceministerio de Justicia y Derechos (Vice-Ministry of Justice and Rights), has made the investigation, search and identification of people who were detained, disappeared and/or executed during Paraguay's 35-year authoritarian regime its main objective. First attempts at excavating a possible mass grave were made in 1993 as part of a project that was directed by an individual whose father had gone missing under the oppressive regime. Due to the lack of professional help from forensic archaeologists or other experts, excavations of clandestine burial sites were carried out by family members with the support of the Agrupación Especializada de la Policía Nacional (National Police Specialised Group, NPSG) in the hope of recovering missing loved ones. This is, however, now rumoured to be changed, as Paraguay is awaiting the confirmation of Argentinian forensic specialists to aid them in their quest. In February 2015, the Paraguayan government approved a budget of $\$ 70,000$ to carry out DNA testing on the skeletal remains and within the Paraguayan population in order to establish the victims' identities (Anonymous 2015). While many people welcomed the governmental efforts in dealing with the wrongdoings of its predecessors, others felt that the nation should move forward and look towards the future instead of focusing on the past. According to a taxi driver I spoke to in Asunción, many believe that any available money should therefore be spent on other, more pressing matters, such as the national education and health system. Although the archaeology 
of Paraguay's dictatorship goes beyond the limits of this book, it serves as a poignant example of the unregulated state of archaeological research in the country.

One area that has received recent academic attention is that of the country's battlefields dating back to the infamous War of the Triple Alliance (1864-70), which almost eradicated Paraguay as an autonomous nation. In 2006, Tony Pollard published 'Seven Eventful Days in Paraguay: Reconnoitring the Archaeology of the War of the Triple Alliance'. Unfortunately, despite the country's rich archaeological record of the conflict, the paper, which forms part of an edited volume on battlefield archaeology (Scott, Babits and Haecker 2006) and promises to present the potential for battlefield archaeology in Paraguay, barely moves beyond a historical analysis of the war. It was not until my first trip to Paraguay in 2011 that the Chaco War, the country's lesser-known conflict, was evaluated for its archaeological potential for the first time. The results of this archaeological work are presented in Chapter 5 of this book.

\section{'Humanity begins with things': Towards an ontological approach to militarised landscapes, objects and people}

In his philosophical conversations with Bruno Latour, Michel Serres states that 'Humanity begins with things' (Serres and Latour 1995, 166). In other words, we exist as humans only through the intimate engagements we build with fellow humans, animals and other non-human entities; we live as hybrids as parts of more-than-human collectives. In archaeology, the turn towards the more recent past has been criticised as a simultaneous move away from 'things' or the role of non-humans in such collectives (e.g. Olsen 2003, 2013; González-Ruibal 2006a; Witmore 2007; Webmoor and Witmore 2008; Hodder 2012; Pétursdóttir and Olsen 2014). Although this might sound like a contradiction, since anthropological material culture studies have been gaining traction ever since Arjun Appadurai's influential publication The Social Life of Things (Appadurai 1988) and the formation of the Journal of Material Culture in 1996, it could be argued that an increasing academic interest in material culture has in many cases really been just a pretence to study ourselves. This accusation has been particularly levelled at a post-processual tradition of archaeology that 'reads' objects and landscapes primarily as symbols and metaphors of human experience. This idea is reflected in Christopher Tilley's theory of objectification, which claims that making 
things involves a 'fabrication of the social self' (Tilley 2006, 63). In this way of thinking, non-human entities are inert matter doomed 'always to live out the social life of men' (Pinney 2005, 259). This is not to say that material culture cannot act as a translator or become a materialisation of identities and ideologies through a conscious manipulation and negotiation by a human actor. To completely reduce material culture to an impassive material waiting to be 'activated by human agency' (GonzálezRuibal, Hernando and Politis 2011, 3; see also Olsen 2007, 2013) is, however, a conceited and restrictive move. Indeed, Latour reminds us that the world is not divided into two contradictory poles of passive objects on the one end and active subjects on the other but instead forms an amalgam of people and things, and the complex hybrid relations that link them (Latour 1993, 13-14). This is especially true in non-western indigenous societies where objects are often thought of as kin, or as agents in their own right. In his anthropological work on the Ayoreo people in the Chaco, Marcelo Bórmida notes that:

the concept of consciousness which western culture attributes to human inventiveness can be approached through a different mechanism of origin, such as consent. Material, which in the rational conscious, is an inert assumption of human intention, can have its own intention. Techniques can reveal themselves not just as mere handicrafts but involve the participation of intents and powers that act independently of man, above him, and sometimes, against him (Bórmida 2005, 113).

In line with this idea, Christopher Witmore and others have called for an ontological or symmetrical approach to the study of archaeological remains (Witmore 2007; see also González-Ruibal 2006b; GonzálezRuibal, Hernando and Politis 2011; Hodder 2012; Olsen 2013). Although a symmetrical archaeology conceives of humans and non-humans as equal factors in the shaping and occupation of a shared existence, it does not see them as one and the same. In his manifesto Witmore clarifies that symmetrical archaeology:

is not a claim to an undifferentiated world. Symmetrical levelling is neither axiological nor ethical. As such, a symmetrical archaeology attends, not to how 'individuals' get on in the world, but rather to how a distributed collective, an entanglement of humans and things, negotiates a complex web of interactions with a diversity of other entities (whether materials, things or our fellow 
creatures). With regard to definition, a symmetrical archaeology is a programme best described as a new 'ecology' packed with things, mixed with humans and companion species (Haraway 2003), and which prioritizes the multi-temporal and multi-sensorial qualities, the multiplicity, of the material world (Witmore 2007, 547).

Such calls from within archaeology have been mirrored across anthropological material culture studies (e.g. Alberti et al. 2011; Henare, Holbraad and Wastell 2007; Kohn 2015; Holbraad and Pedersen 2017; Holbraad, Pedersen and Viveiros de Castro 2014) and heritage studies (e.g. Olsen and Pétursdóttir 2016; Harrison 2013a, 2015, 2018; Pétursdóttir 2016, 2017), where the emphasis on the 'discourse' of heritage (Smith 2006) has been argued to have distracted from an engagement with the affective qualities of objects, places and practices which are designated and experienced as 'heritage' (e.g. Solli et al. 2011; Pétursdóttir 2013). The need to abandon the neat, modernist division between natural and cultural heritage has particularly characterised new, more critical ways of thinking about heritage as material and discursive legacy in the Anthropocene (see e.g. Harrison 2013a, 2015; Breithoff and Harrison 2020a, 2020b; Harrison et al. 2020; DeSilvey 2017). A material-ontological understanding of objects and places and their collective world-making capacities as part of more-than-human social assemblages strongly informs my approach to the archaeology and heritage of the Chaco War outlined in this book.

While the approaches I have taken to the study of conflict material culture and heritage have been strongly influenced by broader material and ontological 'turns' in the humanities and social sciences (e.g. Latour 2007; Coole and Frost 2010; Ingold 2012; Kelly 2014; Kohn 2015; Holbraad and Pedersen 2017), I do not see it as necessary to focus on objects alone to the detriment of humans. In my view, object-oriented ontology (e.g. Bogost 2012; Bryant 2011; Bryant, Srnicek and Harman 2011; Harman 2002, 2011; for archaeology and heritage studies see Olsen 2013; Olsen and Pétursdóttir 2014, 2016; Pétursdóttir 2013, 2017) and other approaches that emphasise the agency and affordances of things broaden our understanding of object-human relationships and do not take away from the role of humans but rather seek to show how humans act and live within material networks. Nor do I agree with critics that such approaches are necessarily apolitical (e.g. Hornborg 2017; Malm 2018). On the contrary, they show how power is distributed unequally across and between more-than-human assemblages and networks (e.g. Bennett 2010; Haraway 2016). They also present ways of 
engaging seriously with indigenous ontologies in which objects often act as agents in human or human-like ways (e.g. Viveiros de Castro 2004b). Conversely, the bodies of humans are also material and have particular material affordances which allow them to function as part of material assemblages. The key points I take from this literature relate to the ways in which the boundaries between humans, objects and landscapes cannot be strictly defined and are often blurred, and the ways in which such assemblages act collectively (see Barad 2007) in making, unmaking and remaking multiple worlds in the pluriverse. Put simply, it is an invitation to understand 'things' differently.

\section{Making, unmaking and remaking conflict landscapes}

In order to overcome an asymmetrical nature/culture or human/nonhuman dualism and its reductive understanding of landscape or material culture as static backdrop to human activity within the context of the Chaco, I adopt Tim Ingold's 'dwelling perspective', which has as 'common point of departure the agent-in-its-environment, or what phenomenology calls "being in the world", as opposed to the self-contained individual confronting a world "out there"' (Ingold 1995, 58; Ingold 2000, 173). For Ingold, the world, nature and environment are not inert surfaces waiting to be bestowed with meaning by human interaction. Like the humans who dwell in them, they are dynamic forces and actively participate in the creation of the landscape and the world as a whole, as landscape is 'the world as it is known to those who dwell therein' (Ingold 1993, 156).

John Schofield asserts that 'landscape is the broadest scale at which the influence of military activity can be felt and assessed. It is also the scale at which the impact of conflict can be best appreciated, whether upon the form of physical landscape, or on the psychology of its inhabitants' (Schofield 2005, 44). Indeed, modern wars seem to have left a military imprint in literally every corner of the world, resulting in a militarisation of landscapes and an overlapping of both military and civilian spaces (Woodward 2004, 3; Pearson, Coates and Cole 2010, 3). According to Chris Pearson, militarised environments are both 'material and cultural sites that have been partially or fully mobilised to achieve military aims' (Pearson 2012a, 1). In this sense, the militarisation of a landscape is achieved through the military's exploitation and manipulation of natural landscape features aimed at transforming the latter into strategic reference points (Woodward 2004, 105-8; Pearson, Coates and Cole 2010, 3). By making unfamiliar terrain familiar, militarisation processes thus not 
only change the physical appearance of landscapes but also alter people's perception of the world they are moving in (see Pearson, Coates and Cole 2010). The destructive and absurd forces of war, however, often contort people's realities beyond recognition. The act of making the unfamiliar familiar becomes a struggle and is one of the practices involved in the incessant making and unmaking of worlds that no longer seem to make any sense to those who are involved in their creation.

Military and environmental historians as well as military geographers have long been interested in landscapes affected by recent conflict. Yet they rarely seem to move beyond what the military geographer Rachel Woodward calls the 'terrain and tactics' (Woodward 2005, 722) approach, which understands combat and its relationship with the landscape as 'essentially a response to environmental possibilities and limitations' (O'Sullivan and Miller 1983; see also Winters 2001a; cf. Russell 2001; Tucker and Russell 2004; Woodward 2004; Brady 2005, 2012; Pearson, Coates and Cole 2010; Pearson 2012). Although a soldier's understanding of topography, vegetation cover, weather and disease is key to military strategy development and execution, and the outcome of military operations in general, such discussions tend to cast landscapes in a static role. This creates a clear division between an active subject (soldier) and a passive object (landscape) that ignores the entangled human and non-human forces at work in the militarisation of landscapes such as the Chaco.

Archaeological research on the destruction of 'traditional' or indigenous landscapes by industrialised war has been limited (for an exception see Shqiarat et al. 2011). Furthermore, little attention has been paid to the active role that landscapes and their natural resources play in warfare. In fact, nature, like people, can be mobilised (Shqiarat et al. 2011, 112; see also Pearson 2012) and in the light of war, ravaged landscapes could even be considered to be victims of industrial destructive forces (Shqiarat et al. 2011, 112). Richard P. Tucker and Edmund Russell 'argue for the importance of understanding war as a major and distinctive force in environmental change, as well as the environment as a force in shaping warfare' (Tucker and Russell 2004, 2). Referring to Gillian Rose's argument that 'a landscape's meanings draw on the cultural codes of the society for which it was made' (Rose 1993, 89), Woodward suggests the technique of 'fieldcraft' as a way of engaging with the landscape on a practical level. 'Fieldcraft', she writes, 'is the art of survival in the battlefield; it is about reading the land in a specific [military] way' (Woodward 2004, 105). She adds that 'the cultural codes of the military ascribe whole new meanings to the landscape' (Woodward 2004, 106). To a soldier's trained eye, natural landscape features are radically 
transformed: trees become hideouts, rocks mean cover and rivers act as obstacles (Woodward 2004, 105-8). To those familiar with the landscape, its resources can provide shelter from the natural elements and even offer protection from enemy bullets. Nature also offers building materials for the construction of houses and military structures (Tucker 2004), and above all, provides food and water. Yet in the same instant nature can turn against humans and kill those who are unfamiliar with its elements. Although this approach grants nature some sort of agency, casting it in the role of a soldier's 'ally' or 'enemy' (Tucker and Russell 2004) - as separate from humans - reinforces the modern conception of a thinking subject who bestows an inert object with symbolic representations of themselves.

This anthropocentric western view of nature is further demonstrated in the idea of 'wilderness' (Cronon 1996). Although today the term is mostly used in the field of resource conservation and ecology (Oelschlaeger 1991), it has passed through centuries of contradicting connotations ranging from biblical associations with the devil and the margins of civilisation, to late nineteenth-century romantic views of a 'wild' and 'pristine' beauty untouched by human interaction (GómezPompa and Kaus 1992; Cronon 1996; Nash 2001). In the European colonial mindset wilderness was widely seen as a 'terrible symbol of chaos' (Whiston Spirn 1998, 19) - an idea that was reinforced by biblical connotations. In Genesis (1.28), for example, God commands Adam and Eve to 'Be fruitful and multiply, and fill the earth and subdue it' (Genesis 1.15-1.31, Coogan et al. 2007, 12). Once they had been thrown out of paradise, Adam and Eve were faced with a 'wilderness' and could only redeem themselves through the painful labour of turning the 'wilderness' into a tamed garden (Cronon 1996, 8-9).

This nature/civilisation dichotomy created what Andrew Sluyter called the 'western myth of emptiness', where desert and wasteland are viewed as synonymous $(2002,6)$. These terra (or rather terrae) nullius or 'empty wastelands' were believed to be in need of improvement through the civilising hand of agriculture and/or military occupation (Brady 2012). As they were not perceived to be exploited by non-indigenous colonisers, they were considered untouched by humans despite an often clear, long and continuous indigenous presence. In fact, indigenous people were generally seen as part of the 'wilderness' as they themselves were considered primitive 'savages' at the mercy of a raging nature. The image of the helpless native waiting to be graced with the gift of western civilisation thus stood in complete contrast with the modern industrial subject who 'through the rational application of scientific knowledge, 
had at last subjugated nature to his sovereign will' (Ingold 2000, 312). Here, the imposition of western modernity onto landscapes dominated by traditional cultures often results in 'a mix of collision, interaction and fusion' of two or more opposing lifeworlds (Shqiarat et al. 2011, 98).

During the Chaco War, the soldiers and Mennonites came to experience nature and 'wilderness' as something that is alien or 'profoundly Other' (Cronon 1996, 8) to themselves. A social construction of nature and 'wilderness' as something alien and contradictory to humans derives from and reinforces the mind/matter dualism specific to what has been referred to as the 'western gaze' (Bender 2006), which has traditionally been directed at instead of being engaged in the world (Ingold 2000). However, this categorisation of the world into thinking human subjects and inert things is not universally practised. In the Chaco, many of the indigenous groups do not see themselves as a separate 'Other' from the animate and inanimate things that surround them. Similar to indigenous communities that inhabit the Amazon region, people indigenous to the Chaco tend to understand the world as a single integrated whole "within which humans are seen as "people-organisms" that maintain social relations with all other existing beings indiscriminately' (Descola 2005, 345; see also Ingold 1996; Viveiros de Castro 1998, 2004a, 2004b; Blaser 2009a, 2009b, 2010). Thus, while the soldiers and Mennonites experienced the bush as an unfamiliar and confusing threat, the indigenous inhabitants of the Chaco tended to feel inherently interconnected with it. Writing in the context of nuclear testing in the American West during the Cold War, Valerie Kuletz notes that, while deserts represent barren and marginal wastelands to the westerner (or in the case of the Chaco, nonnative), many local indigenous groups consider them 'places of origin and emergence, as holy places, and sacred geographies' (Kuletz 1998, 14). Rather than constructing a mental image of the world, indigenous and/ or hunter-gatherer societies often take 'up a view in it' (Ingold 2000, 42).

The Chaco, then, did not need to be domesticated. Ticio Escobar states in his book on the Ishir indigenous people in Paraguay that 'Nature does not present itself as a smooth exterior that must be occupied, but as a multidimensional and mysterious territory filled with secrets, keys and false bottoms, threats, shortcuts, echoes, and hiding places' $(2007,143)$. The deeply rooted 'modern' doctrine of 'seeing is believing' (Cosgrove 1998, 9; cf. Classen 2005), however, makes a consideration of alternative ontologies a challenge and consistently results in inconsistencies arising from indigenous landscapes being interpreted through traditional western landscape ideologies that are defined by the ego-centred human/perceiver/active and landscape/perceived/passive dualisms. 


\section{Sensing, making and investigating worlds in the Chaco}

My approach to conflict archaeology and heritage is significantly influenced by sensory approaches to archaeology and anthropology (e.g. Classen 2005; Howes 2005; Pink 2009; Leonard 2016, 2017, 2019; Leonard and Breithoff 2020). Barbara Bender suggests that engagements with landscapes need to be multi-sensorial as the latter 'are not just "views" but intimate encounters. They are not just about seeing, but about experiencing with all the senses' (Bender 2002, 136). Yet we often take our sensorial engagement with the world for granted: the sound of cars, the smell of rain and the taste of coffee are all ordinary everyday experiences for most of us. Stressful situations such as periods of armed conflict can, however, heighten our senses and intensify our sensorial awareness (see Leonard 2016, 2017, 2019; Leonard and Breithoff 2020). In his work on intimacy during the First World War, Sanatu Das explores the relationship between the sense of touch and modern warfare. Das believes that 'it is through this sense that we have access to the reality of our own bodies' (Das 2005, 20). In times of war, this intimate 'skin knowledge' (Howes 2005b, 27) becomes violated by the disfigurement and destruction of body and mind through the annihilating forces of technological warfare (Das 2005, 23).

With the constant threat of imminent death hanging over him, a soldier instinctively goes into survival mode 'listening out for, and reacting to, auditory signals of warning: remaining alert for, and reacting to, visual signals or signs of danger, and, in darkness using his body to feel and know his immediate environment' (Winterton 2012). John Brinckerhoff Jackson called soldiers 'part-time hunters' as, much like hunters, they 'develop an acute receptivity to the messages sent out by the environment', which they then pass on to new recruits $(1980,15)$. As a result, senses are fused and create new sensorial perceptions such as the so-called 'shell sense', which alerts the soldier to the danger of artillery fire through his spatial and auditory awareness (Stephen Foote as referenced by Das 2005, 83). Destructive forces unleashed by industrial warfare lead to a perversion of the senses or a state of 'sensorial overdrive', distorting and unmaking people's realities and defying their ability to make sense of their world. Amidst the alien surroundings and the apocalyptic chaos of industrial wars, the soldiers' sense of 'how to go on in the world' (Tilley 1994, 16) is erased as they struggle to orientate themselves in, make sense of and above all survive in the face of an absurd supermodernity where all previously inculcated bodily comportment is lost (see Burchell 2014). 
Trench life creates another new reality in which soldiers have to realign their sensibilities in order to stay alive. Writing in the context of trench warfare during the First World War, Dorothee Brantz observes that 'Entrenchment created a new spatiality above and below ground' and that 'Trench warfare forced soldiers to develop a new relationship with space, including intensified sense perceptions' (2009, 74-5). Being situated below the earth's surface, trench life did not offer a panoramic view, instead shifting the soldiers' emphasis on sight to a heightened experience of hearing, smell and touch. The trench landscape thus becomes a 'way(s) of sensing' or what David Howes has called a 'sensescape' (Howes 2005c, 143-5) composed of mud (touch), the deafening noise of artillery and wounded and dying men (hearing), the metallic aftertaste of blood (taste), and the stench of decaying bodies and human waste (smell). In the context of the First World War, mud has become a particularly iconic image of trench warfare (Das 2005). The fear of getting buried alive under the brown and clingy 'slimescapes' that 'confused the categories of solid and liquid' was ever present (Das 2005, 35). Trench mud also brutally and ruthlessly erases the modern separation between humans and non-humans as 'mud was not only mud but was also compounded of organic wastes, industrial debris, iron scraps and even rotting flesh' (Das 2005, 39; see also Saunders and Cornish 2009). In the face of industrial war, objects, landscapes and humans are all the same. The forces of mass destruction do not differentiate between human and non-human entities in the havoc they create. Thus, as Mike Pearson and Michael Shanks put it rather morbidly: 'death and decay await us all, people and objects alike' (2001, 93).

Recent work in science studies has shown how worlds are not separate from the observational practices that build the 'scientific' laws that hold them together (e.g. Barad 2007; Daston and Galison 2010; Latour 1987, 2013). Therefore, archaeology and anthropological material culture studies can be understood to co-create their subjects (e.g. see Dawdy 2010; Lucas 2004, 2005, 2006, 2010; Olsen 2010; Olsen et al. 2012; Pearson and Shanks 2001; Shanks 2012). Researching conflict landscapes and material cultures is itself an embodied and sensorial experience that can provide partial 'windows' into understanding past experience, but such windows are only ever generated from the position of the present looking backwards - a present in which that past is contained and through which that past is created - and from one world 'looking in' to another. While doing fieldwork in the surviving trenches of the Chaco War, it is impossible to escape the scorching heat, dust and 
thorns of the bush. Drenched in sweat and followed by swarms of mosquitoes, following the trail of an overgrown trench in which thousands of Paraguayans and Bolivians lost their lives from 1932 to 1935, a fear of getting lost in the monotonous thicket slowly creeps in. Spent bullets mix with the arms of cacti that greedily reach across the Chaco ground. While such sensorial experiences provide embodied ways of knowing and writing about experiences in the past, they are nonetheless separate from it. No longer are there war cries, the smell of faeces, humming aeroplanes, whizzing bullets and blood that coats the greyish-brown earth a bright red. The bush is eerily quiet.

Although the threat of unexploded ordnance can remain a reality and its consequences can be lethal even today, visiting conflict sites often makes us feel strangely removed from the situation, just as the original event seems both far removed in time and yet ominously close through its material remains. Standing inside a Chaco trench, a Great War tunnel or indeed any other place that has witnessed conflict, decades after the deadly events, it is possible to get a sense of the place and the terrible things people had to endure. Sites of violence have the potential to evoke different feelings and open up a new sensorial dimension: a shiver that runs down the spine or goose bumps in 40-degree heat when the immensity of the human tragedy that unfolded in this exact same spot so many years ago suddenly hits home.

Thus, while my work takes a significant cue from archaeological engagements with the senses in an attempt to gain a better understanding of the human experience of conflict, such an approach also presents insurmountable limitations. Researchers might catch a glimpse of what armed conflict felt, smelled, sounded and looked like, but they are ultimately doomed to fail in reproducing the sensorial pasts shaped not only by personal circumstances but also by fundamentally senseless human actions. Applying a sensorial approach to the material culture, landscapes and heritage of recent conflict allows us to glimpse the violent worlds of war, but also generates new and often unexpected sensations within the researcher, who brings their own particular set of life experiences and disposition to their work. Research itself thus becomes its own world-making practice. As a researcher, I came into the Chaco carrying my own world within me. While everyone's own world is personal and multi-sensorial, an embodied engagement with landscapes and human-thing assemblages offers portals into worlds other than one's own. For researchers engaging with the heritage of recent conflict, this uncanny experience of otherness resonates with the experience of individuals who found themselves in landscapes that were transformed 
and rendered unfamiliar through the process of militarisation and the destructive forces of industrial warfare, or due to people not being native to the area in which battles were fought.

This sense of unfamiliarity has led to the Chaco commonly being referred to as the 'end of the world'. To the incoming Mennonites and soldiers, who experienced its bush as alien and impenetrable, it must have felt this way. Even today, the Chaco seems to retain a sense of geographical isolation and remains a place of punishment, where disobedient Paraguayan soldiers are stationed and tourists rarely venture. However, as in the case of the plural worlds in the title, I use the question mark to challenge this view of the Chaco. To the many indigenous people who inhabited and continue to inhabit it, it constitutes the centre of their world. It is home. The book's title also invokes the simultaneous destructive and creative forces of industrial war, and with it the world-making and unmaking power of conflict, which transformed the worlds as the indigenous people, Mennonites and soldiers knew them. Equally, it speaks to the sense of urgency that has accompanied current discourses surrounding the Anthropocene, and the contemporary apocalyptic sense that we are living in end times.

\section{Methods: Towards an 'archaeology' of the Chaco War and its afterlives as heritage}

With the written record focusing primarily on the military, logistical and political aspects of the war, in this book I propose a material approach that applies a variety of qualitative research methods to the study of the multi-faceted landscapes and objects of the Chaco War. I furthermore suggest an alternative ontological engagement with the material remains of the war and its afterlives as archaeology and heritage, which considers worlds to be composed of chaotic assemblages of human and non-human entities that together create a material world which is embedded within multiple pasts and presents. In order to properly address the manifold and complex realities created by industrial conflict and its aftermath in a hitherto pre-industrial, non-modern landscape, I recognise the need to work across disciplines and to push boundaries, both in a physical and a metaphorical sense. Consequently, in this book I weave together documentary evidence, oral history, photography, artefacts, structures and landscapes to expose the intimate relationships between people, landscapes and objects during the Chaco War and in the present day. By treating the war's surviving physical traces as mementoes of a past which, by 
their very existence and people's engagement with them, are also firmly nested within the present, this book aims to close the gap between past and present, and thus both stage and perform an archaeology 'in and of the present' (Harrison 2011, 141-2).

I make an important distinction here between archaeology of heritage and archaeology as heritage. By the archaeology of heritage, I refer to the use of archaeological methods to document and interrogate heritage objects, places and practices and their material components (see e.g. Harrison 2013b). Here, the material remains of modern conflict are not mere mute witnesses to a bygone past but form part of the present and are actively invoked in the production of new futures. Archaeology thus has a role to play in documenting not only the material culture of past conflicts, but also how these are caught up with and involved in contemporary social and political relations. In some instances, however, archaeological sites themselves come to be actively 'heritagised', and in this case we see how archaeology functions as heritage. An example of this is discussed in Chapter 5 (and picked up again in Chapter 6) in the designation of Fortín Nanawa following the archaeological work that confirmed its location and the sub-surface archaeological remains that were present at the site. An archaeology of conflict heritage is not only concerned with artefacts from the 'past' but is equally concerned with understanding archaeology itself as a set of heritage-making practices which remake these material remains in the present.

The wealth and fluidity of the research material I have encountered in my work has obliged me to be flexible in my methodologies. Limited archaeological guidelines in Paraguay coupled with my dependence on local guides and the Chaco's unpredictable weather conditions and terrain meant that a systematic field survey approach was unrealistic. Consequently, I repeatedly took a step back and, adopting Jeremy MacClancy's approach, 'on a particular issue, item or concept, I have followed my topic wherever it led me' (2007, 23; see also McAtackney 2014 , 43). As the Chaco War and its physical remains are firmly embedded within the present, they continue to have an impact on both the region's physical and people's mental landscapes today. In light of this, I treat Chaco War sites and their related material culture as living entities that have not become but are always becoming through the interactions of human and non-human actors. Hence I do not understand the Chaco as a past and finished event that is both physically and emotionally detached from the present but as one that 'recognizes the agency of humans, non-humans and the collectives themselves as charged with 
latent potential, as generative of new pasts and futures in the present' (Harrison 2011, 157).

To address the volume and scope of the material under scrutiny I engaged with a range of different sources including documents, historical and contemporary photographs, media accounts, artefacts, museums and heritage sites, as well as more conventional 'archaeological' evidence gathered through field survey and excavation. Such multi-source approaches, which involve the critical engagement with and contextual interpretation of a number of different textual and material sources (including monuments, landscapes and artefacts), are now common to historical and contemporary archaeology (see further discussion in Harrison and Breithoff 2017) and critical heritage studies. My engagement with the worlding practices of soldiers, indigenous people and Mennonites draws selectively on a detailed reading of these primary and secondary material and documentary sources and, where possible, on oral accounts of the war. I was particularly guided in locating and interpreting many contemporary archaeological sites relating to the war by the Mennonite guides with whom I worked during fieldwork between 2011 and 2013. In 2011 I visited the handful of war veterans still alive in the Cuártel de la Victoria - a military-run care home for members of the armed forces - in Asunción. Unfortunately, old age and bad health prevented most of them from talking to me. Furthermore, of the two men I conversed with, one spoke only Guaraní. Both veterans seemed to find it difficult to answer any questions and mostly repeated what seemed like rehearsed phrases about their military rank and the unit they formed part of. Although I did not manage to get any information on the veterans' personal experience of the war and their struggle in the Chaco landscape, their automatic replies about their military position reinforced the importance of applying an archaeological approach to the study of the Chaco War in order to allow alternative understandings that go beyond the military history of the conflict to emerge.

I have been reliant on primary and secondary accounts of the war in understanding the lifeworlds of each of the different sets of protagonists. My discussion of indigenous lifeworlds draws especially on anthropologist Marcelo Bórmida's (2005) detailed account of the Ayoreo, Tico Escobar's (2007) ethnographic accounts of the Tomaraho Ishir and Wilmar Stahl's (2007) monograph on cultural interactions between Mennonites, Ayoreo and Nivaclé. The Geschichtliches Archiv Kolonie Fernheim (Fernheim Colony Historical Archive, GAKF) in Filadelfia, Colonia Fernheim, contains detailed accounts of contemporary correspondence between the 
different Mennonite colonies, the Mennonites and the militaries, and much of the work in Chapter 4 relies on my reading and translation of materials from this archive. A particularly rich source of photographic materials relating to the war is contained in the Archivo del Instituto de Historia y Museo Militar del Ministerio de Defensa Nacional (AIHMM), and many of the contemporary photographs included in the book derive from my work in this archive. During the time of my research the AIHMM was in the process of being reorganised and most of the photographs were stored in boxes with no explicit information about their provenance or context.

Despite oral and written evidence forming integral parts of this research, my focus is not simply on the Chaco War's material traces but also on people's engagement with them, past and present. Consequently, rather than trying to measure and record sites, structures and artefacts in the process of ruination using conventional archaeological methods, this study focuses on recording the experience of landscapes and things through their manifold material realities. An archaeological approach to the Chaco War and its afterlives is thus not limited to the analysis of humanly manufactured objects, but also includes consideration of human bodies themselves, along with other non-human entities such as trees and animals, and the landscape itself. A focus on the physical remains further allows a diversity of materials to be examined - ranging from ploughs to mugs and decorated artillery shell cases - and to disclose the multiple worldings that are enacted by and unfold around those things. By including the material culture produced by the Mennonite and indigenous communities in the Chaco, this book attempts to excavate alternative ontologies and materialities that are traditionally ignored in the official narratives of the war. Examining the material culture of the Chaco War thus opens up possibilities for a non-Eurocentric archaeology and non-western engagements with such worlds.

The variety in sources for this study not only stretches intellectual boundaries but also transcends the physical borders of the conflict. Although the war was fought in the trenches and battlefields of the Chaco, the conflict landscapes are not limited to battlefields and military outposts. Instead, they include - among others - material places such as towns, train stations, hospitals, cemeteries, ammunition factories, ports, people's homes and object assemblages situated as far away as the United States (see Chapters 4 and 5). These attest to the recursive and entangled relationships between people, objects and landscapes in a wider social and material context. Hence a bunker, trench or military cemetery cannot be studied in isolation, but should be examined as part of a broader 
assemblage of objects, persons and landscapes that have been shaped by the destructive powers of industrial war. Such collectives are planetary in scale, and function as hyperobjects (Morton 2013). Their causes and effects can only ever be partially viewed and understood by their examination in one locale. Nonetheless, a focus on conflict landscapes and material culture has the potential to reveal the global spread of such phenomena and to literally map the varied ways in which they are manifest in the contemporary world.

\section{Note}

1. French anthropologist Marc Augé first used the term 'supermodernity' to describe the excess of information and space characteristic of the modern age: 'This need to give meaning to the present, if not the past, is the price we pay for an overabundance of events corresponding to a situation we could call "supermodern" to express its essential quality: excess' (Augé 1995, 29). 


\section{2 \\ 'Sin vencedores ni vencidos': The Chaco and its forgotten war}

The Chaco War arguably remains one of the most obscure and understudied armed conflicts of the twentieth century. Fought over a supposedly 'empty' stretch of 'wilderness', it affected military and civilian groups from different ethnic backgrounds. This chapter is an introduction to the Chaco region, the people involved in the war and the history of the conflict. I first outline the geography, climate and flora and fauna of the region. I then introduce the Chaco's indigenous inhabitants, who have inhabited the region for centuries, and discuss their role in the conflict. Following this, I turn my attention to the Mennonites, a religious group that immigrated to Paraguay in the years prior to the outbreak of the war. The Mennonites' background and reasons for moving to the Chaco are reviewed and their involvement in the conflict examined. The chapter also introduces the Bolivian and Paraguayan soldiers and explores their characteristics and attitude towards the Chaco bush. In a final section, I outline the history of the war by reviewing its antecedents as well as summarising its major battles.

\section{The Chaco}

The Gran Chaco is an extensive alluvial lowland plain stretching approximately 250,000 square miles west to east from the foothills of the Andes to the shores of the Río Paraguay (Paraguay River) and north to south from the Mato Grosso do Sul in Brazil to the Argentinian provinces of Formosa and Chaco. The Gran Chaco can be divided into three main areas: the Chaco Bajo (Low Chaco), the Alto Chaco (Upper Chaco) and the Chaco Central (Central Chaco) or Chaco Boreal, with the latter being 
at the heart of this investigation. Today, the Chaco comprises around 60 per cent of Paraguay's total area whilst also constituting the republic's least populated region (Renshaw 2002, 31). It is also the country's hottest and most inhospitable place, in which it is almost impossible to find relief from the sizzling daytime temperatures that often exceed $40^{\circ} \mathrm{C}$. Described by British exploratory journalist Julian Duguid as a 'Green Hell' and a 'colossal block of forest, so vast that the mind refuses to grasp the full immensity of its range' (Duguid 1950 [1931], 19), the Chaco is both frightening and mesmerising at the same time. It is covered largely in dry forest, palm trees, cacti and patches of high grass and shrub savannah; the thought of getting lost in a labyrinth of thorns and dust is indeed a terrifying one. Duguid furthermore states that at first sight, this 'Green Hell' seems 'motionless in the sunlight' and 'just a wood, silent, empty [...]' (Duguid 1950 [1931], 20). Closer inspection reveals, however, that under its monotonous greenish-brown coat, the Chaco bush is surprisingly beautiful and very much alive.

Second only to the Amazon in its extent, the Gran Chaco's ecosystem is teeming with a myriad of insects, spiders and scorpions, many of which are poisonous. It is also home to a multitude of mammals including the tapir, giant anteater, capybara, peccary, armadillo and maned wolf. Reptiles such as caimans, iguanas, tortoises and snakes are also common. Two of the region's shyest and most enigmatic inhabitants are the jaguar and the puma. Rarely sighted, they roam the Chaco underbrush and the human imagination. Like many of the animals that are native to the bush, these big cats are primarily nocturnal creatures that seek refuge from the sweltering midday heat and only become active once the sun has set. The Chaco can indeed appear eerily quiet during the day when only colonies of busy ants seem to be going about their daily business, unfazed by the burning sun. It is not until late afternoon that the creaking and rasping in the underwood begins and the bush slowly comes to life.

Whereas thermometers can fall below zero, and frost is not uncommon during the night in the dry and short winter months, nightfall rarely brings relief from the stifling atmosphere during the summer months of October to April. Summer also brings a short but heavy rainy season, which briefly leaves the Chaco in colourful bloom before turning large desert areas into muddy swamps and infesting the bush with swarms of mosquitoes. July finally sees the start of the much-dreaded dry season, which is characterised by months of severe drought that drain the Chaco of all colour and transform the bush into a 'waterless hellhole' (English 2007, 17). 


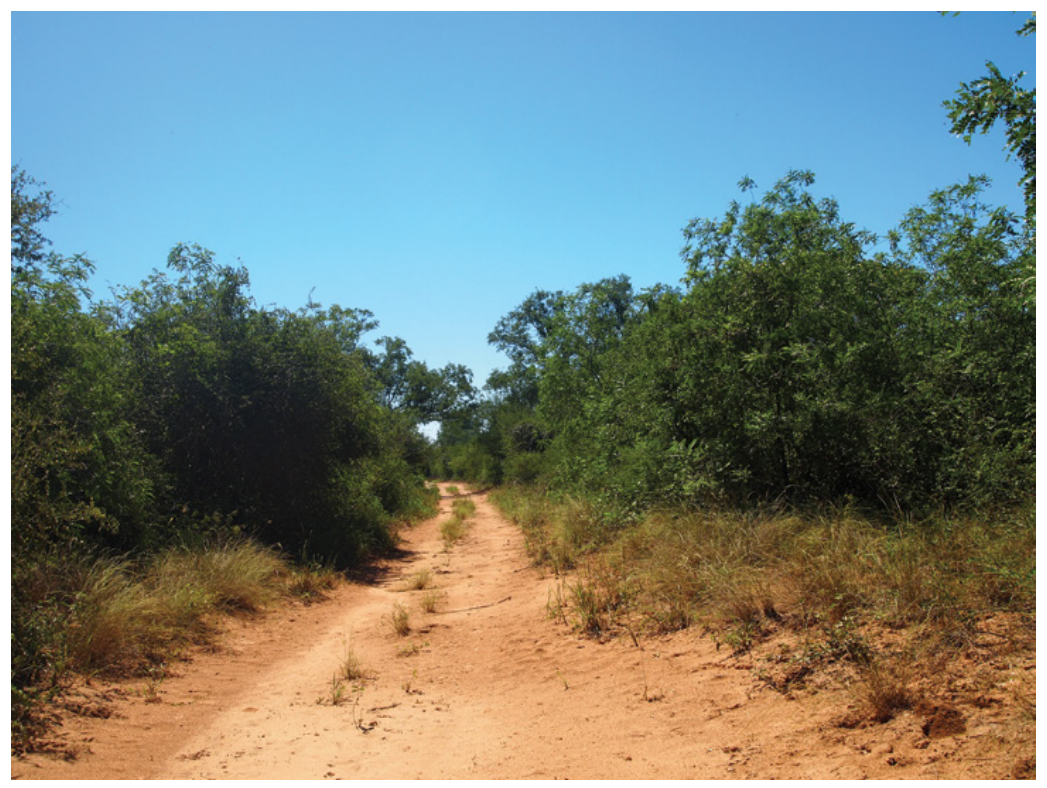

Figure 2.1 Bush landscapes typical of the Central Chaco (Source: author).

\section{The indigenous populations}

"Had it not been penetrated by the "White Man", the Chaco would have been inhabited by around ten different indigenous communities totalling almost 50,000 people at the time of the outbreak of the war', write Luc Capdevila et al. (2010, 8). According to René Harder Horst the Chaco was populated by indigenous peoples from four linguistic families in 1930:

Except for the two Guaraní peoples, tribes in the Chaco shared linguistic ties. The Ayoreode (also Ayoreo) and Ïshïro (Ishir) were members of the Zamuco linguistic group who had traditionally inhabited the northern Chaco, the first closer to Bolivia and the second nearer the Paraguay River. The Enlhit - whom Paraguayans pejoratively referred to as Lengua - as well as the Angaité, Sanapaná, Guan'a and Enenlhit, belonged to the Lengua-Maskoy linguistic group and lived in the central and eastern areas of the Chaco nearer the Paraguay River. The Yofuaxa, Nivaclé, and Mak'a shared MatacoMataguayo linguistic ties and had in historical times lived in the 
central and southern areas. Finally, the Toba-Qom, of Guaicurú linguistic ancestry, had traditionally resided in the south-eastern Chaco (Harder Horst 2006, 15).

The struggle of the Chaco's indigenous populations over their ancestral lands did not, however, begin with the invasion of the Paraguayan and Bolivian armies. Since the end of the nineteenth century they had been subjected to conversion attempts by various religious groups. More significantly, perhaps, Paraguay's, Bolivia's and Argentina's expansion of farming cash crops such as sugar and cotton had resulted in the contraction of their territory and restricted access to resources (Harder Horst 2006, 15).

In 1930, most of the Gran Chaco's indigenous peoples lived at the foot of the Andes, where rivers could supply them with enough water and also separated them from steadily encroaching modernity. Feeling pressured by their ever-shrinking territories, various groups believed that stepping into the 'white world' was their only chance of survival. This resulted in whole families moving to the Argentinian Chaco to work on sugar plantations, only to succumb to alcoholism and disease (see Gordillo 2004). Others migrated to Alto Paraguay to become farmhands on Paraguayan estancias (Harder Horst 2006, 15). During the pre-war years, interaction with the Paraguayan and Bolivian militaries also became a continuous occurrence. In an attempt to flee violence at the hands of plantation owners and soldiers, several indigenous communities decided to take refuge further inland in the Central Chaco, which was home to groups of mobile hunter-gatherers. Despite the latter's best efforts to avoid contact with non-indigenous settlers, they could not escape the consequences of western expansion. The sudden contraction of their ancestral land coupled with the influx of immigrating indigenous groups to the area resulted in warfare between the different indigenous populations (Capdevila et al. 2010, 9).

\section{The indigenous populations and the Chaco War}

Despite the predominant indigenous occupation of the Chaco at the outbreak of the war, neither Paraguay nor Bolivia acknowledged indigenous peoples' exploitation of the land and its resources. The region was never considered indigenous territory, nor were the native populations recognised as citizens of either nation state. Instead, the latter saw the Chaco 
as an empty geographic entity, a 'wilderness' that, nonetheless, formed an integral (if slightly neglected) part of their respective civilised patria. Indigenous people just happened to live there. In fact, according to the general public and military perception of the time, these 'barbarians' simply formed part of the Chaco flora and fauna (Capdevila 2010, 22). Even more disturbingly, indigenous people were regarded as menacing 'creatures without a soul' and as such could be shot like wild prey (Heinz Wiebe, pers. comm.). Even those Bolivian soldiers who were native to the Andes and of indigenous origin saw themselves as superior to the indigenous people of the Chaco lowlands. During the war, both armies would frequently evoke fear in newer and younger recruits by relating gruesome stories of bloodthirsty 'savages' attacking military outposts. In his memoir, Paraguayan soldier Ladislao Bustamante Rodríguez claims that 'not even the tigers or the lions are as dangerous as the Moro Indian' (Bustamante Rodríguez 1987, 36).

Despite their prejudices and fears, both armies recognised at an early stage that indigenous knowledge of the disputed territory was indispensable to a successful military operation. While the bush was an alien place for the soldiers, it was home for the Chaco's indigenous inhabitants. They knew how to survive months of drought and identify the forest fruits and medicinal herbs. The acquisition of an insider's understanding of the Chaco flora and fauna could mean the difference between life and death during the war. The locating of natural water sources, such as pozos indios (indigenous wells), was a necessity that required indigenous guidance and occasionally created a friendly bond between indigenous people and military personnel (Belaieff 1934).

One of the most famous friendships between a member of the Paraguayan military and the Chaco's indigenous populations is that of Russian-born General Juan Belaieff and the Chamacoco (now Ishir) and Maká indigenous groups. An ex-official of Tsar Nicholas's Imperial Guard, Belaieff had moved to Paraguay after the Bolshevik Revolution in 1917. Upon his arrival, he was immediately employed by the Paraguayan military for his cartographic skills. He became known as an explorer of the Chaco, and his personal interest in anthropology and his host country's indigenous populations led to the formation of close relationships with Ishir and Maká men. Although he was appointed the Paraguayan army's chief cartographer, Belaieff can be considered an early anthropologist of the Chaco, with his written observations focusing on both the region's geographical features and its indigenous populations (see Belaieff 1941). His interest in and support of the Chaco's indigenous people did not end with the war. During the agricultural expansion and the 
contraction of indigenous territories in the Chaco in the 1940s, Belaieff became an advocate for Maká land rights, securing the group land for a reserve (Chesterton and Isaenko 2014).

Although friendly collaborations between indigenous people and soldiers existed, the belligerent parties soon realised that the former were also easily exploitable workforces (Riester 2008, 193). Indigenous men were made to take on the role of sappers, hacking dirt roads and digging trenches in the bush, while indigenous women frequently became victims of sexual abuse (Paniagua 1994, 105; Harder Horst 2006, 16-17). Indigenous people were furthermore used as guides and spies, which often resulted in their execution owing to fears or allegations of espionage and betrayal of a nation state - a concept that they most likely did not understand and were not considered part of. Others fell victim to various diseases spread by the soldiers, while thousands more were uprooted by the militarisation of their ancestral lands and forced to move to unfamiliar territory (Harder Horst 2006, 15, 16-17; Capdevila et al. 2008, 48-56).

Most significantly perhaps from the perspective of the belligerent states, the hitherto largely ignored indigenous presence in the Chaco suddenly proved essential to the national cause. In fact, indigenous people were seen as living proof that survival in the bush was possible and that the latter was worth fighting over (Capdevila et al. 2008, 20). In addition, their indigenous status was now being used by both countries to legitimate their ownership of the Chaco. On their part, the Paraguayans claimed that the Guaraní indigenous people and their various sub-groups, and not the people of the Bolivian Altiplano, were the first and, hence, rightful occupiers of the Chaco. As mestizos of both Spanish and Guaraní descent, sharing language and customs with their Guaraní ancestors, the Paraguayans believed they were entitled to the Chaco as far up as the Bolivian lowlands (Capdevila 2010, 30). Bolivia, which as a nation was predominantly made up of mestizos and Quechua and Aymara indigenous people, concluded that their own country's indigenous heritage justified Bolivian ownership of an indigenous Chaco. Similar to the use of the Choctaw language by Navajo 'code talkers' in the Second World War (Santella 2004), the Paraguayan and Bolivian armies both adopted their respective indigenous languages in an effort to disguise military communications. The indigenous code talking proved less successful for the Bolivians as their military officials were of mainly white European and mestizo origins and did not have any knowledge of the Quechua or Aymara language. This language barrier constituted a further major problem within the Bolivian army, as the majority of the Quechua and Aymara soldiers did not speak any Spanish. The Paraguayans, on the 


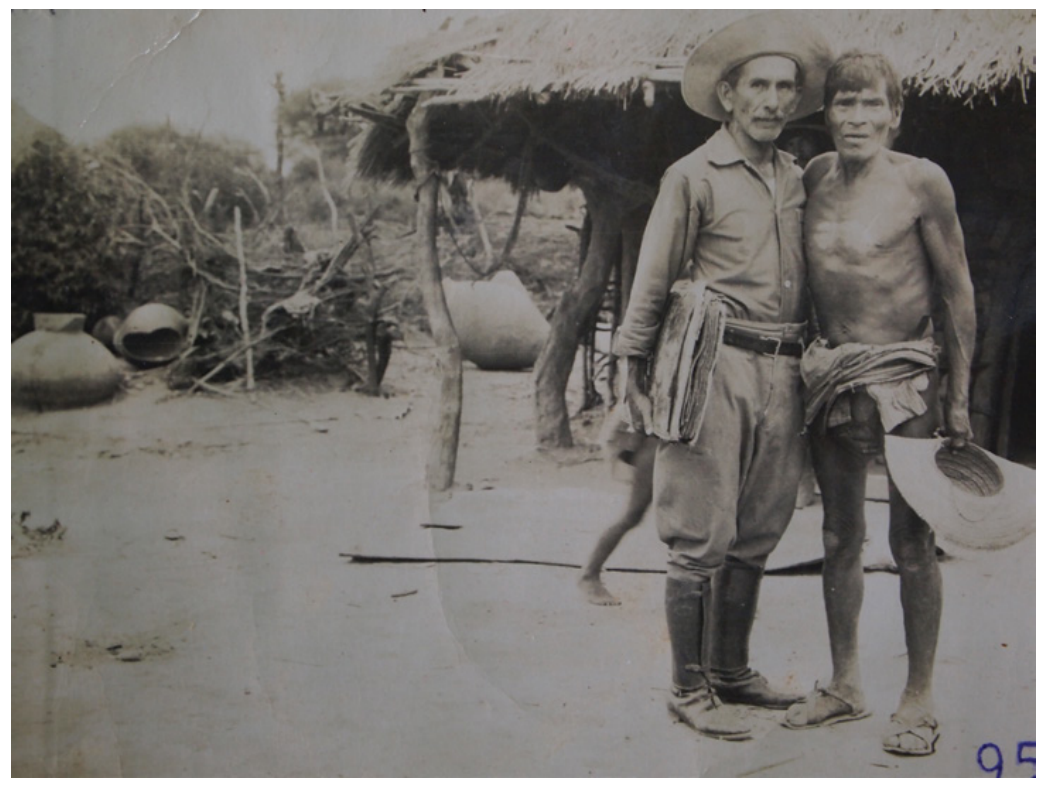

Figure 2.2 Military-indigenous encounters during the war (Courtesy of AIHMM).

other hand, mastered the Guaraní language and were able to successfully employ it in the communication of secret information during the war. While Paraguay adopted a colonial attitude towards the Chaco's indigenous populations, Bolivia failed at 'nationalising' them and only managed to conscript a small number of Chulupí and Enlhet men to join their Quechua and Aymara brothers in the defence of 'their' Bolivian patria (Capdevila et al. 2008, 24; Capdevila 2010, 32).

\section{The Mennonites}

The Mennonites, named after their religion's founder Menno Simons (1496-1561), are an evangelical free church that arose from the radical Anabaptist movement during the Reformation in the sixteenth-century Low Countries. Traditionally, Mennonites practise adult baptism and aim to lead what they perceive to be a simple and peaceful yet hard-working life, secluded from the technological and social progress of modern society. They believe in pacifism and therefore oppose any involvement in armed confrontation. However, throughout history, persecution and the 
restriction of religious freedom continuously forced them to emigrate, and in 1926 the first group of Mennonites arrived in the Chaco, with a second wave following in 1930, and a third in 1947. ${ }^{2}$

When the first Russian-Canadian Mennonite families set out on their voyage to Paraguay - and what they believed at the time to be a Paraguayan-owned Chaco region - they carried little more than the clothes on their backs and a profound trust in God. Only 60 years earlier the parents of those packing up their lives to move to South America had arrived in Canada from Russia as the latter country no longer granted them the privileges that the community thought essential to their faith and culture. Leaving and uprooting whole communities was again deemed a necessary but by no means easy step. The Mennonites had come to cherish Canada, where they lived a secluded and simple farming lifestyle undisturbed by the outside world.

After the First World War, however, their situation suddenly started to change. The standardisation process taking place in the Englishspeaking part of Canada meant that English was to be the only language used in classrooms. This new regulation, however, was not reconcilable with the Mennonite faith, as the Mennonites were adamant that the Bible be preached, and their children be taught, in German. As a result, a group of more traditional 'Old Mennonites' decided to emigrate to Mexico. Having come to love their home country, the remaining communities decided to accept English in their schools. When the Canadian government then decided to employ its own teachers within Mennonite schools and to drop religious education, more Mennonites felt the need to leave Canada. There was also a general anti-German feeling in the Canadian population at the time and this was often directed at the German-speaking Mennonite communities. Yet it was the intensification of military conscription and the country's advocacy of a stronger national defence that most clearly contradicted the Mennonite pacifist belief system, as compulsory military service could not be reconciled with their worldviews (Friesen 2004, 10-12).

Religious faith is one of the pillars of the Mennonite doctrine and people strongly believed that the only possible explanation for why God would lead them into such an inhospitable jungle as the Chaco was that he wanted them to 'show the indigenous people how to lead a humane life through a sedentary lifestyle and hard work' (Heinz Wiebe, pers. comm.). Unity and solidarity are further key tenets of the Mennonite community. In other words, the common good should always come before self-interest. This belief is also reflected in people's attitude towards physical labour. Mennonites are hard-working individuals who consider 
the labour and diligence, commitment and perseverance of each member essential for the survival and success of the community as a whole.

Once the decision to leave Canada was made, the Mennonites started looking for a new place that they could call home. They contacted Samuel McRoberts, a wealthy and well-travelled financier in New York, who agreed to help. During a journey by ship to Buenos Aires in 1920, McRoberts happened to meet Manuel Gondra, the newly elected President of the Republic of Paraguay, who showed a keen interest in the Mennonite cause. Shortly after their chance meeting McRoberts sent his emissary, Fred Engen, to explore the Chaco for suitable farmland. Engen was a Norwegian-born pacifist who dreamed of founding a 'state of peace' and was sympathetic to the Mennonites' situation. In his quest to find a place appropriate for colonisation he had just returned from a pioneering trip into the Chaco. He was accompanied by a handful of local Toba indigenous people, who knew both the bush and the Enlhet communities that inhabited the area they were going to inspect, and three packed mules. A few months prior to the expedition, heavy rain had inundated large parts of the Chaco, so when Engen and his small delegation arrived, they found much of the bush under water. Setting out right after the wet season meant that the Chaco was green and in bloom, and the lagoons carried abundant water. After two arduous weeks of cutting through the thick and swampy underbrush the men finally got to a dry elevated area that would later become known to the Mennonites as Kamp. ${ }^{3}$ The Kamp was covered in lush high grass, which Engen concluded would make excellent pasture for cattle to roam on and feed from. Little did he know that the cows would not eat this particular type of grass and that heavy rain in the Chaco would be followed by months of intensive drought, which cracks open the earth and would later continually threaten the existence of both livestock and men. One year later and unaware of the challenges that any potential coloniser would inescapably face, Engen guided a group of Mennonite delegates to the elevated area that had showed so much promise on his previous visit (Friesen 1997, 79-97).

Prior to the Mennonite immigration, the Paraguayan government worried that Mennonite settlement efforts in the Central Chaco would fail as previous colonisation attempts of the region had done so. The Mennonites were, however, known for successfully settling remote and difficult-to-farm areas in Prussia, Russia and Canada in the past (Friesen 1997). To encourage and facilitate their move to Paraguay they received financial and logistical aid from the North American-based Mennonite Central Committee (MCC) in the setting up of their villages. Ahead of the 
group's move, a small delegation of Mennonites accompanied by indigenous guides was sent to the Chaco to examine this potential new home. As it happened, the members arrived after heavy rainfall had turned much of the region into marshland. The muddy ground coupled with the lack of roads made progress painfully slow. Moods were lifted, however, when the group finally reached an elevated dry region. The sight of Kamp areas covered in high grass delighted the experienced Mennonite farmers, who were blissfully unaware of the fact that it was not suitable for cattle consumption. Their hopes were raised further when they spotted the small vegetable and fruit patches that the welcoming indigenous people maintained. They had already noted potatoes and cotton growing abundantly around the town of Puerto Casado (Quiring 2013, 168). Could this really be the 'promised land' as it had previously been described by Engen (Friesen 1997, 79-97)?

Situated $678 \mathrm{~km}$ north of Asunción on the west bank of the Río Paraguay, Puerto Casado was a bustling and booming place that was largely owned and controlled by Carlos Casado, a wealthy Argentinian businessman whose family had bought large parts of the Chaco from the Paraguayan government after the War of the Triple Alliance. Casado had established the very successful Carlos Casado Company, which specialised in the production of tannin. This was gained from the hardwood quebracho tree that is native to the Chaco. In order to transport the tree trunks Casado had built a railway running from his factory in the centre of town $60 \mathrm{~km}$ into the bush, and this was eventually extended for Mennonite and later military use.

Negotiations with government officials and Casado started upon the group's return from the Chaco. The delegation expressed their positive impression of the Chaco's agricultural potential and their keenness to relocate their people into this 'wilderness'. Official consent was given by Paraguayan authorities and soon after the Mennonite communities in Canada received an invitation for immigration to Paraguay (Friesen 1997, 158-61). Much to the regret of the hopeful Mennonite families, the move to South America had to be put on hold for a four-year period due to an economic crisis in Canada. Negotiations with Casado were eventually reinstated in 1925 and McRoberts' US-based Intercontinental Company proceeded to buy 179,200 hectares of land in the Central Chaco, 53,760 of which were at the Canadian Mennonites' disposal (Friesen 1997, 532).

Intercontinental Company Limited, owned by McRoberts and various US business partners, was a Winnipeg-based company dealing specifically with the Canadian Mennonite emigration to Paraguay. In return for their land in Canada, the company offered the Mennonites land that 
it had bought from the Casado family in the Chaco. The Corporación Paraguaya, its sister company, was later established in Paraguay to manage the land purchases and allocations in situ (Friesen 1997, 193-204; Quiring 1934b, 36). Of the 179,200 hectares that the company bought in the Chaco only 30,760 were given to the establishment of a Mennonite colony as McRoberts was hoping to sell the remaining land to other Mennonite and non-Mennonite communities interested in settling the Central Chaco (Friesen 1997, 532).

In 1926, the first group of Mennonite immigrants finally arrived in Puerto Casado by boat from Manitoba, Canada, via Argentina. More Mennonite families made their way over in 1927 and not long after their arrival the hopeful group boarded the train headed west into the unfamiliar Chaco scrubland. As they travelled into the depths of the bush, they felt more and more disheartened. They were expecting lush open grassland but instead had to fight their way through thorny forests. After arriving at the terminus they continued their arduous journey on foot and with the help of oxcarts for a further $220 \mathrm{~km}$ before finally getting to their designated plots of land (Friesen 2004, 10). Colonia Menno, with its administrative town of Loma Plata and its members commonly known as Menno, became the first ever Mennonite settlement in the Chaco and Paraguay as a whole (Klassen 2012, 13).

From 1930 to 1932 the Menno were joined by a total of 2,000 Russian Mennonite refugees who had managed to flee the Soviet regime in Russia. Pressured by Germany, which had granted them temporary residence, to find a different home, and enticed by the privileges offered by Paraguay, the Russian refugees were now hoping to start a new life in the Paraguayan outback (Friesen 1997, 535-42; Quiring 1934a, 62-4). Having arrived in Puerto Casado, they boarded the train, whose tracks by now extended $145 \mathrm{~km}$ into the bush. A group of Mennos was awaiting them at the terminus with oxcarts to take them $110 \mathrm{~km}$ to their allocated plots of land northwest of Colonia Menno (Abercrombie 1933, 1174; Friesen 1997, 549). Like the Canadian Mennonites before them, they looked in awe at the alien wilderness they were crossing with such difficulty, wondering how they were going to build an existence in this stunted forest (Quiring 1934a, 65). Dedication, endurance, solidarity and an unshakeable trust in God ultimately resulted in the establishment of Colonia Fernheim with its administrative centre of Filadelfia and a tight-knit community of Fernheimers.

Established between 1947 and 1948, Colonia Neuland with its centre of Neu-Halbstadt is the third and final Mennonite colony founded in the Central Chaco. Like the Fernheimers, they had fled the Soviet regime 


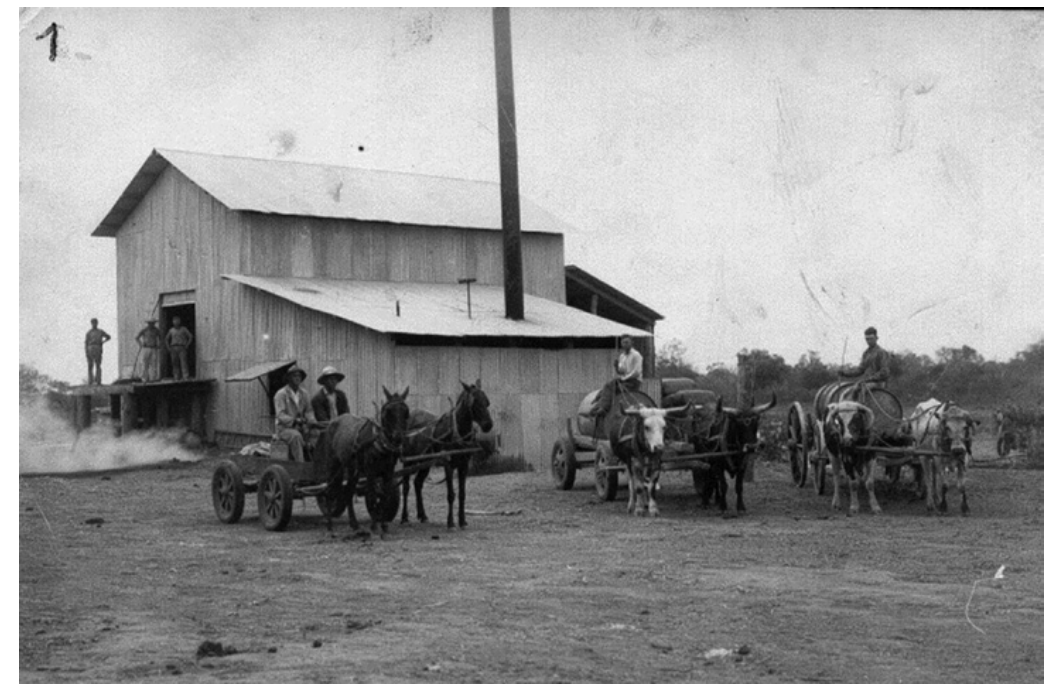

Figure 2.3 Chaco Mennonites in the 1930s (Courtesy of GAKM).

in Russia and had arrived in Paraguay via Germany. ${ }^{4}$ The new settlement was founded approximately $450 \mathrm{~km}$ northwest of Asunción and south of Colonia Fernheim. Although at that point the newly denominated Neuländer constituted the largest group of Mennonite immigrants to the Chaco, they now form the smallest colony.

From the start, all three colonies relied on help from Enlhet indigenous people, and later the Ayoreo, to survive in their new environment. Today the Mennonites claim that, attracted by the fact that the Mennonites always had food, the Enlhet 'left the bush' of their own free will to become workhands on Mennonite farms (male Fernheimer, pers. comm.). Relationships were generally amicable, and the Mennonites soon started to convert and baptise the first indigenous people. Conversion efforts temporarily came to a halt when the military started to encroach on the area. Frightened by the soldiers, most Enlhet retreated into the depths of the bush where they were hiding out until the end of the war (see Stahl 2007).

\section{The Mennonites and the Chaco War}

Referring to the fighting in the Chaco in a 1933 issue of the Christian Century, a contemporary observer notes that the Mennonite immigrants, 'although a peaceful noncombatant people, seem to be the immediate 
cause of all trouble' (Abercrombie 1933, 1173). Yet according to Mennonite author Gerhard Ratzlaff (and a general belief amongst the modern-day Chaco Mennonites), Paraguayan officials lured the oblivious immigrants into the bush with all sorts of privileges such as freedom of religion, control over their own education system and exemption from military service, so as to use them as a 'political weapon' against Bolivia (Ratzlaff 2009, 20). The Mennonites' arrival in Paraguay was evidently met with suspicion from local politicians and the general population, who feared that all these concessions could lead to the creation of a Mennonite state within the Paraguayan state (Ratzlaff 2009, 14-21; Chesterton 2013, 98-9). Even so, Paraguay hoped to 'civilise' the Chaco by establishing a permanent human presence in its centre (Chesterton 2013, 99). In fact, the Paraguayans believed that because they turned the Chaco 'wilderness' into arable farmland and permanent villages, they were entitled to it (Ratzlaff 2009, 20-1). The Mennonites were thus recruited not as soldiers armed with rifles but as an 'army of freedom, which carries the plough as a weapon of attack and presents the cross of Christ as a weapon of defense' (Genaro Romero, President of Bureau of Immigration Services as quoted in Friesen 2004, 7). Addressing the President of the Republic during a congress meeting a few years earlier about a possible Mennonite emigration to Paraguay, Senator F. C. Chaves stated that:

Nowadays, President, one does not defend one's homeland solely with a rifle on one's shoulder; one defends it by solving the problem of subsistence; while the military forces are fighting, it is essential that others are working the land with the noblest duty of supplying provisions ... One has to bear in mind that the privilege, exemption from military service, to be given to the Mennonites, will be compensated with other services, while they are staying in our country ... They are going to settle and become land holders, an action which will constitute the strongest bond; so that while they will not serve us in the trenches, they are going to serve us there, they will cultivate the land, where we have never even visited let alone worked. Because this is the truth, the Chaco is a desert, unpopulated ... The Mennonites are going to represent an army, which is capable of effectively defending our sovereign rights ... (quoted in Ratzlaff 2009, 17-18).

Prior to their move, the Russian-Canadian Mennonites had received a letter from the Bolivian Embassy in Washington stating that the Central Chaco was Bolivian territory and that the entering Mennonites would in fact need a Bolivian visa. Upon enquiry, they were assured that the 
area in question was Paraguayan as it lay east of the status quo line defined in 1907 (Klassen 1993, 55-7; Ratzlaff 2009, 21). Although the Mennonites encountered various manned Paraguayan military posts upon penetrating the Chaco, they did not seem worried as they were convinced that it was impossible to stage a war in such a 'wilderness' (Ratzlaff 2009, 24).

It was thus in a strange twist of fate that the Mennonites, who as a Christian denomination reject all armed violence and strive for a peaceful isolated existence, settled in close proximity to military outposts. In the case of the Russian-Canadian Mennonites, they had 'escaped the claws of Communism' in the Soviet Union only to move into the heart of another conflict zone that would eventually claim thousands of lives (Friesen 1997, 546). Instead of the peace and quiet they were hoping to encounter in the Paraguayan hinterland, the Mennonites found themselves surrounded by the distant sound of artillery fire and the threatening hum of aeroplanes. As their villages became passage routes for Paraguayan soldiers on their way to the front, trade between the two groups soon emerged (see Chapter 4). Mennonite community buildings were converted into military hospitals and the already meagrely filled village wells became invaluable lifelines for thirsty soldiers (Klassen 1993, 2009, 2010). Remembering the Mennonites' escape from the Bolshevik regime, Martin W. Friesen states that "The "world", which we fled with such big sacrifices, was now frighteningly close again' (quoted in Ratzlaff 2009, 24).

\section{The Bolivian soldier}

Prior to the war, Bolivia and Paraguay had been largely pre-industrial and 'pre-modern' nations, in the western understanding of the term. As neither country operated a domestic arms industry, all weaponry and heavy equipment had to be imported from Europe and the US (Hughes 2005, 416). Most weapons consisted of old and often faulty leftover matériel from the First World War (Pendle 1967, 26). The same weapons, which had already claimed countless lives on the battlefields of the Great War almost two decades earlier, were now about to be unleashed on men thousands of miles away in the remoteness of the Chaco. The horrors of European industrialised warfare were now imposed on armies composed of largely non-literate indigenous and Spanish-mestizo Amerindian peoples to fight in a conflict created and dictated by a Hispanic elite (Breithoff 2012, 148; 2013, 67). 
At first sight Bolivia appeared far better prepared for war. With around 60,000 recruits, its military forces were almost three times the size of its enemy's and its experienced German-trained officers promised a prompt victory. In preparation for conflict, Bolivia had signed a deal worth $£ 3$ million with British arms manufacturer Armstrong-Vickers, which, due to Bolivia's financial restrictions, was eventually reduced to $£ 1.25$ million. With Chile and Argentina denying Bolivia passage through their ports, the landlocked nation had to turn to the port of Mollendo in southern Peru. A third of the military equipment ordered never arrived in sufficient quantity or quality and a substantial part of the freight simply 'vanished' upon arrival in Peru (Hughes 2005, 318).

Getting the equipment to the front line constituted a further challenge at the start of the war. Unlike the Paraguayan capital, which was situated relatively close to the centre of operations, Bolivia's main cities were all located at a considerable distance from the initial battle zone. In addition, the dirt roads hacked into the Chaco bush were rudimentary at the best of times and often became impassable after heavy rain. The long supply lines coupled with the extreme weather conditions of the region resulted in frequent delays in getting water, food and weapons as well as soldiers to the front line.

The real disadvantage for Bolivia was its military's unfamiliarity with the Chaco region. As with every war, intimate knowledge of the terrain is crucial and the soldiers' ability to read, understand and use the landscape they are fighting in to their advantage is key to military success (Woodward 2004). The Bolivian forces were primarily made up of Aymara and Quechua indigenous people from the Andean Altiplano, which rises majestically hundreds of kilometres away from the theatre of operations. Used to the cold conditions of the mountains where they had primarily worked as miners and farmhands, the Aymara and Quechua soldiers felt uprooted and disorientated in the Chaco scrub. According to Querejazu Calvo, the indigenous men were accustomed to the vast open spaces of the Andean highlands where transpiration is limited. The density and heat of the Chaco thicket, on the other hand, made them feel claustrophobic and lost (Querejazu Calvo 1975, 128). Their lack of knowledge of the Chaco flora and fauna ultimately led to thousands of soldiers dying from thirst and to generally low morale among the troops (see Chapter 3).

In contrast to the indigenous recruits, most army officers were of Spanish ancestry, while the commander-in-chief, General Hans Kundt, was a German who had served on the Eastern Front in the First World War. Prior to that, Kundt had served in the Bolivian army as a trainer and counsellor, and enjoyed a great reputation amongst national politicians. 
Bolivia therefore hoped that his expertise in modern warfare and experience in the trenches of Europe would ensure a victorious counteroffensive after the Bolivian defeat in the Battle of Boquerón in 1932. It was, however, Kundt's frontal assault military tactics, which he had acquired on the battlefields of the First World War, that would repeatedly bring defeat and great human loss to the Bolivian army (Zook 1960, 126; Farcau 1996, 87-9). Consequently, Bolivia soon realised that his ignorance of the Chaco terrain had catastrophic consequences for the soldiers and the outcome of the conflict as a whole. In addition, communication between the higher and lower military ranks was often a challenge as the common foot soldier did not speak Spanish and the generals were not familiar with the indigenous languages used by their subordinates.

Equipped with German-style heavy green-grey woollen uniforms, heavy boots and steel helmets, the Bolivian forces were also inappropriately dressed for combat in the Chaco scrubland. Bolivian soldier and writer Emilio Sarmiento remembers that although he was made familiar with the use of modern weapons such as the German Mauser rifle and the light machine gun (both of which were used during the Chaco campaign), his military education followed the manual for war in the mountains, ignoring the possibility for armed conflict on Chaco territory (Sarmiento 1978, 42). The extreme heat in the Chaco and the country's precarious economic situation eventually led to the use of lighter khaki cloth uniforms and leather-brimmed hats during the war (Farcau 1996, 230; De Quesada with Jowett 2011, 11). Still, many of the regiments remained inappropriately geared up for the Chaco scrubland, presenting a picture of an incongruous troop 'equipped for fighting in the mountains with designs from the First World War' (Sarmiento 1978, 68). The Bolivians' ignorance of the terrain was further illustrated by their employment of tanks. Although this seemed like a smart strategic move, it proved to be a catastrophic decision in the field. The terrain was treacherous and the risk of suffocation inside the tanks forced the soldiers to open the hatch, which inevitably made them an easy target for enemy gunfire.

The fate of the Bolivian soldiers was ultimately nothing short of a tragedy. Separated from their families by hundreds of kilometres of unfamiliar and impenetrable forest, the Quechua and Aymara 'served as cannon fodder in the errors of inept commanders' (Querejazu Calvo 1975, 131). Even so, they showed a great amount of courage. Despite the heat, hunger and thirst that tortured them in the Chaco, they kept defending a stretch of land that ultimately meant nothing to them (Querejazu Calvo 1975, 131). 


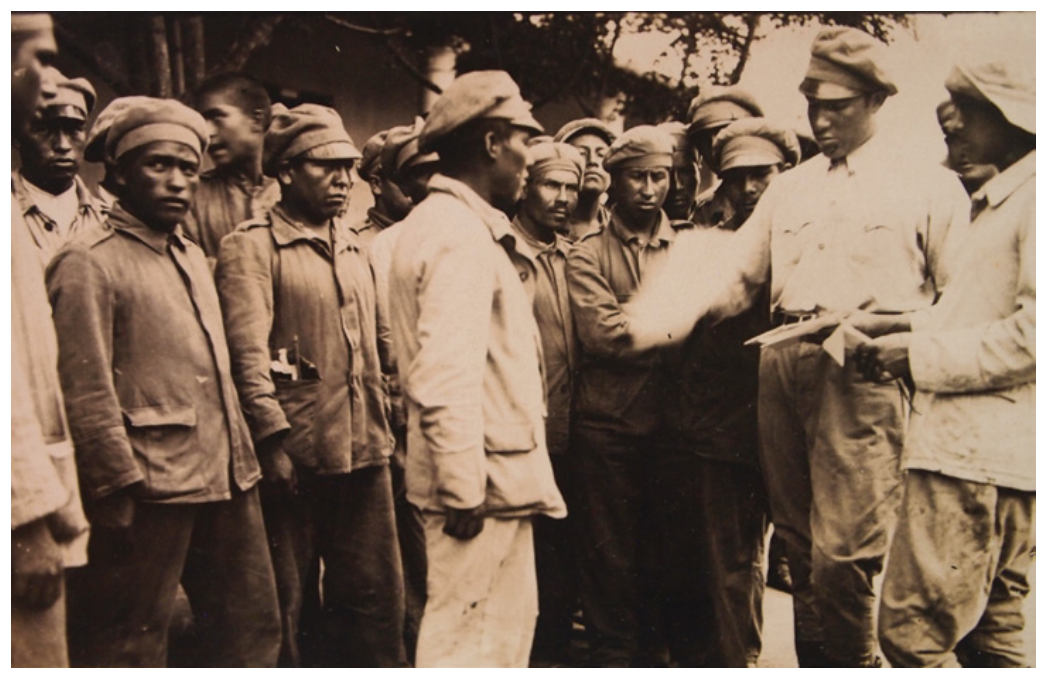

Figure 2.4 Bolivian soldiers receiving instructions from their superiors (Courtesy of AIHMM).

\section{The Paraguayan soldier}

At the start of the war Paraguay was an agricultural nation primarily made up of Guaraní-Spanish mestizo farmers. The country's economy was weak and its infrastructure limited. Like its Bolivian counterpart, the Paraguayan army was equipped with outdated weaponry from the First World War (Hughes 2005, 418; De Quesada with Jowett 2011, 6-7). Although Paraguay's forces were a lot smaller than the enemy's, they not only profited from the unofficial support of neighbouring Argentina but also enjoyed logistical advantages at the start of the war. Unlike Bolivia they had the use of Puerto Casado's train line to transport soldiers and equipment into the Central Chaco. Paraguay also had a better senior command under Lt Col. (later General, and finally Marshal, upon his death in 1940) José Félix Estigarribia, who, in contrast to the Bolivian general, had a superior knowledge of the Chaco landscape.

Although the common Paraguayan soldier had generally never set foot into the Chaco bush before the war, he had internalised strong emotional ties with the region. In fact, the defence of the Chaco was an opportunity for the Paraguayan nation to redeem itself after its defeat in the War of the Triple Alliance almost eighty years before (Chesterton 2013 , 6). In the Paraguayan rationale, the conflict against the merged powers of Argentina, Brazil and Uruguay was nonetheless considered 
a national victory achieved by rural heroes. Paraguay, a nation of simple peasants, had taken up arms ready to sacrifice men and children against its neighbouring powers, and against all odds managed to save the country from extinction (Kraay and Whigham 2004). At the dawn of the Chaco War, the Paraguayan farmhands were once again ready to swap their ploughs for rifles in the defence of the patria (Chesterton 2013, 103). They did not care what their and Bolivia's politicians were agreeing or disagreeing about in international meeting rooms. The only thing that mattered to them was the restoration of their national honour (Chesterton 2013, 104). As a result, the Chaco War helped shape Paraguayan identity as 'the event was a powerful catalyst for national sentiment' (Capdevila et al. 2010, 11). The 'mobilised farmer' from the slopes of eastern Paraguay was once more elevated to the status of national hero as he 'was not [a]soldier, but a warrior' who was proud of his mixed Spanish and Guaraní indigenous heritage (Benítez 1976, 58). Bridget María Chesterton encapsulates the essence of the Paraguayan Chaco War recruit when she writes that:

A combination soldier and agriculturalist was the idealized version of the Paraguayan citizen during the years preceding the Chaco War. This individual - whose racial identity was mestizo, but who often was called 'Guaraní, as learned men and soldiers called the citizens of Paraguay - was the man whom the Paraguayan Liberal regime would call upon to fight the Bolivians in the Chaco. Paraguayans based their ideas about the ideal citizen in the early decades of the twentieth century on the assertion that Paraguayan men must work to farm the land and fight to defend the same land from foreign invaders (Chesterton 2013, 105).

Known to the Bolivians as pila (short for pata pelada or 'unshod'), the Paraguayan soldier generally went barefoot. To anyone who has ever visited the thorny Chaco thicket this might seem a risky and rather foolish undertaking. Although Paraguay's precarious financial situation at the time would explain a shortage of boots, the soldiers' absence of footwear appears to stem from a long-standing provincial tradition rather than economic shortcomings. Writing in the context of the War of the Triple Alliance, Jerry W. Cooney states that despite fears of a cold winter in 1867, women did not need to waste their labour and meagre resources on the fabrication of boots as 'all common Paraguayans - soldiers and civilians alike - went barefoot' (Cooney 2004, 28). 


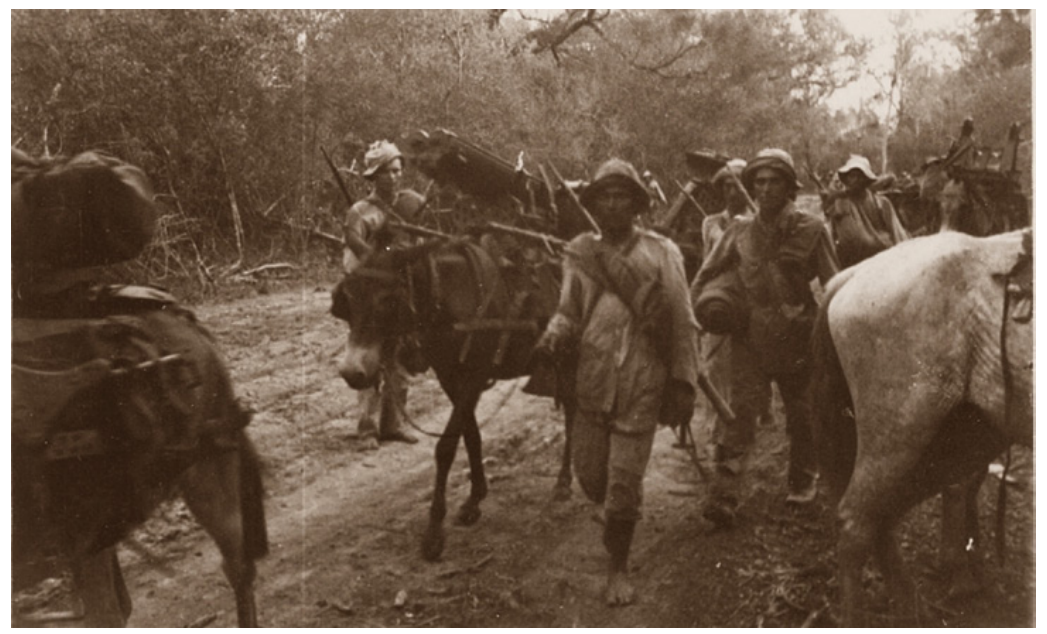

Figure 2.5 Barefoot Paraguayan soldiers with mules carrying arms and equipment (Courtesy of AIHMM).

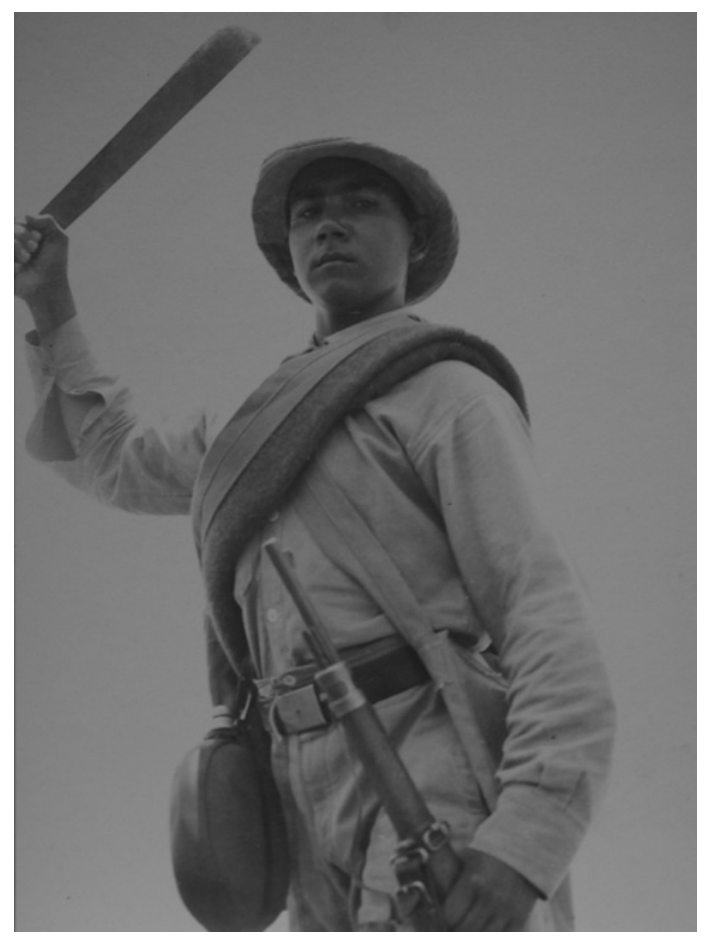

Figure 2.6 A Paraguayan soldier (Courtesy of AIHMM). 
His simple uniform, home-made cow-horn canteen and allimportant machete for cutting through the shrub stood in stark contrast to the European Mauser rifle which he carried. Arming indigenous and mestizo farmhands with industrial weaponry inevitably resulted in the clashing of two completely opposing worlds. Like the Bolivian indigenous soldier, the Paraguayan infantryman had left his crops and livestock behind, swapping his wooden ploughs for Madsen automatic rifles and Stokes Brandt mortars to fight an enemy he did not even know in a landscape he was unfamiliar with. Although he was used to the tropical climate of eastern Paraguay and Bolivian soldiers frequently described him as moving through the bush with 'feline speed and agility' (Querejazu Calvo 1975, 129) and 'like fallow deer' (Sarmiento 1978, 69), the Paraguayan soldier also struggled to survive in the Chaco. Like his Bolivian counterpart he was at the mercy of the natural elements and the Chaco landscape, in which thousands of men lost their lives.

\section{A concise history of the Chaco War}

If one were to define colonialism in its most basic form as 'the conquest and control of other people's lands and goods' (Loomba 2005, 8), the Chaco War could be interpreted as a colonial war fought between two nation states over the annexation of an indigenous territory. In contrast to other so-called colonial wars, such as the American Indian Wars (16071890) with their Indian Removal Act of 1830 , which sought to remove indigenous populations from their ancestral lands by force (Pierpaoli Jr 2011, 381-3), the conflict in the Chaco was not a war fought against the 'Indian', nor was the Mennonite settlement of the Chaco Boreal a deliberate attempt from Paraguay to convert and dominate indigenous people. It was neither the Bolivian nor the Paraguayan state's aim to occupy indigenous territory or to combat, subject, expel or exterminate its indigenous inhabitants (Capdevila 2010, 16-17). In fact, both sides largely ignored the indigenous presence in the area and their exploitation of the Chaco's natural resources. Each nation state saw the Chaco as an 'empty' stretch of land as it was not being exploited in a way which they recognised (Capdevila 2010, 22). In their eyes it was the respective armies' honourable duty to 'civilise' this forgotten part of the nation and bring it into line with the rest of the patria (Capdevila 2010: 27). Although the concept of colonialism evidently goes far beyond military action, I agree with Luc Capdevila that in its essence, the Chaco War was not a war of conquest 
but a 'defence' of the patria against an invading neighbour (Capdevila 2010, 15, 27-8).

The causes of the Chaco War remain disputed amongst scholars. Although rumours of possible oil sources were sparked in the 1920s, oil does not seem to have played a decisive factor in the outbreak of the war (Zook 1960, 72). In the case of Bolivia, possession of the Chaco was of strategic and economic importance. Having lost its coastal province to Chile in the War of the Pacific (1879-83), Bolivia was struggling with its new status as a landlocked country. It therefore sought access to the Atlantic Ocean via the Chaco and the Paraguay River to secure a fluvial output for the export of the tin produced in the mines of Potosí and Oruro (Cote 2013, 741). Moreover, in order to satisfy the increasing demand for petroleum to fuel the mining industry, Bolivia turned its attention towards the Chaco. During the 1920s the Standard Oil Company had secured concessions on a huge tract of oil lands in the Sub-Andean region on the western edge of the Central Chaco but was in constant conflict with Bolivian authorities over legal regulations. The only way for Bolivia to develop its oil sector was by developing the Chaco, the country's much-dreaded region to the east which was 'merely' inhabited by Guaraní indigenous people (Cote 2013, 741-2). Considered a 'desert wilderness' and avoided by foreign investors due to its harsh climate and barren soils, the Bolivian east remained, at least from a western point of view, unexploited (Cote 2013, 741). Bolivia thereupon decided to base its legal rights over the region on territorial regulations dating back to Spanish colonial rule (Farcau 1996, 5-15).

Across the border, Paraguay was still in grave financial debt from the War of the Triple Alliance. The government therefore turned towards selling large plots of land west of the Paraguay River. A significant portion of this land was sold to Argentinian cattlemen, such as the influential Casado family, who then went on to establish their highly successful tannin industry and the associated train line in the area. Missionaries from various religious denominations, such as the Anglicans and the Salesians, also settled the region in an effort to convert the Chaco's indigenous populations (Chesterton 2013). Paraguay consequently believed that it was entitled to the territory through its occupation and exploitation of the area, even though it never expanded into the heart of the Central Chaco due to the latter's limited economic prospects (Farcau 1996, 5-15).

Throughout the 1920s diplomats tried to resolve the border issues between the two nations. Yet while agreement on the matter diminished around official negotiating tables, both armies were busy establishing 
fortines (singular: fortín - military outpost) in the Chaco and confrontations between armed patrols increased in the disputed territory. On 5 December 1928 a small Paraguayan patrol seized a Bolivian outpost in the far northern corner of the Chaco, killing several Bolivian soldiers and triggering a number of armed attacks from both sides over the next few years (Farcau 1996, 12-15). In 1932, while the parties were negotiating possible troop withdrawals at a conference with the Commission of Neutrals in Washington, DC, both governments were busy sealing more or less successful international arms deals (Hughes 2005). It was, however, both countries' general lack of organisation, logistics and equipment that momentarily halted the escalation of the skirmishes into a state of full-blown war (Scheina 2003, 86-7).

While the belligerent nations were trying to organise their armed forces, the latter continued to build fortines and slowly advance in the Chaco whilst closely observing each other's movements. The decisive factor in the building of fortines was access to potable water. The lack of proper roads and transport possibilities, and the sheer distance that both armies had to travel to reach the heart of the disputed territory, meant that a local water source was key to the troops' survival. Whoever controlled a well or a lake controlled the surrounding area. The progression of the war was thus ultimately dictated by the respective armies' access to and control of water sources in the area, meaning that 'Water [was] more important to warfare in the Chaco than fuel' (Klassen 1993, 71; and see Chapter 3). Whereas rising water levels often led to the evacuation of inadequately positioned outposts along the Pilcomayo River, the serious water scarcity in the Central Chaco turned the establishment of fortines into a challenging endeavour (Farcau 1996, 30).

Unsurprisingly then, the discovery of a large freshwater lake by a Paraguayan patrol further exacerbated tensions between the two nations. It was with the help of the Chamacoco/Ishir indigenous people that soldiers led by General Belaieff reached the extensive water source in March 1931, and by July the Paraguayan army had constructed Fortín Carlos Antonio López, a small outpost on the shores of the lagoon, which came to be known as Lake Pitiantuta to the Paraguayans and, later, Lake Chuquisaca to the Bolivians. As control over a freshwater lake as big as Lake Pitiantuta/Chuquisaca in the centre of the arid Chaco scrubland was strategically vital for both sides, Bolivia soon seized what they supposedly believed to have been an abandoned Paraguayan outpost in June 1932 (Farcau 1996, 30-1). One month later, a successful counterattack by Paraguay was followed by a Bolivian seizure of various Paraguayan fortines and the partial mobilisation of the nation (Farcau 1996, 29-36; 
Querejazu Calvo 1975, 31-50). Paraguay reacted with a full mobilisation and with the appointment of Lt Col. José Félix Estigarribia, deputy chief of staff, as head of Paraguayan field operations. To this day, Estigarribia remains undoubtedly Paraguay's most celebrated national hero from the Chaco War, after which he briefly served as President from 1939 to his sudden death in a plane crash in 1940. In the Chaco campaign he acted against official orders to stay on the defensive and launched what came to be known as the First Battle of Boquerón or the First Paraguayan Offensive (Scheina 2003, 93; and see Chapter 5).

David Zook writes that in the morning hours of 9 September 1932, 'the enthusiastic, inexperienced young Paraguayan army disturbed the silence of dawn with “iViva el Paraguay!” [Long live Paraguay!]' (Zook 1960, 94). Although the Paraguayan attackers dramatically outnumbered the men stationed inside Fortín Boquerón, they ignored the additional defensive structures that the Bolivians had added to the original small Paraguayan fort. In the end, it took Estigarribia's troops a further long and agonising 28 days before the Bolivian outpost and its close to 500 remaining exhausted defendants were finally under their control (Farcau 1996, 62).

Their defeat by South America's smallest and poorest nation in the Battle of Boquerón knocked the confidence of the Bolivian army and nation. They had firmly believed that it would be relatively easy to emerge victorious from the war, as they were superior to their neighbour in both weaponry and manpower. Low morale and poor preparation, however, resulted in Bolivia also losing fortines Toledo, Arce and Alihuatá (Scheina 2003, 95). In December 1932, Kundt was made General-inChief of the Field Army by then-President Salamanca. Paraguayan Fortín Nanawa constituted Kundt's chief target (see Chapter 5). Considered the 'backbone' of the Paraguayan defences (Scheina 2003, 96), the site was of great strategic importance to both sides. Nanawa constituted Bolivia's gateway to the Paraguay River and, consequently, the ocean (Zook 1960, 127-8). A Bolivian advance to the river and, eventually, the port town of Concepción would have been a threat to Paraguay's survival as a nation - a menace still all too present in people's minds from the War of the Triple Alliance (Chesterton 2013). The attack on the Paraguayan fortín came to be known as the First Battle of Nanawa (20-26 January 1933). Failing to secure the outpost, the Bolivians dug themselves into a defensive line in front of the fortín while elsewhere in the Chaco various outposts kept changing hands during a number of attacks (Scheina 2003, 97; Zook 1960, 129). After a failed attempt to come to a border settlement with the help of the League of Nations and almost a year after the 
Lake Pitiantuta/Chuquisaca incident, Paraguay officially declared war on Bolivia on 10 May 1933 (Zook 1960, 139-42).

From 4 to 9 July 1933, the Bolivians staged the Second Battle of Nanawa by launching a massive frontal attack on the fortín but despite the use of artillery, aeroplanes, tanks and flamethrowers, they were soon overthrown by the Paraguayan forces (Farcau 1996, 129-40). Throughout the war Kundt repeated the strategic mistake of going on the offensive - a tactic borrowed from the Germans on the Eastern Front in the First World War that proved equally ineffective in the Chaco bush. Kundt, often without any clear objectives and plans and without any knowledge of the terrain, had evidently failed to learn from his previous mistakes (Zook 1960, 148).

Throughout 1933 Paraguay advanced further into the Chaco under the capable command of Estigarribia, who had now been promoted to the rank of general. The Bolivians experienced a devastating defeat at Campo Vía and their weakened forces were no longer able to hold their military headquarters at Muñoz. Finally, a 20-day Christmas ceasefire was agreed upon by the exhausted belligerents (Farcau 1996, 149-64). Not long after fighting had resumed in January 1934, the Bolivian President was forced to resign and, blamed by the nation for Bolivia's high losses, Kundt was finally replaced by General Peñaranda (Zook 1960, 210-15).

After a Paraguayan win at the Battle of El Carmen and the capture of Fortín Ballivián - a major Bolivian base on the Pilcomayo River - the tables suddenly seemed to turn. Having almost reached the foot of the Andes, the Paraguayan supply lines grew, and resources shrank (Farcau 1996, 162). Nonetheless, General Estigarribia made some further large advances in the north and finally entered undisputed Bolivian territory in January 1934. Faced with unfamiliar hilly terrain and a fully stretched supply line, the Paraguayan troops' morale was low and advance towards the Bolivian oilfields petered out. Although the Bolivian forces were better equipped and trained for fighting in the Andes Mountains, their military leaders were incapable of staging a major offensive against the now disadvantaged enemy (Scheina 2003, 102-3). In reality, both sides were simply economically, physically and psychologically exhausted.

At last, a truce was arranged on 12 June 1935. A little over a month later generals Peñaranda and Estigarribia met up amidst the trenches of no man's land to shake hands in a symbolic act of mutual respect and appreciation for the bravery of the opposing army (Querejazu Calvo 1975, 480-2). It was not until 21 June 1938, however, that a peace treaty was signed in Buenos Aires. Astonishingly, it would take an additional 


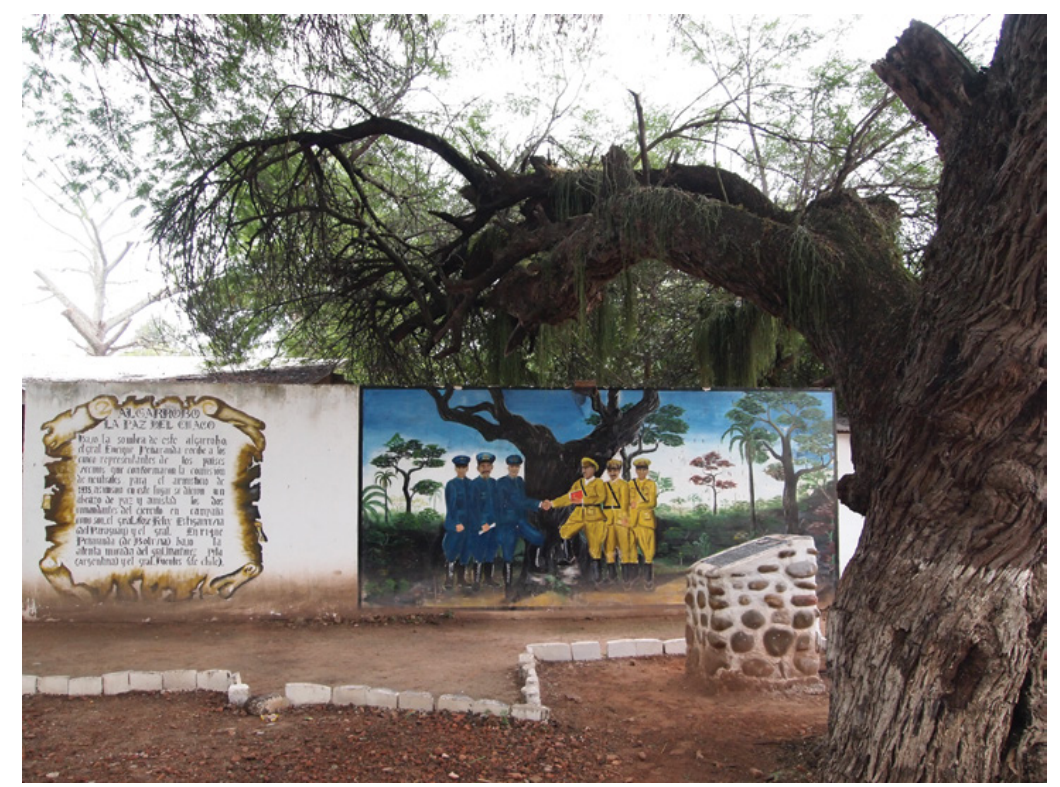

Figure 2.7 'Algarrobo Chaco Peace' mural under an Algarrobo tree in Villamontes, Bolivia, depicting Bolivian and Paraguayan military officials shaking hands over the truce made in 1935 under the very same tree (Source: author).

71 years before a final report on the official demarcation of the international boundary between Bolivia and Paraguay was presented in a 2009 meeting - an event described by the Bolivian President Evo Morales as a 'historic day for Bolivia and Paraguay, a time of friendship and peace, of solidarity between the peoples' (quoted in Ziegler 2016, 175).

\section{A historiography of the Forgotten War}

Whilst I have earlier referred to the Chaco War as the 'Forgotten War', over the past 80 years significant Spanish-language publications on the Chaco War have been published in Paraguay and Bolivia. Nonetheless, these histories of the war are embedded in their own social, historical and political contexts. An exploration of these sources thus helps explain the need for an archaeological approach to the Chaco War and its material and discursive legacies. 
The post-war years witnessed the birth of a literary movement known as la Generación del Chaco (the Chaco Generation), with its most famous contribution being the novel Hijo de hombre (Son of Man) by Paraguayan writer Augusto Roa Bastos, first published in 1960. Many of the books written in the decades following the war are personal accounts by men who fought on both sides. Surprisingly, the majority of these texts are of a technical rather than a sentimental nature. They also tend to be heavily biased and often express nationalist sentiments (e.g. Macias c. 1940; Olmedo 1959; Benítez 1976). There exist, however, a small number of books that yield insight into the Bolivian and Paraguayan soldiers' intimate experience of the horrors of industrial wars. Often beautifully written, these narratives move beyond the practicalities and logistics of warfare. Indeed, these personal accounts are 'riddled with sounds, whiffs, stenches, the feel of violence as well as the tender caresses' (Smith 2015, 5) and thus represent a vivid image of the soldiers' struggle to survive in the Chaco scrubland (e.g. Céspedes 1973, 1975; Sarmiento 1978; Zotti 1974; Florentín 1984; Bustamante Rodríguez 1987; Paniagua 1994).

Patriotic tendencies are further reflected in the Paraguayan and Bolivian traditional military histories dealing with the organisation of the respective armies, the type of weaponry employed and the military strategies implemented in combat (e.g. Ríos 1950; Olmedo 1959; Espínola 1960; Machuca 1962; Adorno Benítez 1963; Mendoza 2013). One of the most famous Paraguayan military histories is the reproduction of Marshal Estigarribia's field diary (Estigarribia 1950). Although Estigarribia focuses on a technical retelling of the Chaco campaign, personal reflections on the events nonetheless occur from time to time (see also Bray 1981). As many of the other authors of military histories were veterans like Estigarribia and not necessarily academics, their work often lacks proper referencing. Their historical accuracy is questionable at times, and I have been cautious in the interpretation of both military histories and personal accounts written by Paraguayan and Bolivian nationals.

In contrast, the more nuanced local sources seem to be those produced by historians of the two protagonist nations. In the case of Paraguay, the works of Alfredo Seiferheld, Luis Verón and Hugo Mendoza represent a more nuanced view on the events. While Seiferheld (1983) sheds light on the diplomatic and economic history of the war (see also Chiavenato 1989), Verón (2010) and Mendoza (2013) provide concise but informative military histories of the events. Although both publications show a deep knowledge of the topic, they remain very much in the diplomatic and military realm. Across the border, however, Roberto 
Querejazu Calvo (1975) manages to reveal a more intimate account of the Bolivian soldiers' personal experiences without adopting a nationalistic undertone.

Besides the military and diplomatic histories written about the war, there are a small number of specialised publications in Spanish, German and French that stand out. These include Gabriela Dalla-Corte Caballero's work on photography, cinema and literature on the war (2012a), as well as her study on the Casado family and the railway in the Chaco (2012b). Silvio Gaona's (1964) book on the chaplains of the Chaco War and Juan E. Melgarejo's (1969) study, which highlights the communication methods used by both armies during the war, also add to the Chaco War literature. Further examples are General Belaieff's (1934) short but thorough report on the Paraguayan fortifications and water situation and Estela Mary Sosa's (2010) work on women's role during the Chaco campaign (for an English-language source on women's role during the war see Chesterton 2014). English-language sources dedicated to the study of specific aspects of the conflict include Hagedorn and Sapienza (1997), exploring the emergence of air warfare in a South American context, and Bridget María Chesterton and Anatoly V. Isaenko's (2014) article on Belaieff's perception of the Chaco landscape as a White Russian.

In Paraguay, a small number of books have been written in German and Spanish on the Mennonite experience of the war. As the authors are members of the Chaco Mennonite communities themselves, one has to be careful in evaluating the material. The brothers Peter and Paulhans Klassen have published extensively on the subject but these works repeatedly interweave fact with fiction and often lack proper referencing (Klassen 1993; Klassen 2008, 2009, 2010). This contrasts with Gerhard Ratzlaff's (2009) scholarly book, in which he convincingly argues for the importance of minority religious communities in the unfolding of the events with documentary sources and photographs.

Perhaps the most significant contributions dealing with a specific aspect of the war are those exposing the hidden voices of the indigenous populations affected by the conflict. Written by a group of historians, anthropologists and ethnographers, Richard (2008a) and Capdevila et al. (2010) examine the indigenous experience of the war and the relationships between the militaries and indigenous people of the region (see also Richard, Capdevila and Boidin 2007). They combine historical research with oral testimonies from members of the various indigenous communities. Topics addressed include indigenous exploitation, colonialism, cultural change and land struggles. Unfortunately, the 
books remain largely inaccessible to the English-speaking world (for concise English sources on the indigenous involvement in the war see Harder Horst 2006, 2010; Langer 2016).

English-language literature on the Chaco War is limited both in sources and in its focus, as it almost exclusively concentrates on the military, political and diplomatic history of the conflict (for a diplomatic history of the Chaco Peace Conference after the war in English see Rout 1970). Zook (1960) constitutes the earliest and one of the bestresearched English sources on the war. It was only in 1996 that Bruce W. Farcau published The Chaco War: Bolivia and Paraguay, 1932-1935. While both books give a detailed synopsis of the events and their antecedents, Farcau also manages to periodically expose the humans holding the guns by referring to the demoralising state of the soldiers and the trenches they fought in. For those who seek a brief introduction to the war, Alejandro de Quesada and Philip Jowett's (2011) illustrated volume is an adequate source. Filled with colourful images and black and white photographs, it gives a thin but nonetheless satisfactory overview of the armies, major battles and the war's aftermath. Matthew Hughes's (2005) article, which focuses solely on the logistics of the war, is a further useful contribution. There are also a number of general texts that dedicate chapters to the Chaco War. Two examples are Scheina (2003) and De La Pedraja (2006). Even though both books compress the conflict into one chapter, they nonetheless manage to give a good overview of the major battles. Yet whereas Scheina and De La Pedraja focus mainly on the military operations, Peter Lambert and Andrew Nickson compiled a number of texts that include poetry and personal anecdotes by veterans into one chapter in The Paraguay Reader (2013).

Two English-language texts that stand out are Bridget María Chesterton's excellent The Grandchildren of Solano López: Frontier and Nation in Paraguay, 1904-1936 (2013) and her edited volume The Chaco War: Environment, Ethnicity, and Nationalism (2016). The former looks at the development of Paraguayan nationalism through the nation's ideas of history, nationhood and mestizo identity and how all of this has shaped and has been shaped by the Chaco frontier. In her edited book Chesterton has managed to collect a large variety of papers on the Chaco War covering topics such as the impact of oil on Bolivia and the war (Cote 2016), the social differences amongst Bolivian prisoners in Paraguay (Shesko 2016), the Bolivian effort of national development through modern infrastructure (Nobbs-Thiessen 2016), the role of Asunción's botanical garden in the creation of Paraguayan notions of space and national identity, indigenous resistance (Langer 2016) and the disclosure of the more 
fleeting and intimate moments of the war through the material culture that was created and left behind (Breithoff 2016).

$* * *$

A human tragedy for both sides, and for the indigenous people involved, the war - which supposedly ended sin vencedores ni vencidos (without winners or losers) - resulted nonetheless in a Paraguayan claim over a large part of the disputed area. The Paraguayan success in the Chaco War can be attributed to a multitude of factors. The newly arrived Mennonites had done their share by materialising their host country's vision for the Chaco: establishing a firm human presence, exploiting the land in the western understanding of the term and reconnecting it with the rest of the patria. Whereas Bolivia suffered from international isolation, weak military leaders, tumultuous internal politics and long supply lines, Paraguay enjoyed support from neighbouring countries such as Argentina, excellent military command and a better infrastructure to get soldiers and supplies to a relatively close front line (Hughes 2005, 416).

Yet the logistical, political and economic aspects that make up the diplomatic and military histories of the conflict often overshadow the personal, human elements that helped shape the outcome of the war. Although thousands of men from both countries suffered and lost their lives in the bush, the Paraguayan soldiers' attitude to the Chaco contrasted heavily with that of their Bolivian counterparts. Due to the patriotic sentiment instilled in them, the Paraguayans recognised the Chaco - at least mentally - as an intrinsic part of their homeland and its defence as an honourable duty. This was simplified by the Paraguayan familiarity with the local climate and, to a lesser extent, vegetation. To the Bolivians, on the other hand, the Chaco represented a completely alien landscape as they were unaccustomed to its oppressive heat and dense forests. Even though this resulted in low morale, the Bolivians kept fighting for what they were told was rightfully theirs.

Paraguayan writer Justo Pastor Benítez once claimed that the Chaco is not a green hell but a beautiful region that is in need of human touch, contact with work instruments, without which all of earth's territories would be uninhabitable deserts' (Benítez 1976, 99). On the eve of war, the belligerent nations both saw their armies as carriers of modernity and 'pioneers of civilization' (Capdevila 2010, 28). In their eyes, the Chaco was a blank sheet, an empty place that was waiting to be bestowed with the gift of civilisation in the form of fenced pastures and military outposts. Paraguay and Bolivia ignored the fact that the Chaco had already been inhabited and exploited by various indigenous groups 
with their own complex societies and lifeworlds. Nonetheless, both nations made recourse to their own indigenous heritage in an effort to justify their territorial rights over the Chaco. They considered it national territory even though the place was completely alien to them. Still, they rushed to defend what they believed was a neglected but intrinsic part of their respective patria. However 'exotic' and 'foreign' it was in reality, the Chaco was 'national' in the Bolivian and Paraguayan minds. In the words of Luc Capdevila, the 'Chaco War took place in a space that was simultaneously different and familiar, foreign and patrimonial ... a territory that was both empty and roamed; inhabited and valued by ten thousands of indigenous people but not exploited in an apparent way' (Capdevila 2010, 33).

\section{Notes}

1. In Paraguay people commonly refer to the jaguar as tigre (Spanish for tiger) or yaguareté (Guaraní for jaguar) and to the puma as león (Spanish for lion). During the war the Paraguayan soldiers referred to the Chamacoco (Ishir) Indian as Moro (Richard 2008c, 75-6).

2. Although they were all of Mennonite faith and denomination, the three colonies differed - and still differ - significantly in cultural practices. The Menno, who were by far the most conservative group, were several generations removed from their Russian heritage and struggled to identify with both the Fernheimer and the Neuländer. Even though Colonia Fernheim and Colonia Neuland were both founded by refugees from Russia and Ukraine respectively and shared some of the hardships endured under Communist rule, they did not seem to bond over their common experiences. Marlene Epp suggests this is owing to the fact that by the time Neuland was founded, Menno and Fernheim had only just started to stand on their own two feet after years of challenges and hard work in the Paraguayan wilderness; they might therefore have been reluctant to engage with the newcomers (Epp 2002, 97-8).

3. Kamp (German) or campo (Spanish) is a term used to describe a grassland plain - a large open area covered in high espartilla or bitter grass (Elionurus múticus) and the occasional large tree. Kamps were very common in the Central Chaco during the time of the Mennonite immigration and the Chaco War. As the lack of coverage meant high exposure to the enemy, traversing a Kamp was extremely risky for soldiers during the war. Today, Kamps are a rare sight as most of them have been turned into agricultural land.

4. Interestingly, the majority of the newly founded Neuland community consisted of women, many of whom were widowed with children. Most of these women had fled Russia heavyhearted, leaving behind husbands, brothers and fathers in Russian concentration and work camps (Epp 2002). For these women and their children, building a new existence in the Paraguayan wilderness became an even bigger challenge. Even though the Fernheimer, and to a lesser extent the Menno, initially helped the newcomers with clearing the land, building houses and digging wells, relationships between the three colonies did not develop until significantly later. For a more detailed account of the female Mennonite experience of Communist rule in Russia, their move to Paraguay and the challenges encountered in building a new existence, see Epp 2002. 
3

\section{Dwelling place, promised land and green hell? The many worlds of the Chaco}

The arrival of the Mennonites and militaries in the Chaco created new, parallel and conflicting lifeworlds. To the newcomers, the Chaco was a 'wild' and ultimately hostile place that was waiting to be subdued and 'civilised' with the tools of modernity. To its various indigenous inhabitants, the Chaco was not 'wild', but, despite its many challenges, a place of life and nurture. These conflicts were, however, not simply ideological. While the Mennonites came with ploughs, the armies marched in with rifles and machine guns, each of which simultaneously remade the Chaco in distinct and contrasting ways. The aim of this chapter is to examine the different worlds made and perceived by the Mennonites and the soldiers in the Chaco, and how these differed from indigenous worlds. In doing so, I engage directly with the notion of industrialised war as an Anthropocene hyperobject (Morton 2013) in and through which multiple worlds and futures are both made and unmade.

I first assess the Mennonites' efforts to adjust to the climatic and geographical conditions of their adopted homeland, and to turn the Chaco bush into arable farmland. I then focus on the soldiers' experience of the Chaco. Aymara, Quechua and Guaraní mestizo perceptions of the bush will be explored, before the study moves on to discuss the soldiers' struggle to not only survive a modern war but also stay alive in the Chaco bush. Food, and especially water, were scarce in the arid scrubland and the soldiers often depended on indigenous interlocutors' knowledge of the landscape to survive. I examine what sources were available to them and the impact that hunger and thirst had on the soldiers' bodies and minds. I then turn to the sensorial dimensions that thirst, the experience of mechanised war and the environment of the Chaco presented to the soldiers, and conclude with how the latter managed to deal with their reconfigured realities. 


\section{Dwelling place, promised land and green hell?}

Although the origins and meaning of the term remain disputed, it has been suggested that 'Chaco' derives from the Quechua chacu, which refers to the region's indigenous populations and can be loosely translated as 'hunting ground'. Where local indigenous groups perceived the landscape as a productive environment, Chaco denoted an infierno verde or 'green hell' to the newly arrived Mennonites and the encroaching armies (Bray 1981, 171; Friesen 1997, 548). As mentioned earlier, this discrepancy in the different worlds of the Chaco was not simply a case of 'modern meets traditional' as the boundaries of these worlds had already started to blur long before the war, resulting in a curious mix of Christian and indigenous cosmologies as well as sometimes contradictory racial ideologies. Whereas some Paraguayan veterans, for example, attributed Bolivian soldiers' supposed lethargy and fearfulness to their indigenous heritage, they saw their own Guaraní roots as the reason for their self-proclaimed superior warrior nature (Macias c. 1940; Benítez 1976). Despite both the belligerent states and the Mennonites being considered 'western', their views were often fundamentally different, as reflected, for instance, in their stance on armed conflict. Nevertheless, they showed a similar colonial attitude towards the Chaco landscape, which they considered a 'wilderness' that needed to be subdued and domesticated by humans. This was, however, no easy task.

The Mennonites' view on nature was founded on the idea that it was God's will for humans to control nature. In short, God created earth for humans to use (Stahl 2007, 111-12). Deeply religious, the colonists believed that like the Israelites before them, they had been led into a 'promised land'. The Mennonites saw it as their Christian duty to transform the dusty bush into a fertile 'garden in the wilderness' (Stoesz and Stackley 1999, 1) with permanent settlements and fenced pastures, reinforcing the clear divide between culture and nature. During his excursions into the heart of the thorny scrubland, Fred Engen, the Norwegian-born Chaco pioneer and Mennonite sympathiser, felt that the Chaco was in need of the 'skilful and industrious man' as:

there is not a place on earth except Paraguay that offers such attractions with so few obstacles to overcome. Beautiful nature in the Chaco seems to say to those endowed with vision and foresight: 'I am yours; come and exploit me; take all that you are capable of taking, as I am inexhaustible in resources.' Riches lie dormant awaiting men of energy, thrift, and skill to turn the immense, wild, 
uncultured prairies and meadows into a paradise. There are all resources for the creation of wealth, coupled with the most wonderful climate which can be found anywhere on the globe. The sacred silence in the Chaco inspires one to high and noble aims, and the solitude and the atmosphere purifies the soul, filling it with wonderful dreams of a life sublime and beautiful. I do not wish to convey that paradise is already there; it has to be made from the material which lies dormant awaiting men with brains and muscle (quoted in White 1927, 441).

Yet upon their arrival in the Chaco, the Mennonites were filled with despair. Where were all those inexhaustible resources and the wonderful climate that Engen had promised them? In the absence of any agricultural guidelines for what was perceived to be an 'uncultivated' region, the farmers were faced with major challenges and years of trial and error. Crops such as potato, corn and fruit that had thrived on Russian and Canadian soils did not survive in the heat of the Chaco. Like their produce, the Mennonites suffered from the devastating month-long droughts, in which pozos indios - wells dug and used by indigenous people - were often the only water sources available. Floods caused by the ensuing rainy season and swarms of grasshoppers repeatedly destroyed those things that did grow, most notably cotton and peanuts. The Chaco wildlife also posed a threat to people and livestock while termites were eating away at the wooden boards of the farmsteads (Abercrombie 1933, 1175).

Over the years, the Mennonites had to learn how to survive in the Chaco bush. This would not have been possible without the help of local indigenous groups, especially the Enlhet and later the Ayoreo, who showed them the use of wood, how and when to plant local seeds and, most importantly, how and where to dig for potable water. Often they had to dig between two and ten metres under the constant threat of collapsing walls before reaching water (Stahl 2007, 311). The Chaco bush also taught the Mennonites how to survive in it. The colonisers quickly realised that adding an overhanging roof to their houses not only provided them protection from the Chaco elements but also allowed them to collect rainwater (Stoesz and Stackley 1999, 183-4). Devout and hardworking, the Mennonites persisted and eventually managed what no-one in eastern Paraguay thought possible: by the start of the Chaco War they had turned the 'wild' Chaco into the cultivated piece of patria thousands of men were now rushing to defend.

Much like the Mennonites, both armies struggled to survive in the Chaco. Leaving their homes in the Andean highlands, Bolivian soldiers 
often had to walk for weeks before reaching the Chaco front. 'Through walking', Tilley notes, 'landscapes are woven into life, and lives are woven into the landscape, in a process that is continuous and never-ending' (Tilley 1994, 29-30). The Aymara and Quechua recruits, however, felt disconnected from the Chaco landscape (Querejazu Calvo 1975, 131). Used to the rugged vastness of the Andes, they felt homesick and confined in the Chaco 'prison made of plants' (Sarmiento 1978, 76), as one soldier recounts:

In this eternally flat landscape, each time I come out of the scrubland and I see a bit of the horizon, my glance searches instinctively and longingly the silhouette of our mountains. How do we Andean inhabitants contain within ourselves the mountain! More than the culinary ambrosia, the warmth of the home or the affection of the fiancée, my nostalgia is today devoted to the mountains and ravines. It is a subtle and terrestrial longing. What would I give to set foot into the rocky slopes again or to rest my spirit and eyes on a horizon drawn with the beloved solemn and paternal humps! (Querejazu Calvo 1975, 133).

The Aymara and Quechua recruits' lifeworlds were rooted in an Andean cosmology that has a profound respect for the almighty Pachamama (Mother Earth) and the powerful Apus - mountain deities that form part of her. Pachamama gives life to everything but also controls the malevolent elements such as thunder, earthquakes and floods. Apus act as protectors of humans and animals but can also cause gusting winds (Bolin 2002, 32). In order to appease these forces, people aspire to a 'spiritual dialogue among humans, animals, and the powers of nature' that does not 'separate the natural from the spiritual environment' but considers all things - animate and inanimate - as living entities (Bolin 2002, 32). As a result, the indigenous people of the Altiplano, like the indigenous people of the Chaco, inhabit worlds in which humans, animals, nature and objects share an entangled existence free from the nature-culture divide. Such attachments are embodied in specific landscapes, and the Chaco must have presented considerable challenges in which aspects of the environment were both similar to but also uncannily different from the Andes from which the majority of the Bolivian soldiers hailed.

These lifeworlds were significantly disrupted by the arrival of the Spanish and the introduction of a capitalist tin and silver mining industry that forced Aymara and Quechua men to exploit their sacred mountains, most famously Cerro Rico in Potosí (see Nash 1979). This resulted 
in a curious fusion of Christian and Andean beliefs and practices inside the dark and claustrophobic tunnels which, like entrails, were winding their way deep inside the mountains' interior (see Miller 2001). By the outbreak of the Chaco War the mining identity was deeply engrained in Andean culture. This did not go unnoticed by the Paraguayans, who observed that 'The Aymara soldier prefers to fight buried - the subterranean and the caves are his elements' (Macias c. 1940, 63). Narrating his experience inside a tunnel dug by Bolivian sappers in Fortín Nanawa, Augusto Céspedes notes that:

A tiny hole brought in light and air from outside! It was below the scrubland. Advancing a little, I encountered the complete vision of a naked man, shiny with sweat, crouched, perforating the bottom of the underground passage. He was the ghost worker, the sombre miner from the mountains who brought his subterranean skills to the tragic and tropical lands of the Chaco (Céspedes 1975, 67-8).

However, the Chaco earth the Bolivian miner-sapper was now penetrating was not the Pachamama he was familiar with. It was an alien place, an 'earth without sense', that subjected him to a harsh climate and terrain 'in whose thorns he left the threads of his Andean soul' (Céspedes 1973, $163,88)$.

On the Paraguayan side, the 'soldier-agriculturist[s]' (Chesterton 2013 , 114) felt a close relationship with the arable red earth they had been cultivating for generations before the war in eastern Paraguay. This fondness for their native lands was however not naturally transferred to the dusty and arid plains of the Chaco, as the latter evoked fear of its supposedly aggressive indigenous inhabitants, exotic wildlife and impenetrable foliage (Bustamante Rodríguez 1987, 36). Aware of the fact that war with Bolivia was imminent in the 1920s, the Paraguayan government sent out scientists to study the region and its indigenous groups with the ultimate goal of nationalising the Chaco and instilling a sense of patriotism towards it in the general population (Chesterton 2013, 60-78). Although the Chaco might have looked like a self-evident part of the patria on maps, it felt unfamiliar to the soldiers in the field. Indeed, it stood in stark contrast to the lush vegetation of eastern Paraguay with its abundance of fresh water sources. Albeit used to high temperatures, the soldiers struggled with the oppressive heat and the lack of water in the inhospitable Chaco bush. Faced with unfamiliar flora and fauna, they quickly realised that the Bolivians did not pose the only threat, as one Paraguayan soldier recalls: 'The resistance of the desert presented itself 
as almost insurmountable. Victory had to be achieved against the enemy and against nature' (Bustamante Rodríguez 1987, 83).

The Paraguayans were, however, not completely defenceless against the Chaco 'wilderness'. Due to survey missions conducted by General Belaieff for the military in the decade preceding the war, the army was aware - at least on paper - of some of the challenges posed by the region's climate and topography (see Belaieff 1934). Unlike their Bolivian counterparts, Paraguayan foot soldiers were equipped with a weapon that in the first instance might seem inappropriate in a mechanised war but soon established itself as the key tool for survival (besides the water canteen) in the Chaco bush. 'Sharp, curved like a cutlass, penetrating like a dagger, strong like a hand saw', the machete cuts through thicket and even wood. Prior to the war it had been primarily used in agricultural activities such as ploughing the earth and cutting weeds that threatened to cover it (Benítez 1976, 56-7). In the Chaco it became the Paraguayan weapon of choice to try to beat the thorny bush into submission.

According to Benítez the machete was useless in the hands of the Bolivians as they spent their lives below the earth's surface working in tin mines instead of cultivating the soils above them. The machete was thus considered a component of Paraguayan identity - 'a terrible extension of their skilled and confident arms with nerves made of steel' (Bustamante Rodríguez 1987, 20). Most importantly, it was seen as 'an instrument of civilisation' (Benítez 1976, 56) and progress, used by the modern and advanced Guaraní mestizos in their quest to dominate nature. Benítez elaborates that in the hands of Paraguayans the machete is 'an advanced cavalry of printing and electricity. It is the sharp extension of the arm. In this strong and fertile land, a farmer without a machete is a knight with a wooden sword' (Benítez 1976, 57). In the Chaco, the machete did not only enable Paraguayan soldiers to cut and move freely through foliage. In fact, with every stroke an area was cleared in the bush and transformed into a 'plot of his nationality' (Benítez 1976, 56). Similar to the harsh alpine fighting experience during the First World War where 'the mountains made the man' (Keller 2009, 256), the Chaco turned simple farmhands and miners into national heroes, whilst they themselves remade the Chaco. This continuous interplay between human and non-human entities is an example of the ways in which such interactions create a reciprocal relationship in which 'we touch the things and the things simultaneously touch us' (Tilley 2006, 61). The soldiers and the Chaco made, unmade and remade each other in this process.

Contrarily to the Mennonites and militaries - who were convinced that the Chaco bush had to be exploited and controlled through the stroke 
of a plough or machete - the populations native to the region believed that appropriate 'social' relations with nature guaranteed access to natural resources and, ultimately, survival. Similar to pre-contact Andean indigenous populations, they adhered to 'the mutual dependence of all that exists' (Blaser 2009a, 13; see also Descola 2005; Ingold 1996; Viveiros de Castro 1998; Blaser 2009b, 2010). The Nivaclé and Ayoreo, for example, thought that everything - human, animal, nature or object has a double, which Wilmar Stahl (2007) argues can be compared to a shadow that the physical shell casts. As a result, all things animate and inanimate have both a physical and a spiritual dimension. According to Stahl, indigenous people appease the spiritual energy of a plant, animal or rock (which can transform into a malevolent force that would bring bad luck or illness) by maintaining strict and attentive relations with the environment. This familiarity with the Chaco bush allows people an intimate knowledge of and access to its 'physical shell'. Nature is thus considered a close and 'generous relative' with whom humans are intertwined in a symbiotic relationship of respect (Stahl 2007, 79-81, 97). Contrary to the practical and possessive views expressed by the Mennonite and military scouts such as Belaieff, indigenous understandings of the Chaco landscape are infused with stories that express actions and sentiments of gratitude and affection for the generosity of its non-human agents (Escobar 2007, 143). These acts of storying and 'dwelling' (Ingold 2000) are themselves world-making and generative.

In the eyes of the Mennonites and soldiers, the Chaco was a 'colourless hell' where everything merges into a grey-brownish green against which only the bright red of blood stands out (Céspedes 1975, 162). In contrast, to the Ishir indigenous people, red represents not only the colour of blood but also the striking beauty of the caraguatá plant (Aechmea distichantha), which is associated with women's genitalia (Escobar 2007, 93-4). The spiky leaves of the plant were furthermore used in the weaving of baskets. Yet, to the Mennonites and soldiers the caraguatá was a painful nuisance, whose sharp thorns ripped both cloth and skin. Similarly, while the sun plays a significant role in Ishir mythology as a transmitter of human life skills such as hunting (Escobar 2007, 227), it was a source of great pain for the soldiers, who felt it like 'a mask of fire' on their face (Céspedes 1973, 123).

When different ontologies collide, dominant worlds tend to enforce themselves upon others, making and remaking parallel lifeworlds in the process. Woodward argues that militarised landscapes (and the same could be said for 'agriculturalised' landscapes) are never detached landscapes as they always impose themselves onto 
already existing ones (Woodward 2004, 7). In the Chaco, this is perhaps best exemplified in people's relationship with trees and wood. The palo santo or 'holy wood' tree (Bulnesia sarmientoi), for example, was of major importance to local indigenous communities. Valued for its many medicinal properties, it was also used in burial purification rites due to its intense smell and luminosity when set on fire (Escobar 2007, 287; Barbrooke Grubb 2011, 168). During the war, the same fragrance must have also filled the trenches and bunkers lined with its freshly cut timber, mixing with the stench of human faeces and decomposing bodies (see Saunders 2014, 24).

Writing of Amazonian Indians, Philippe Descola has noted that indigenous people tend to treat 'discontinuities between humans, animals and plants as mere differences of degrees and not of kind' (Descola 2005, 22). The concept that humans and all things animate and inanimate are interlinked in the shaping of a single undivided world is also shared by indigenous peoples in the Chaco. To many of the different local indigenous groups, trees are of major cosmological importance. In some instances, they represent the 'cosmic tree' that is linked to the axis mundi (Escobar 2007, 80). In his ethnographic work on the Tomaraho (an Ishir sub-group), Ticio Escobar explains that:

The tree is an archetype of nature and its link to other dimensions. The image is enriched by the phallic connotations of a firm trunk that is deeply rooted in the earth, ascends vertically and opens its branches to the sky; it is laden with associations of a natural source that renovates itself cyclically, that produces food and flowers, shade and wood, and that shelters birds and beasts in its leaves. This exemplary model is linked to the concept of the pillar that sustains and retains the sky, the stairway that leads to its heights, and the channel that communicates with subterranean worlds (Escobar 2007, 80).

The devastating impact of industrial war, however, forcefully changes and reconfigures both the physical and discursive constitutions of arboreal landscapes. Before the First World War, for example, European ideas about trees and forests were embedded within a visual artistic tradition that favoured romanticised depictions of an idyllic and innocent natural world. However, when the mechanical forces of war were unleashed upon the fields and forests of Europe and beyond, trees were reduced to shell-splintered trunks and 'natural and social worlds were forged anew, and sensibilities realigned' (Saunders 2014, 22). In the Chaco, the use 
of a local tree from the Bombacaceae family generally called samu'û in Guaraní and palo borracho (drunken tree) or árbol botella (bottle tree) in Spanish serves as a poignant example for the destruction and reshaping of an indigenous landscape and lifeworld. This invokes the question of ontological politics (see e.g. De la Cadena and Blaser 2018) and the antagonisms that arise when conflicting worlding practices come into contact with the same object, in this case the tree.

Named after its shape, the bottle tree is typical of the Chaco and plays an important role in indigenous culture. Considered the 'primal tree, from which the fish sprouted' in Ishir culture, the fall or death of the samu'û represents the completion of the cycle (Escobar 2007, 80) and people are thus 'as much bound up in the life of the tree as is the tree in the lives of the people' (Ingold 2000, 204). Known as the 'green cistern' as rain accumulated inside naturally formed holes in its trunk without evaporating, the bottle tree was also valued by many indigenous groups for its practical function as a form of natural water storage (Klassen 2009, 232). The holes in the trunk further served as storage places for food and clay water jugs (Klassen 2009, 229). In times of extreme food scarcity, indigenous people would cook and eat the tree's semi-ripe seeds (Stahl 2007, 315), and along the Paraguay River men would hollow out the soft inside of the trunk and use the remaining shell as a canoe (Fast 2004, 49).

In the early years of colonisation, the Mennonites recall hollowing out bottle tree trunks to use as coffins during the cholera epidemic in 1930 (Stoesz and Stackley 1999, 47). Whereas hollowed-out trunks were turned into cattle troughs during the rainy season, their soft interior was fed to starving cattle during times of drought (Heinz Wiebe, Mennonite guide from Colonia Neuland, pers. comm). During the Chaco War the soldiers also took advantage of the tree's malleable properties by hollowing out its trunk and using it as a prison for punished soldiers (Boschmann 2012, 126) and as a sniper's hideout. Similar to soldiers hiding inside artificial trees for camouflage during the First World War, the man positioned inside the bottle tree became 'literally as well as figuratively embodied within the trunk' (Saunders 2014, 24; Coutin 2012, 102). Here, modernity forcefully subverted and reconfigured indigenous moral and natural ontologies as the Ishir symbol of life had suddenly been turned into a bearer of death and a physical marker of war in the landscape. 


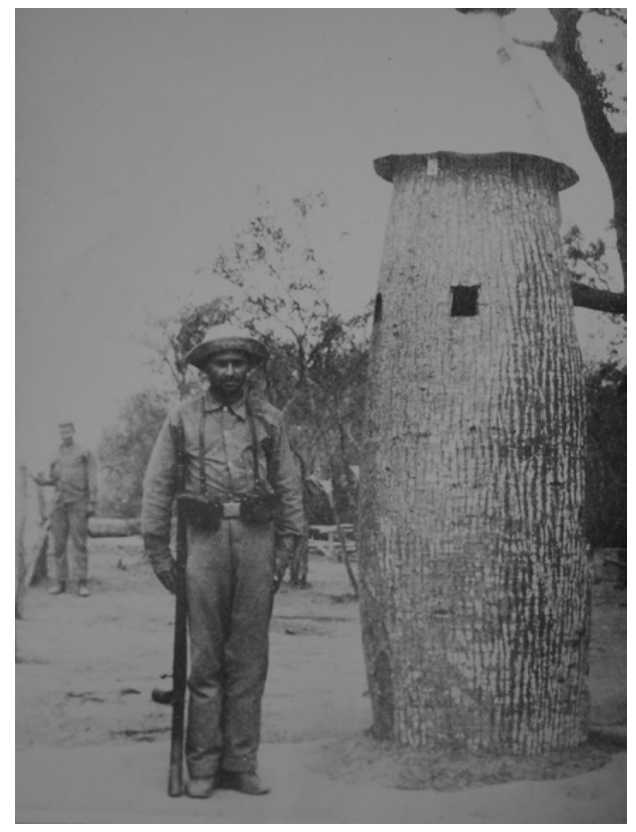

Figure 3.1 Sentry box made out of the hollowed-out trunk of a bottle tree at Fortín Isla Po'í (Courtesy of AIHMM).
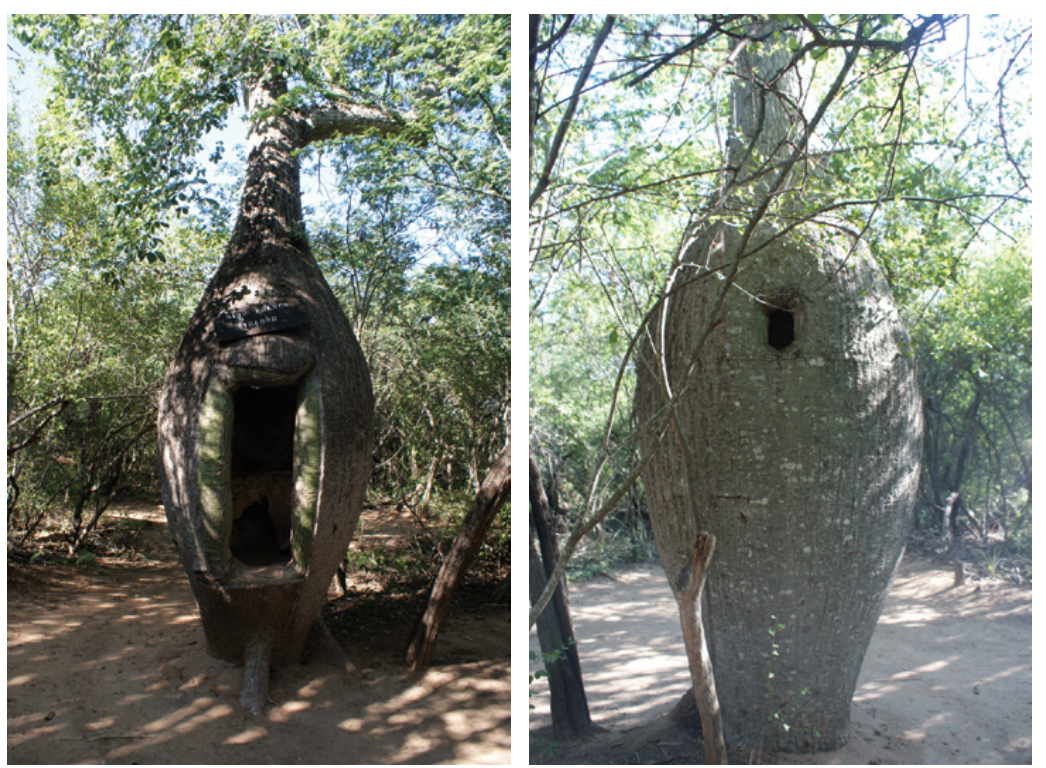

Figure 3.2a and 3.2b Reconstruction of a hollowed-out bottle tree used as a sniper's hideout at Fortín Boquerón (Source: author). 


\section{The 'white death'}

\section{Hunger and food}

For the Chaco's indigenous inhabitants, knowing the bush was key to survival. By contrast, Bolivian and - to a lesser extent - Paraguayan soldiers were not always familiar with the natural food sources that the Chaco had to offer. Although it might seem impossible to those who have not grown up there, the Chaco thicket provides everything humans need to survive, including wild fruits and vegetables, such as wild cucumber, prickly pear and wild palm heart; wild legumes, such as beans and roots; and a multitude of animals and insects safe for consumption. However, as a number of the Chaco's wild food sources can be poisonous when not carefully prepared, an intimate knowledge of the food's properties and people's potential reactions to it was essential (see Stahl 2007, 303-24).

Paraguayan veteran Anibal Zotti recalls that by December the snails, which had been a welcome and necessary source of vitamins and protein for him and his comrades, became scarce. Famished, the men devoured anything they could get their hands on - fresh leather, roots, insects, the malleable flesh of the bottle tree and toxic fruits - ignoring any potential health hazards (Zotti 1974, 120-1). Hunger thus became the driving force behind people's behaviour (see Butterly and Shepherd 2010, 158). Bustamante Rodríguez remembers greedily sucking ripe ñangapiry guazú, the colourful fruit of a small tree of the Myrtaceae family, and not caring about the formation of blisters on the tongue and lips that they caused (Bustamante Rodríguez 1987, 126).

Food was scarce in the Chaco, especially during battles that could leave soldiers sitting inside their fortines and trenches, cut off from supply lines for weeks on end. Desperate for something to eat, the men had to slaughter their mules - and thus consume their means of transport - in order to maintain physical strength themselves (Farcau 1996, 55, 180-1). The Chaco heat and the lack of water to cook the meat meant, however, that it was soon covered with maggots. Starving, the men had no choice but to eat the rotten meat, even when infested by botflies that had previously feasted on the bodies of their dead comrades (Zotti 1974, 46). Hunger also pushed soldiers to trade their personal equipment, such as overshoes, for a handful of rice (Zotti 1974, 153). Although trading military supplies constituted a serious offence and demanded punishment, being subjected to unbearable hunger was overwhelming.

Soldiers who had personal links to nurses used empty fuel canisters to smuggle food such as sugar, yerba (herbal tea), tinned beef and milk to 
the front. As the meagre rations given to the men were never enough to survive on, these illegal goods were received with great joy and generally shared with hungry comrades (Zotti 1974, 90). Another rare treat were the big galletas or biscuits baked by the nearby Mennonite communities. Although stale, dirty and covered in moss from humidity, they were a delight to the soldiers and gave them temporary relief from hunger (Zotti 1974, 121). When he lost his tin plate, an empty food can was often the only thing a Bolivian soldier owned to carry food and water (Céspedes 1975, 160). Those who still had their equipment spread out their trembling arms in the hope of receiving a spoonful of pitiful rations. One soldier recounts that food was so scarce that they could literally count every single grain of rice on their tin plate (Zotti 1974, 150). The soldiers' empty tin plates and the suffering they represented must have left a lasting impression on the men, who would occasionally decorate their own piece of equipment to pass on as a souvenir at the end of the war.

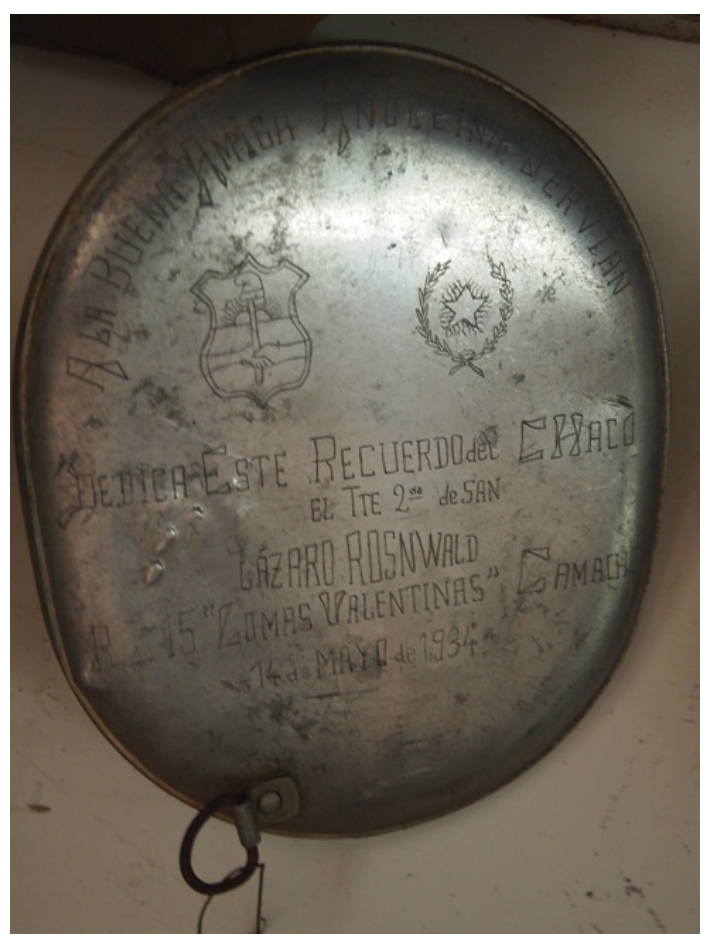

Figure 3.3 Inscribed tin plate made by a lieutenant as a souvenir for his 'dear [female] friend' in the Museo Militar Asunción (Source: author). 
The lack of food and the soldiers' general unfamiliarity with the Chaco thus had a momentous impact on the troops. Countless men succumbed to diseases such as dysentery and scurvy, which prevented them from chewing the little food they had (Zotti 1974, 120). Others suffered from diarrhoea and fevers. Yet with hunger a soldier lost not only his physical health but also his sensibility and spirituality, and slowly his soul, to the point that 'misery gradually consumed soldiers' individuality' (Zotti 1974, 121).

\section{Thirst and water}

Thirst is a powerful sensation. First felt as a mere discomfort in the throat, it keeps niggling away until satiated. If thirst is left unquenched, however, dehydration soon manifests itself as an all-encompassing presence that inevitably consumes the body and the mind, wreaking havoc on the senses. In conflict, the physical weakness and feelings of disorientation produced by the lack of water are intensified by the horrors of modern warfare. During the Chaco War, thirst weaved itself into the sensorial experience of war amidst thorny cacti and hissing bullets. Firmly in the grip of dehydration, thousands of men lost their lives to this invisible killer, which, without shedding a drop of blood, nonetheless created an often gruesome and manifold entanglement of people, nature and material culture.

Thirst was without a doubt the most tormenting sensation a soldier had to endure before he eventually succumbed to the 'white death' (Roa Bastos 2005, 194). Indeed, as Paraguayan writer and Chaco War veteran Augusto Roa Bastos once poetically wrote: 'Thirst, white death, walks arm in arm with the other one, the red one, in dusty hoods' (Roa Bastos 2005, 182-3). During the First World War, 'white death' signified death by avalanche or freezing to death on the alpine front, as opposed to a 'red death' by enemy artillery fire (Keller 2009, 265). With regard to the Chaco War, it is generally believed that more soldiers died a 'white death' (Céspedes 1973, 14) and of disease than from bloody bullet shots. Amongst the thorny plants, venomous snakes and disease-carrying mosquitoes of the Chaco, Paraguayan veteran Silvio Macias poignantly states that 'The tragedy of the Chaco is the spectre of thirst' (Macias c. 1940, 1). Similar to the situation in the Italian Alps, the enemy rifle or grenade did not pose the biggest and most immediate threat to a soldier stationed in the Chaco. Instead, it was the bush itself, or perhaps more appropriately the men's unfamiliarity with the Chaco landscape and its resources, that represented the greatest challenge to survival. Yet whereas the men stationed in the European mountains had to endure freezing temperatures 
and snowstorms at extremely high altitudes (Keller 2009; see also Balbi 2009), the Paraguayan and Bolivian troops had to face the hostile thicket and heat of the Chaco, where 'the juice of cacti replaces water' (Zook 1960, 23).

Accustomed to the colder conditions of the Altiplano, the Bolivian soldiers especially struggled in the desert-like temperatures and were plagued by an all-encompassing thirst. The agonising memory of thirst and its physical and psychological consequences continued to haunt many soldiers after the war and was repeatedly detailed in personal accounts of the conflict. Céspedes writes that:

Thirst, with its bitter incandescence, chapped our lips and swelled our tongues. No one sweated anymore. A demon licking my throat took control over my pharynx, and I felt my blood like gum. My mouth seemed strange, like a cardboard box covered in dried paint, something unusual and unpleasant. The act of swallowing was repeated mechanically, hitting my throat a painful blow at every instant (Céspedes 1973, 139).

Thirst is a primary biological function and as without water we would not be able to survive, drinking is a fundamental human need (De Garine 2001, 1). During the course of a day, a healthy adult loses about 1.5 litres of water as urine and faeces, and around $800 \mathrm{ml}$ evaporates through the skin and the simple act of breathing. In order to compensate for this loss, humans need to drink and eat food with high water content. A person's age, general health and exposure to high temperatures can greatly influence their body's water loss (Vargas 2001, 14). During the Chaco War, the general scarcity of food and water coupled with high temperatures and lack of shade resulted in thirst being a constant companion. In addition, illnesses such as malaria and typhus caused ravaging fever, diarrhoea, vomiting and excessive sweating. Consequently, the men's already ravaged bodies were losing even more water and, without the intake of sufficient liquid to recuperate the loss, slowly started to shut down.

However, thirst and dehydration do not only affect the human body. The effects of water deprivation seize a person's mind and control their entire existence. Men would leave their positions upon spotting an indigenous well in no man's land and run towards it under enemy fire. Roa Bastos writes that piles of bodies would surround a well, with some of them having submerged their faces in the water 'where they have remained drinking in all eternity'. Others, he continues, 'are hugging each other closely, quietly and satisfied. Khaki and olive-green uniforms mixed up, joined 
together by coagulated crimson, sewn into an indestructible brotherhood' (Roa Bastos 2005, 184). Sarmiento adds that men frequently went delirious with thirst, which caused 'a feverish anxiety and the nerves created obsessive manifestations' (Sarmiento 1978, 72).

As the human body is incapable of storing water, carrying a caramayola (also caramañola and caramagnola) or canteen was crucial in order to avoid dehydration. The water shortage also meant that the caramayola was often a soldier's only life source and his most important piece of equipment. The canteen thus quickly became a símbolo vital, a symbol of life (Sarmiento 1978, 70). The aluminium container was always kept close to the body as the loss or theft of it could result in the death of its owner. As caramayolas were rarely filled up to the brim, every drop was precious and the container was not to be left out of sight. Besides their canteen, Paraguayan soldiers also carried hollowed-out bull horns or aluminium jugs for holding drinking water (Quesada with Jowett 2011, 7). On various occasions these jugs found alternative uses. After heavy downpours, for example, the clattering sound of jugs used to scoop out the accumulated rainwater that was a nuisance and brought colds to the already frozen stiff soldiers could be heard (Zotti 1974, 87). During times of rest, the smooth aluminium exterior of the caramayolas and mugs served as a surface for engravings and personal and artistic expression.

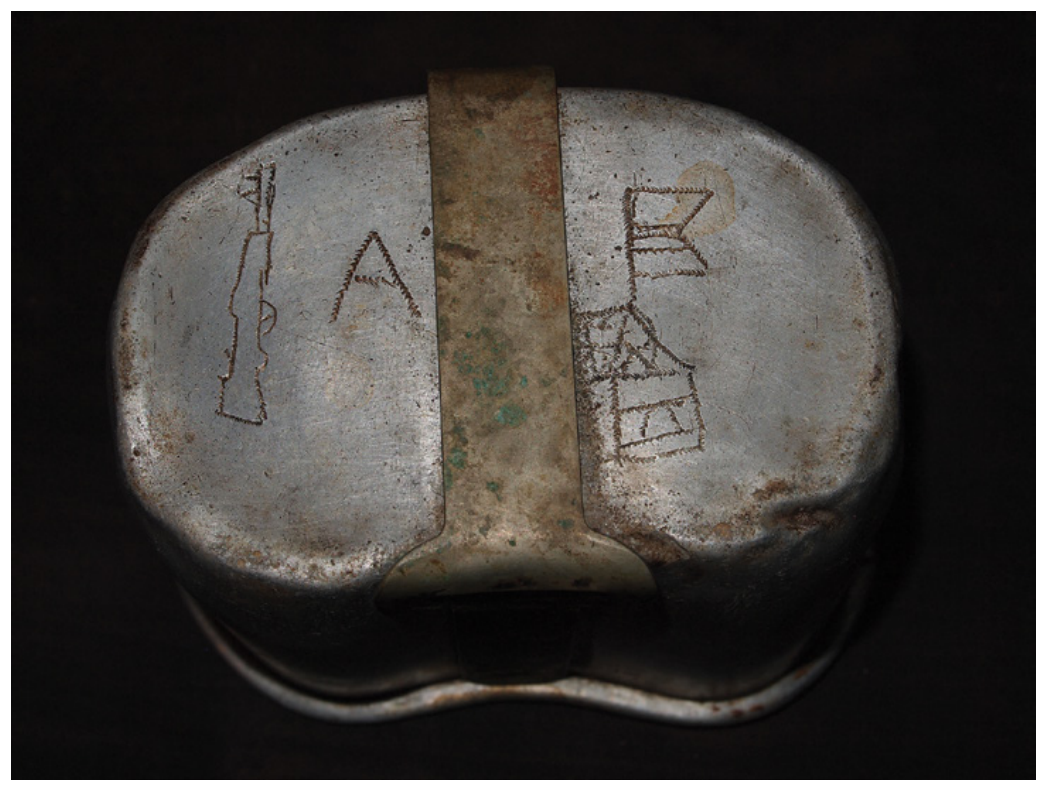

Figure 3.4 Tin mug with engravings of a rifle and possible fortín on its base at the Museo Mitológico Ramón Elias (Source: author). 


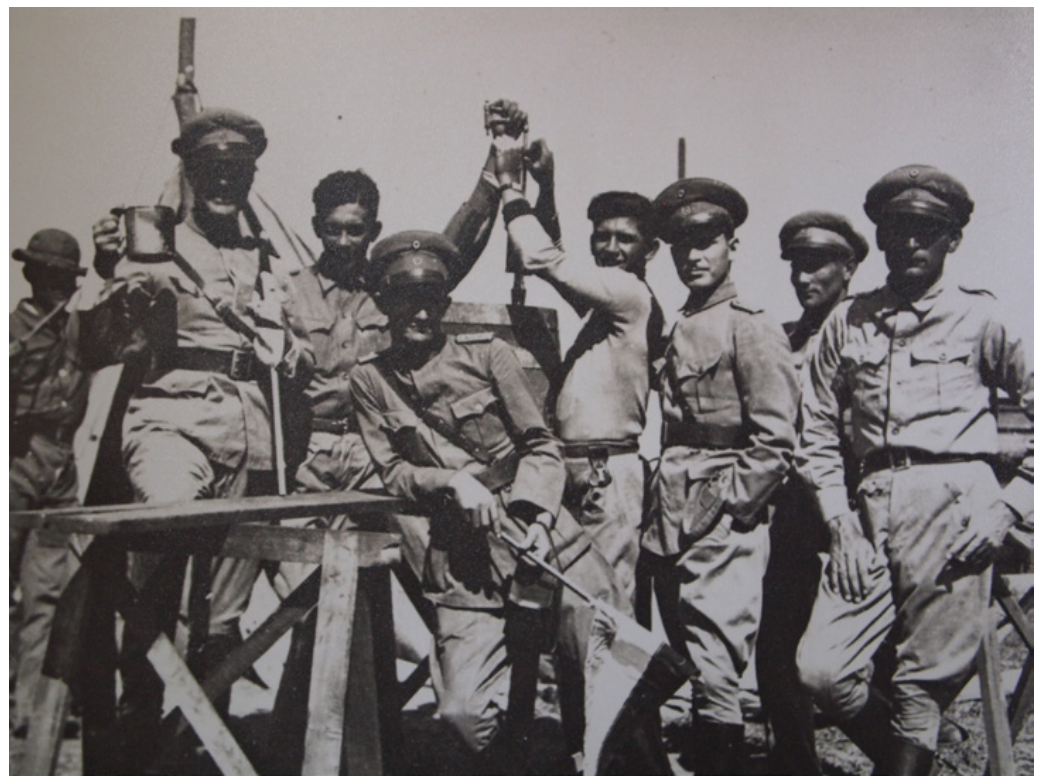

Figure 3.5 Paraguayan official on the left holding a tin mug (Courtesy of AIHMM).

Fighting in a landscape where months pass without a single drop of rain and temperatures soar up to $50^{\circ} \mathrm{C}$, finding a potable water source is crucial. The number of lakes and indigenous and Mennonite wells was limited and often they did not carry enough water to sustain a whole battalion. Inside the fortified military posts the little water available was frequently contaminated by decaying corpses (Sarmiento 1978, 71). The scarcity of natural water sources and the armies' general lack of local knowledge meant that most of the water for the troops had to be brought in from outside the Chaco. The isolated location of the Central Chaco, the lack of proper roads and the shortage of trucks turned the supply of water into one of the major challenges of the war. During times of drought, the Chaco's earth consists of a fine dusty sand, which made the vehicles' wheels spin under their heavy load. Traversing the Chaco during the rainy season was, however, an even greater challenge as many of the rudimentary roads became completely impassable, and the aguateros or water carriers got repeatedly stuck in the sand, which had now turned into a viscous sea of mud. 
Due to the precarious financial state of both Bolivia and Paraguay, only a small number of trucks were available for transport. Most of the time mules and oxen, as well as designated soldiers, carrying up to 30 caramayolas dangling from their body, acted as aguateros or water carriers. Aguateros lived in constant danger of being attacked and robbed by thirsty soldiers from both sides. On numerous occasions their vital cargo did not reach its final destination due to pillaging, bumpy roads or evaporation, leaving countless men fighting in the trenches without a drop of water (Roa Bastos 2005, 183). An anonymous source gives a heart-rending description of the tragic fate of the human water carrier:

The caramagnolas, hopeful anticipation of the thirsty, target of he who risks his life for a sip. And there marches the man with his thirty caramagnolas zigzagging, while the lead encloses his silhouette in a closing circle. He throws himself to the ground, crawls like a feline, seeks shelter behind immobile and naked tree trunks; he arrives or does not arrive, depending on his luck. When he arrives, he will have lost half of the caramagnolas perforated by bullets, riddled by the bursts of gunfire; or he never arrives, because when advancing with his precious load he is made to turn around with a gunshot to his forehead ... THIRST. The aguatero almost always dies this way (Anonymous 1980).

It soon became clear that the armies could not solely rely on water being brought in from outside the Chaco. During his early military expeditions into the region, Belaieff had already realised that 'the clue of the Chaco is in the hands of the Indians' (quoted in Chesterton and Isaenko 2014, 632). In a pamphlet written for the Paraguayan military, he outlines local terrain, climatic and hydraulic conditions and notes what type of plants are indicative of potable water sources (Belaieff 1934, 25-8). Nonetheless, countless soldiers died of thirst because they did not know the local plants (Schuchard 2008, 175).

Although it is scarce and often hidden out of direct sight, the centuries-old indigenous presence in the region was testament that potable water does exist in the Chaco. The water shortage, however, forced indigenous groups to lead a mostly nomadic and hunter-gatherer existence, which centred around permanent lakes during the dry season. When the militaries moved in and took control over those lakes, they forced indigenous communities out of their territories (Stahl 2007, 311). Both the Mennonite and military occupation of these water sources resulted in a 


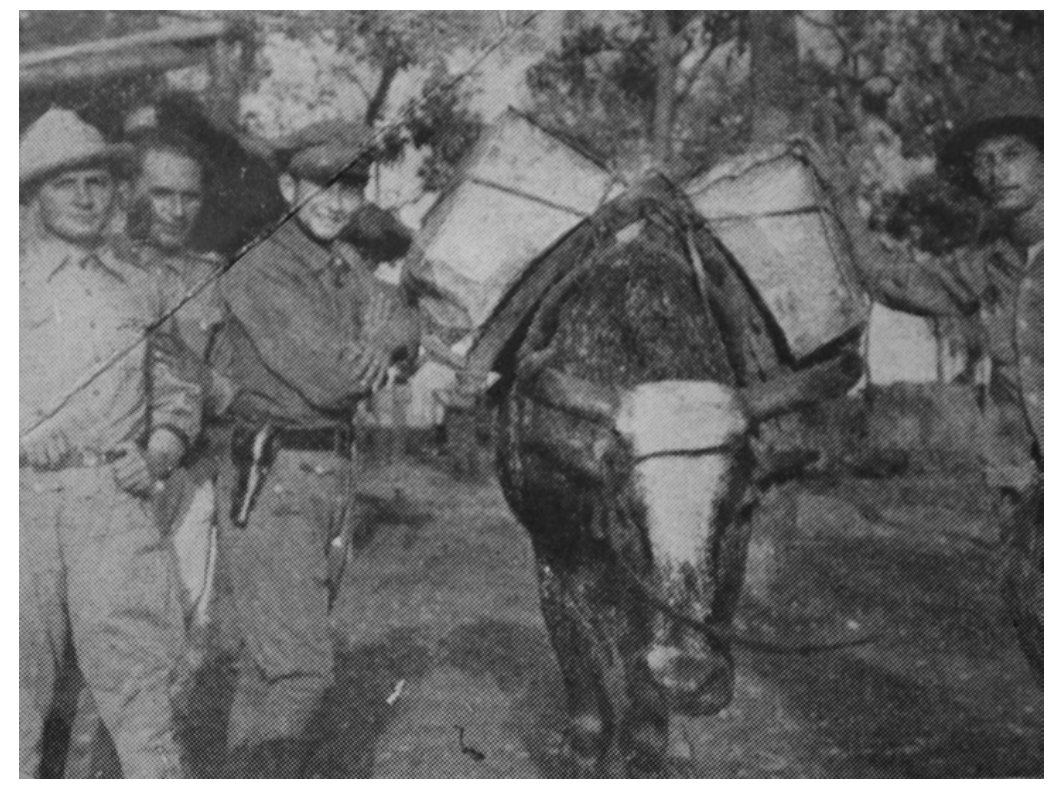

Figure 3.6 Oxen water carrier (Courtesy of AIHMM).

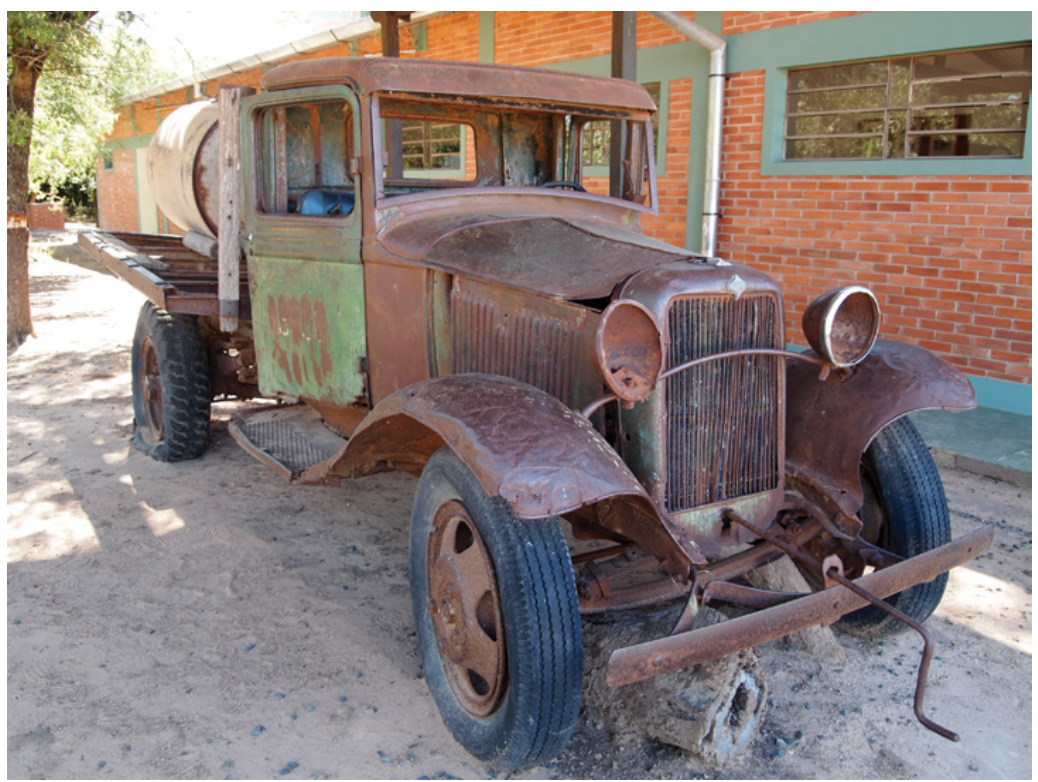

Figure 3.7 Original Ford Cuatro water carrier outside Museo Boquerón inside Fortín Boquerón (Source: author). 
change of living conditions for indigenous people (see Von Bremen 2008, 344-5). Often whole families had to move to faraway alien parts of the Chaco, reluctantly leaving behind a place with which they had shared a deep relationship over many generations (Gordillo 2004). In forcing such groups out of the Chaco, the Mennonites and militaries were also unknowingly expelling the very sources of knowledge that could make the landscape habitable. Indigenous people had learned many ways of finding water in this difficult environment. They knew that bottle trees store rainwater inside shafts in their trunk and that the precious liquid can be sucked out with a reed. They also knew that certain types of wild pineapple plants accumulate water between the leaves at the base and that the thick leaves of the prickly pear cactus also known as tuna (Opunita cactaceae) can be chewed for hydration (Stahl 2007, 311). They understood the bush and its natural resources; they knew what plants were poisonous, and which type of sand was hiding water underneath it (Chesterton and Isaenko 2014, 631-2). Although the soldiers drank drops of water accumulated on plant leaves (Sarmiento 1978, 76) and learned that sucking the moisture from the roots of plants such as the caraguatá and the bitter-tasting leaves of the gigantic prickly pear cactus (Bustamante Rodríguez 1987, 83), could appease their dry throats, they were often unaware of or could not identify other natural life-saving water sources in the bush.

John Renshaw observes that in extreme droughts, entire indigenous groups are forced to survive on a tuber known locally as yvy'á (Jacaratia hassleriana), which - due to its high mineral content - causes stomach cramps if used for more than a couple of days (Renshaw 2002, 86). Local Mennonites assert that a person could die of thirst in the Chaco while unknowingly standing next to a natural water source (Heinz Wiebe, pers. comm.). The plant, which above ground reveals nothing but a fine leafy stem, hides an enormous turnip-shaped fruit $60-80 \mathrm{~cm}$ below the surface. The watery flesh can be chewed in little pieces or wrung into a container or straight into the mouth. Zotti (1974, 250-1) describes a fellow soldier carving a number of holes into the lid of an empty meat can, which he then used as a peeler to slowly grate thin slices of the tuber, while at the same time collecting its juice inside the can. This was a slow and unrewarding process as it took a whole hour to fill half the can with liquid. The remaining grated parts were turned into a type of starchy tortilla seasoned with grease and salt. Although this is mentioned in various memoirs as a water source that the Paraguayans could identify (see Zotti 1974, 37, 250-1; Sarmiento 1978, 760; Bustamante Rodríguez 1987, 


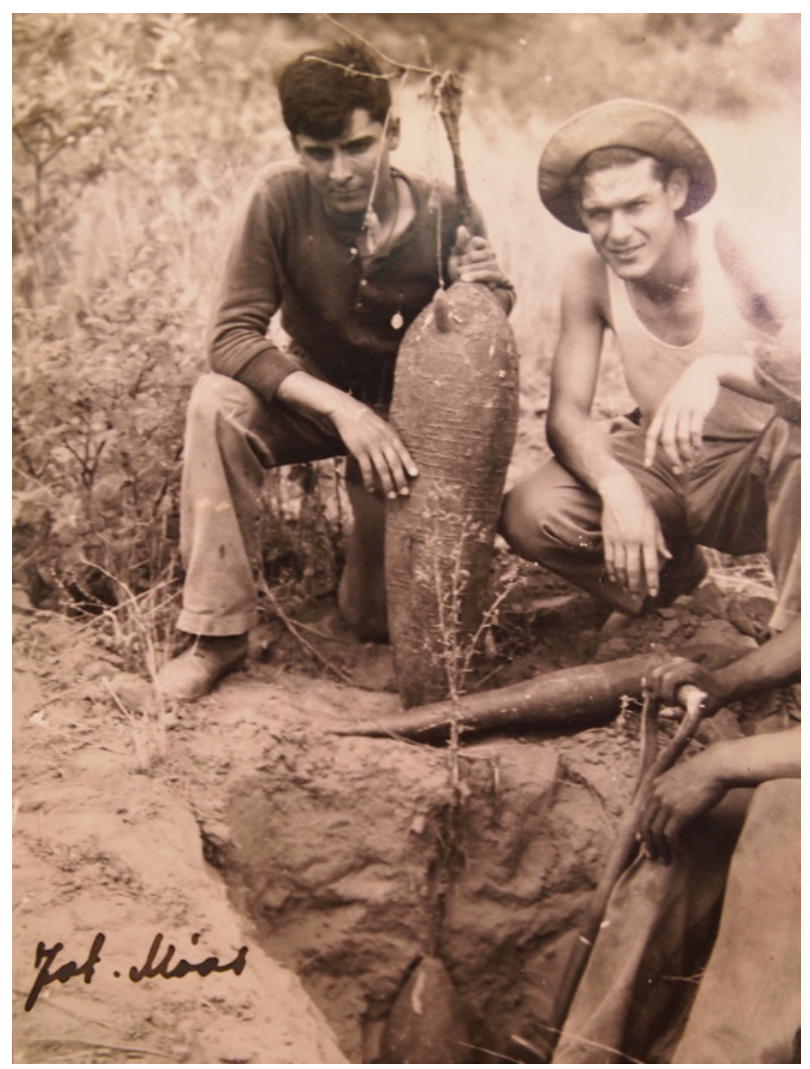

Figure 3.8 Paraguayan soldiers posing with a freshly excavated yvy'á (Courtesy of AIHMM).

83), one cannot help but wonder how many soldiers might have stamped on the little shrub, delirious with thirst, unaware of its buried treasure.

Desperate for fluids, the soldiers would drink the water stored in the jackets of their water-cooled machine guns, which they then refilled with their own urine (Zotti 1974, 37; Céspedes 1975, 164). In many cases, however, even urine was too precious to be wasted and many a soldier - albeit reluctantly - filled his canteen with it (Céspedes 1973, 139; Sarmiento 1978, 73). In the Chaco, the myth of mechanised warfare as the 'modernist super-artefact and the supreme signifier of universal progress and modernity' (Buchli 2002, 4) was exposed as a perverted illusion that killed thousands of people without even pulling the trigger. Here, the 'white death' came to act as both a terrible manifestation of modernity gone wrong (González-Ruibal 2006a, 177) and a reflection 
of the absurdity of the Chaco War and industrial conflicts in general, as one anonymous source notes: 'Water, sister of the Chaco, you who makes warriors beg, armed with all the weapons, they lack you, the most essential weapon, the indispensable one' (Anonymous 1980).

\section{Sensing the Chaco}

\section{(Con)fusing the senses}

War is a powerful multi-sensorial experience. In the context of the Chaco War, the excruciating effects of thirst on the human body and mind open up a uniquely Chacoan dimension of sensoriality amidst the horrors of industrial war within a landscape that was alien and thus full of new sensory impressions to most of the soldiers. The experience of armed conflict in the Chaco created an enmeshment of material realities and sensations that were often difficult to process and demanded new engagements with the landscapes and 'sensescapes' (Howes 2005c, 143-5) of the Chaco.

In his short story 'El Pozo' (The Well), which takes on the voice of an imaginary Bolivian official, Céspedes recounts the digging of a well, day after day, by a small detachment of Bolivian sappers in desperate need of water (Céspedes 1973, 17-36; see also Vera 2000, 26-8). Obsessed with finding the precious liquid, the soldiers keep digging for months - with thirst, silent yet omnipresent, always looming over them. The moist sensation of mud underneath the sappers' feet awakens a flicker of hope, which is quickly crushed by more layers of dry earth, 'Earth, earth, thick earth that tightens the lungs with the mute cohesion of asphyxiation' (Céspedes 1973, 26). The well takes on a terrifying personality, torturing the men who continue their descent into the entrails of the planet (Céspedes 1973, 28). With every metre they become more wormlike and less human, and yet they keep 'scratching the belly of the monster' (Vera 2000, 27). Forty metres. The well keeps denying them water but opens up a new world away from the blood and cries of the battlefield. Inside the suffocating darkness of the well, the war does not exist. There is no sound but the banging of shovels and the men's heavy breathing. The only thing that matters is finding water. Men faint, but thirst pushes them on. The lack of oxygen and their desperation make them hallucinate. After months of digging, the well remains dry. In the end, a group of thirsty Paraguayans attacks the detachment of sappers and after a short battle the dead are tossed into the hungry black hole in the ground. Instead of being a source of life, the well has turned into a grave, devouring men and hope alike. 


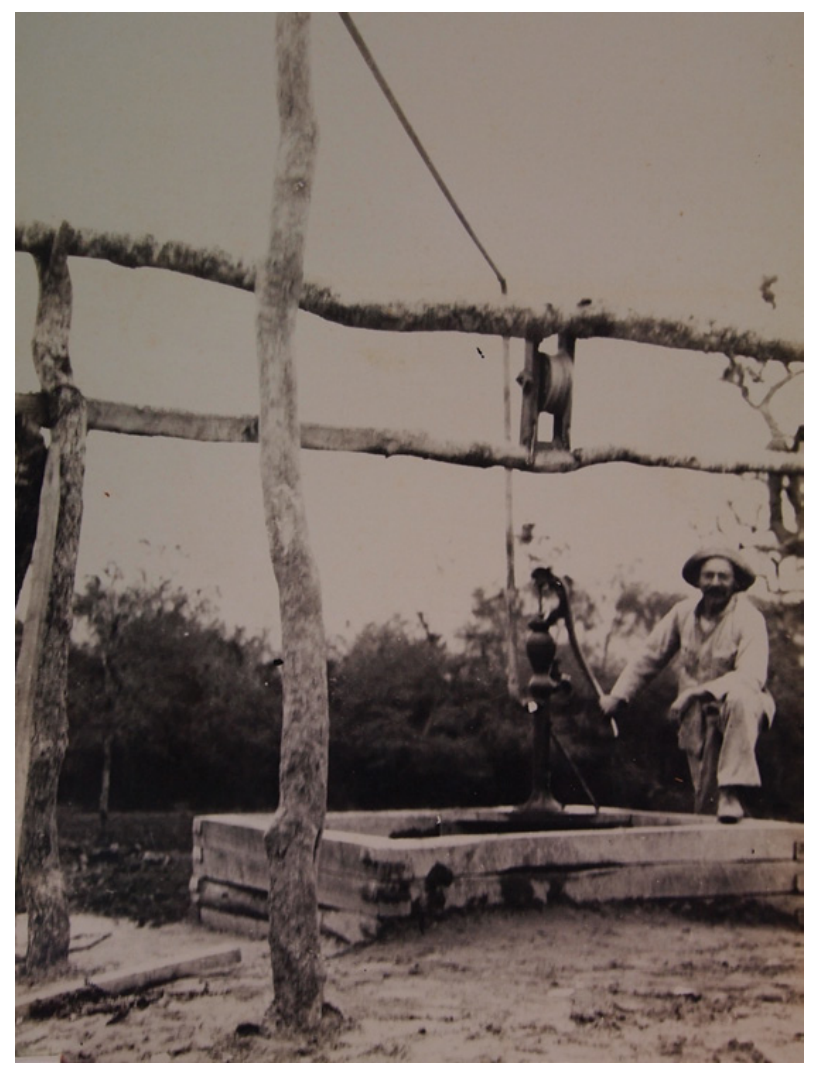

Figure 3.9 Paraguayan soldier posing next to a well (Courtesy of AIHMM).

Above ground, the immediacy of the horrors of war, thirst and the hostility of the bush further intensified the soldiers' awareness of their surroundings. The habit of going barefoot, for example, opened up a strong sensorial dimension to the Chaco experience of the Paraguayan soldier. As Ingold notes, boots 'imprison the foot, constricting its freedom of movement and blunting its sense of touch' (Ingold 2004, 319). Walking over the hot Chaco surface which was cracking from the heat and lack of water, his feet covered in dust, the Paraguayan soldier was continuously exposed to 'the thorns that do not respect leather, nor calico, injure our skin with every step and produce painful blisters' (Bustamante Rodríguez 1987, 62). Less prosaically, perhaps, going barefoot might also have helped the men in their attempt to bond with the Chaco by physically creating a feeling of connectedness with the earth they were defending with their lives. As Ingold suggests, 'it is surely 
through our feet, in contact with the ground that we are most fundamentally and continually "in touch" with our surroundings' (Ingold 2011, 45).

This entanglement of humans and things - animate and inanimate, industrial and natural - is reflected in written accounts by veterans. Similar to the soldiers in the American Civil War (1861-5), who fought in and at times against an unfamiliar landscape and used 'natural imagery to articulate their mental landscapes' (Shively Meier 2010, 40), the Paraguayan and Bolivian soldiers frequently expressed their emotions through language referring to the Chaco's flora and fauna, as well as its atmospheric conditions. At night, in the darkness of the trenches, the glow of cigarettes - a rare and savoured treat sent to the front from a faraway outside world - was likened to fireflies landing on soldiers' mouths (Céspedes 1975, 114). Too thirsty to sleep, Zotti contemplated his surroundings, which cast human-like shadows in the semi-darkness of the Chaco night. Nature, just like humans, seemed to be struggling as 'the erect foliage of the tuna cactus resembles arms, extended as if to plead with the star-filled sky for a little bit of water to appease the heat and thirst that reign during the day of the hot months' (Zotti 1974, 122-3).

During long and agonising marches under 'the rain of sun pins that pierced through the foliage burned from the heat' (Céspedes 1973, 138),

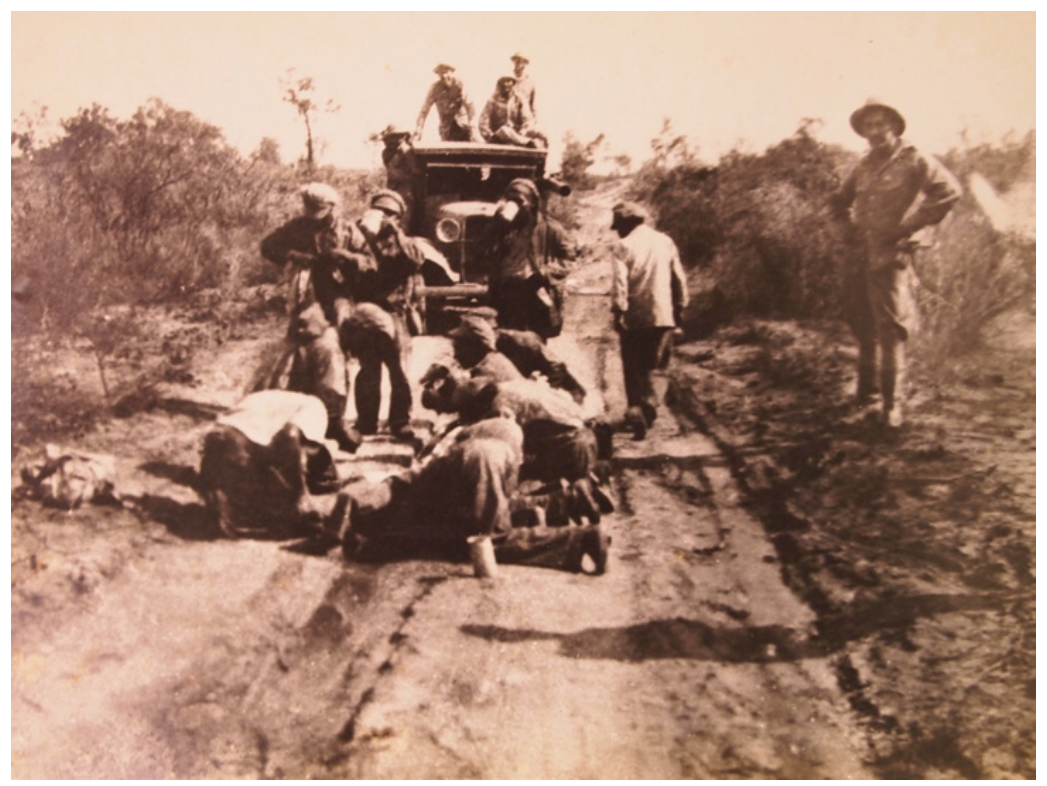

Figure 3.10 United by their struggle to survive. Paraguayan soldiers giving water to dying Bolivian troops on what came to be known as the picada de la desesperación (path of desperation) - a waterless stretch of land so dry that it is said to have claimed the lives of thousands of men (Courtesy of AIHMM). 
the soldiers' tongues became heavy and their vision blurred. As a result, their minds would frequently trick them into believing that they could hear the sound of running water or see the precious liquid shimmering in the shape of a lagoon or a small dirty puddle, but it generally revealed itself as a mirage in the landscape (Anonymous 1980). The bodies of men who had succumbed to thirst and dehydration were lining the dusty trails in the Chaco. The sight of dead comrades and gnarled enemy bodies had a strong effect on the survivors. The hollow cheeks, sunken eyes and open mouths that seemed to be desperately pleading for water were a constant and very real reminder to those who were passing that a similar fate would await them if they lost or emptied their water canteen.

After days without a drop of liquid, every cell in the soldiers' bodies was desperately craving water. Yet when it suddenly came in the form of a torrential rainfall, water often turned from a long-awaited saviour into a dreaded assassin. The emergence of large swamps and the flooding of trails made the terrain impassable, and the transport of much-needed medical supplies, food and military equipment was impossible. Like the fields of France and Belgium in the First World War, the grasslands of the Chaco were turned into a sea of mud, in which supply trucks and mules would sink (Farcau 1996, 102). Worse still, the trenches and battlefields became a deadly mix of mud, human body parts, metal splinters and diseases, inside which the soldiers and their equipment were literally drowning (see Das 2005, 39; Saunders and Cornish 2009, 5). Within the context of the First World War, Santanu Das tells us that mud's 'aggressive agency' and 'its leech-like suction on the skin' blurred the categories of object and subject (Das 2005, 45). Mud thus merged both the physical and psychological into a constant threat of 'dissolution into formless matter at a time when modern industrial weaponry was eviscerating human form: it brought the soldiers to the precipice of non-meaning in a world that was already ceasing to make sense' (Das 2005, 37).

Moreover, the men would get drenched, their soaking uniforms clinging to their haggard frames and giving them colds and even pneumonia (Farcau 1996, 100). Yet while the soldiers both eagerly anticipated and cursed the rainy summer months, they did not find relief during the short-lived winter weeks either. Many a soldier who lay dying of pneumonia or thirst somewhere in the impenetrable scrub must have wondered who they were actually fighting. In the struggle to survive, the boundaries between the natural and the industrial often became blurred. The intertwining cacti that cover large parts of the Chaco undergrowth and tortured the soldiers, for instance, resembled the lethal barbed wire entanglements positioned along the trenches. Addressing a Chaco in which the merging of nature and industrial war had generated hell 
on earth, Céspedes writes in his poem 'Terciana Muda' (Silent Fever): 'You were ploughed by cries and cannons, they flowered, your roses: the wounds, they ripened, your fruits: the grenades, oh garden of torture!' (Céspedes 1973, 15).

During a long and agonising march under the scorching sun, Céspedes furthermore vividly describes the auditory experience of a sudden rain shower as 'the rain that resonated crystal clear like a heavenly machine gun' (Céspedes 1973, 146). On the battlefields, supermodernity and nature merged into a powerful olfactory impression when, according to Zotti, 'The only thing that remains of the battle is the vague smell of gunpowder, dust clouds and death, mixed with the aroma of the Algarrobo tree and Esparto grass' (Zotti 1974, 64).

In their constant struggle to stay alive in the deadly blend of natural and industrial forces, the soldiers had to be alert at all times. The troops thus had to get closely acquainted with both the Chaco's natural environment and the enemy army, as the greatest instinct for the soldier body was to survive (see Winterton 2012). Sarmiento aptly describes his ears as 'little antennae' $(1978,70)$ that detected every sound and intrusion. In the Chaco certain animal noises also influenced the soldiers' perception of a world in which war had interwoven the 'industrial' with the 'natural'. A certain type of grenade, for example, became known as yacaveré as the noise it made was similar to the call of a local bird of that name (Zotti 1974, 35). The sounds of the Chaco also fused different indigenous and Latino Paraguayan ontologies. The distinct birdsong of the tove tojo or pájaro agorero (pessimistic bird, Herpetotheres cachinnans; also guaicurú in Guaraní) was considered a bad omen by the Ishir. In fact, tove tojo translates as 'leave' or 'go far away' and that is precisely what a person should do upon hearing the bird sing in the morning (Florentín 1984, 47; Escobar 2007, 226). During the war the tove tojo became well known among the Paraguayan soldiers, who believed that its song was a warning of the imminent appearance of enemy troops (Florentín 1984, 47; Paniagua 1994, 39). Others thought that the bird was lamenting the death of its female companion in one of the bloody battles fought by humans. Whereas other animals had long since withdrawn from the war-ravaged landscape, the mourning tove tojo had stayed and kept singing his sad melody while the soldiers groaned in pain on the ground below (Silva Lara 1979, 57-9).

Just as with any war, it is difficult for those not directly involved to imagine the multi-sensorial experience of trying to survive during the Chaco War. The land these men were fighting over was killing them; 
therefore nature was often personified as a hostile adversary. Sarmiento clearly remembers the fear of becoming a victim to both the Paraguayans and the Chaco bush: 'There existed an implicit and irrevocable commitment to not fall prisoner, but we were frightened by the notion of having already fallen into the trap of the scrub, identical [to the Paraguayan] in his hostile appearance' (Sarmiento 1978, 76).

\section{Comforting the senses}

Being trapped inside the Chaco scrubland, this 'prison of plants' with its thorns and deadly diseases, instilled in the soldiers a dread of being 'devoured by the jungle' that mixed with the constant fear of being hit by enemy artillery (Sarmiento 1978, 76). This all-encompassing feeling of impotence and inescapability weighed hard on the homesick men who dreamed of being with their loved ones. Nonetheless, there were a few things that allowed the soldiers temporary respite from the sensorial intensity of the war and the Chaco bush.

Men on both sides had the rural tradition of drinking mate, a type of tea made from yerba mate. The name yerba derives from the Spanish word hierba (herb) and the drink is made from the dried leaves of Ilex paraguariensis, a small tree native to subtropical South America. The leaves are harvested, dried and then crushed to a loose powder and placed into a guampa: a drinking vessel usually made from gourds, but bamboo and cattle hooves and horns are now also frequently used. The yerba is steeped in hot water and sipped through a metal bombilla (straw), which acts both as a straw and a sieve (Folch 2010, 9). Mate cocido or boiled mate is a blend of yerba and sugar, which caramelises when placed under a stack of embers. To finish, the whole mixture is added to boiling water and, depending on personal preference, topped off with a little milk (Folch 2010,24). Yerba mate is high in vitamins and has medicinal properties. It is also believed to enhance mental clarity and 'lift one's spirits' - properties that have earned it the name of 'green gold' (Benítez Alvarenga 1997, 24, 64).

When water was available during the Chaco War, both mate and mate cocido constituted a valued part of the soldiers' morning routine (Paniagua 1994, 44). The men would apparently filter the often foul-smelling water through the strong and bitter-tasting leaves in order to mask the stench. As the smoke from a fire inside the trenches would have given away their position to the enemy, the soldiers had no other choice but to have cold mate, also known as tereré (Benítez Alvarenga 1997, 52-3). Consumption of the tea (hot or cold) went far 
beyond the soldiers' biological demands and the desire to satisfy thirst. In fact, mate and tereré are part of a ritual, with a serving and drinking etiquette that is vigorously respected by those who participate (Folch 2010, 9-10). Mate and tereré are about sharing, as according to Derlis Benítez Alvarenga:

Tereré creates a space for the peaceful and fraternal gathering amongst friends; a gathering with the other where time is a gift that allows the sharing of the good and bad, the joys and pains. It is the space where one listens and is being listened to. In short, it is the space that every human being needs, for his/her own eminent condition (Benítez Alvarenga 1997, 13-14; see also Benítez Alvarenga 2013).

In the trenches of the Chaco, preparing yerba mate was a comforting tradition that not only linked the soldiers with their distant pre-war lives but also synergised two radically different worlds. More poignantly perhaps, and in an effort to make the unfamiliar familiar, the ritual of passing around the guampa amongst comrades created a temporary safe haven in which they experienced collective solace from the disorientation and hardships they faced in the bush, and the absurdity and horrors of modern war.

Faced with the excruciating effects of thirst, a soldier's sense of comradeship was often tested. After hearing his superior's words of caution to the squad about rationing the little water they had before a battle, Zotti remembers securing his canteen tightly to his belt on the eve of the Battle of Boquerón and although thirst was torturing him, he did not take a sip. He soon drifted off, listening to the water swishing inside the container, but he suddenly awoke, startled. His thoughts immediately turned to his caramayola and he only calmed down upon feeling it still securely attached to his belt. Yet to his great surprise it was empty. It was only later that he learned that one of his comrades had stealthily crawled over, opened the lid, inserted a bombilla and drained the canteen of its meagre contents (Zotti 1974, 36). The desperate water situation during the war had turned the bombilla, an instrument used to strengthen social relations during mate and tereré ceremonies, into a tool for survival.

Although it is generally accepted that the indigenous populations were preparing mate long before the Spanish conquistadors discovered the drink and its properties (Folch 2010, 11), Paraguayans believe that the widespread national tradition of drinking tereré - which has also 
infiltrated into Mennonite life (see Stoesz and Stackley 1999, 183) - is rooted in the Chaco War (Benítez Alvarenga 1997, 52-3). In fact, today tereré is more than just a drink in Paraguay: it is a part of the nation's identity and a source of national pride, linking Paraguayans with both their Guaraní roots and their mestizo forefathers who died as heroes in the defence of the patria (Benítez Alvarenga 1997, 43).

On the Bolivian side, mate also formed an integral part of Andean culture and the soldiers' routine. For the Aymara and Quechua recruits, however, it was coca, the leaf from a small Andean shrub (Erythroxylon), which provided them the greatest relief from the hardships of industrial war (Bustamante Rodríguez 1987, 143). The coca leaf has been shown to provide vitamins, help with digestion and altitude sickness, and suppress hunger, cold and stress (Gootenberg 2008, 16). To benefit from its effects, a wad of leaves is stashed inside the hollow of the cheek and sucked for about an hour. A small portion of powdered alkaline ash is usually added to release and enhance the plant's medicinal properties. According to the archaeological record, the chewing of coca leaves goes back at least 3,000 years in the region (Rivera et al. 2005). Although coca was briefly forbidden as 'an invention of the devil' by the Catholic Church in the sixteenth century, the Spanish soon realised that indigenous miners could subsist

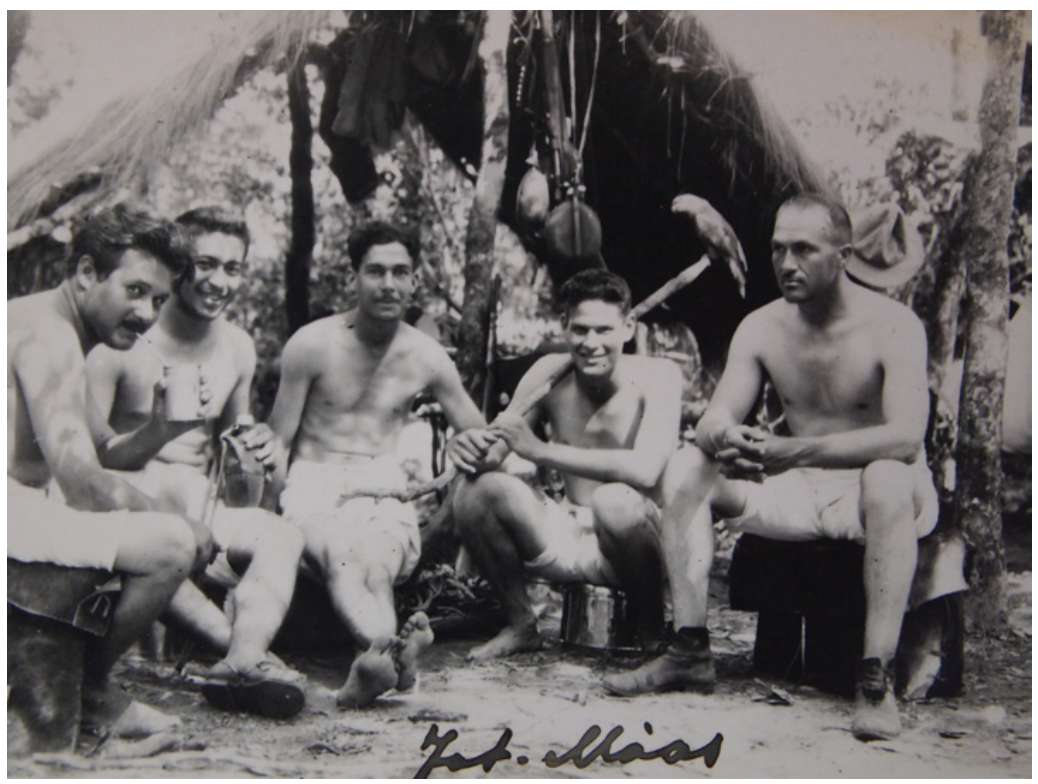

Figure 3.11 Paraguayan soldier on the left enjoying some tereré with his comrades (Courtesy of AIHMM). 
on a minimum of food and drink and work longer hours when sucking on coca leaves (Gagliano 1994, 49-51). When war broke out between Paraguay and Bolivia in 1932, Céspedes notes that 'With his bag of coca and stoicism, the Indian does not need anything else to work. Now, during the war, he also needs a light machine gun or a rifle, the first instruments of mechanical precision that civilisation put into his hands' (Céspedes $1975,113)$. As the ration of coca leaves was limited in the Chaco, the men were often forced to go weeks without the familiar bulge in their cheeks (Céspedes 1975, 114). Left without the calming numbness, the soldiers now had to face the physical and psychological effects of war with heightened senses.

The significance of the coca leaf transcends the suppression or numbing of bodily urges. Indeed, much like the drinking of mate and tereré, the chewing of coca leaves is a ritual that follows a strict etiquette that is integral to Andean indigenous identity and 'is used to mediate between man and the environment, and to appease the anger of the spirits of the ancestors living in the hills and mountains' (Morales 1989, 24). The coca leaf erases the modern division between mind and matter (Latour 1993) as it acts like a mediator blurring the boundaries between humans and the material and more-than-human world:

coca chewing provides the context par excellence in which communication takes place ... The offering of coca leaves draws one into social interaction and participation in the activities at hand. This social interaction includes not only the other persons present, but entities immanent in the living Earth as well: Mother Earth, the Mountain Lords, the ancient dead. Understanding the nature of this communicative bond, forged by coca chewing, means exploring an attitude in which land is experienced as animate, powerful and imbued with consciousness - a parallel society of Earth Persons with whom one is in constant interaction (Allen 1988, 23-4).

While the coca leaf intimately tied the Aymara and Quechua soldiers to Andean cosmologies and landscapes, it seems to have failed to connect them with the alien surroundings of the Chaco. In the flat and frightening scrubland, the coca leaf must have nonetheless been a comforting presence and a link with the much-missed Andean mountain range. In a world that was continuously changing and ceased to make sense to the soldiers, the coca leaf allowed them to temporarily escape their confusing realities and find solace in the deep-rooted constancy of the coca-chewing tradition. Thus, amidst the absurdity and horrors of modern industrialised 
warfare, the coca-chewing indigenous soldier embodied the transcendence of temporal realities by fusing an indigenous tradition going back more than three millennia with twentieth-century supermodernity.

$$
* * *
$$

The Mennonite introduction of agriculture, with its permanent settlements, pastures and Christian values, and the arrival of industrial warfare with its belligerent armies imposed themselves on what had hitherto been a predominantly hunter-gatherer landscape, resulting in the making and unmaking of a series of simultaneously contrasting and conflicting worlds in and across the Chaco's thorny forests (Breithoff 2012, 147). The Mennonites considered the taming of the Chaco a test of faith from God and proof of the creating force of the industrious and pious man. Condemning violent conflict, they decided to arm themselves with a plough to 'launch a peaceful war with the wilderness' (Anonymous 1933, 27). The armies, on the other hand, arrived with trucks and carts full of mechanised weapons, ready to take the Chaco by force. Yet, despite their modern tools, the soldiers and the Mennonites struggled to survive in the bush. The soldiers in particular soon realised that in the face of nature, modernity became useless.

Both the armies and the Mennonites were dependent on local indigenous knowledge of the terrain and its resources in order to stay alive. Understanding the Chaco and 'seeing' it through the eyes of its indigenous people was the key to unlocking its secrets. It is thus vital that the dominant discourses about the Chaco as wasteland in need of mechanised intervention are counterbalanced by alternative indigenous perspectives (see Kuletz 1998). Indeed, the latter should not be dismissed as romantic or mythical fairy-tales but rather taken seriously as 'worlds and knowledges otherwise' (Blaser 2010, 17).

In contrast to the region's indigenous communities, the Mennonites and soldiers considered nature an enemy, a threatening 'Other'. Despite their indigenous roots, which tied them to the physical and spiritual forces of the Andes, the Aymara and Quechua soldiers could not find 'Mother Earth' in the Chaco and felt detached from it. Even though the Paraguayan soldiers were used to the hot climate and had some knowledge of the local flora and fauna, they also struggled to connect with the Chaco beyond their purely patriotic duty.

This was, however, not a simple case of humans against nature but of humans in natures (see Winters et al. 2001a). Thirst and its powerful effects on body and mind operated in both a practical and symbolic dimension and, by doing so, brutally linked the soldiers to the Chaco often for eternity. The lack of water forced the men to physically scavenge 
and get to know the bush in their desperate search for a natural water source. On a symbolic level, the 'white death' became representative of the futility of the conflict. Like the digging of the dry well in Céspedes' story, the Chaco War made no sense. In a world that the soldiers could no longer comprehend, thirst exposed them to new sensorial realities, in which humans, nature and the material culture of conflict were enmeshed. In this sense, the Chaco War is emblematic of modern conflict as a form of Anthropocene hyperobject. Although the soldiers (and Mennonites) entered the bush determined to model it after their respective ideological beliefs, they came out of it with their own personal and social identities shattered and reshaped by the natural forces of the bush and the experience of modern war. The armed conflict both made and unmade the Chaco whilst it simultaneously made and unmade each of its participants in new and ultimately transformative ways. 


\section{4 \\ Trade, trash, treasure: Recycling conflict, making worlds}

Industrialised conflicts generate unexpected interactions between human and non-human actors that create and open up hitherto unknown worlds. The Chaco War was a war of matériel of gigantic proportions - as I have argued, an Anthropocene hyperobject - that left a lasting physical imprint on the bush and created manifold emergent and entangled relationships between humans, objects, nature and more-than-human agents. It was obvious from the start of the war that the Paraguayan army could benefit from the logistical support of Mennonite pioneers, whose settlements were situated in close vicinity to Paraguayan military outposts. In the early days of the conflict, the Bolivian trenches by contrast were located in an isolated area and at a great distance from the Bolivian bases. Consequently, the Bolivian military was more dependent on indigenous resources. In contrast, on the Paraguayan front, the army had to constantly negotiate with the owners and overseers of estancias over the military's use of indigenous workhands (Capdevila, Combès and Richard 2008, 23-4).

This chapter considers the relationships between Mennonites, soldiers and indigenous people and their engagement in trade as a means of survival among cacti and artillery shells. As the interactions between soldiers and indigenous groups have been detailed elsewhere (e.g. Richard 2008a; Capdevila et al. 2010; Harder Horst 2006, 2010; Langer 2016), I focus primarily on the relationships between soldiers and Mennonites and only briefly touch upon indigenous-Mennonite and indigenous-military relations (see also Nobbs-Thiessen 2017). I examine how lack of funds and resources forced people to interact in new ways with the material world by outlining the concept of recycling in relation to trench art during and after the war. I present military trench art, discuss motifs and suggest possible interpretations, then expose the wider implications of the Chaco War through the examination of Mennonite trench art. Finally, I consider 
recycled objects made by Ayoreo indigenous people and show how these objects trouble and help deconstruct the very concept of trench art itself.

As the technicalities regarding the production of trench art in the form of decorated artillery shell cases have already been discussed elsewhere (e.g. Kobialka 2019; Saunders 2000, 2002b, 2003; Milwright and Baboula 2014), I focus here on why rather than how people recycled war debris. Employing a symmetrical ontological approach to the material culture of the Chaco conflict, I suggest that such objects should not be seen simply as passive repositories for human symbolism, especially - but not exclusively - in the context of traditional non-modern societies, but rather as active participants in the production of entangled, parallel lifeworlds.

\section{Trading to survive}

When the Mennonites arrived in the Chaco, they believed it was God's will to convert the region's indigenous populations. They soon made contact and by 1929, 300 Enlhet indigenous people were reported to have been living as labourers on Mennonite properties. The colonists described them as peaceful and helpful workers who cleared the land for Mennonite fields and pastures in return for watermelons, clothes and tin cans (Faust 1929, 186-7). It was not long before the first indigenous people were reported to have converted to Christianity (see Krieg 1934; Regehr 1979; Unruh and Kalisch 2014). However, the armies' intensified militarisation efforts in the area and the imminent outbreak of the war forced the Mennonites to temporarily suspend their mission as many indigenous families retreated back into the bush to avoid contact with soldiers. The militarisation of their territories forced others to uproot their families and travel to distant parts of the Chaco or risk contracting new diseases or being recruited or shot by the belligerent armies (Richard 2008a; Capdevila et al. 2010). Although the Mennonites tried their best to protect their remaining indigenous labourers, the latter often suffered at the hands of both the Bolivian and Paraguayan military (Stahl 2007, 399-400).

When war broke out, the Fernheim Mennonite colony was in a particularly vulnerable geographical position because of its close proximity to the Bolivian and especially the Paraguayan front. Having fled the Bolshevik regime only a few years prior to the start of the Chaco War, the Mennonites felt that the war 'had caught them even in the midst of the forest where they never thought to hear the roar of cannon' (Anonymous 1933, 27). Suddenly the world, which they had left behind to start a 
new life away from the horrors of armed conflict, was alarmingly close again. Although they never witnessed any direct fighting in the Chaco, the Mennonites could hear the thunder of artillery fire in the distance and the roar of aeroplanes, which resounded over the quiet bushland for the very first time. Yet despite its close proximity, the colony's centre only ever sustained one Bolivian air attack in which the colony sawmill was damaged (Ratzlaff 2009, 39). Nonetheless, the war infiltrated everyday Mennonite life. The train station at Km 145 was buzzing with Paraguayan soldiers, who made their way to the military headquarters at Fortín Isla Po'í and various other outposts via the dirt roads passing through the Mennonite colonies (Ratzlaff 2009, 24). Soon a succession of trucks and ox-carts loaded with men, provisions and equipment was crawling through Mennonite villages where army musicians stopped to play military marches. Thus, before long, the Paraguayan military had occupied and militarised the land around the Mennonite colonies and the peaceful unspoiled 'wilderness' was peaceful and 'wild' no more.

The Paraguayan army not only brought the war to the Mennonite colonies but was also responsible for spreading a range of infectious diseases that often required urgent medical care. Due to their close proximity to the front and the army's need to deal with the vast number of sick and injured soldiers, Mennonite villages were promptly turned into military camps and schools into military hospitals. In return, the Mennonites enjoyed free medical treatment, which saved countless lives as it was superior to the limited healthcare they had previously received in the precarious conditions of the Chaco bush (Ratzlaff 2009, 85). Military medical personnel would travel from village to village to vaccinate whole Mennonite families against diseases such as typhus and smallpox and in return were invited to stay in the colonists' homes (GAKF, 22 October and 16 March 1933). Thus, by establishing friendly relationships with the Mennonites, the militarisation of the Chaco by the Paraguayan forces went beyond a purely physical occupation of the landscape and encouraged a feeling of Paraguayan nationhood in the recently arrived colonists.

A contemporary observer notes that 'Colonization was a weapon that Bolivia could not match' (Abercrombie 1933, 1173). As the Bolivian front never reached the Mennonite colonies, interaction with Bolivian soldiers was limited. Although the Bolivian military sent an official letter to the Mennonite colonies stating that their farms and fields were situated on Bolivian land and that, as a result, the Mennonites were Bolivian citizens under the military protection of the Bolivian forces, they never managed to win over the colonists (Ratzlaff 2009, 33-4). Realising their potential strategic importance for the enemy (Zook 1960, 84-5, 90), 
Paraguay ordered the evacuation of the colonies on 6 November 1932 (GAKF, 6 November 1932). The colonists were distraught. For the past two years their communities had worked tirelessly to build an existence in the bush and now they would have to leave everything behind. As their ox-carts were not able to carry all their belongings, the families worried that their crops would fail and that upon their eventual return the 'thieving Indians' would have left them with nothing (Anonymous 1933, 27). Concerned, they sent a letter to military officials explaining their plight and soon after received official permission to stay (Ratzlaff 2009, 24-5).

The Geschichtliches Archiv Kolonie Fernheim (Colonia Fernheim Historical Archive) in Filadelfia contains the written correspondence between Mennonite authorities and Paraguayan military officials, as well as Mennonite authorities and their communities. Due to the unreliable weather and road conditions in the Chaco, the colonists had developed a 'note' system, which consisted of short typed or handwritten notes usually composed by the community authorities and communicated to the villagers via foot messenger. Once the note had reached the first home it was that family's responsibility to start a communication chain so that the message could spread to every household in the community. This system, which lasted up until the 1970s, kept villagers up to date with everything that went on in the colony. During the war, the notes were primarily concerned with military-related issues and often gave rise to much debate between Mennonites and military officials as well as leading to disagreements between the colonies of Fernheim and Menno.

A note dated 6 October 1932 records one such example of disagreement. In the message, the Paraguayan military officials demanded that both colonies put 60 of their own ox-drawn carts and animals at the troops' disposal for the transport of provisions and military equipment to the Paraguayan headquarters and other camps and outposts (GAKF, 6 October 1932). While Colonia Fernheim agreed to provide the requested service, Colonia Menno refused and returned a petitionary letter, which pointed to the fact that its members had officially been exempted from military service by the Paraguayan government as part of their immigration conditions. It furthermore stated that as the Mennonites followed the teaching of the Bible, the army's request could not be reconciled with their Christian pacifist values. They did, however, promise to do everything in their power to serve the nation through their colonising and agricultural contributions by 'making a wilderness arable' (GAKF, 7 October 1932; Mennoblatt, October 1932). Shortly after the first note a second one followed, this time asking each of the two colonies to bake $80,000 \mathrm{~kg}$ of bread for the soldiers fighting 
on the front (Mennoblatt, January 1933). Again, colony members met to discuss the proposal and this time both colonies agreed to travel to the train station and pick up flour provided by the government. After all, they reasoned, baking bread was not the same as transporting war material, and they believed that by helping men in need they were not directly fuelling the war machine but rather fulfilling their Christian duty. In light of this, they decided to bake biscuits as well as collect eggs and other useful items to surprise soldiers stuck in trenches over Christmas in 1933 (GAKF, 19 December 1933). The Mennonites were, however, concerned that they provided more than their meagre harvests and wells permitted, jeopardising the survival of their own communities (Faust 1929, 188). In December 1934, for example, the Mennonites were forced to reduce their own egg intake so that the military could have a week's worth of produce (GAKF, 3 December 1934).

Although their trading relations with the army were dictated to a certain degree by religious conviction, they also fulfilled a more pragmatic purpose. Life in the Chaco was hard, and the flourishing relationships with the army allowed some Mennonites to improve their existence, as one man from Colonia Menno recalls:

We Mennonites sold many things to the soldiers: eggs, watermelons and chickens. We also traded them for flour and rice. We only traded food, never for metal or weapons. We had nothing. This was the first time since our arrival in the Chaco that we were able to make a little bit of money (male resident of Colonia Menno's old people's home in Loma Plata, pers. comm.).

The Fernheim archive keeps a written record of lists detailing who traded or sold what objects and what personal belongings disappeared during the military occupation of the villages (GAKF, 15 August 1933). While they are certainly a testament to the organisational skills of the Mennonite communities, they also illustrate the extent of their trading business with the military. In an ironic twist, industrial war, which in its very essence symbolises large-scale destruction and death, allowed the Mennonite colonies to survive.

Relationships between Mennonites and soldiers were, however, not always trouble-free. Driven by hunger, soldiers would resort to stealing cattle and chickens, and the occasional armed assault on a loaded Mennonite cart (GAKF, 1932, month unknown). In light of this, the Mennonites were told to stamp their horses with a special seal, so they could be distinguished from the military ones and ownership could be 
established in case of theft (GAKF, 24 September 1932). A small number of notes also warn women and girls against leaving the farm and steering a cart by themselves as soldiers stationed in and around the villages could pose a threat. Indeed, a letter addressed to the President of the Republic denounces the rape of a young woman by a soldier, while a note addressed to members of the colonies reports a break-in that almost resulted in the rape of a heavily pregnant woman (GAKF, 9 August 1932).

For children, the war years were for the most part an exciting time. A Mennonite man, who was 11 years old at the start of the conflict, remembers Paraguayan squadrons marching through his village and planting the Paraguayan flag in the middle of the main dirt road. It was the first time many of the children in the community had seen what was now their national flag. The children were in awe of the soldiers and although their wary parents prohibited any engagement with the uniformed men, curiosity would often get the better of them. Occasionally, the boys would catch a ride on one of the army trucks that were running to and from the front line. In addition to the excitement and novelty of travelling in a vehicle, the ride was a welcome respite from long daily walks to school (male resident of Colonia Menno's old people's home in Loma Plata, pers. comm.).

Children also traded with soldiers, looking to obtain military equipment such as rifles (GAKF, 4 April 1934). Similarly to children collecting and trading shrapnel during the Second World War in Britain, the Mennonite boys were trying to compete with and impress their friends with the most valuable traded item, and thus managed 'to control or domesticate the material culture of violence by integrating it into their dynamic social worlds of trade, status, mischief and play' (Moshenska 2008b, 109; see also Moshenska 2019). However, whereas this was an innocent and adventurous game for Mennonite boys, it was a real and dangerous struggle to survive for the soldiers. In fact, a soldier was not allowed to trade or sell any of his Ministry of Defence-owned equipment and exchanging a mosquito net for a load of bread could lead to physical punishment in the form of lashings (Klassen 1993, 105-8). Military officials and Mennonite authorities also instructed the colonists not to buy from or trade with any soldiers and warned them not to house soldiers who were not able to identify themselves, as they were most likely deserters trying to hide (GAKF, 10 February and 16 November 1933).

The consequences of trading military equipment were not limited to the individual experiences of soldiers and Mennonites but had much broader cultural implications for the different indigenous groups of the Chaco: 'From then on', an elderly man recalled, 'the Nivaclé [indigenous 
people] had rifles, because the Paraguayan soldiers traded them for watermelons. Then soldiers would not return to the front because they had lost their weapons' (Seelwische, quoted in Harder Horst 2006, 29). This probably serves as the most extreme and poignant example of the 'destructive clash of industrial technology and nonindustrial communities', which Alfredo González-Ruibal argues 'is characteristic of the relationship between people and things in supermodernity' (GonzálezRuibal 2008, 253). Until the arrival of the Paraguayan and Bolivian armies, most indigenous groups had only had access to traditional weapons such as wooden spears. Thus, by using a modern rifle of German or Italian origin the indigenous warrior was unconsciously becoming part of a globalised industrial conflict that linked him to distant multinational corporations funding the war that forced him off his ancestral lands.

\section{One man's trash is another man's treasure}

When war broke out, the vision of a 'civilised' Chaco soon lay shattered amongst crippled trees, human limbs and metal debris. Mechanical forces had ravaged the landscape, exposing the 'fragility of the natural world and of human beings [exposed] to the steel and iron of industrialised war' (Saunders 2013, 29). The war destroyed everything in its path and left in its wake the remnants of a failed modernity. 'The dream of reason', writes González-Ruibal, 'produces rubbish' (González-Ruibal 2006a, 194). Thus, even in their most destructive form, Anthropocene conflicts both unmake and make worlds. In the wake of the Chaco War, the bush was littered with bits and pieces of war matériel that looked strangely out of place among the thorny shrubs: rifles, parts of military vehicles, shrapnel, oil canisters, a single boot. With the fighting over and the armies gone, these abandoned and often fragmented objects had turned into decaying matter void of their original purpose. Tim Edensor notes that having left the realm of human control, 'the material status of objects in ruins is transient, so that they are in a state of becoming something else or almost nothing that is separately identifiable' (Edensor 2005a, 319).

Prior to the war, resources were limited in the Chaco and people were for the most part self-sufficient, relying on the local environment for food and the provision of building materials. Yet the excess of 'things' generated by modern warfare had suddenly opened up new material possibilities. Iron and steel objects, especially, constituted a welcomed source of metal that was hitherto only scarcely available in the bush. 
With the train line from Km 145 to Puerto Casado as their only lifeline to the outside world, the Mennonites had to import all metal items. Metal, and particularly iron, was also a highly desired but rare commodity in indigenous communities. Written accounts by Jesuit missionaries dating back to the eighteenth century tell of monks exchanging metal tools for access to indigenous villages. At the end of the nineteenth century, explorers write about attacks by various indigenous groups in search of metal goods. The emergence of military forts throughout the 1920s and 1930s gave rise to further sporadic attacks by members of Ayoreo communities and competition would often result in conflict between different Ayoreo groups (Capdevila et al. 2010, 64-6). After the war, indigenous people collected leftover ammunition and other bits of metal for personal use in the production of metal spearheads and other tools (Capdevila et al. 2010, 65). Surprisingly, perhaps, they also traded precious pieces of metal for Mennonite bread, which they supposedly liked so much that, according to a local Mennonite saying, 'Once he tasted Mennonite bread, the Indian never wanted to return to the bush again' (Hans Fast, Mennonite guide based in Loma Plata, Colonia Menno, pers. comm.).

For their part, the Mennonites also collected scrap metal left behind by the armies on battlefields and along dirt tracks. Shortly after the war, the Mennonites received official permission from the Paraguayan military to collect leftover material from nearby military outposts (GAKF, 2 November 1935), which they then proceeded to sell at village auctions (GAKF, 13 January 1936). The bush was in fact so full of industrial debris that, according to an official document from the Paraguayan presidential office, 'cemeteries of vehicles' together with 920 tons of scrap metal were still present in the Paraguayan military controlled part of the Chaco in 1945 - 10 years after the end of the war! The document further notes that in its current corroding state, the debris is no use to the military and thus concludes that it should be collected and sold off as scrap metal and/or melted down to be recycled in the fabrication of armaments by the Paraguayan Armed Forces (AIHMM). The removal of war debris was not without its dangers, as many of the shells and grenades would still have been volatile and in need of disarmament before being considered for recycling.

Nicholas J. Saunders has defined the recycling of war matériel or trench art as 'any item made by soldiers, prisoners of war and civilians, from war matériel directly, or any other material, as long as it and they are associated temporally and/or spatially with armed conflict or its consequences' (Saunders 2003, 11). The recycling, reuse and reinterpretation of material constitutes part of a continuing social process that is 'open to varied forms of expression and entanglement' (Reno 2009, 30, 43). 
Jeremy Coote et al. suggest that the process of recycling comes in various forms such as the complete transformation or 'meltdown' of objects to make them 'virtually formless before new forms are created' (Coote, Morton and Nicholson 2000, 21). In other cases, the pre-existing forms of things are slightly adjusted so as to serve their new purpose (Coote, Morton and Nicholson 2000, 18). In the case of the Chaco War, the scarcity of other available resources forced soldiers, Mennonites and indigenous people to become creative with the debris generated by industrial warfare.

\section{The Chaco War in a shell case: military trench art}

Stuck in trenches for weeks on end between battles, the soldiers were often left with little to do to pass their time. With war detritus all around them, they fabricated playing cards from thick cardboard ammunition boxes, prepared their meagre breakfast inside used gas canisters and made instruments out of caramayolas, telephone wire and natural plant fibre (Zotti 1974, 123, 150; Pacheco Bellot 2000, 55). The soldiers also picked up artillery shell cases and turned them into 'three-dimensional testaments to the experiences of war' (Saunders 2003, 163). Because of their availability and their physical properties, empty artillery shell cases acted as readily available substitutes for paper, while bayonets and knives served as pens. Their smooth surface permitted men to express their experiences in carving and thus transformed the shell on both a physical and symbolic level. In a twist of irony, the precise object that caused so much fear and grief on the battlefield and in the trenches now presented a temporary escape from these same terrors.

The decorated shell case is undoubtedly the most iconic (and ironic) of all trench art objects (Saunders 2003, 72-3). Highly explosive, the artillery shell was (and still is) produced to kill. During the First World War, it became the embodiment of the destructive powers of industrialised conflict. Due to the practice of trench warfare and the horrors that unfolded inside the dugouts, the Chaco War soon turned into a South American version of the Great War fought with leftover weaponry from that same conflict (Pendle 1967, 26). Sometimes referred to as the 'Verdun of the Chaco', the Chaco War was a 'meat grinder' that claimed thousands of victims (Farcau 1996, 103). The deafening sound of and continuous threat from artillery shells became integral parts of the soldiers' existence in the Chaco, where 'the cicada's song has been replaced by the whizzing sound of bullets' (Céspedes 1975, 124) and 'The artillery 


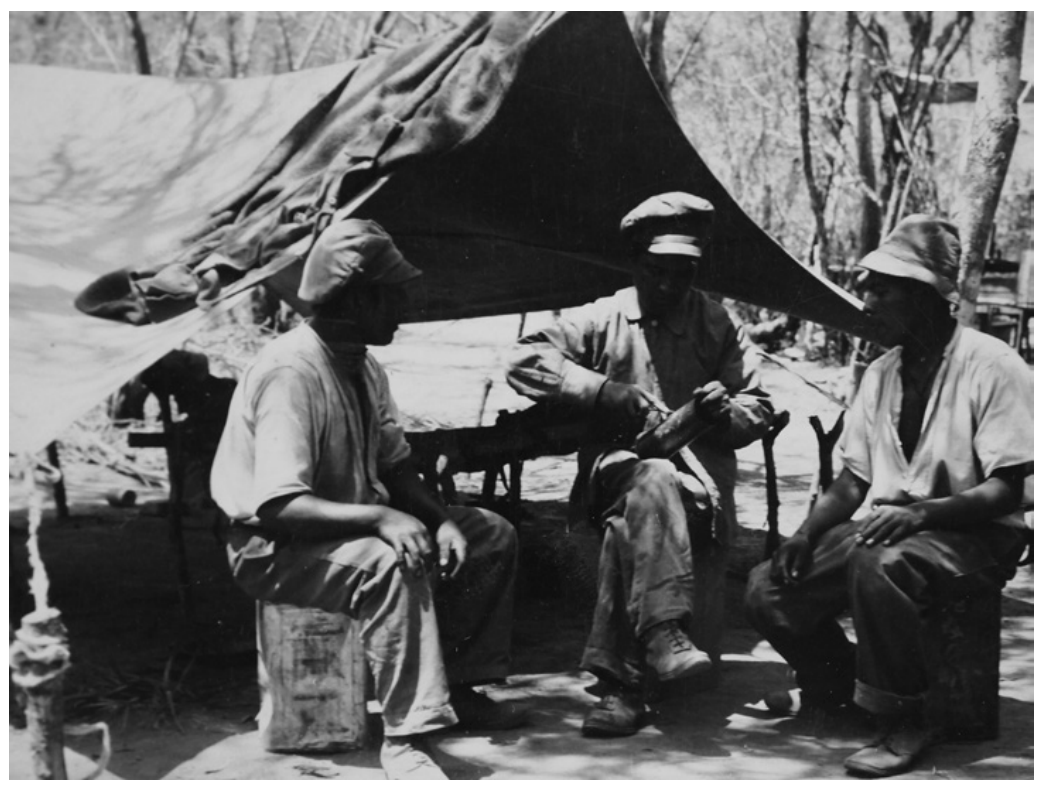

Figure 4.1 Bolivian soldier engraving a shell case (Courtesy of AIHMM).

and mortars ejected their grenades and shells that spread death, horror and terror in a roaring symphony' (Paniagua 1994, 155). The menacing sound of artillery fire kept haunting the men beyond the battlefield. Although weeks and months spent inside filthy trenches had dulled the soldiers' senses, the clamour of war lingered on inside the men, only to resurface suddenly at night long after fighting had ceased, as Céspedes vividly remembers: 'far away from the war, all the noises deposited in my nerves woke up during the middle of the night, followed me in my delirium, like the noise of a train' (Céspedes 1973, 108).

The impact artillery shells had on soldiers is embodied in a 75 MP.M/928 Schneider shell case dated 1929. The object belongs to a private collection in New Mexico that totals 63 Chaco War shell cases (see further details in Breithoff 2015, Appendices 2 and 3). The collector received the shells from a fellow trench art aficionado whose Paraguayan friend had saved them from a rubbish dump. They now form part of an extensive trench art collection that includes pieces from different time periods and conflicts all over the world. The examples from the Chaco War boast a diverse range of decorative motifs, ranging from floral and faunal designs to human representations and religious symbolism. The 
recurring motif of the Paraguayan coat of arms suggests that most modified shell cases from this collection were made by Paraguayans. Almost all of them also have place names, signatures and/or dedications engraved in them, which could facilitate the identification of the artist.

One side of the 192975 MP.M/928 Schneider shell case depicts the Paraguayan coat of arms complete with lion, staff and liberty cap, wreath and the national slogan Paz y Justicia (Peace and Justice). It also names Fortín Nanawa as a place and 5 May 1933 as a date. The other side of the shell case shows a depiction of a field gun with five soldiers dressed in uniform kneeling behind it. Below the field gun the artist engraved a protective shield sheltering three more soldiers. The men are kneeling around an ammunition box from which they are passing artillery shells to their comrades loading the field gun. The attention to detail and artistic skills reflected in the engraving suggest strong personal dedication on behalf of its creator. Decorating this shell case would have been time- and energy-consuming, as well as a technical challenge. Creating artillery

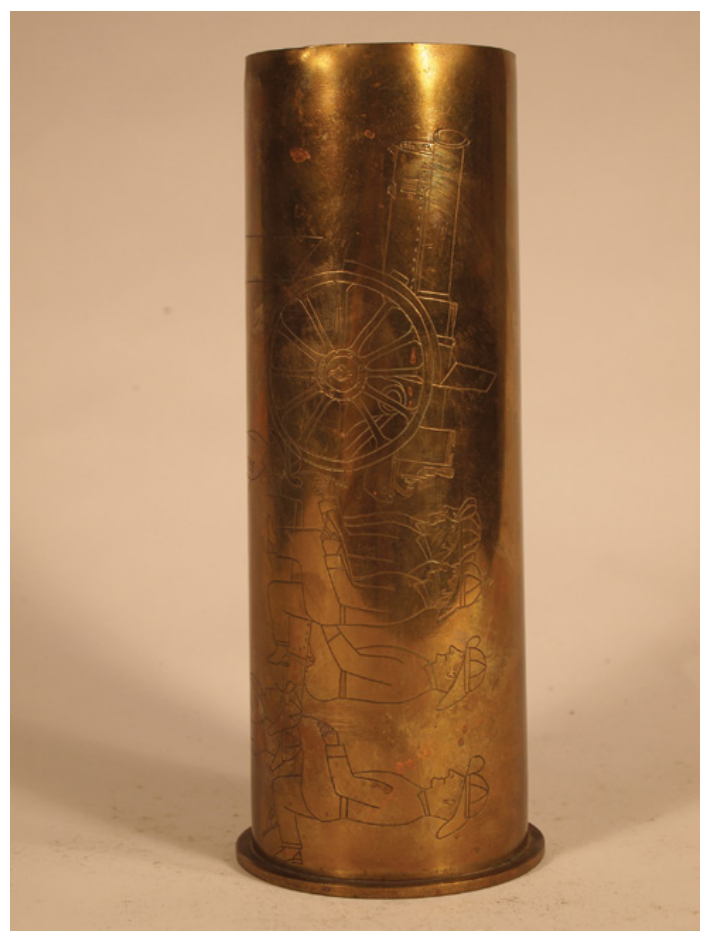

Figure 4.2 Engraved shell case depicting soldiers operating a field gun (Source: author). 
shell case trench art is indeed no easy undertaking. The awkward shape and hard surface of the shell often complicate and prolong the process of decorating. Making trench art thus requires a certain degree of craftsmanship, artistic skill and dedication (Saunders 2003, 59-61). The choice of motif would therefore have been unlikely to be random on the 75 MP.M/928 Schneider shell case. For one reason or another, the soldier who depicted the field gun felt strongly about this piece of artillery. Was he one of the men loading or firing it? Or is the decoration on the shell case a silent reminder of the deafening noise that undoubtedly announced death to numerous of his comrades?

Considering the richness in artistic talent and the diversity in decorative motifs and messages, it is perhaps surprising that the Chaco War's engraved shell cases have so far been completely overlooked. The exhibition areas of national museums such as the Museo Militar based inside the Ministerio de la Defensa Nacional in Asunción, the Museo Fortín Boquerón in the Chaco and the Museo Histórico Gral. Div. Enrique Duarte Alder in Paraguarí are crammed with different kinds of weaponry, uniforms and all sorts of other paraphernalia dating from the war. Although each museum has a number of shell cases on display, none revealed decorations on closer inspection. Three engraved artillery shells were however stacked on top of a cupboard in a little room away from the exhibition area in the museum in Paraguarí. Similarly, the Museo Fortín Boquerón revealed a further decorated artillery shell case hidden inside a cardboard box in the museum's storage room. Why those trench art pieces do not form part of the general exhibition remains open to debate. People might simply not know what to make of the shells as they do not belong to any familiar category of wartime objects. As the level of artistic skill applied to the various shell cases varies greatly, some of the objects might not be deemed 'pretty' enough to go on display. On the other hand, shells that are adorned with floral designs may not be considered suitable reflections of the masculine culture embedded within Paraguayan military culture. Yet, when it comes to uncovering the stories inscribed in the shells one needs to transcend the purely military nature of the decorations and reveal the person, not just the soldier, behind the engravings.

This issue is illustrated by another decorated shell case from the private collection located in the United States. The example is a $191175 \mathrm{~mm}$ Schneider shell case with the inscription (translated from Spanish): 'For my unforgettable and dear grandmother/Republic of Paraguay/Souvenir from your grandson EC'.

The inscription is made up of tiny zigzag lines, which were most likely produced with a bayonet or other type of knife. The dedication to 
a beloved grandmother evokes the image of a young homesick soldier engraving the shell case somewhere in the remoteness of the Chaco. Separated from his loved ones by hundreds of kilometres of dense bush, the thought of his grandmother must have filled the man with a sense of melancholy for a better, safer life far away from the deafening sound of artillery fire and the smell of rotting bodies. Like thousands of other young men he most likely swapped his plough for a rifle, determined to defend his beloved patria Guaraní (Chesterton 2013). On the shell case this deep-seated devotion to homeland and Guaraní heritage is expressed in the depiction of the national coat of arms with its olive and palm branch wreath surrounding a five-pointed star. With the possibility of a premature death constantly looming over the soldiers, the initials on the shell might represent the artist's intention to preserve part of himself in the shell case that, unlike him, may someday find its way to his grandmother's home.

The most evocative decoration on the shell case is perhaps the butterfly depicted on the reverse of the case. The delicate beauty of the butterfly stands in stark contrast to the destructive power of the artillery shell itself. Consistent with the other imagery, the simple yet appealing insect design is made up of tiny zigzag lines. Butterflies are common in the Chaco and the artist might have simply engraved what he observed in the bush. Maybe his grandmother had a special liking for these winged creatures and they came to act as a reminder of family members left behind? In his memoir, Felino Paniagua recalls an episode in which he and his comrades had been walking under the burning Chaco sun for a whole day without a drop of water when they suddenly saw thousands of butterflies fluttering around in front of them. He describes the yellow and white swarm as a 'carpet interwoven with the attractive colours of these fragile creatures of nature' (Paniagua 1994, 44). The men soon realised that the butterflies were hovering over a puddle of water. Beside themselves with thirst, the soldiers imitated the butterflies and threw themselves to the ground, crushing some of the insects in the act. Desperate, the men tried to soak up the foul water with a dirty tissue or the corner of their mosquito net (Paniagua 1994, 44-5). Could the butterfly on the shell case be the embodiment of a similar harrowing experience suffered by the artist? Like the butterflies in the Chaco, moments like these must have been abundant. Unless they are remembered in personal diaries such as Paniagua's, these ephemeral episodes often slip through the cracks of time and go unmentioned in history books. Examining the material culture of the Chaco War - such as a decorated shell case - through the lens of archaeology and critical heritage studies thus allows us to 'increasingly emphasize the common soldier's experience of war' (Saunders 2003, 13) 
as well as the divergences between these experiences, and the parallel and contrasting lifeworlds they produced.

Decoding these embodied experiences is not always straightforward as adornments on shell cases often appear to have mere aesthetic qualities. As already noted, the butterfly engraved on the artillery shell might not be purely ornamental. The butterfly is a highly symbolised creature and the butterfly motif has been widely used across different times and cultures. The ancient Greeks, for example, saw the butterfly as a representation of the human soul. Due to its metamorphosis from egg to caterpillar to pupa, from which it finally emerges complete in its winged splendour, the butterfly is often considered a symbol of rebirth and transformation (Kritsky and Cherry 2000, 7-9). During the Chaco War the soldiers underwent a change comparable to that of the insect. In numerous cases this was a physical transformation at the end of which the soldiers, like the butterflies, emerged unrecognisable, as one soldier recounts:

While I suffered the occasional ordeal before the war, I suffered ten simultaneously during the war. My face bears the traces that are still fresh. My hair has turned grey at barely 23 years of age and my whole self is nothing more than a heap of suffering meat (Meyer Aragón 1935, 59).

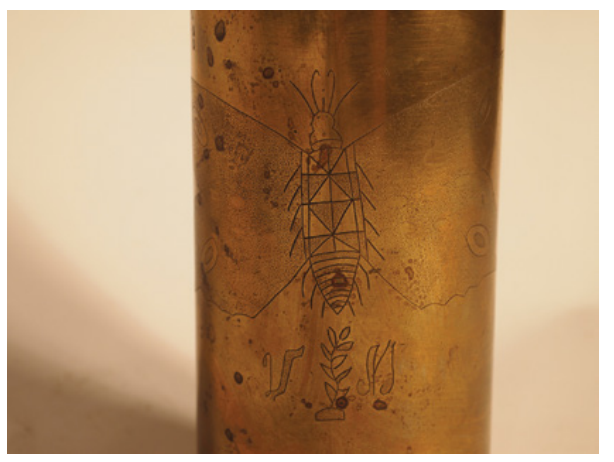

Figure 4.3 Detail of engraved shell case showing butterfly design (Source: author). 
The destructive power of industrialised warfare wreaked havoc on the human body and left countless men with missing limbs and disfigured faces. Although not every soldier returned with serious physical damage, most if not all men must have suffered a severe psychological transformation. Since the end of the war Paraguayan and Bolivian historians and members of the militaries have written a myriad books about the conflict and the respective national military. As many of these are highly subjective and interwoven with nationalism, this has resulted in a romanticised view of the soldier's emotional transformation. In the eyes of the nationalist, a man's bravery, pride, loyalty and love for his patria turned him into the supreme Guaraní soldier who was not afraid to die for his country. This glorification of the Guaraní soldier and his at times almost superhuman qualities undermines the true nature of mechanised wars and their effects on the human mind. Although most of the young men were undoubtedly devoted to the defence of their homeland, they were certainly not prepared for the inhospitable nature of the Chaco bush and the horrors of modern warfare that they were about to face. The appalling conditions in the trenches and the massacres on the battlefield were deeply traumatic experiences that, like the First World War, left in their wake 'a generation that was destroyed by the war - even those of it who survived the shelling' (Remarque 2005, 212).

Amidst the deadly blend of artillery shells and the Chaco's thorns, the Paraguayan and Bolivian recruits found themselves united in their misery and uncertain fate. These shared experiences often provoked a feeling of commiseration rather than hatred in soldiers from both sides (Zotti 1974, 69). They were all yearning for peace and their old lives outside the hostile Chaco thicket. This mutual longing for a brotherly co-existence of the two nations is illustrated in a fusion of the Paraguayan and Bolivian coats of arms on a 1929 MKK shell case with the words Bienvenidos Resquin (Welcome Resquin) and a date (23-VII134) inscribed into it. The central engraving depicts a wreath, presumably borrowed from the Paraguayan crest, with two arms engaging in a handshake while also holding a pole with the cap of liberty on top of it. The depiction of a sun rising above the image seems to represent the sun ascending above the holy mining mountain of Potosí found on the Bolivian coat of arms. The merging of the two crests is highlighted by a further engraving on the other side of the shell. Here a wreath encircles a star (found on the Paraguayan crest) with sun rays sprouting from it, thus reinforcing the notion that the Paraguayan and Bolivian soldiers, despite fighting for opposite sides, were ultimately brothers in arms. 


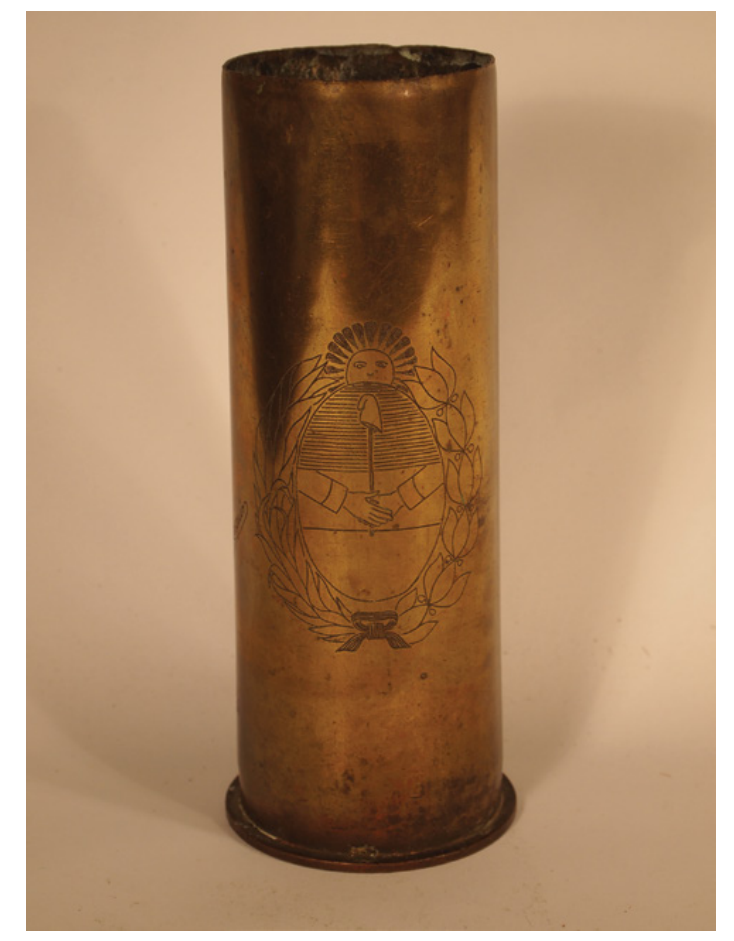

Figure 4.4 Engraved shell case showing solidarity between the two nations at war, as well as the fusion of the Paraguayan and Bolivian emblems (Source: author).

Few things made life more bearable in the trenches. One of them was the madrinas de guerra (war godmothers or war patrons), to whom a number of decorated shell cases are dedicated in gratitude. The concept of madrinas or marraines de guerre was first introduced in France during the First World War. To raise the morale of men fighting on the front, French women volunteered to become a type of pen pal to the soldiers. These women were often members of patriotic movements that were religious and conservative in nature. Many women decided to become a 'godmother' to a soldier after the loss of a husband or son in the war. Borrowed from a religious repertoire, the term marraine originally referred to a person who watches over your faith and guides you through the path of a Christian life. In the context of the First World War, 'godmothers' sent letters and parcels to soldiers in the trenches - most of whom they had never even met - for emotional support. This created a special bond between the men and their designated 'godmother' and often an initially platonic relationship later turned into a romantic pursuit (Kalmar et al. 2012). 
During the Chaco War, women from all social classes in Paraguay volunteered as madrinas, fulfilling their patriotic duty and creating an important link to the outside world for the soldiers (see Sosa 2010, 79-91). Stuck inside trenches in an unfamiliar and threatening environment, the men were desperately waiting for news from their loved ones back home. During the rainy season, however, the post was regularly delayed for weeks as trucks would get stuck in the mud. When it finally managed to reach the front, the soldiers would huddle closely together in hopeful anticipation of a parcel. The lucky recipients would carefully open their letter and read the words of comfort and the promises of a golden future with delight. Presents such as sweets, buttons, thread and cigarettes - luxuries in the Chaco bush - were also received with great joy. Zotti remembers that for the homesick soldier on the front, his madrina was 'a balm that soothes the painful wounds of absence' (Zotti $1974,123)$. While the Bolivian military supposedly facilitated occasional female visits to the front to raise the soldiers' spirits, most Paraguayans never met their madrina (Sosa 2011, 84-5). For many she came to represent the lush valleys and cobbled streets of their distant villages, which stood in stark contrast to the arid and dreaded landscape of the Chaco bush. More importantly perhaps, the madrina embodied the virtues of the Paraguayan woman: selfless and strong, she managed house and farm while the men were away defending the very land she was cultivating. Similar to her status in the War of the Triple Alliance less than a century before (see Potthast 2004), the Paraguayan woman once more became a symbol of patriotism and 'Paraguayaness'.

Of the 63 shell case exemplars in the private collection in the US, nine are explicitly dedicated to a madrina, while another 11 have women's names engraved on them. In the case of the former, recurrent motifs are the national coat of arms, hearts and flowers, as well as names, dates and place names. Interestingly, the flower and heart motifs stand in stark contrast to what the artillery shell they are engraved on actually represents. Artillery shells embodied the destructive forces of modernity and were, as Saunders points out, 'the icons of twentieth-century industrialized war' and yet they were 'covered with designs from a more innocent pre-war era' (Saunders 2003, 62-3; see also Saunders 2002b). Did the Paraguayan trench-art makers think that flowers and hearts were appropriate designs for the female recipient of their shells? Were they trying to romanticise the experience of armed conflict or shield women from the gruesome realities of modern wars?

One example that stands out is a 75 MRM 1928 Schneider shell case that a certain Sargent Bernabé Benítez Mendoza from the First Regiment 'Dos de Mayo' dedicated to his madrina Guiosmar Meaurio as 
'proof of appreciation from her protégé'. The artist also added the words Chaco paraguayo, Republica del Paraguay paz y justicia, and a complete coat of arms. What sets this example apart from the others, however,

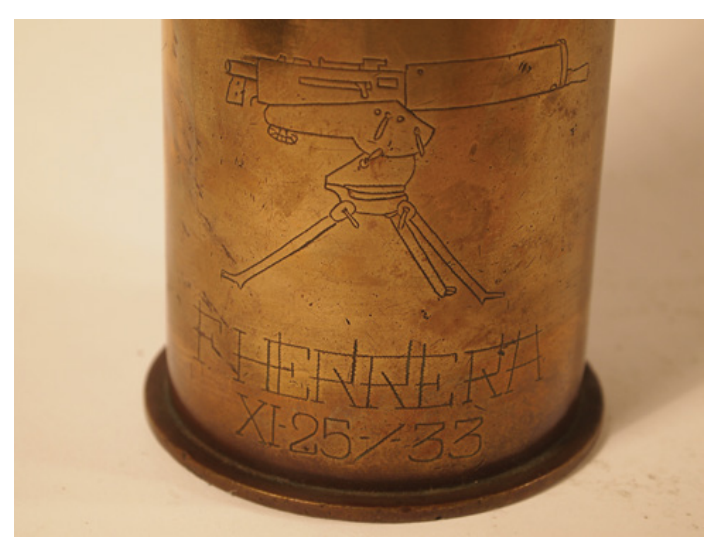

Figure 4.5 Detail of engraved shell case depicting a machine gun and the name and date of the battle at Fortín Herrera (Source: author).

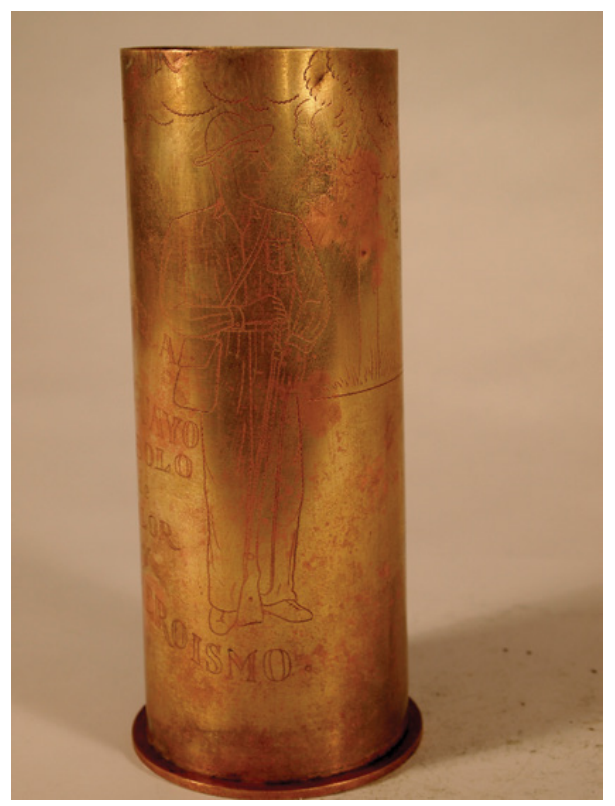

Figure 4.6 Detail of engraved shell case showing a Paraguayan sentinel with a tree in the background (Source: author). 
is the depiction of an M1917 Browning machine gun with the words ' $\mathrm{F}$ Herrera' and a date (XI-25-I-33) - most likely referring to the Battles of Fernándo Herrera, which took place in January and March 1933 - underneath it. Contrary to the makers of other madrina-dedicated shell cases, this artist seems to have consciously avoided a 'romantic' theme. Did the Paraguayan soldier operate one of these machine guns during the Battles of Fernándo Herrera? Was he trying to impress his 'godmother' with an image of the heroic Guaraní soldier so ingrained in Paraguayan culture?

This belief in an almost superhuman Paraguayan-Guaraní 'warrior race' (Benítez 1976, 51) is also reflected in a 192975 MP.M/928 Schneider shell case that reads (translated from Spanish): 'Glory to the Paraguayan sentinel symbol of bravery and heroism'. The shell depicts a Paraguayan soldier in uniform and hat, carrying a satchel across his chest and holding a rifle in his hand. A tree can be seen in the background with what appears to be a hole in the trunk. Could this be a representation of a bottle tree in the hollowed trunk of which countless gunmen lost their lives once their secret hideout had been detected by the enemy?

\section{Beating swords into ploughshares: Mennonite trench art}

With official permission from the Ministry of Defence, the Mennonites collected war matériel at the end of the war. They organised cart trips to the various nearby military outposts and returned with wagons loaded with empty artillery shell and cartridge cases, parts of army vehicles and other metal debris ready to be sold off at auction. Rolls of barbed wire were an especially welcome resource to the Mennonite farmer. Whereas during the war it kept the enemy out, barbed wire now kept the cattle in as it allowed the farmer to demarcate the 'modern borders' (Brönstrup 1966, 157) of his fields and pastures.

Other objects were simply adapted to fit a new purpose, an example of which can still be found today in a number of villages that have preserved the old village bell made from wheel rims taken from military Ford Cuatro vehicles. Struck to announce school and Mass, the village bell fuses the two opposing worlds of armed conflict and belief in pacifism. The military Ford Cuatro vehicles were also used by Mennonites for transport after the war, and a small number can now be found in museums and private homes. One Mennonite man who owns a Bolivian example carefully restored the vehicle to its former glory with authentic replacement parts from Bolivia and an original number plate that he had found in the bush (pers. comm.). 

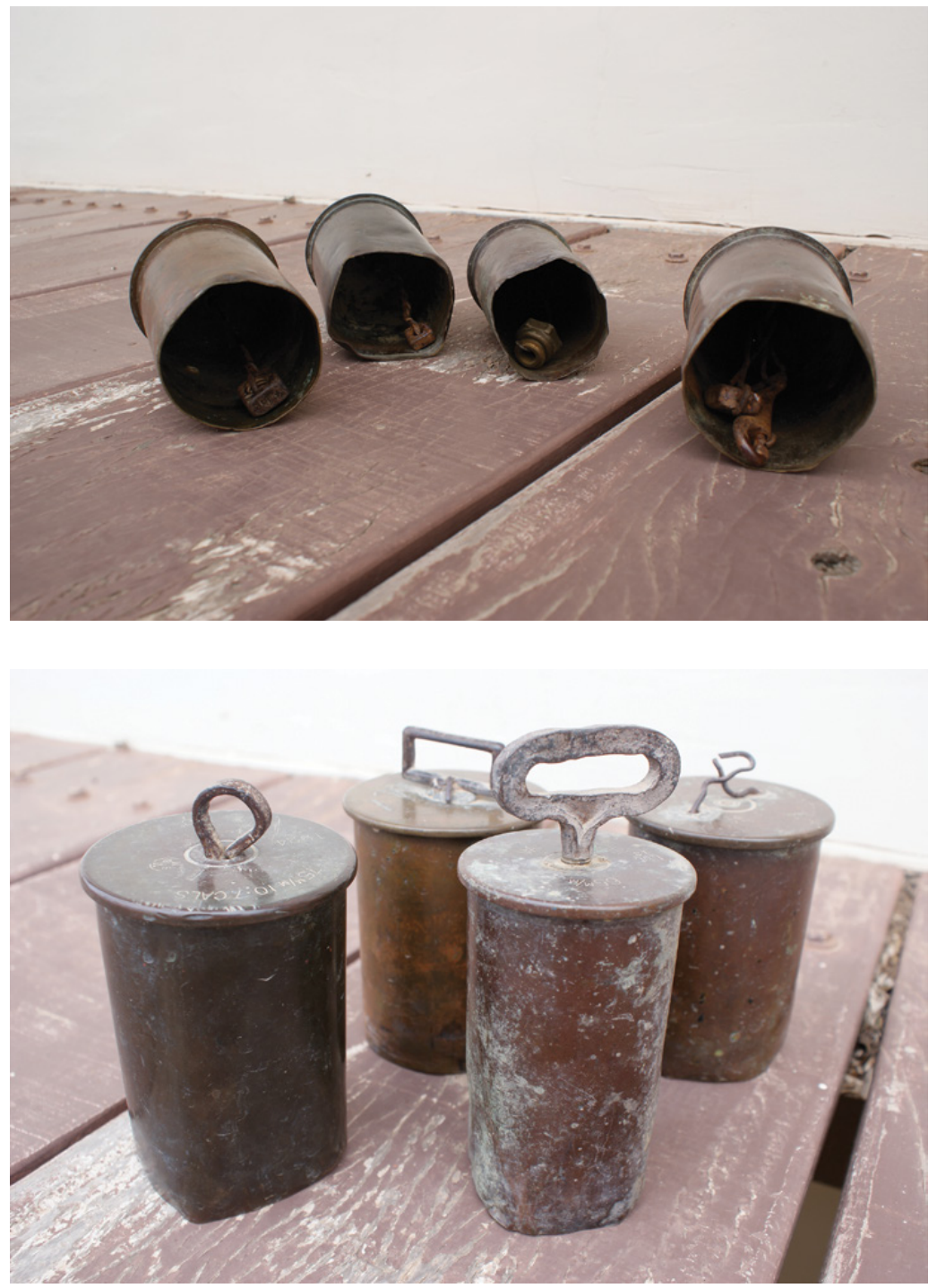

Figure 4.7a and 4.7b Mennonite cowbells made from empty shell cases on display in Koloniehaus museum in Filadelfia, Colonia Fernheim (Source: author). 


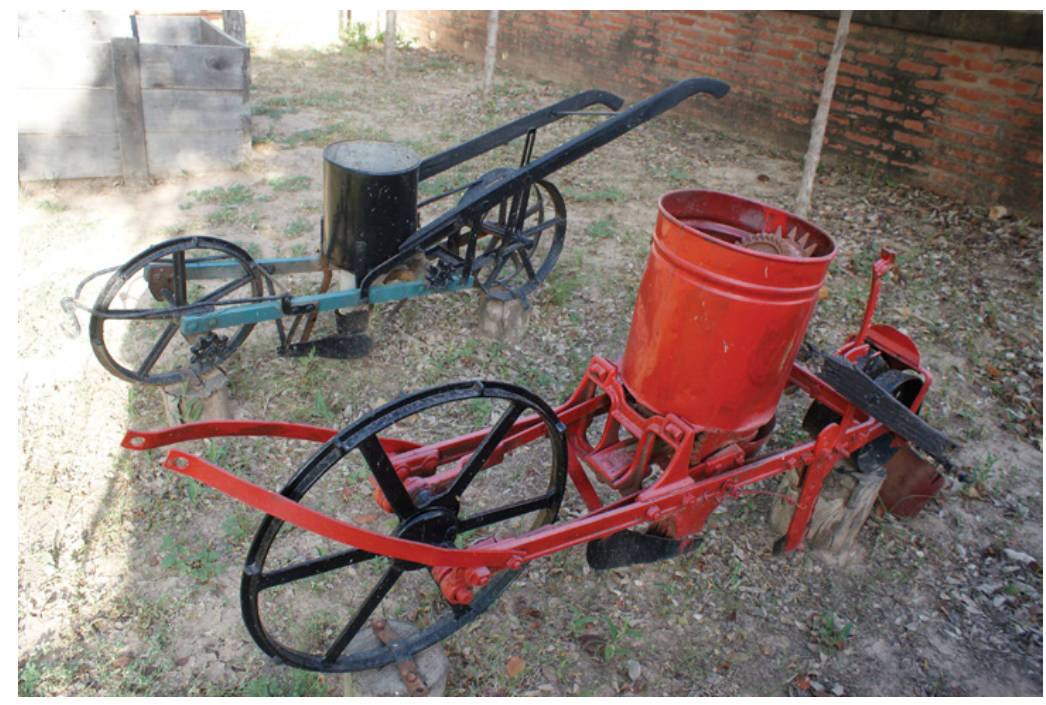

Figure 4.8 Mennonite seeders made from metal debris and oil canisters from the Chaco War in Colonia Menno (Source: author).

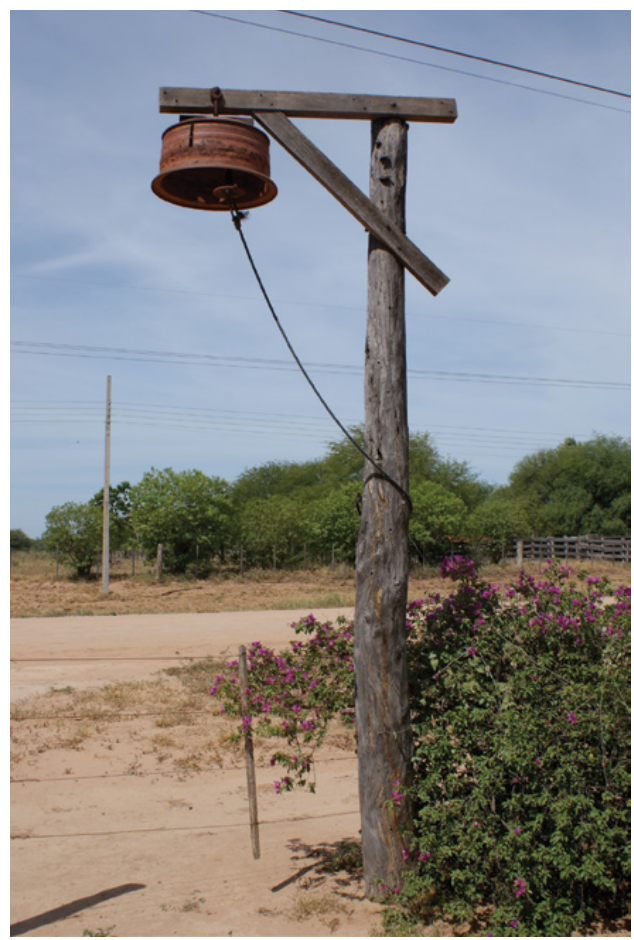

Figure 4.9 Bell made from the wheel rim of a Chaco War military vehicle in a Mennonite village (Source: author). 
Much of the metal was handed to the village blacksmiths, who usually melted objects such as empty cartridge cases down to rework them into predominantly utilitarian everyday objects (Ratzlaff 2009, 86). These were mostly household items including pots, strainers, mugs and soap-cutting machines. The abundance of metal discarded by the military also allowed the Mennonites to produce farming equipment such as cow bells, watering cans, shovels and ploughs. When asked today why the pacifist Mennonites did not refuse the use of military equipment, members of the colonies repeatedly replied that they did as the Bible says, and literally 'beat their swords into plowshares' (Isaiah 1.24-2.4, Coogan et al. 2007, 980; Hans Fast and Heinz Wiebe, pers. comm.). In their struggle to survive in the harsh conditions of the Chaco, the Mennonites transformed matter associated with death and devastation into objects to cultivate the land and promote growth. Converting these items originally produced to kill into tools to cultivate the land and, subsequently, life, was one tangible way in which objects, places and people came together and collaborated in the unmaking and remaking of new worlds.

Many items were handed down through generations, and often ended up lost or discarded along the way. Others have survived and remain in private homes or in the colonies' small museums. Thus, over the years, the artefacts have accumulated dust on mantelpieces, in storage sheds and in the back of cupboards. Their provenance is often ignored and overlooked, or simply forgotten. When asked whether they possessed any such items, an elderly Mennonite woman who was a child during the war remembered that her family drank from mugs that the local metalsmith had fashioned out of melted-down metal from the war. She added that these mugs were not a thing of beauty and that over the years some were handed down and others thrown out (female resident of Colonia Menno's old people's home in Loma Plata, pers. comm.).

\section{The political ontology of things: indigenous trench art?}

The material culture produced with industrial metal debris by indigenous people, such as the Ayoreo, during and after the Chaco War serves as an example of how archaeology and critical heritage studies can reveal alternative stories and 'open up the possibilities for more symmetrical translations and relations between diverse worlds' (Blaser 2010, 20). With metal suddenly readily available, the Ayoreo began complementing organic materials such as wood and natural fibre with industrially produced metal and wire. They also shaped items such as metal knives into 
arrowheads, which they attached to a wooden cane with a piece of telephone wire; and they used war detritus in the manufacturing of jewellery and certain musical instruments and ritual artefacts in an astonishing display of recycled hybrid material culture. I will argue that the exchange of organic materials for metal war debris transformed not only the material function of these objects, but also their symbolic and social function and their associated worldings. These findings of the simultaneous material, discursive and social transformation of indigenous technologies are consistent with observations of indigenous use of metal materials in Australasia (e.g. Harrison 2002, 2006) and the US (e.g. Ehrhardt 2005; Ferris 2014; Silliman 2014) which emphasise the ways in which these materials are not evidence of 'acculturation' but instead represent the development of significant new indigenous-material entanglements and novel, emergent lifeworlds.

In Colonia Neuland, a local ethnologist of Swiss origin possesses an extensive private collection of indigenous objects made out of metal debris from the war. Artefacts include a pumpkin rattle filled with seeds and attached to a wooden handle from which a bullet is dangling on a string of natural fibre. There are also belts made of natural fibre from which hang two rattles fashioned from metal war debris and which, according to the ethnologist, were traditionally worn by men during festivities, and for signalling their peaceful intent upon approaching another

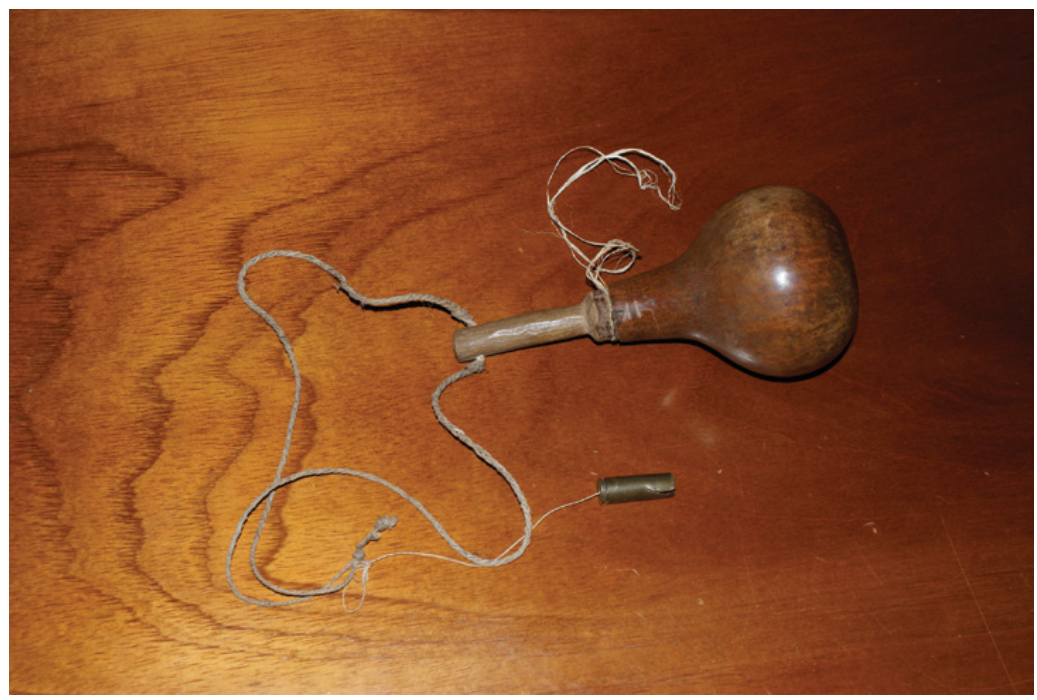

Figure 4.10 Ayoreo pumpkin rattle with bullet attached to a string of natural fibre (Source: author). 


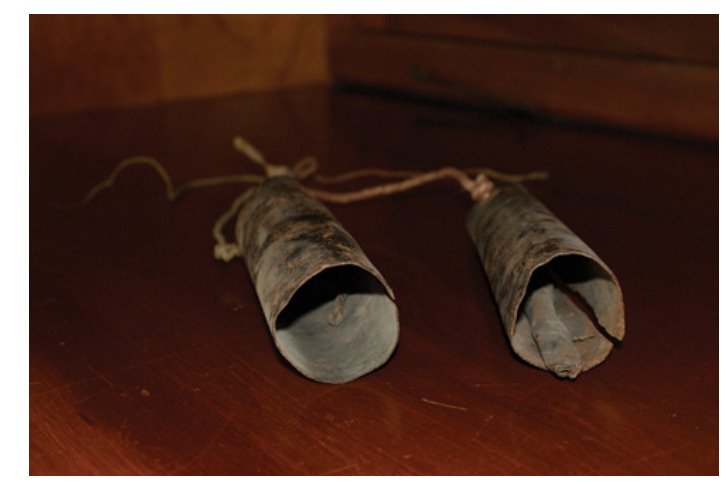

Figure 4.11 Ayoreo belt with rattles made of recycled war metal (Source: author).

community (pers. comm.). Looking at these belts, it is very tempting to suggest a 'rational' western interpretation that would understand the artefacts as objectifications of human symbolism and meaning: originally made and worn to express peace and celebration, they were now generated from material produced and employed to kill people, and could thus be regarded as an indigenous South American variation of the widespread trench art philosophy of 'swords into ploughshares'. However, in order for us to grasp the Ayoreo world and the role of such materials in it, we have to free ourselves of the modern straitjacket that enforces the 'active mind/passive matter' dualism as the only possible reality in which 'facts have displaced gods, ancestors, spirits, and custom as the source of moral answers' (Blaser 2010, 110-11).

Amerindian ontologies are complex and heterogeneous, and their study goes beyond the scope of this book (see e.g. Descola 1996; Viveiros de Castro 1998, 2004b; Blaser 2010; Bessire 2014). They are, however, linked by an understanding of the world in which there is no clear separation between humans, non-humans and more-than-humans. In this sense, the notion of 'humanity' is fluid and is not only attributed to people but also extends to animals, nature and artefacts. Writing in the context of Amazonian peoples, Viveiros de Castro notes that 'the original common condition of both humans and animals is not animality but, rather, humanity' (Viveiros de Castro 2004b, 465, original italics; see also Viveiros de Castro 1998, 472 afer Descola 1986, 120). Indeed, in many Amerindian myths the world is an intrinsic entanglement of human and animal characteristics and communications that blur the boundaries between humans, nature and animals in the present-day world (Viveiros Castro 2004b, 464). 
Similarly, in Ayoreo ontologies the world is an intertwining of what is human and what is not, what was human and today is an entity that preserves part of that substantiality of that first entity' (Corcuera and Dasso 2005, 3). According to anthropologist Marcelo Bórmida, the Ayoreo's existence is governed by ancestral spirits that are malevolent towards them. This malicious ancestral presence is omnipresent and is felt as a 'hair-raising sensation' that hides in every plant, animal, rock and song (Bórmida 2005, 110). Consequently, the Ayoreo live in constant fear of these malignant ancestral forces that could afflict them any time and anywhere. Thus the Ayoreo do not have the autonomous power to modify their existence as it is always already governed by forces beyond the human realm. Ayoreo also lack a personal consciousness that would allow them to be creative and invent their own instruments and establish their uses as they were also already given to them by pre-existing forces that act outside of human control. As a result, humans are limited in their powers to alter material realities in the production process of an artefact, as the finished product and its purpose are always modelled after a prototype determined by a conscious more-than-human force. In a sense, objects become conscious entities that can revolt against their human maker and 'present themselves as something alien, filled with life, their own will and powers, as if after having left the hands of their maker, they face him as something strange and menacing, and rarely benevolent' (Bórmida 2005, 110).

This understanding of the world poses challenges of an existential nature when trying to examine Ayoreo material culture crafted out of metal - and especially iron - debris from the Chaco War. The problem starts with the fact that there is no equivalent word for iron in the Ayoreo language. Instead Ayoreo people refer to an object made of iron, such as 'iron of the machete' (Bórmida 2005, 170). ${ }^{1}$

As all objects are already given to humans by pre-existing forces beyond their control, the Ayoreo did not perceive the metal to be leftovers from the belligerent armies. Although Bórmida mentions in his extensive study on the Ayoreo that objects made from war metal seem to have originated in a time closer to the present day than other artefacts made from traditional natural resources, the provenance of their raw material is nevertheless never linked to the soldiers or the war. Ayoreo people are, however, aware of the fact that they cannot produce iron. Not being able to get to the material in its raw form and thus make an artefact from scratch (as for example in the case of objects made of wood or natural fibre), Ayoreo people know that the human production process of metal objects is limited to cutting and shaping the metal (Bórmida 2005, 169-70). 
According to Ayoreo mythology, the origins of iron can be traced back to a time long before the present in which all the iron in the world belonged to a female star in the sky. One day the star had visitors who all took bits and pieces of her metal. Those who came first took the biggest and most precious items. While the red woodpecker got hold of a big machete, the heron managed to get the largest piece of all. Those who came last had to content themselves with lesser-valued metals such as aluminium, which due to its ineffectiveness in the production of spearheads and knives was referred to by the Ayoreo as 'the iron that can't be used for anything' (Bórmida 2005, 137). In a further myth, iron, as humans know it today, originated from the buried body of the heron that took the biggest machete from the star. After the bird was killed, people buried his remains deep in the Chaco earth. They later dug up the bird and manufactured iron objects from its various body parts and the earth around its burial (Bórmida 2005, 130-7). As metal had always been a precious but scarce resource to Ayoreo people, its sudden widespread availability after the war was explained through a continuation of the metal myth in which people's repeated digging of the bird's burial site resulted in the surfacing of more and more metal (Bórmida 2005, 168-9).

In light of this, the western concept of 'trench art' is troubled and ultimately annulled in the context of an indigenous ontology. The chisel made from an iron point attached to a wooden handle with telephone wire can no longer be defined as an item that was made by a civilian who was spatially or temporarily associated with the Chaco conflict or its consequences. Instead, in a time long before the war, the wooden handle and

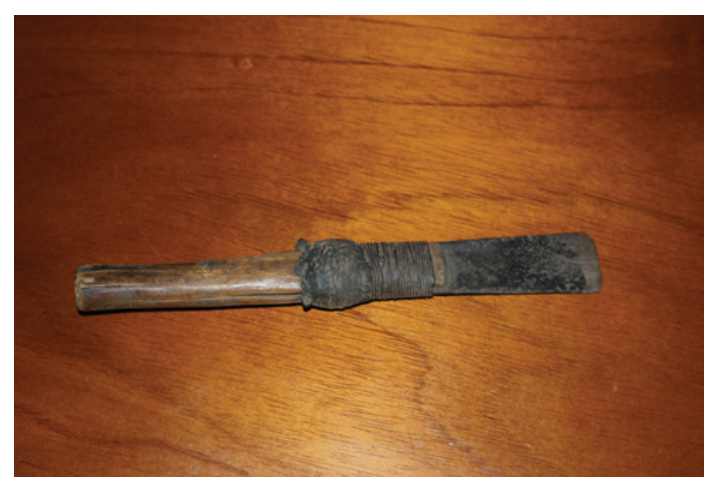

Figure 4.12 Ayoreo chisel made from Chaco War metal and telephone wire (Source: author). 
wire (often woven by a spider) were put together for the use of future generations by the Chaco woodpecker, who is the owner of all things made of wire (Bórmida 2005, 118, 168). In other words, the objects produced by Ayoreo people transcend the human realm as they originated independently of people's actions and outside the context of the Chaco War in a world where the concepts of subject and object and human and non-human are both complex and blurred.

$$
* * *
$$

At the start of the war, indigenous territories became militarised, forcing families to leave their lands and the Mennonite farms they had been working on. Whole Mennonite villages were turned into military camps and hospitals. Soon the sight of heavily loaded vehicles and wounded soldiers, and the sound of distant artillery fire, became an everyday reality. Although devoted pacifists by conviction, the Mennonites formed an integral part of Paraguay's war machine. Their crops were no longer merely for self-subsistence but turned into an invaluable addition to the nation's military campaign and a veritable lifeline for hungry soldiers. By baking for and trading with the military, the Mennonites became actively involved in the war. Although they refused to transport any war material and did not actively engage in any fighting, the plough became their weapon of choice. The trading activities, however, not only served the soldiers but also allowed the Mennonites to build an existence in the Chaco bush. In fact, had it not been for the money they made by trading with the military, the colonies might not have survived. In the case of indigenous groups in the region, modernity infiltrated communities through the trade of military rifles in exchange for watermelons and other food.

During and after the war, military equipment and war debris - 'the material textures of decay' (Shanks, Platt and Rathje 2004, 74) - became an inherent part of people's lives in the Chaco. The hard and durable consistency of metal allowed soldiers, Mennonites and indigenous people to recycle these materials into both decorative and practical items. In the case of the decorated artillery shell cases engraved by soldiers, Saunders argues that trench art artefacts reveal themselves as 'objectifications of the self' (Saunders 2010, 51) and act as a 'resource for the exploration of meaning in objects' (Saunders 2003, 163). Although this understanding of objects allows things some form of 'communicative agency' (Tilley 2002, 25), it remains dependent on human agency. In other 
words, objects are believed to be mere repositories for human experience. This casts trench art and things in general in a static role dependent on human action. Objects, however, transcend this passive function, as human meaning and symbolism are 'but one facet of the nature of things, not necessarily and not always the most crucial' (González-Ruibal, Hernando and Politis 2011). Here I have shown how such objects engage people and places actively in parallel world-making and unmaking processes, and their designation and involvement in such worlding practices can be seen as a matter of ontological politics.

This is especially true in indigenous or traditional non-modern societies such as that of the Ayoreo, who understand objects as conscious agents (Bórmida 2005, 114). The Ayoreo items produced using metal debris from the war are thus not the result of a human autonomous creation but are ascribed to the action of forces that go beyond the human realm. As the Ayoreo do not associate the emergence of metal with the war, the objects made from it cannot be studied as materialisations of human experiences of conflict. Originating from a time long before the current Ayoreo reality, these metal items belong to a world beyond human awareness while at the same time forming an intrinsic part of human lifeworlds. Adopting an ontological approach to the material culture of the Chaco War thus allows us to go beyond a definition of objects as malleable containers filled with human symbolism to instead understand them as material agents that are actively involved in the shaping of parallel worlds, and, within the context of the war itself, the making and unmaking of Anthropocene futures.

\section{Note}

1. For the purpose of this study I will use the word 'iron' according to its sense and use in the English language. 


\section{5 Ruins of modernity: Archaeology
and heritage in the Chaco}

Surviving in the Chaco landscape constituted a monumental struggle for both the Paraguayan and Bolivian soldiers. In addition, the region's hostile geographical and extreme climatic conditions hampered the militarisation of the bush. Logistics were thus imperative to a successful military campaign and, ultimately, played a decisive role in Paraguay's victory (see Hughes 2005). Eighty years later, the Chaco poses a different kind of challenge to the archaeologist in search of the material remains of South America's first 'modern' conflict. The lack of clear regulations concerning the protection and maintenance of archaeological sites has resulted in the neglect and disremembering of many Chaco War sites. In addition, as most war-related structures were built with local organic material, their preservation has been at the mercy of the natural elements and agricultural expansion in the area.

This chapter is a first attempt to identify, record and analyse the material remains of the conflict and its relationship with the Chaco landscape. It does so by following recent work on the archaeology of the contemporary past (see e.g. the summary in Harrison and Breithoff 2017; see also González-Ruibal 2018b) to mainly adopt an 'archaeology-assurface-survey' approach (Harrison 2011, 141) to documenting Chaco War sites, rather than employing more conventional archaeological excavation methods. In doing so, my aim is not to reconstruct each site 'as it was' in the past, but instead to document and discuss aspects of its material and discursive legacies in the present. In particular, I focus on the ways in which each site was (or was not) actively being commemorated and interpreted at the time I recorded it, drawing on approaches from critical heritage studies (e.g. Harrison 2013a, 2013b). Although the mobilisation of the Paraguayan and Bolivian nations moved far beyond the geographical boundaries of the Chaco, I focus here specifically on the 
Chaco territory. In order to do so, I first outline the militarisation efforts in the region and the importance of natural resources in the construction of military structures. I then establish the importance of an archaeology of the Chaco War before introducing the three main categories of conflict sites that make up an at times well-preserved - if often hidden - record of modern warfare and its intricate enduring legacies.

In order to determine what remains of the past within the present (Olivier 2004, 2011; Olsen et al. 2012) and how it continues to collaborate with human as well as non-human entities in the making and unmaking of emergent, parallel lifeworlds, this chapter describes six conflict sites that act as a sample of, and exemplify, the different kinds of Chaco War sites within the region. First, I describe Puerto Casado and Km 145, which are two examples of war-related sites that never saw any actual ground fighting. The other four sites are fortines or military outpost sites. The sites of Fortín Isla Po'í, Paraguay's military headquarters in the Chaco, Fortín Toledo and Fortín Boquerón have all undergone various degrees of physical restoration. In each case I describe the tangible remains from the war that persist in the contemporary landscape, as well as more recent material interventions for the purposes of heritage management and interpretation, and how they interact with the Chaco bush and local human and non-human actors. I also discuss the preliminary findings from my more conventional archaeological recording and excavation of the site of Fortín Nanawa, a previously little-known archaeological site, to demonstrate how archaeology is itself entangled in the afterlives of conflict heritage sites, acting as a material intervention that contributes to the production of new futures. This chapter is not intended to be a complete record of the archaeology and material heritage of the Chaco War, but rather to lay the foundation for future archaeological engagements with the war and other conflict heritage sites in Paraguay and beyond.

\section{Militarising the 'wild'}

Throughout the 1920s, the Paraguayan authorities sent out military patrols whose mission consisted in the localisation and obstruction of the Bolivian penetration efforts in the Chaco by building fortines in strategically adequate places, which preferably included a more or less permanent natural lake. Although fortín translates as 'little fort', at the start of the war the structures were not the heavily reinforced fortifications that their name suggests. More camp than fort, a fortín was originally 'a military post established primarily to protect against Indians and bandits. 
Typically, it was made up of a few huts, a barrack, a corral, and, most critically, a watering hole, [and] sometimes the site was surrounded by a trench' (Scheina 2003, 405; see also Zook 1960, 41).

Over the years both armies gradually moved deeper into the bush until the Paraguayans reached the central part of the Chaco and the Mennonite communities, who with their fenced fields and permanent villages had also been busy imprinting a 'modern' way of life onto the Chaco landscape and its indigenous communities. When the border skirmishes intensified, and an armed confrontation seemed inevitable, both sides started to intensify their military occupation of the Chaco. The fortines were reinforced with defence lines of subterranean trenches and ditches covered by quebracho tree trunks, running various distances in front of the outposts' centre. Observation points were put up in trees, and machine gun nests, artillery and infantry positions dug into the earth below. In addition to pre-existing indigenous trails that had already been appropriated by the militaries, new picadas (dirt tracks) were cut into the bush to allow for the movement of troops and supplies between the different fortines (see Belaieff 1934). ${ }^{1}$ Soon 'The racket from the machetes and trucks seemed to wake up the dead Chaco by mixing the apathy of nature with the work of men. This gave life to the former, creating "roads", trails, fortines, dwellings, subterranean deposits, landing strips, hospitals, which filled the desert and proved in this barren task the creating force of a nation' (Céspedes 1975, 159).

Militarising the Chaco was a monumental task as the armies faced the logistical challenges of mobilising a 'wilderness'. Whereas Belaieff originally stated that the best way to move in the bush was on foot and horseback (Chesterton and Isaenko 2014, 636), most soldiers were left without a horse as they had perished from lack of water or had been consumed by hungry troops (Bejarano 1967, 22-9). Logistically, Paraguay profited from the relative proximity of its urban centres and the railway line running 145 (and later 160) $\mathrm{km}$ into the Chaco. However, a serious shortage of lorries on both sides meant that oxen and donkeys had to pull wooden carts loaded with everything needed to 'modernise' the Chaco: rolls of barbed wire, boxes filled with ammunition, machine guns.

In order to build their defence system, both military forces appropriated and revalued the region's natural resources. Army sappers played a vital role in the reshaping of the Chaco's hitherto largely unmodified landscape into mechanised battlefields. Armed with an axe and a machete, they opened up the dense bush, hacked trails, felled trees and dug trenches - always ready to swap their sapping equipment for a 
loaded rifle (Paniagua 1994, 113-14). Often the sappers had nothing but their bayonets and aluminium plates and jugs to use as picks and shovels, and were even known to dig ditches with their bare hands (Bejarano 1967, 21; Céspedes 1975, 159).

During the process of militarisation, thousands of trees were cut down in order to make space for the fortifications, landing strips and firing ranges. Trees and their foliage were, however, also crucial in the field as they offered natural shelter and camouflaged both man and machine (Belaieff 1934, 11-15). Their trunks furthermore provided natural protection from enemy artillery fire (Belaieff 1934, 19; Sarmiento 1978, 73). Thus, in a conflict where both sides were subjected to serious economic restrictions and the supply of any available material was hindered by the lack of infrastructure, local natural resources, such as trees, played a key role in the construction of war structures. White and red quebracho (genus Schinopsis), for example, are types of wood valued for their hardness and durability (quebracho derives from the Spanish quebrar hacha, meaning 'axe-breaker'), as well as their availability in the Chaco (Escobar 2007, 288). Whereas their trunks were extensively used in the fortification of bunkers and trenches, snipers surprised the enemy by firing from wooden platforms positioned in their treetops (Farcau 1996, 61; Sarmiento 1978, 69). Mixing with the thorny underbrush, barbed wire entanglements these physical manifestations of modernity (Netz 2004) - ran along the positions operating in 'that paradoxical zone, between protection and division' (Krell 2002, 162) and blurring the line between natural and industrial worlds. Concealed in trenches behind them, the soldiers also became part of the Chaco and a constantly changing landscape of conflict in which 'natural entities and cultural matter circled each other, blending, overlapping, and becoming incorporated into new forms both during and after the war' (Saunders 2014, 23).

\section{Archaeology and heritage in the Chaco}

The Chaco War persists on both a physical and a conceptual level. That it has undoubtedly left a long-lasting impression on people's imagination is reflected in modern-day oral accounts of the Chaco bush reverberating with screams, shots and the thrumming noise of passing aeroplanes at the dead of night (Gordillo 2004, 241; also pers. comm. from various Latino Paraguayans). In 1984 Paraguayan veteran Heriberto Florentín 
wrote that since the end of the Chaco War 'This whole region has suffered from a notable transformation, where man's hand can't reach to tame the wilderness at his will, nature takes charge of giving it new shades, new forms like the eternal law of organic life' (Florentín 1984, 12-13). Yet what tangible traces remain of the region's violent past within the manifold landscapes of the present-day Chaco?

Despite agricultural and urban expansion having resulted in the clearing of vast stretches of the Chaco and the destruction of much of this material record, evidence of conflict is still present in the form of 'bones and material remains that impregnate the Paraguayan bush with living echoes of the Chaco War' (Gordillo 2004, 241). Although the impenetrable forest inevitably poses a major challenge to archaeological research, it simultaneously forms an integral part of it, as it cannot be detached from the material remains that survive in it. Thus, littered with war debris in isolated areas, the Chaco bush is a place where 'memory seems to be eternally inscribed in space, erasing historical time and making old battles linger indefinitely' (Gordillo 2004, 241).

Many of the old battlefields and fortines are situated on what is now privately owned land - their fate in the hands of those who control the property, and the persistence of the scrubland. As a result the bush, which is teeming with non-human lifeforms, has been slowly but surely reclaiming the Chaco War's 'ruins of modernity' (Hell and Schönle 2010; see also Olsen and Pétursdóttir 2014; DeSilvey 2017). The trenches and bunkers are overgrown and have repeatedly been reduced to shallow ditches, and much of the surviving material culture is concealed from view by layers of sand and thorny thicket. The archaeology of the Chaco War is nonetheless visible, even in developed parts of the bush: empty bullet cases sticking out of the ground, bits of rusty metal scattered in the underbrush, a military uniform button covered in earth. Over the years, Mennonite farmers have collected various bits and pieces of war material that they have found on their properties. There is talk of an intact bunker still filled to the brim with boxes of live ammunition. The landowner, however, is reluctant to disclose its location for fear of it all being confiscated by the military (Hans Fast, pers. comm.). In light of the immensity and inaccessibility of the Chaco, one is left to wonder how many more war secrets the bush is concealing from view.

This question is reinforced by the lack of documentation on Chaco War sites. The chaotic and incomplete collections stored in the military archives in Asunción hamper access to information that may exist. Many 
of the isolated outposts are not mentioned in the literature at all and the descriptions of those that have been commented on in books simply act as contributions to the military and logistical histories of the conflict. Although a number of written personal accounts go beyond mere technical depictions to give us a glimpse of the soldiers' personal experience of the war, they remain intangible narrations, nonetheless. In contrast, an archaeological approach to the Chaco War and its material remains allows access to both a tangible dimension of, and alternative perspectives on, the conflict. Unlike social historical research that commonly adopts a more generalising and collective voice, an archaeology of Chaco War sites examines the 'debris of individuals' (Moshenska 2009, 53) to disclose the local and personal everyday life stories that have hitherto remained camouflaged by the bush. Indeed, as, González-Ruibal states in relation to sites of modern conflict, 'One feels the need to dig beneath grand narratives, to excavate and expose sorrow' (2006a, 179).

The archaeology of the Chaco War and its material afterlives is now both timely and critical. The scarcity of the literature and the dwindling number and health of witnesses - military and civilian - leave us with the conflict's material culture to fill in the gaps left by historical sources and also, more importantly, provide alternative stories to complement or challenge the official accounts of the war. In addition, the fragile and perishable nature of many of the organic structures from the war years makes them highly susceptible to the natural elements and agricultural and urban expansion. The absence of clear governmental regulations concerning the protection of archaeological sites in Paraguay also calls for an archaeological recording of Chaco War sites before they disappear.

Sites were identified through my reading of the historical sources and discussions with local Mennonite informants. The sites discussed here were selected largely due to access conditions and their proximity to the Mennonite colonies. Recording of these sites took the form of a photographic survey of surface features and detailed descriptive recordings of the surrounding landscape. These archaeological accounts were combined with historical documentary and photographic sources to interpret the sites and their relevant features. In many cases this interpretation was supplemented by local accounts of the land use histories of each of the sites. In some instances I was able to return to a site multiple times and have been able to record changes in its uses between visits which are also examined here. 
Archaeological sites in the Chaco dating to the time of the Chaco War can be divided into three main categories:

1. War-related sites: sites that were affected by the war but were not used as battlefields per se. Examples presented here are Puerto Casado and $\mathrm{Km} 145$.

2. Fortines: military outposts, which were generally reinforced with trenches and bunkers and often served as battlefields. Examples studied are Fortín Isla Po'í, Fortín Toledo, Fortín Boquerón and Fortín Nanawa.

3. Cemeteries: include unmodified military cemeteries dating to the war, military cemeteries dating to and modified since the end of the war, and mass graves dating to the war. (These do not form a separate category for description here but are discussed in Chapter 6 and explored in more detail below where they are contained within the fortines sites.)

\section{War-related sites}

\section{Puerto Casado}

Puerto Casado is a town situated $678 \mathrm{~km}$ north of Asunción on the west bank of the Río Paraguay in the Department of Alto Paraguay. It is the most southerly town of this riverside region, which leads up to the Pantanal, and marks the end of eastern Paraguay and the start of the Chaco. The region is characterised by large areas covered with Karanda'y palm trees (Copernicia alba). Puerto Casado has a tropical climate and fertile land ideal for agriculture and livestock. As of 2014, the town had 7,800 inhabitants.

The site was surveyed in June 2011. The main visible features relating to the war at the time of recording were the skeletal frames of three buildings from the Carlos Casado S.A. tannin factory; three steam engines; four train wagons; train tracks leading away from the factory; twentieth-century brick factory workers' houses; La Chaqueña (the house of then Lt Col. Estigarribia); the wooden platform of a docking site; a Chaco War memorial; and a cemetery. The atmosphere and buildings 
of Puerto Casado reflect the precarious economic situation of the town. With the tannin factory now defunct, the buildings, steam engines, train wagons, train tracks and docking site are in disuse and disrepair. The brick workers' houses, which serve as family homes, and La Chaqueña are in poor condition. Puerto Casado can be accessed via boat or vehicle. Going by car is unreliable, however, as there are no paved roads and the dirt roads often become impassable during the rainy season. Bus journeys to and from Asunción are limited to once a week and take around 17 hours.

Puerto Casado, also known as La Victoria ('The Victory', referring to the Paraguayan victory in the war), was founded in 1889 as a base for the Argentine tannin industry owned by the Carlos Casado S.A. company, which owns large stretches of land in the area and gave the town its name. Over the next hundred years Puerto Casado flourished and became a symbol of hope and economic and social upsurge after the horrors of the War of the Triple Alliance. During its years of commercial success, the town developed into a bustling and prosperous place with attractive streets lined with beautiful colonial-style buildings. A railway was built for the tannin factory running $145 \mathrm{~km}$ into the Chaco in order to facilitate the transport of quebracho trees used in the manufacturing of tannin (Barreto 1985, 469-83; see also Dalla-Corte Caballero 2012b).

The Puerto Casado railway line and its related facilities undoubtedly contributed to Paraguay's success in the war. It gave the country a huge logistical advantage over Bolivia as it allowed for a quicker and more efficient way of transporting men and equipment even during times of flooding. In the years leading up to the war the train carriages and railway line were used by the Paraguayan military to transport provisions, cattle, tools for drilling wells and medication in order to supply the soldiers who were busy hacking trails and building outposts in the bush (Barreto 1985, 469).

Although the tannin factory and its train line were never officially mobilised by the military, the foreign company cooperated voluntarily with the Paraguayan army by letting them use its premises and trains. Carlos Casado was himself responsible for the maintenance of the railway line and the smooth running of the trains. He also agreed to have the line extended to $\mathrm{Km} 160$ to avoid flooded grounds during the rainy season, but this station served primarily for the transport of quebracho trees and was rarely used by the military due to its strategically unimportant position. Although business continued as normal for the Casado company during the war, the port and train line were busier than usual with new soldiers arriving and leaving continuously (Barreto 1985, 471-2). 
It was also at the port of Puerto Casado that the Mennonites first arrived in the Chaco in 1927. As the land allocations for their villages had not yet been finalised, they were forced to set up a temporary camp in town. Not used to the water and extreme climatic conditions of the region, many Mennonites died of typhus and were buried at the local cemetery (Friesen 1997, 297-328). Those who survived were transported by train to the Fred Engen railway station at Punta Riel, also locally known as Km 145 , from where they continued their journey by foot and oxcart.

During the Chaco War, Puerto Casado played an important strategic role due to its location on the river and its railway line into the Chaco. Thousands of military recruits arrived by boat from Asunción at the docking site in Puerto Casado. From there, as the Mennonites had done before them, they took the train to Km 145 from where they started their tormenting journey by foot over the dusty trails to the different fortines via Isla Po'í, the Paraguayan headquarters in the Chaco (Ratzlaff 2009, 24). In 1931, Estigarribia accepted the post of Commander for the Infantry Divisions established in Puerto Casado. The Casado family offered the general and his wife and mother a spacious house in the city centre, which became known as La Chaqueña. Estigarribia lived there until the Battle of Pitiantuta in 1932, when he moved to Fortín Isla Po'í.

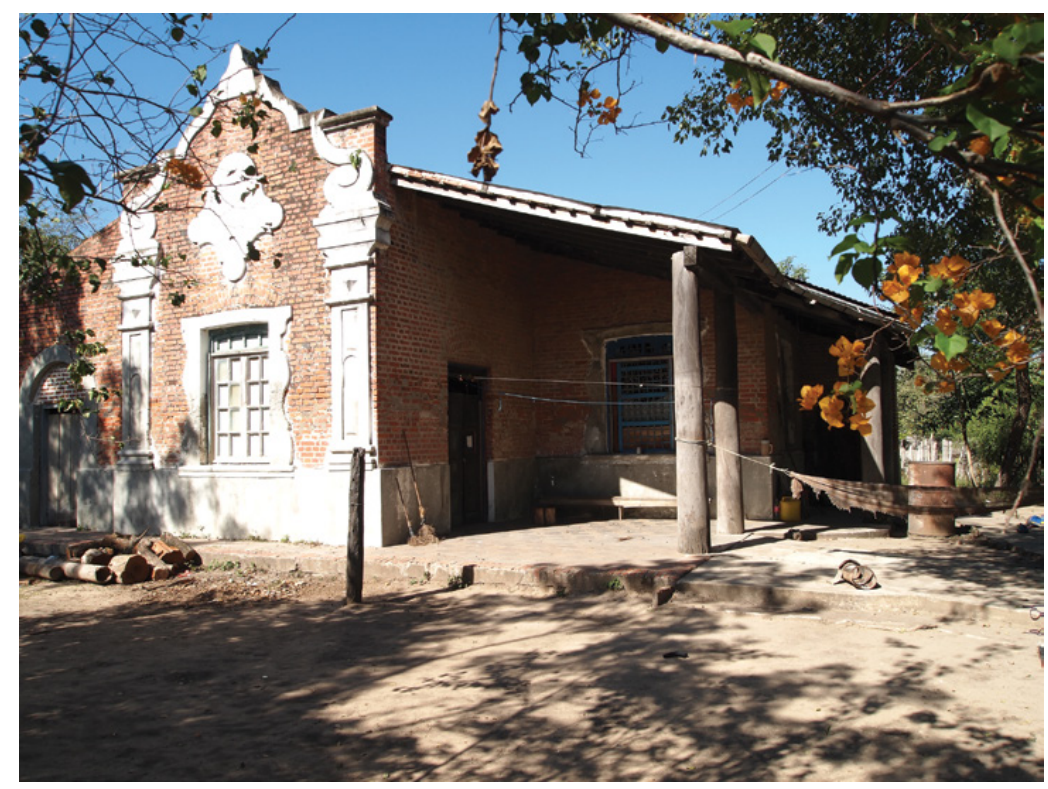

Figure 5.1 La Chaqueña in the town centre of Puerto Casado (Source: author). 
Today Puerto Casado is said to be the poorest town in Paraguay. By the 1980s the tannin industry had gone into decline as tannin could now be created synthetically, and the factory was completely closed in 1996. Much of the town itself and the surrounding land have been sold to a congregation of the Korean Moon sect, which has led to continuous protests by the town's inhabitants and has added a secretive atmosphere to the place (BBC News Online 2000). Puerto Casado also emits an air of lost grandeur and desperation. The houses built for the factory workers are slowly crumbling and of the colonial-style hotel only the walls remain. There is no work in Puerto Casado, no tourists, no petrol station. The disastrous economic conditions have forced people to become inventive with what material is at hand. The result is what has been described as 'local recycling' (Coote, Morton and Nicholson 2000, 18). In the 1980s, for example, one resident started the process of melting down stainless steel once used to store the tannin in the factory and turned it into guampas (cups used for the drinking of mate and tereré). Today hand-crafted stainless steel guampas are a local tradition and they are sold as souvenirs

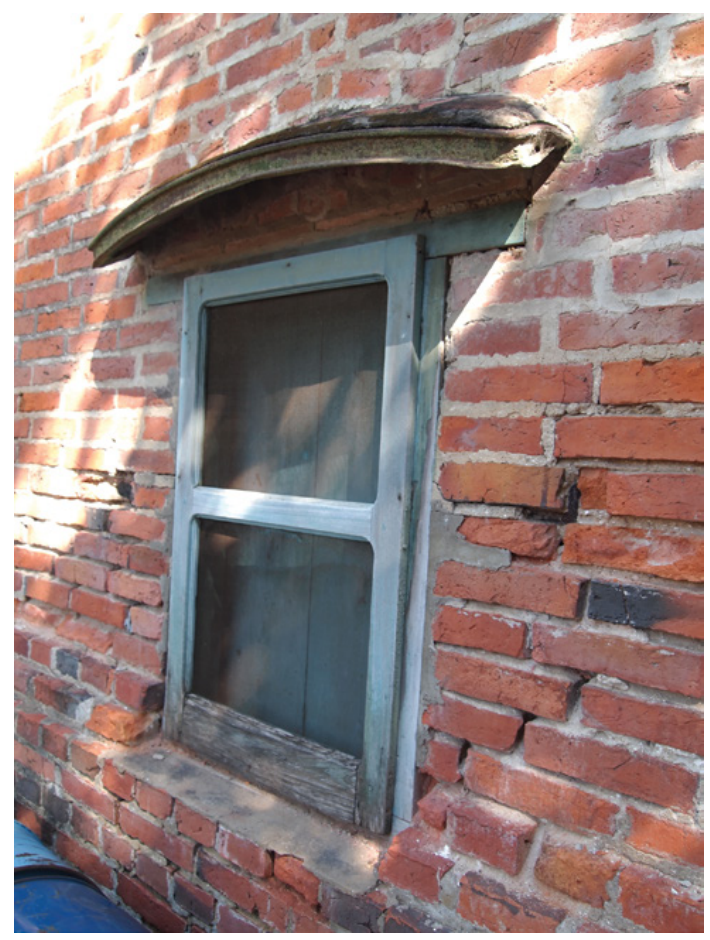

Figure 5.2 Bent railway track serving as decoration above a window (Source: author). 
all over the country. In certain cases, residents made use of 'pre-existing forms, adapting them to new purposes' (Coote, Morton and Nicholson 2000, 18). On a number of houses in Puerto Casado, for example, pieces of bent railway track that once led thousands of soldiers and Mennonite settlers $145 \mathrm{~km}$ into the Chaco now serve as decoration above windows. Although the now disused railway of Paraguay was declared a national monument in 2003, local businessmen have been employing indigenous people in the dismantling of the old tracks leading into the Chaco so they can be sold as scrap metal. While some people have described the act as 'blatant theft' and a violation of national cultural heritage, others maintain that Puerto Casado's devastating economic situation pushes those affected by it to these drastic actions (Anonymous 2006b).

Looking around the run-down centre of town, 'the material excess of ruin' (Harrison 2013a, 80) is visible everywhere. What to do then, asks Rodney Harrison, with the abundance of physical remains from our 'industrial heritage' (Harrison 2013a, 80)? In Puerto Casado, La Chaqueña is now privately owned. An old carob tree, under which Estigarribia supposedly used to enjoy his tereré, still stands outside the house. A small plaque commemorating the marshal's tea-drinking habit used to be nailed to the tree. Despite Estigarribia being a national hero who led Paraguay to victory in the Chaco War, the plaque was stolen. In a town where people are struggling to make a living, national pride and history have been pushed aside by many but not all inhabitants, as one female resident points out: 'It hurts me that the people don't value what they have. They don't care about the history of their town. They have stolen everything from Casado's and Estigarribia's respective houses and the police were the biggest criminals in all of this' (pers. comm.).

A short distance from Estigarribia's former home, the skeletal frame of Casado's old factory stands as a distant reminder of a once booming economy. The buildings have been stripped of everything that can be sold on the black market and all sorts of things now lie piled outside people's decrepit homes: corroding remnants of modernity waiting to be bartered away. Many of the train tracks have been sold off as scrap metal, often at low prices by local residents (González Vera 2009; Manena 2012). In an effort to protect the town's industrial legacy, the remaining train tracks (as well as La Chaqueña) have since been declared historical cultural heritage by law. Two of the train tracks survive on the factory grounds. Disuse and abandonment have allowed nature to invade and make them disappear into the bush. Similarly, the shells of a number of spared locomotives and train carriages from the time of the war are slowly corroding away inside the crumbling factory buildings, adding an eerie atmosphere and an air of 'disorderly aesthetics' (Edensor 2005b, 72-9) to the abandoned place. 


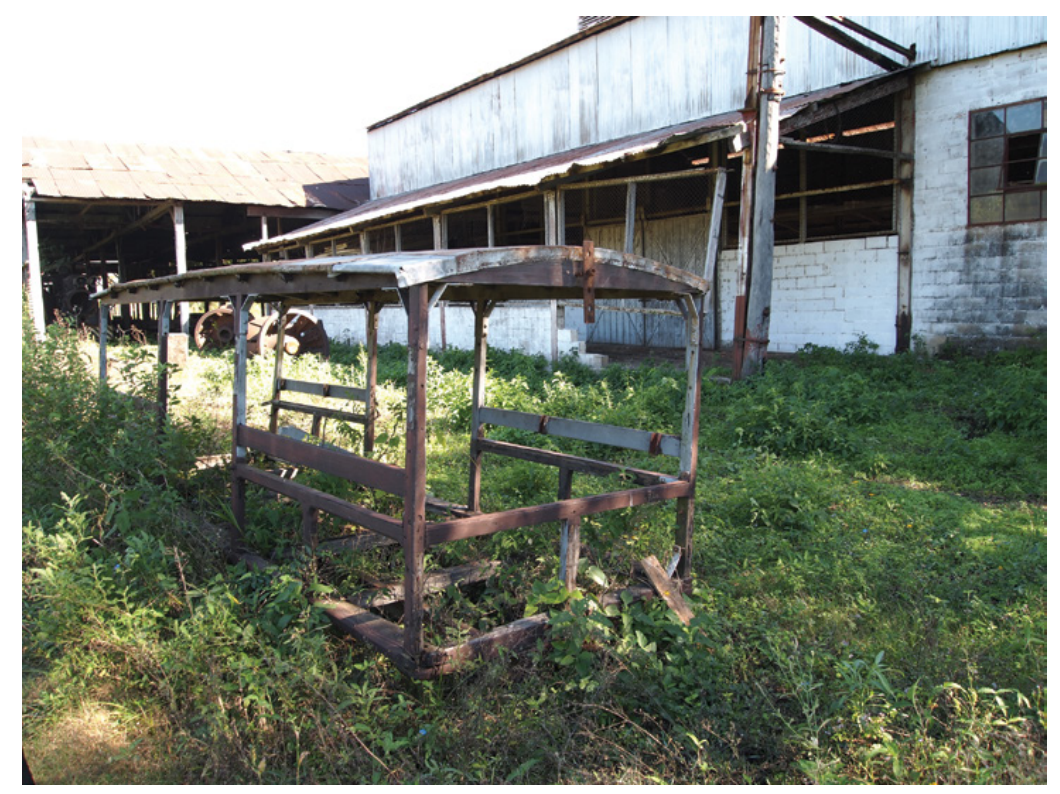

Figure 5.3 Skeletal frame of a railway carriage at the old Puerto Casado tannin factory (Source: author).

On the other side of town, where the soldiers and Mennonites used to arrive by boat, the remaining fragments of the original wooden platform from the docking site are also in continuous decay. A large war memorial in the curious shape of deer antlers with a large cross in the middle has been erected on top of a heavy cement block. Simple black metal letters on the grey base of the memorial read: A los Defensores del Chaco, Pto Casado 1932-1935 (To the Defenders of the Chaco, Pto Casado 1932-1935). The monument looks grim and out of place. Although significant in both size and meaning, it appears to have been forgotten by the town's inhabitants.

At the outskirts of town - a short walk from the memorial, and in stark contrast to its bleakness - lies a colourful cemetery, which holds the graves of the first Mennonite colonists and soldiers, who died of diseases upon arrival in Puerto Casado. For those who survived, Puerto Casado acted as the gateway into the unknown 'wilderness' of the Chaco. The new recruits arrived in the harbour town with an adventurous spirit and full of admiration for the beautiful scenery. To them the Chaco was not yet the green hell that would later haunt their memories. The young men did however realise that going to war was no adventure, as the train taking them to an uncertain future might 


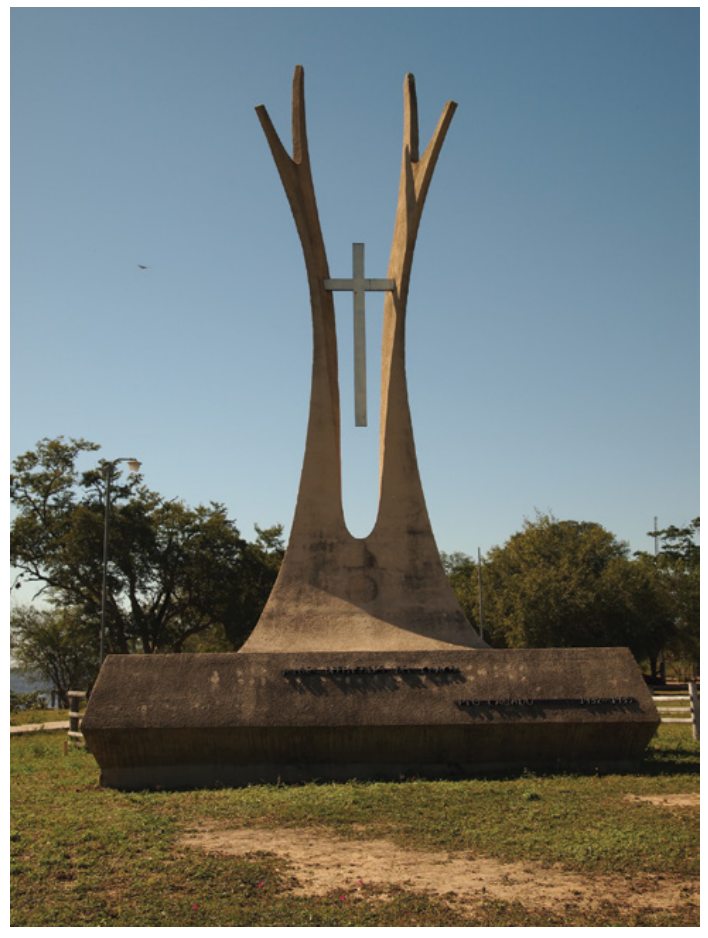

Figure 5.4 A los defensores del Chaco (To the defenders of the Chaco) war memorial in Puerto Casado (Source: author).

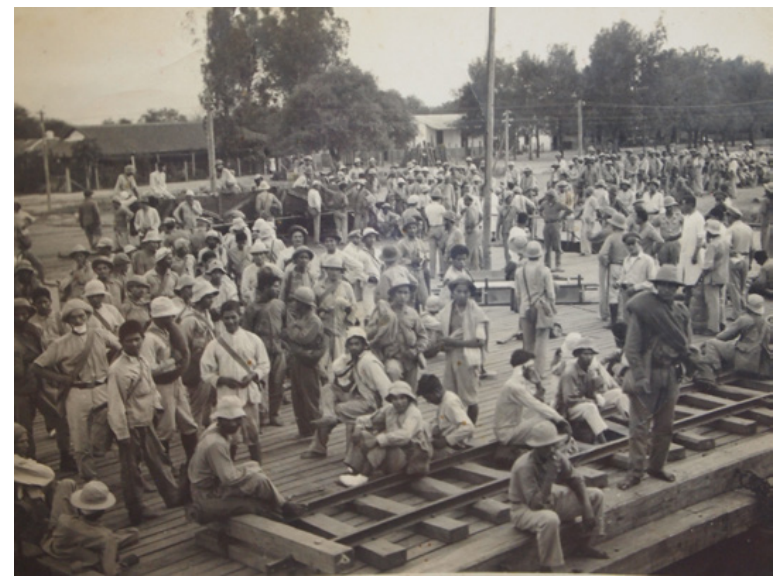

Figure 5.5 Paraguayan soldiers waiting on the railway tracks in Puerto Casado to start their journey into the heart of the Chaco (Courtesy of AIHMM). 
have 'looked like a little toy, but it carried a serious cargo' (Zotti 1974, 31 ). Whereas it was considered a symbol of economic progress prior to the outbreak of the war, the train thus quickly turned into a 'monster of steel, that in the stillness of the night, was devouring distances' (Bustamante Rodríguez 1987, 27). Like the souls crossing Hades on a boat from the land of the living to the land of the dead, the soldiers boarded the train, leaving Puerto Casado and their lives behind to travel $145 \mathrm{~km}$ into the heart of the Chaco where imminent death was looming.

\section{Km 145}

This former railway station site, surveyed in June 2011 and April 2013 , is situated next to a dirt road within a clearing in the forest consisting of thorny bushes (Prosopis sp.), shrubs and cacti (Cactaceae). Scattered trees (Aspidosperma quebracho, Bulnesia sarmientii and Schinopsis sp.) and shrubs dominate patches of grassland (Elyonurus spp.). At the time of the survey, the site consisted of two restored brick buildings that once served as the train station and the station guardian's house; an original gatepost made of red quebracho with its original lock; train tracks and a stone platform with an original wooden station sign; two coal ovens; two bomb craters; telephone poles and wire; and the original Mennonite well and cistern. The buildings have been adapted for reuse as sleeping quarters for Mennonites on family or school trips.

Punta Riel(es) or Fred Engen Station, ${ }^{2}$ locally simply known as Km 145 , marked the penultimate station of the Puerto Casado railway into the Central Chaco. The train ride, which took a whole day and night, was only the start of a long and agonising journey for the soldiers. Once they had arrived and refilled their caramayolas with water, they started their march to the various military outposts, generally via the Paraguayan military headquarters at Fortín Isla Po'í, situated about 60 km southwest of $\mathrm{Km} 145$.

The site is of great historical significance to the Mennonite communities as it is where their parents and grandparents first arrived in the 1920s and 1930s. When the Mennonites left their initial base in Puerto Casado to move into the central Chaco, they boarded the train that took them deep into the bush to $\mathrm{Km} 145$. Until the building of the Ruta Transchaco in the 1960s, Km 145 constituted the colonies' only link with 
the outside world (see Ratzlaff 1998). It would take days to travel the $60 \mathrm{~km}$ from Loma Plata (Colonia Menno) with ox-drawn carts heavy with produce such as cotton and peanuts that the Mennonites were hoping to get on the train and sell in Asunción or exchange for sugar and flour that incoming trains would bring. During the Chaco War, the station was operated by a Swiss employee, Heinrich Troxler, of the Carlo Casado S.A. Upon disembarking, the new military recruits were greeted by a sight of multiple storehouses made from carandá palm tree wood (Copernicia alba) with grass roofs, among which a bustling mixture of soldiers and Casado employees went about their daily business (Bustamante Rodríguez 1987, 33).

Today, the site emits an air of calmness and tranquillity. The only people continuously present are a Mennonite couple who now live in the old station house and are employed by Colonia Menno to look after the site. Until their purchase by the colony in recent years, the surviving buildings of $\mathrm{Km} 145$ and adjacent land were owned by Carlos Casado S.A. (Schneider 2007). The Mennonites have since turned the site into a popular weekend and educational destination for Mennonite families and schoolchildren. The house where Troxler used to live in his years as stationmaster has been turned into a small museum that displays panels and photographs from the early days of the Mennonite colonisation. The house also has two rooms that serve as basic guest accommodation. Outside the old station building, the original well and cistern that supplied the station with water survives, its wooden wheel long replaced by an electric pump. Although the buildings have been lovingly restored and the grounds are kept in good order, the tourist facilities are modest, which follows the general Mennonite belief in a simple life without superfluous possessions. Outside the guest accommodation an old oil canister from the war has been turned into a flowerpot - modernity beautified in an effort to present $\mathrm{Km} 145$ as a success story of Mennonite immigration instead of commemorating it as a place that witnessed the horrors of industrial war.

Behind the museum and guest accommodation some of the train tracks disappear into the bush, where they form occasional train bridges as the tracks run along a dry riverbed that tends to flood after heavy rainfall. Tracing the tracks in the thicket poses a major challenge and is often impossible without the help of a machete. In addition, the 


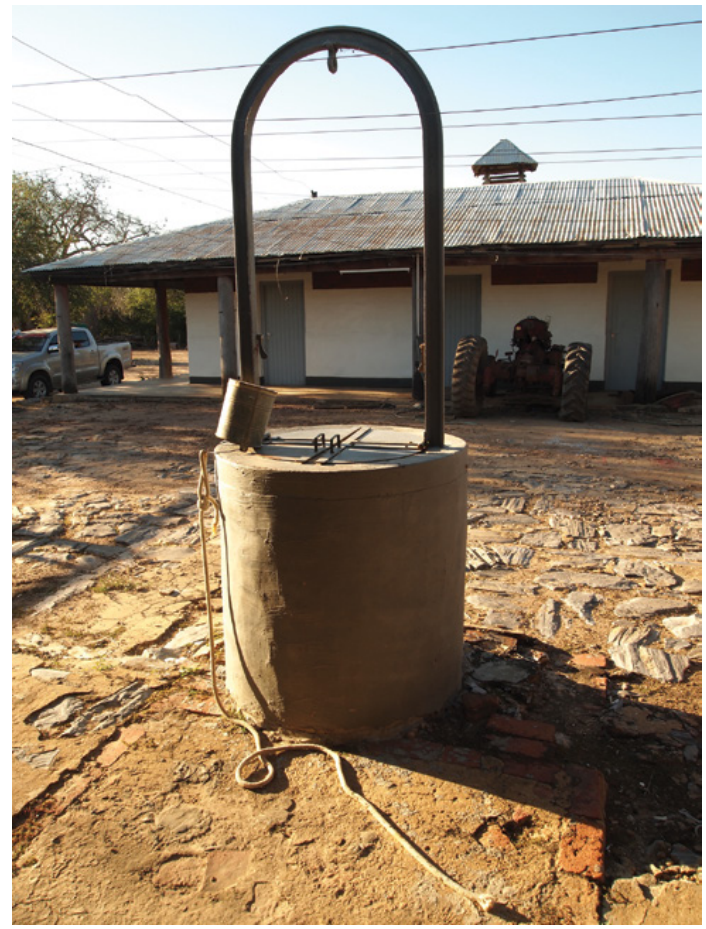

Figure 5.6 Mennonite well with the restored railway station house in the background at Km 145 (Source: author).

Chaco's impenetrable forest is infested by bloodthirsty mosquitoes. Although thankfully no longer carriers of malaria, they still make conducting research in the bush very uncomfortable. Alongside the train tracks the occasional telephone pole and wires - reminders of a disappointing modernity that failed to establish a good communication system during the war - are still visible in the thicket. A pair of round brick coal ovens used to fuel the train also survive next to the train tracks. The shores of two bomb craters that fill up with water after heavy rainfall have become a popular picnic area. Here, nature is no longer seen as an enemy but as something that can be enjoyed, as Mennonite guide Hans Fast explains: 'Until recently Mennonites thought that the Chaco had to be fought and tamed. It was a long learning process for them to realise that its plants and animals can be valued. For a long time killing a plant or an animal was considered a triumph' (pers. comm.). Nonetheless, the Mennonites' desperate efforts to maintain the manicured appearance of the site and control the encroaching bush continue to uphold the modern culture/nature divide. Thus, almost a century 


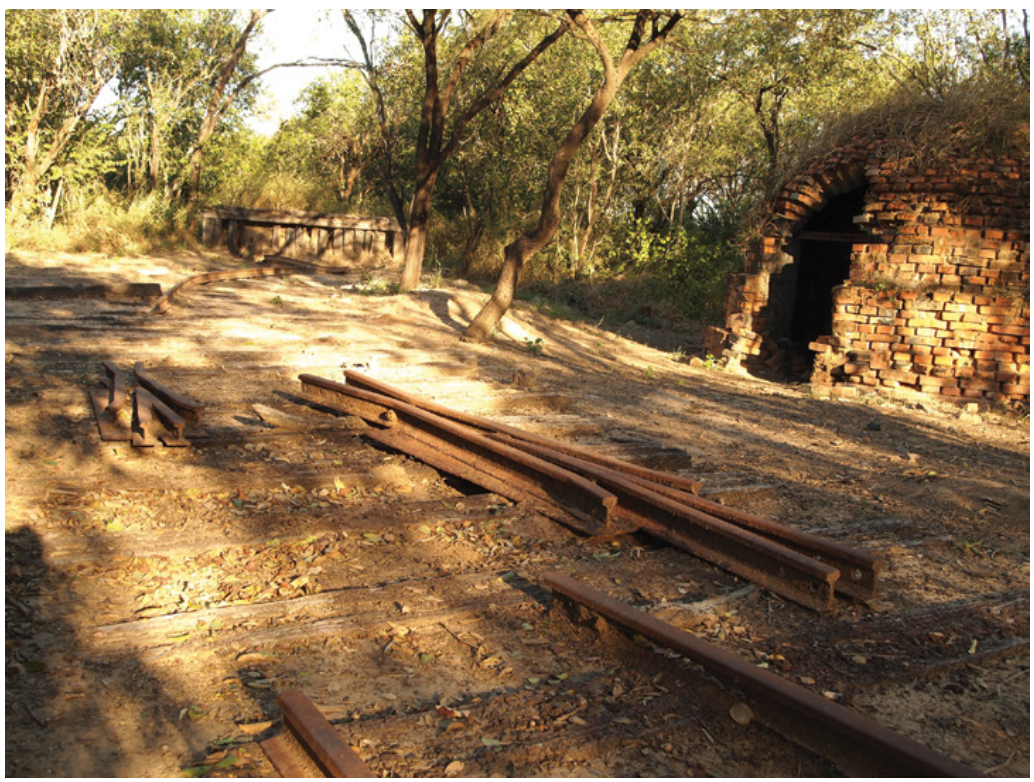

Figure 5.7 Remains of train tracks and red-brick coal oven at Km 145 (Source: author).

after they first arrived in the Chaco, the Mennonites still see it as an 'Other' (albeit a more tamed one) that continuously needs to be separated from and controlled by humans.

\section{Fortines}

\section{Fortín Isla Po'í}

Fortín Isla Po'í was surveyed and revisited several times in the course of my research, in June 2011 and April 2013 and on 12 June 2013 during the Día de la Paz del Chaco (Chaco Armistice Day) celebrations. ${ }^{3}$ The part of the site accessible to visitors sits within a clearing in the forest consisting of thorny bushes (Prosopis sp.), shrubs and cacti (Opuntia sp.), with scattered trees (Aspidosperma quebracho, Bulnesia sarmientii and Schinopsis sp.). During the survey in 2011, the lake north of the site was dry and access to it and a nearby cemetery was impossible due to the density of the bush. The thorny forest and shrubs dominate patches of grassland (Elyonurus spp.). In 2013 the bush was cleared in preparation for the inauguration of the partially restored site on Chaco Armistice Day. 


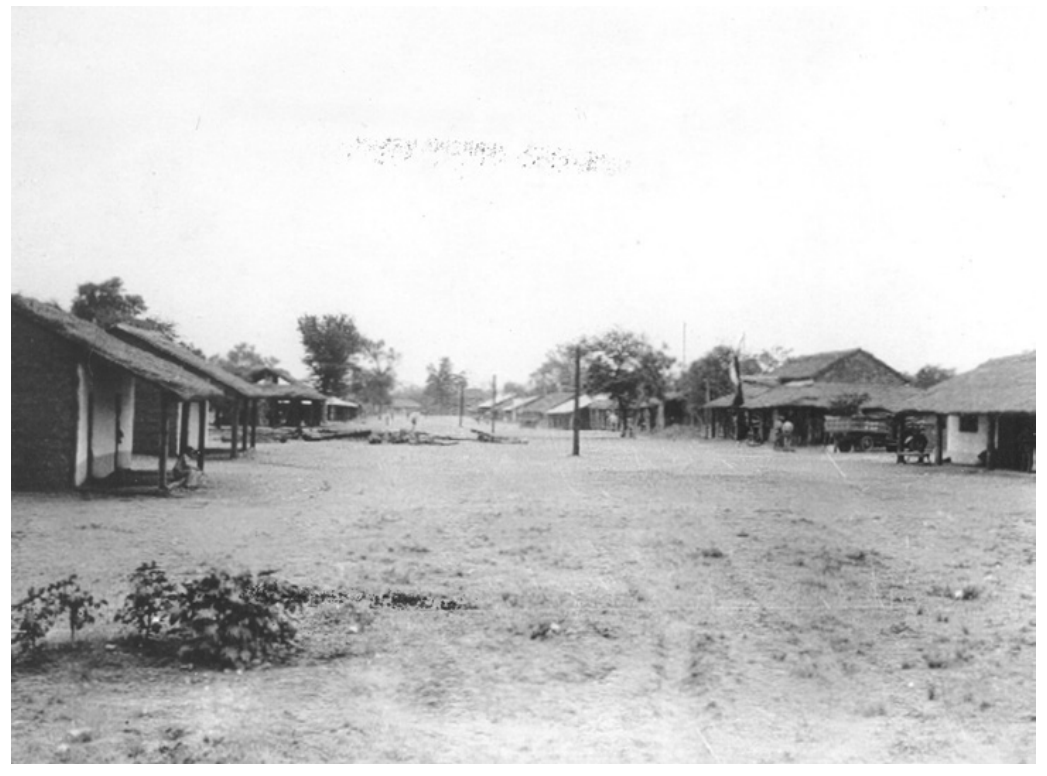

Figure 5.8a Fortín Isla Po'í during the war (Courtesy of AIHMM).

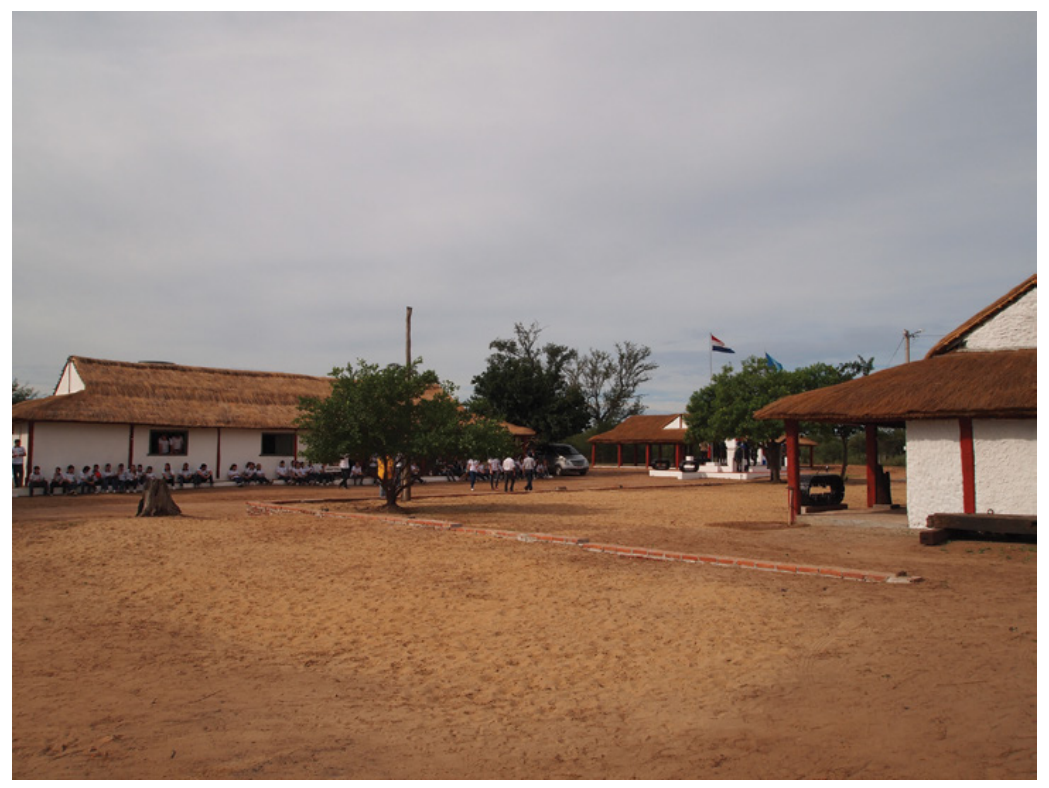

Figure 5.8b A partly restored Fortín Isla Po'í in June 2013 (Source: author). 
The main visible features at the times of the survey were the command hut; a house that once served as military officials' sleeping quarters and is now a private home; seven Bolivian caterpillar tank track plates; a memorial to Marshal Estigarribia; a war memorial made from a bomb case; and a section of brick wall belonging to a former military hospital. In June 2013 signage and an information board as well as a memorial to pilot Walter Gwynn had been added to the site. I was also able to gain access to the associated cemetery containing a series of small white crosses.

The condition of the site changed significantly over the course of the three visits I made between 2011 and 2013. Although it had undergone previous restoration efforts, in June 2011 the site was in a general state of neglect and was inhabited by a Paraguayan family. In April 2013, the bush had been partly cleared to expose the cemetery. By June 2013, the site had undergone substantial restoration efforts.

Situated at just over $100 \mathrm{~km}$ from Km 145 and in close proximity to the Mennonite communities, Fortín Isla Po'í was the general command post of General Estigarribia and as such represented the headquarters of the Paraguayan army in the Chaco. Although it was only ever attacked from the air, the outpost was fortified by a battalion of sappers and guarded by two infantry divisions and one cavalry brigade ready to push back an advancing enemy (Benítez 1976). Ironically, the name of Fortín Isla Po'í (formerly known as Fortín Villa Militar) means 'beautiful island' in Guaraní. During the rainy season, the land surrounding the old military fort tends to flood, making the fortín stand out like an island among seasonal sea salt lakes. The outpost was built at the shores of and named after Lake Isla Po'í, a large and rare freshwater lake that provided a lifeline to the Paraguayan soldiers.

Prior to the official outbreak of the war, the fortin had the characteristics of a modern industrial town with the drumming noises of its big mechanical workshops and a mixture of soldiers and civilians continuously loading and unloading all kinds of materials and provisions (Florentín 1984, 44). Hitherto believed to be impenetrable in the Paraguayan national imagination, the Chaco landscape was now being tamed through industrial progress: its wood served as building material and its meagre water sources fuelled both man and machine.

Fortín Isla Po'í indeed stood out like a beautiful island, a modern oasis in the heart of the Chaco 'wilderness'. Yet the outpost's bustling atmosphere was deceptive, as its true purpose served a sinister reality: the nation was preparing for war and Isla Po'í was to become its military centre. At the first warning of a possible bombardment by Bolivian forces, all civilians were evacuated to Puerto Casado and all abandoned 
buildings were turned into barracks that were soon overcrowded with newly arrived recruits, eager to defend with their lives what they believed was rightfully theirs (Florentín 1984, 43-4).

Today the only noise that can be heard around the old outpost is the buzzing of mosquito swarms that infest the bush that is now slowly but surely encroaching on the once vital site. A single rusty sign announces the fortín, which can be accessed via an old wooden gate and a bumpy dirt road. A second, bigger signboard depicting a horse and what appears to be a Paraguayan and a Bolivian army official shaking hands has been put up next to the gate. Curiously, the sign announces Rodeo Isla Po'í, an annual livestock exposition organised by the Menno colony. Although the event has no direct relation to the area's military past, it is named after the nearby fortín and takes place on 12 June, coinciding with Chaco Armistice Day. Modern local traditions thus seem embedded in the history of the place. Indeed, through the image of the reconciling soldiers and the horse 'fragments of the past are inscribed in the materiality of the present' (Olivier 2013, 172).

Over the years, the only nearby freshwater lake that allowed the military troops to survive, and behind which the soldiers used to sleep under mosquito nets, has been reduced to no more than a large puddle. In 2006, 2007 and finally 2013 (Anonymous 2006a, Anonymous 2008)

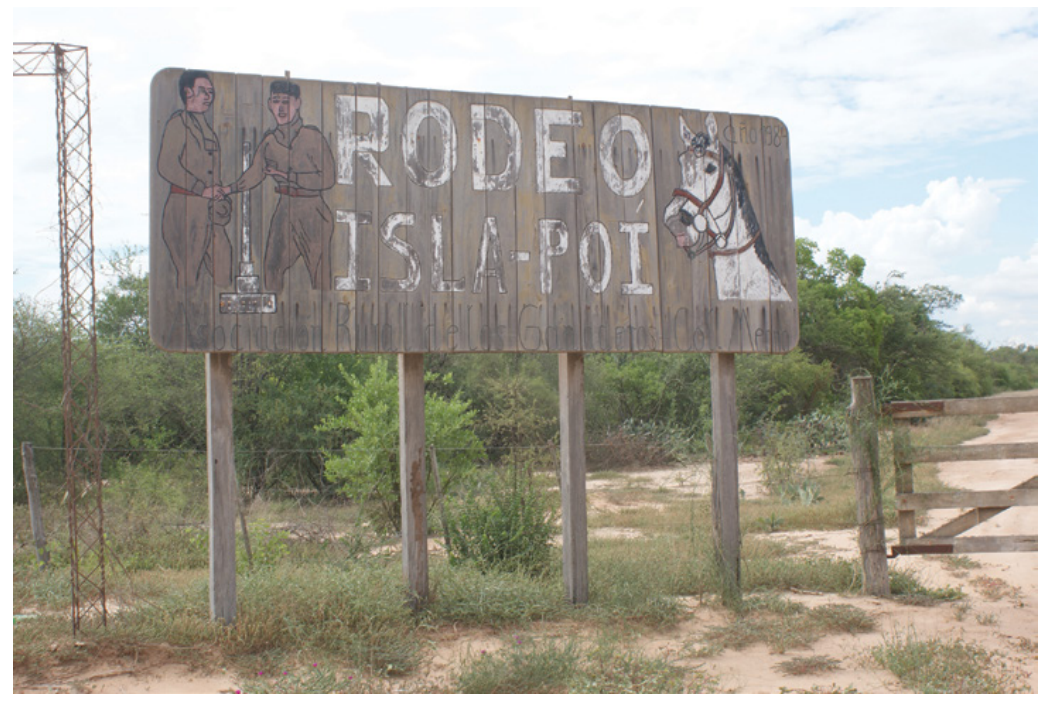

Figure 5.9 Rodeo Isla Po’í signboard depicting military officials shaking hands (Source: author). 
the Paraguayan Ministry of Defence, together with the Department of Public Works and funding from the Mennonite communities, restored the military post but the lack of maintenance means that the site has since fallen back into disrepair. The son of a war veteran who was stationed at Isla Po'í and his family have been living on the site since 1993. Whereas in 2011 they were still living without power in a precarious house that had previously served as accommodation for military officials, they have since been moved into a nearby newly built house for health and safety reasons (Hans Fast, pers. comm.).

In honour of Estigarribia, a bust of the marshal together with a commemorative plaque has been erected next to an empty bombshell case and a small plane-shaped memorial to commemorate Walter Gwynn, a pilot who lost his life in an airstrike defending the outpost. ${ }^{4}$ Not far off, a small interpretation board in Spanish has been put up in the centre of the site. The officers' mess has long gone and only a small part of a brick wall and a few wooden posts remain of the field hospital. Countless soldiers injured in conflict or stricken with disease were brought to overflowing field hospitals similar to the one at Isla Po'í (Sarmiento 1978, 82). During the war

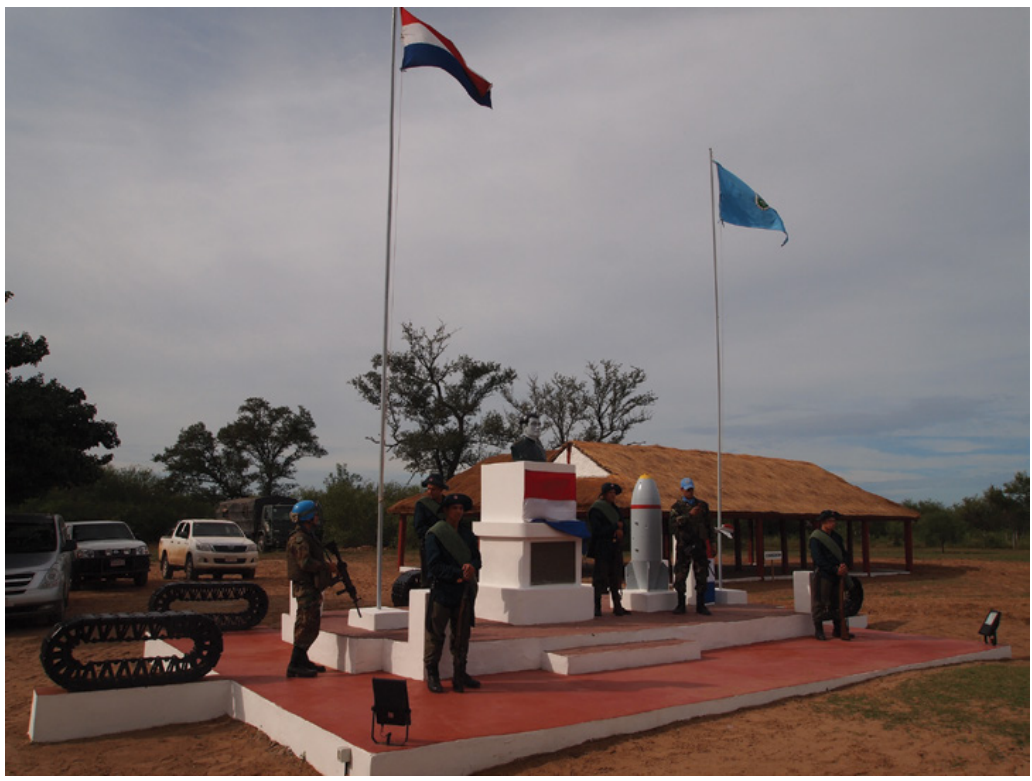

Figure 5.10 Members of the Paraguayan military next to Marshal Estigarribia's bust and the bomb case memorial with the restored military mess in the background during the inauguration of the partially restored site in June 2013 (Source: author). 


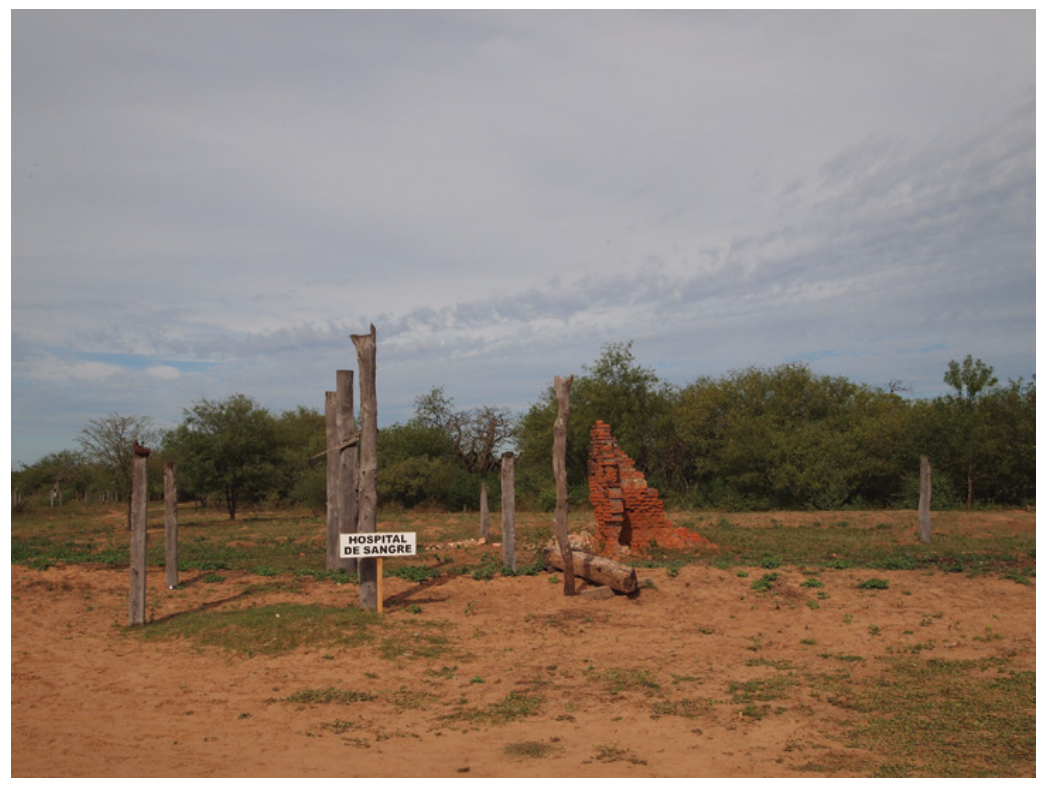

Figure 5.11 Brick wall and wooden post remains of the field hospital at Fortín Isla Po'í (Source: author).

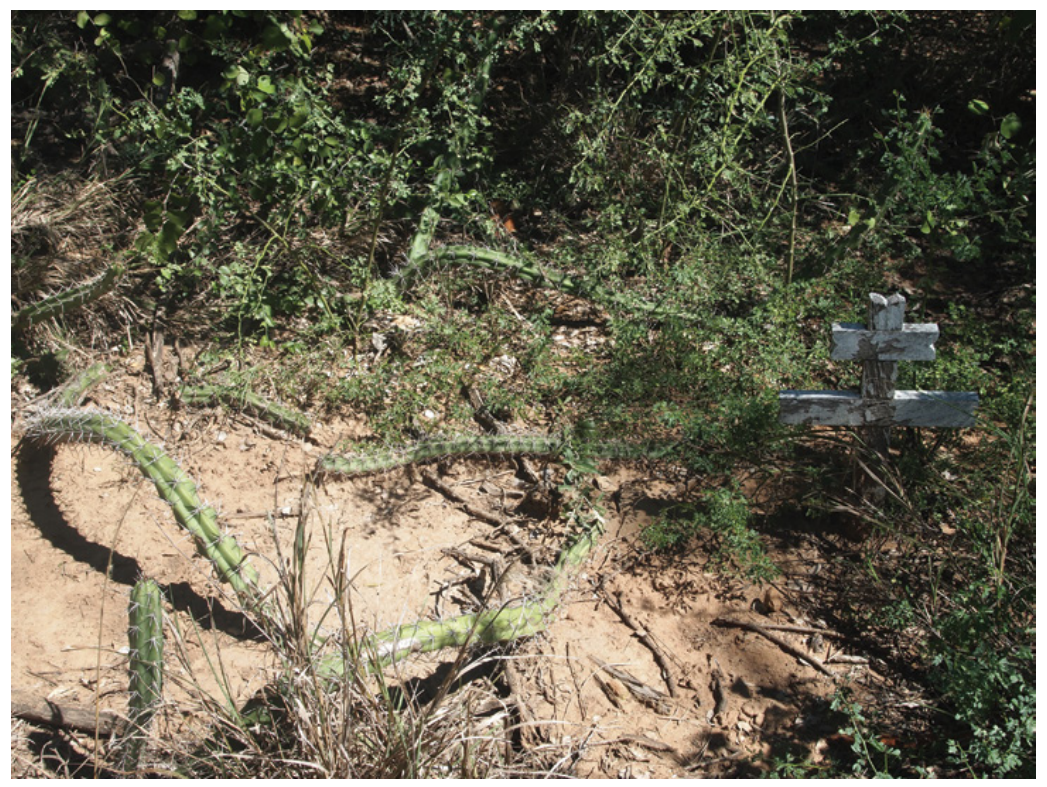

Figure 5.12a Overgrown cemetery in Fortín Isla Po'í in April 2013 (Source: author). 


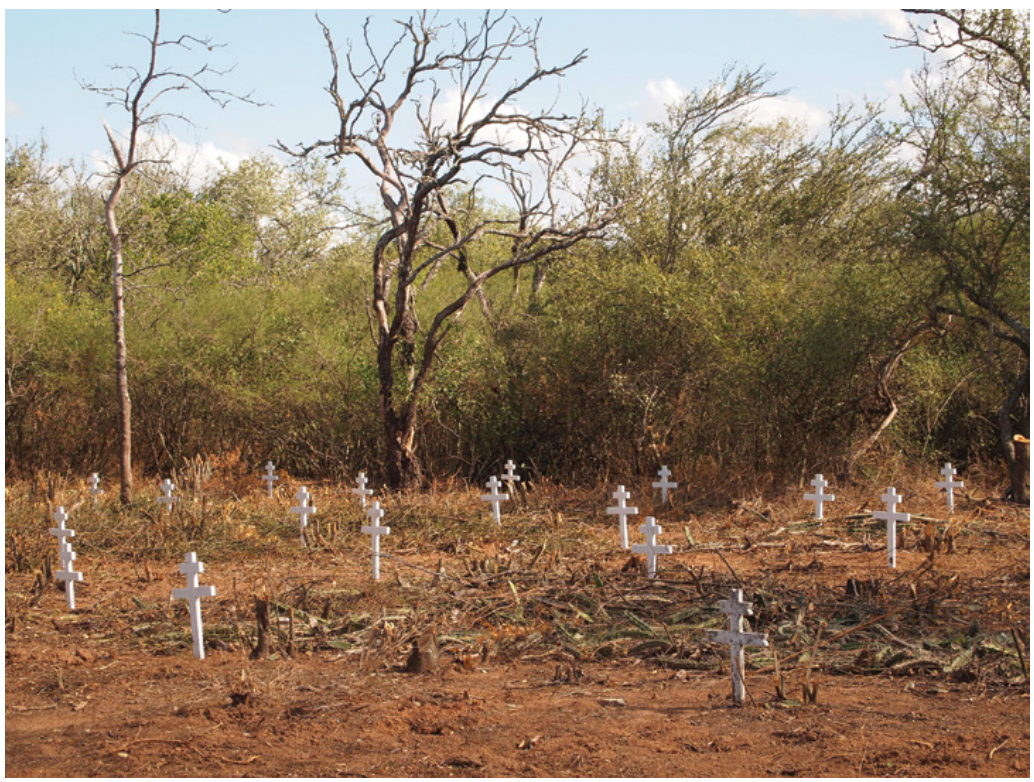

Figure 5.12b Cleared cemetery in June 2013 (Source: author).

a path used for the transport of the sick and wounded led into the fortín and to the hospital (Florentín 1984, 61). Today the same path leads to a small military cemetery. Whereas in April 2013 the cemetery had been completely overgrown and as a result was inaccessible without the help of a machete, by June that same year the bush had been cleared to reveal nameless white crosses marking the resting place of fallen soldiers. The exact number of crosses is unclear as they disappear into the Chaco underbrush, which is already slowly but surely starting to reclaim the site.

\section{Fortín Toledo}

This site was surveyed and recorded in January 2011, and revisited in April 2013. It is situated within a forest consisting of thorny bushes (Prosopis sp.), shrubs and cacti (Opuntia sp.), with scattered trees (Aspidosperma quebracho, Bulnesia sarmientii and Schinopsis sp.). Narrow trails have been cut through the bush to allow movement but not all features from the war can be accessed due to the denseness of the thicket. The thorny forest and shrubs dominate patches of open grassland (Elyonurus spp.) in the near vicinity of the site. At the times of recording, the main extant features were one partly reconstructed bunker; four unreconstructed ruined 
bunkers; and a series of overgrown trenches. All of these features were built by members of the Paraguayan forces. At the time of the last visit the site was in a state of total neglect and overgrown by vegetation.

Fortín Toledo witnessed an armed confrontation between the two enemy armies that lasted 16 days, and claimed the lives of around a thousand soldiers in February-March 1933. The Paraguayan outpost was built in 1927 to the west of Mennonite-owned land. It was briefly seized by the Bolivians in 1932 before it was recaptured by Paraguayan forces (Farcau 1996, 107). Written sources on the quality of the fortification work at Toledo vary significantly. Whereas according to Paraguayan politician and writer Justo Pastor Benítez the trenches and fortified positions were 'gigantic', allowed for perfect communications and showed the nation's 'spirit of progress' (Benítez 1976, 100), American military historian Bruce Farcau notes that

Toledo was poorly sited for defence, as the heavy woods that dominated the area made it difficult to clear fields of fire for more than fifty meters in any direction. Estigarribia had ordered the fortin held primarily because of its position at a vital crossroads and also because of the morale factor of preventing the impression that a Bolivian offensive was actually gaining momentum. The defenders lacked the tools necessary to establish an interconnected line of trenches, so they organized a system of company-sized strong points about a hundred meters apart with interlocking fields of fire to cover the gaps. The strong points were composed of shallow trenches, deep enough to shelter a kneeling rifleman, with separate bunkers with overhead protection for refuge during artillery bombardment. The Paraguayan defenses bulged southward, forming a rough semicircle around Toledo itself, and then extended eastward along the northern edge of a broad, grassy meadow (Farcau 1996, 107).

Today Fortín Toledo sits on Ministry of Defence-owned property in the vicinity of the Mennonite colonies. Hidden in the forest, it emits an air of abandonment and oblivion. Next to it is a fenced-off nature reserve with a small breeding population of Chaco peccary, which until their scientific rediscovery in the 1970 s were thought to be extinct. A small rusty sign instructs the visitor to enter the old military post through a little wooden gate. Just behind the gate stands a lone information board concisely recalling the events of 1933 in Spanish. Behind it a narrow path leads into the bush and to the surviving war structures. With the exception of one restored bunker made with wooden planks and 
posts, four others have collapsed, and are gradually being reclaimed by nature. Hans Fast explains that locally tuka means bunker and that the word derives from the Guaraní tuka tuka, which refers to the warning sound of a subterranean rodent (Ctenomys conoveri) that, like the soldiers, builds and hides in underground tunnels (pers. comm.).

Besides the remains of the collapsed bunkers, the outlines of trenches are still visible, although they are often hard to discern by an untrained eye. Over the years, heavy rainfall, soil erosion and neglect have reduced the trenches at Toledo to small ditches crossing the landscape. Like the crumbled bunkers, they are overgrown with thorny shrubs, and inhabited by stinging insects and birds, whose song Benítez remembers from the days of fighting like an 'irony of nature in the face of men's foolish impulse to destroy' (Benítez 1976, 100).

In the first two decades after the war, the site of Toledo became an exciting playground for local Mennonite children, who were curious to see the battlefields that they had heard so much about from their parents and grandparents. Fast recalls playing in the abandoned bunkers as a child during the 1950s and 1960s. 'This was not without danger', he says. 'We children often found live ammunition and grenades' (Hans Fast, pers. comm.).

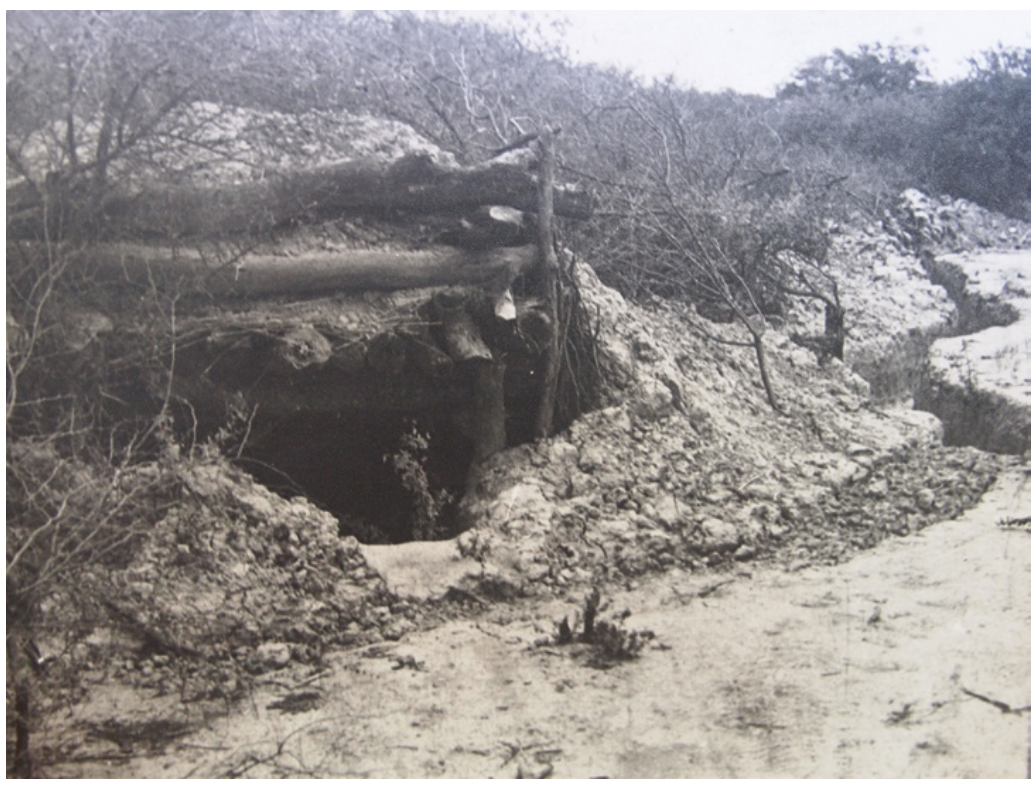

Figure 5.13 Photograph of a bunker and trench taken during the war, location unknown (Courtesy of AIHMM). 
Spaces that are considered forbidden or dangerous thus often represent 'spaces of fantasy, spaces in which unspeakable and illicit acts occur, places of unhindered adventure' (Edensor 2005b, 25). In his discussion

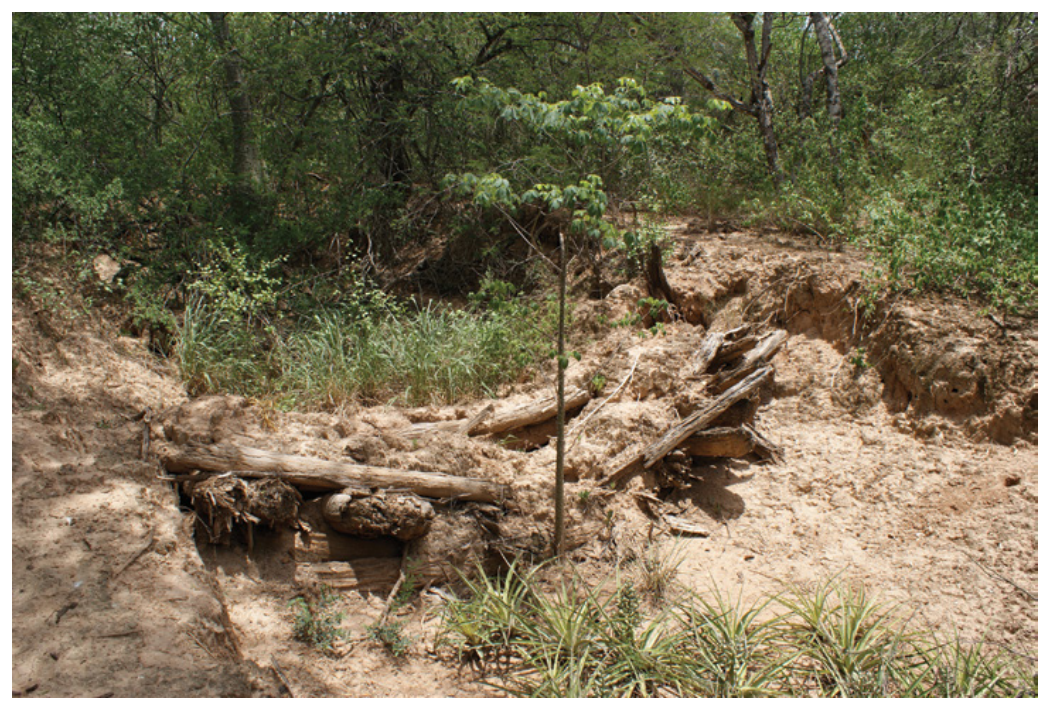

Figure 5.14a Remains of a collapsed bunker at Fortín Toledo (Source: author).

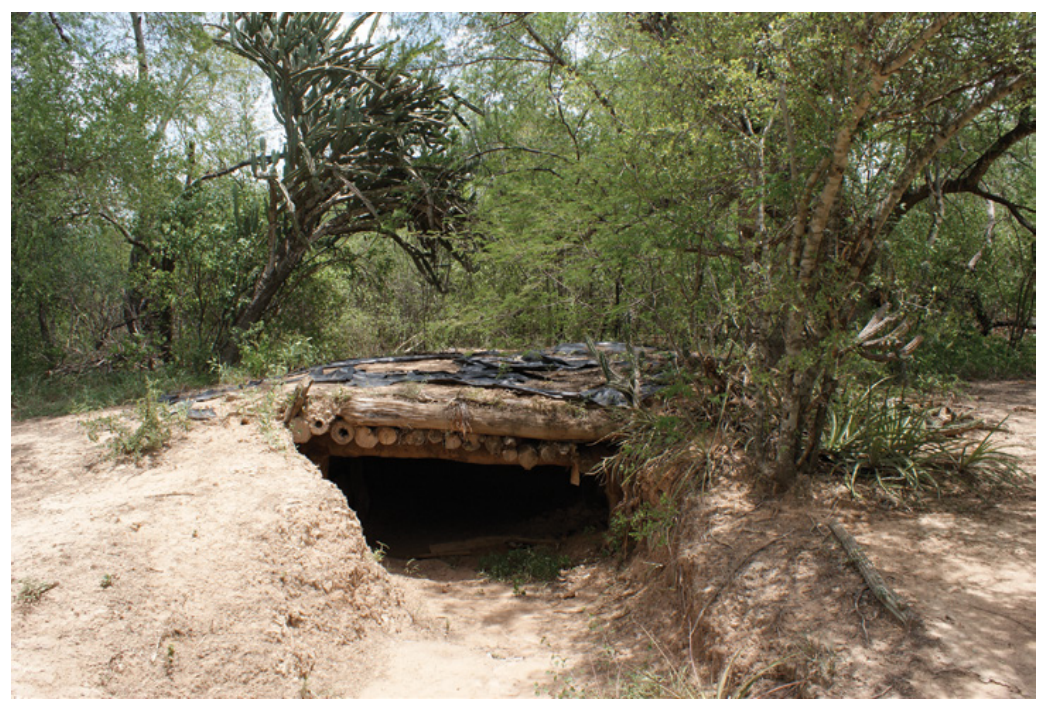

Figure 5.14b Reconstructed bunker at the same site (Source: author). 
of Second World War urban bombsites as playgrounds in Britain, Gabriel Moshenska argues that these disordered spaces are 'sites of memory' that shape the 'experience of childhood in a world at war' (Moshenska 2014, 238). However, at the site of Toledo, the children's engagement with war material was cut short. As Fast went on to explain, in later years the Paraguayan military commissioned a local Mennonite man to clear the site of its conflict debris (Hans Fast, pers. comm.). Stripped of all their metal and left without maintenance, the wooden bunkers and trenches of Toledo have been consigned to their fate, hidden away in the bush by which the site is slowly but surely being engulfed. Michael Roth notes that 'as things fall apart, out of their remains emerge new forms of growth' (Roth 1997, 2 ). In the case of Toledo, it is only a matter of time before the remaining war structures will have been completely reclaimed by nature.

\section{Fortín Boquerón}

Fortín Boquerón was visited and surveyed several times, in January 2011, April 2013 and June 2013. Large parts of the site are situated within a forest consisting of thorny bushes (Prosopis sp.) and cacti (Opuntia sp.), with scattered trees (Aspidosperma quebracho, Bulnesia sarmientii, Schinopsis sp. and Chorisia speciosa). Trails have been hacked to access major places of interest but most of the trenches are inaccessible owing to the denseness of the bush. To the north lies a lake within the thorny forest. Large patches of open grassland (Elyonurus spp.) surround the site, at the heart of which lies a clearing.

The main visible features at the times of recording included the lake; overgrown trenches; one reconstructed bunker; one reconstructed sniper's hideout inside a hollowed-out bottle tree; a Paraguayan military cemetery; a Bolivian military cemetery; the separate grave of a Paraguayan and a Bolivian soldier buried together; an original aguatero vehicle (water truck); a reconstruction of a casino (officers' mess) and command post; the reconstruction of a bread oven; a Chaco War museum; and eight war memorials. Fortín Boquerón is the major tourist attraction relating to the Chaco War in Paraguay. As such, the site is generally in good condition and as of 2013 was inhabited by a well-informed Latino Paraguayan man in charge of the museum, and his family. The trenches are still visible in the landscape although they are overgrown by vegetation.

Established by the Paraguayans in 1928 and then briefly captured by the Bolivians, Fortín Boquerón was finally taken back by Paraguay on 29 September 1932. Over the course of 21 days, the two armies fought a bloody battle here that left more than 7,000 casualties and marked 
the official outbreak of the war. Surrounded by open grassland, Fortín Boquerón:

comprised a handful of adobe huts located in the heart of an isla of heavy woods surrounded by open grassland with a few gnarled trees. The fortin was constructed in the shape of a blunt arrowhead pointing southwest toward the Bolivian outpost of Yucra, and with its forked tail aligned roughly north and east, measuring approximately five hundred meters in length. The place was fortified by Jordan and Santanella with a line of trenches reinforced with barbed wire entanglements and clusters of sharpened stakes around the perimeter. Lanes had been cut through the surrounding bush to the north and to provide interlocking fields of fire for automatic weapons. Machine guns had been set up in platforms in the trees to give them improved observation, and chapapas (bunkers reinforced with earthworks and quebracho log walls) housed key strongpoints (Farcau 1996, 46).

Entrenched for three weeks on end, the Bolivian soldiers gradually ran out of supplies. Rotting bodies contaminated the little water available to those who were still alive inside the military post (Sarmiento 1978, 71). The nearby wells used by the Paraguayans were also running dry and the soldiers were exhausted. The Bolivians finally surrendered on 29 September and the victorious Paraguayans stormed the fortification that had so long resisted their attacks. Inside the fortin they were met by the excruciating sight and smell of rotting bodies covered with maggots and filth. Injured soldiers looked up to them with 'eyes too dry to tear' and the Paraguayans could not believe that these 'scarecrows' were operating the weapons that had killed so many of their comrades (Farcau 1996, 60-1). 'These poor animals', Farcau states, 'were not the monsters the Paraguayans had pictured crouching behind their machine guns' (Farcau 1991, 61). He continues:

The defenders' pitiful appearance brought home to the Paraguayans that the Bolivians, their enemies, had actually been facing the same enemies all along: thirst, hunger, and the fear of a sudden death, or worse yet, a slow lingering one. One by one the Paraguayan soldiers offered a packet of cigarettes, a canteen of water, or a crust of bread, which the Bolivians accepted with hands trembling with fear, humiliation, and hunger. Then, one by one, they all fell to crying, Bolivians and Paraguayans alike. They cried for the men they had killed, the 
friends they had lost, and for themselves, helpless pawns torn from their comfortable little lives and hurled by titanic forces into this hell. For a moment the war stopped (Farcau 1996, 61).

Today, a lone grave located inside the old military post stands as a reminder of human compassion and friendship in a war between brothers. Marked with a small commemorative plaque inscribed with the names of two army generals, the grave holds the remains of a Paraguayan and a Bolivian soldier who became friends during the war and requested to be buried next to each other. The names on the plaque and the story associated with them do not merely give a face to the deceased

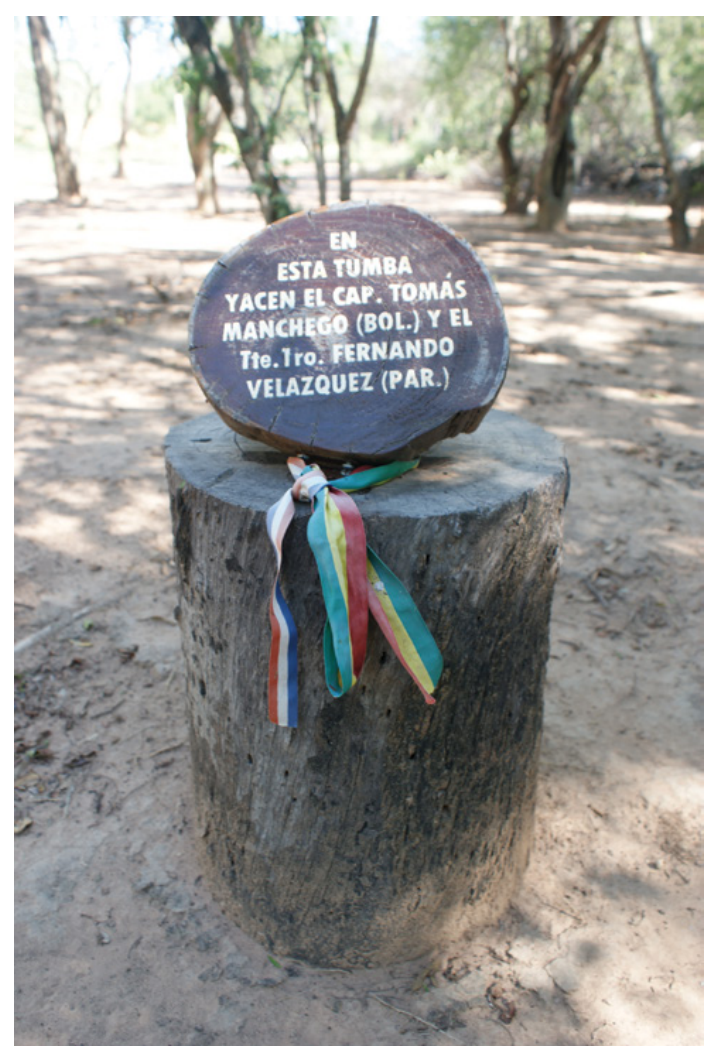

Figure 5.15 Simple tombstone marking the shared grave of a Bolivian and a Paraguayan soldier, who had requested to be buried together (Source: author). 


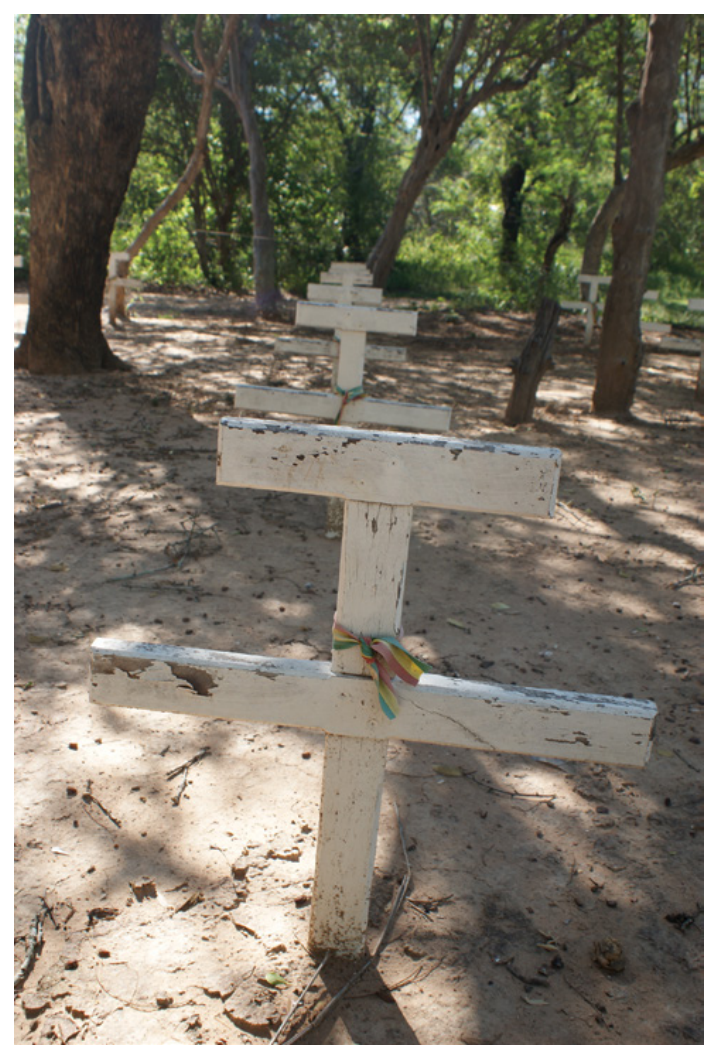

Figure 5.16 Close-up of a cross decorated with a ribbon in the colours of the Bolivian flag in the Bolivian cemetery (Source: author).

but also represent a human side to the destructive nature of industrial war. Two ribbons in the national colours of the enemy countries are tied together around the memorial plaque, emphasising the fact that during the war the soldiers were not always enemies. They were human beings, brothers from neighbouring countries, who were forced to fight each other in the most inhumane way within inhospitable territory in a war whose purpose often escaped their full understanding. With their gaunt faces and haggard frames both the Paraguayan and Bolivian soldiers resembled the gnarled trees under which they desperately tried to find some shade and make sense of their situation, as Céspedes recalls: 
'We lived, emaciated, miserable, the trees prematurely aged, with more branches than leaves, and the men, with more thirst than hatred' (Céspedes 1973, 18).

Nevertheless, on the edge of the site and at a considerable distance from each other lie two cemeteries, one for Paraguayan soldiers, the other for Bolivians. Local people claim that both cemeteries are in fact mass graves containing an unknown number of nameless dead (Heinz Wiebe, Mennonite guide, pers. comm.). Rows of a symbolic number of white crosses commemorate the bodies that have been robbed of their identity - present but 'missing', liminal entities who are truly betwixt and between (Turner 1995, 95). Closer inspection reveals that the Paraguayan crosses are slightly more elaborate than the Bolivian ones. By creating two separate cemeteries and a clear distinction in the commemorative crosses, Paraguay is conveying a poignant political message: even in death Bolivian soldiers remain enemies (Breithoff 2012, 153).

Unlike Fortín Toledo, Fortín Boquerón has undergone major conservation efforts and attracts a number of mostly national but also international tourists (Anonymous 2002). Some of the stronghold's original features, such as the military bread oven, the military officers' mess and the command hut, have been rebuilt. Others, such as a bunker, have been restored. An old Ford Cuatro automobile, which was used to transport water, is also on display. Alongside it is a small museum, housing weapons and other military equipment. The walls are covered with black and white photographs and information about the Battle of Boquerón and the war in general. Outside the museum, wooden signposts marking places of interest are situated along a trail that takes the visitor around the site. The path runs along and cuts through the surviving trenches which, like the trench system at Fortín Toledo, have been reduced to shallow ditches, overgrown with thorny bush. Alongside the dusty paths running through the fortín, the occasional wooden post pokes through the shrub. Mennonite guide Heinz Wiebe explained that after the war local Mennonites dismantled the military huts in order to use the wood in the construction of their own houses (pers. comm.).

Over the years Fortín Boquerón has also received considerable attention from the Paraguayan authorities, the military and the national media. The government declared 29 September, marking the Paraguayan victory at the Battle of Boquerón, a national holiday. Various memorials have been put up around the site's central space, with the majority of 


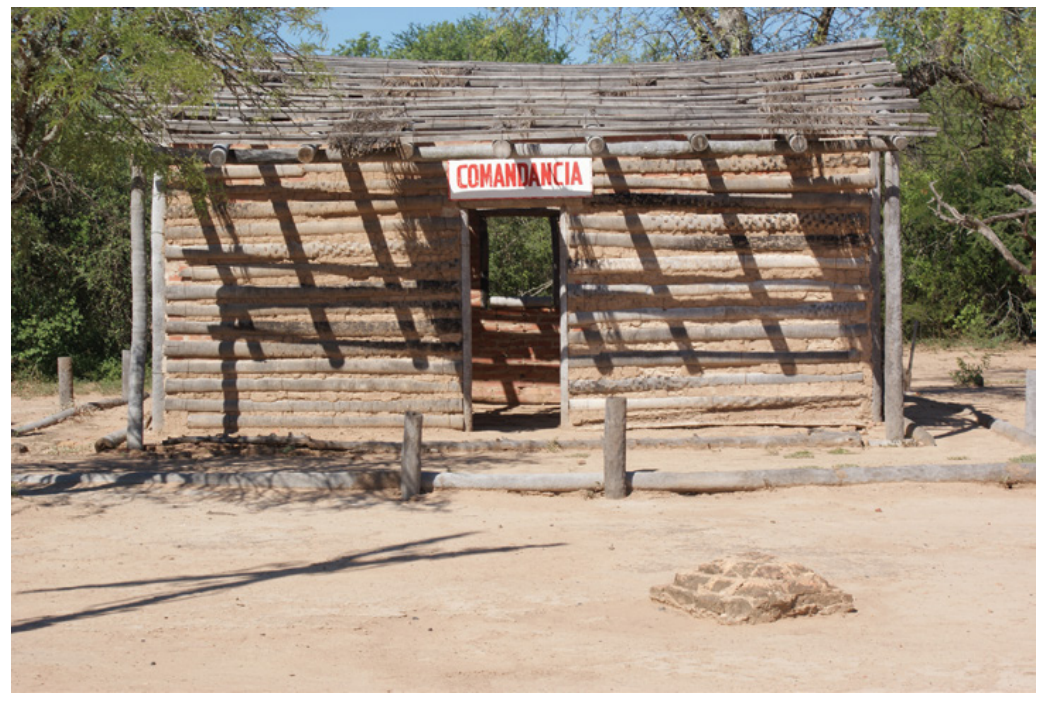

Figure 5.17 Reconstruction of command hut in Fortín Boquerón (Source: author).

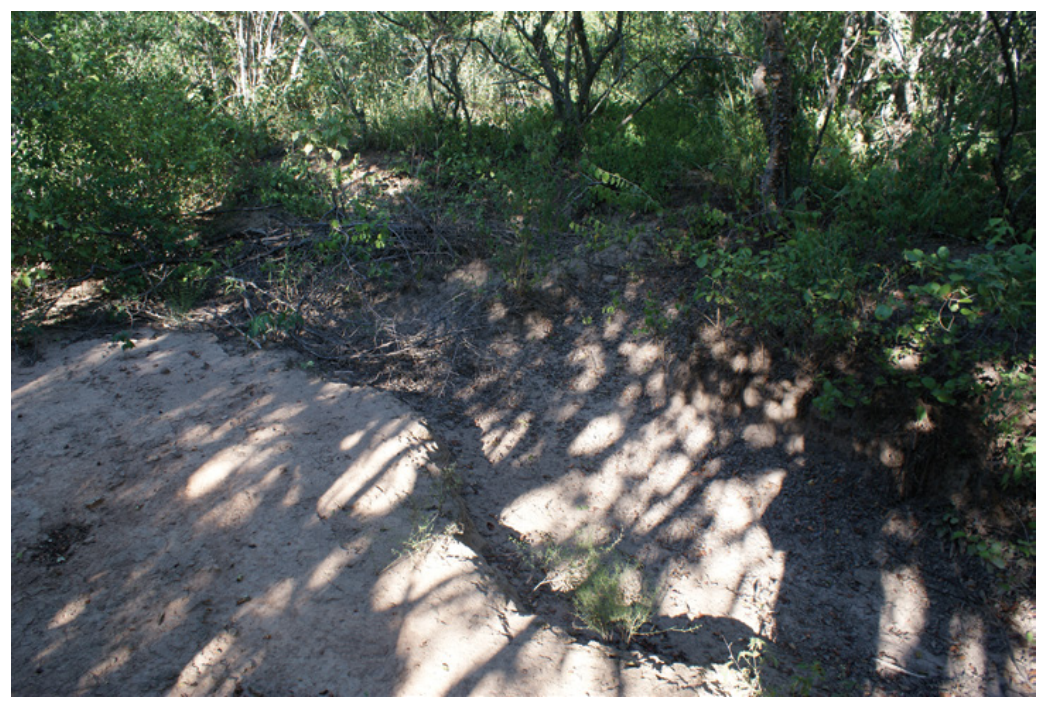

Figure 5.18 Overgrown trenches surrounding Fortín Boquerón (Source: author). 
them commemorating the brave and proud Paraguayan soldier, almost completely ignoring the Bolivian victims, reflecting the dominant historiographical approach to the war within Paraguay (see discussion in Chapter 2). One of the simpler and yet most powerful features of Fortín Boquerón is a large wooden cross erected outside the museum. Wiebe claims that farmers still come across human bones in the Chaco grasslands surrounding the fortín (Heinz Wiebe, pers. comm.). Over the years, these bones have been buried under the big wooden cross, which has come to act as a substitute grave for countless men who died in the anonymity created by this large-scale industrial war.

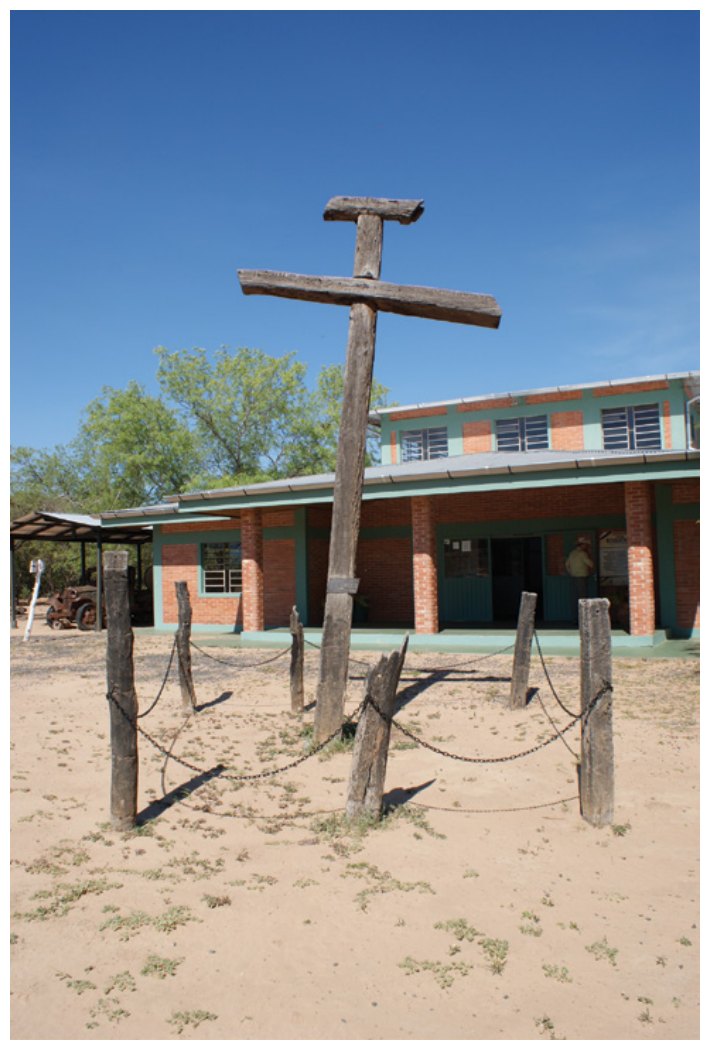

Figure 5.19 Wooden cross outside the Museo Fortín Boquerón with the Ford Cuatro water truck in the background (Source: author). 
On the other side of the clearing and overlooking the site stands the imposing gleaming statue of a Paraguayan soldier. Rifle in hand, he looks like he is on the move, ready to defend his patria. To further demonstrate the Paraguayan national sentiment, the artist decided to cut the soldier's heart out in the shape of the country's map, which unites eastern Paraguay with the Chaco region. At a short distance from the memorials, small circles of burned wood are reminders of barbecues that people enjoy inside the old fortín on family days out, recalling modern-day picnic sites along the old Western Front in France and Belgium (Saunders 2001, 47). An unexploded shell that is sticking out of the ground nearby has been covered by a protective case. On a site that has become a place of nationalistic commemoration and leisure, this corroding piece of modernity acts as a silent reminder and material embodiment of the misery and destruction caused by industrial war.

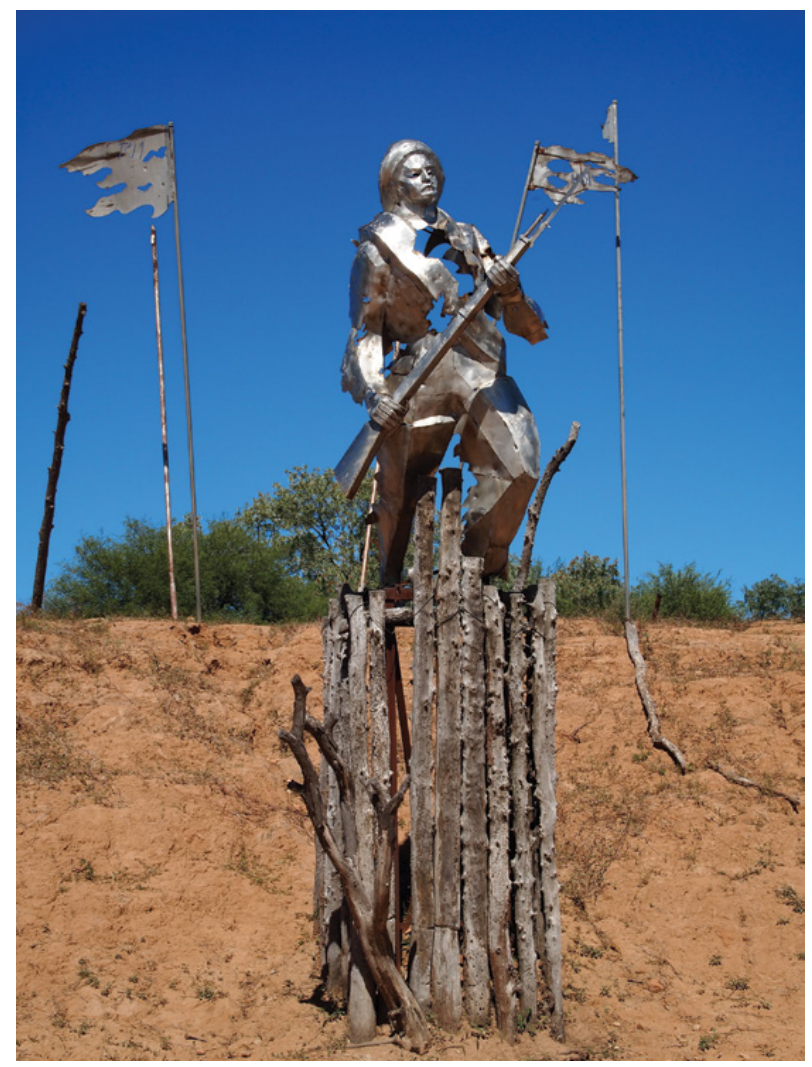

Figure 5.20 Memorial in honour of the Paraguayan soldier (Source: author). 
The site of Fortín Nanawa, recorded in May 2013, sits within patches of dense forest amid open grassland (Elyonurus spp.), thorny bushes (Prosopis $s p$.), shrubs and cacti (Cactaceae). Scattered trees (Aspidosperma quebracho, Bulnesia sarmientii and Schinopsis sp.) partially obscure the main visible features, which include two monuments (monolito); an unidentified wooden structure (a camp?); the remains of a Bolivian tank; a signpost/ memorial to Punta Mojoli (see below); Paraguayan trenches and firing positions; and scattered war debris. At the time of recording no preservation efforts had been made, and the site and trenches were overgrown, while the monolito (set of memorials) and Punta Mojoli signpost were in a general state of deterioration.

A $2 \times 2 \mathrm{~m}$ subsurface archaeological test trench, which was excavated in a firing position inside one of the Paraguayan trenches at Punta Mojoli, revealed a rich assemblage of artefacts which demonstrates the potential for further subsurface archaeological work on similar sites in the region. Finds included buttons, pieces of boot leather and brass eyelets from soldiers' clothing and footwear, spent German Mauser 98 and British Vickers 303 rounds and clips, a range of unidentified animal bone, and metal nails. The excavation was undertaken with the assistance of Ruth Alison Benítez de Casanova from the Departamento de Arqueología y Paleontología within the Secretaría Nacional de Cultura, and two soldiers from the RC1 Valois Rivarola military division in Pozo Colorado. Enthusiastic media coverage followed the release of information about the excavation to local and national media (Anonymous 2013a, 2013b; see the further discussion of the outcomes of this media interest in Chapter 6).

Originally a small Anglican missionary settlement, Nanawa became the 'backbone' of the Paraguayan armed forces during the Chaco War and as such the main target of the Bolivian army (Scheina 2003, 96). The word nanawa is said to translate to 'over there are quebracho blancos' in the Enlhet language (Unruh and Kalisch 2008, 101) and 'place of two quebrachos' in the Maká tongue (Espínola 1960,13). Dotted with dense forest, which includes amongst others the white quebracho tree, the 30-km-wide area around Nanawa looked like a lake with islands of trees from the air (Céspedes 1975, 41). The fortín was situated within such a wooden island with a cluster of wooden huts in its centre that was protected by a Paraguayan trench system stretching $12 \mathrm{~km}$ around the forest 


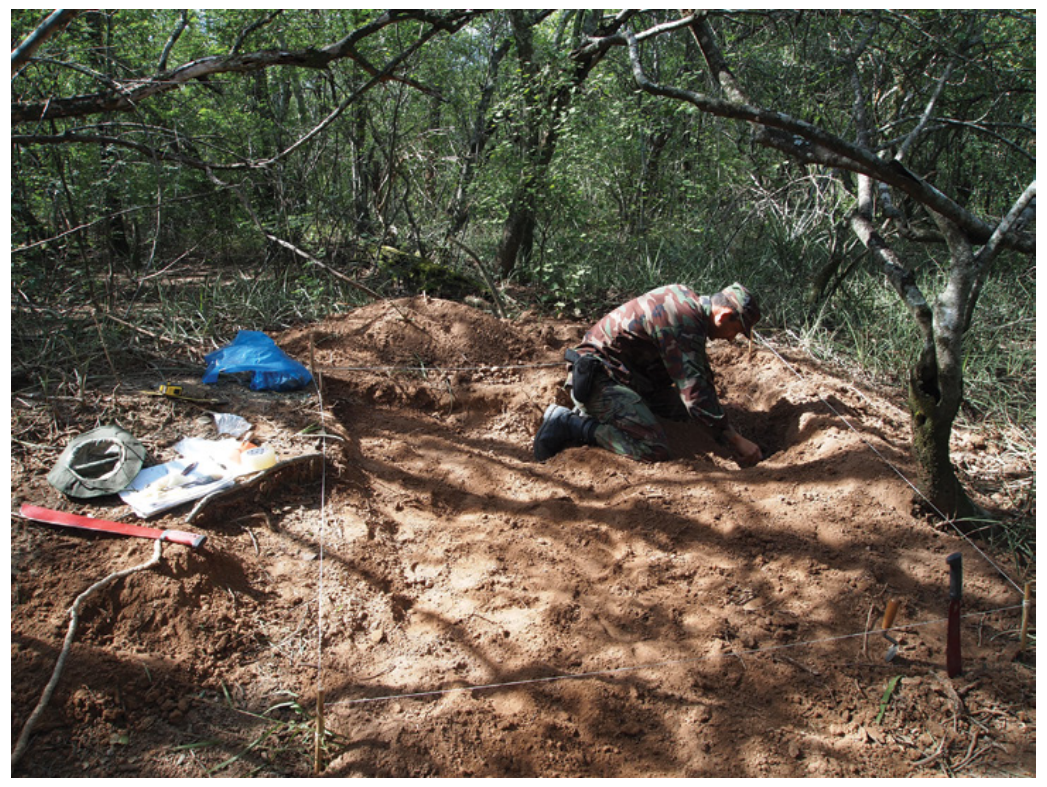

Figure 5.21 Trench being excavated at Fortín Nanawa (Source: author).

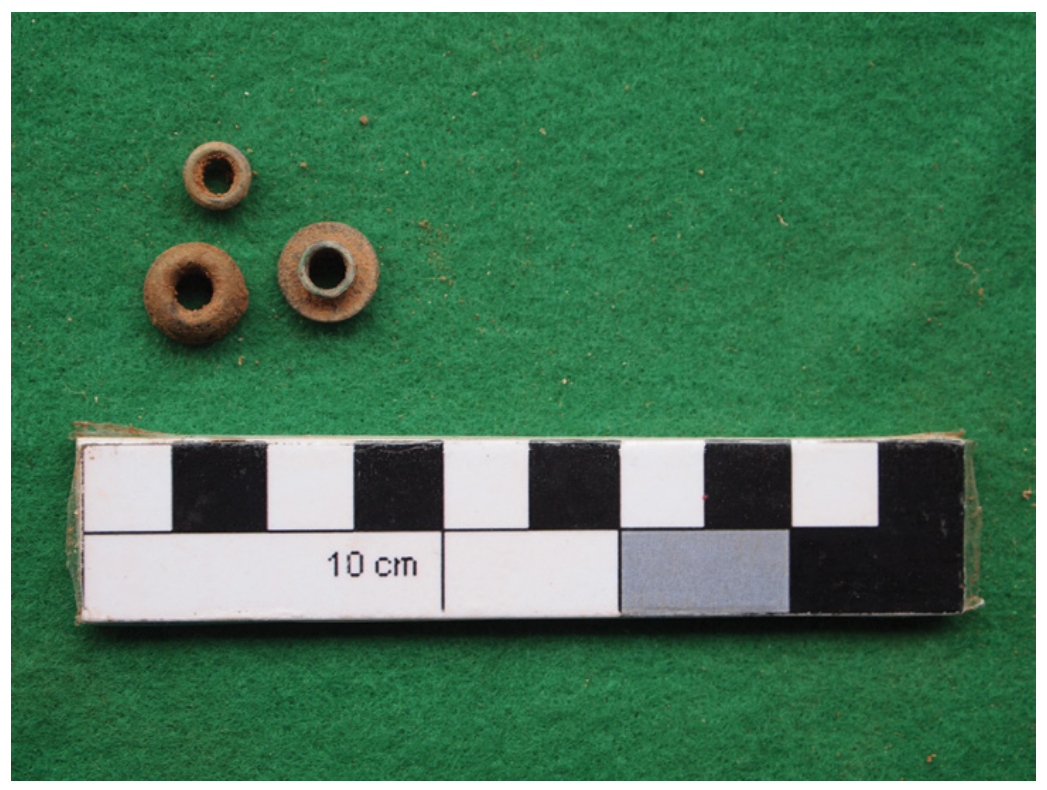

Figure 5.22 Eyelets from the excavation at Fortín Nanawa (Source: author). 
of Nanawa. Aware of Bolivian intentions to capture the fortín in order to advance towards the Paraguay River, the Paraguayans started to heavily fortify the outpost based on defence-building instructions provided by Belaieff and his fellow White Russian Nicolás Ern (Scheina 2003, 96; Farcau 1996, 98). Nanawa thus became appropriately known as the 'fortified island' (Espínola 1960, 22) where, according to Farcau:

The works ran in a rough semicircle, with the open end facing eastwards. The fortifications consisted primarily of a tangle of barbed wire reinforced with mines located fifty meters in front of the firing positions and designed to hold the attackers in the killing zone as long as possible. The firing positions themselves were shallow trenches to protect kneeling riflemen with occasional crew-served weapons emplacements, and were reinforced with thick quebracho logs (Farcau 1996, 98-9).

The Bolivian positions followed the horseshoe shape of the enemy trenches, sometimes encroaching on them and at times moving away from them (Céspedes 1975, 41). Fortification work was slow on both sides as the soldiers had to carry the wood from nearby forests under the protection of the darkness of the night (Espínola 1960, 21).

The First Battle of Nanawa took place from 20 to 26 January 1933. After three failed frontal attacks, the Bolivians managed to temporarily seize some of the Paraguayan trenches located on the periphery of the semicircle's open end before bad weather put a halt to their operations and allowed the Paraguayans to recapture the positions. Bolivia suffered large numbers of casualties, with 2,000 men dead compared to the 248 Paraguayan losses, which included missing and wounded soldiers (Scheina 2003, 96). Over the next four months Bolivia staged various largely unsuccessful assaults on other Paraguayan outposts while the Paraguayan units entrenched in Nanawa were busy improving their positions. By the end of June, the whole defence system had been reinforced and extended by $20 \mathrm{~km}$ (Scheina 2003, 96-7).

The forest acted like a protective shield against prying enemy eyes and allowed a secure circulation between the fortified command posts and the defensive positions, which were connected via communication trenches (Espínola 1960, 22). Across the scrubland and unnoticed by the Paraguayans, Bolivian sappers had been spending much of their time digging a mine under one of their enemy's positions. Its detonation on 4 July marked the beginning of the Second Battle of Nanawa. The mine did not, however, manage to weaken the Paraguayan defence as the position 
had been unmanned at the time of the explosion. The misfortune of the Bolivians did not stop here. Under the command of General Hans Kundt they launched an extensive frontal assault, a strategy that again proved not merely unsuccessful but downright disastrous to the Bolivian forces. Although the roughly 9,000 men armed with superior weaponry attacked an equal number of ill-equipped Paraguayans, the number of Bolivian losses was triple that of their enemy (Scheina 2003, 97).

Today the heart of Fortín Nanawa is situated on private farmland, while the extended trench systems are located on various different properties. The land housing the central part of the outpost is owned and managed by two Latino Paraguayan farmer brothers. Although it is now primarily used for agricultural purposes, the farmers claim that they try to leave the old fortin as untouched as possible but occasionally attend to the monolito, a set of two run-down memorials erected in the memory of those who fought and lost their lives in the forest of Nanawa (estancia owners, pers. comm.).

In close proximity to the monolito, in an area of open high grass, sits a small thicket of trees that hide from view parts of a wooden structure and an old tin bucket. Could these be the remains of a military camp? One of the brothers shakes his head: he does not know. 'Follow me, I'll show you something,' he says, and with his machete in hand he turns his back

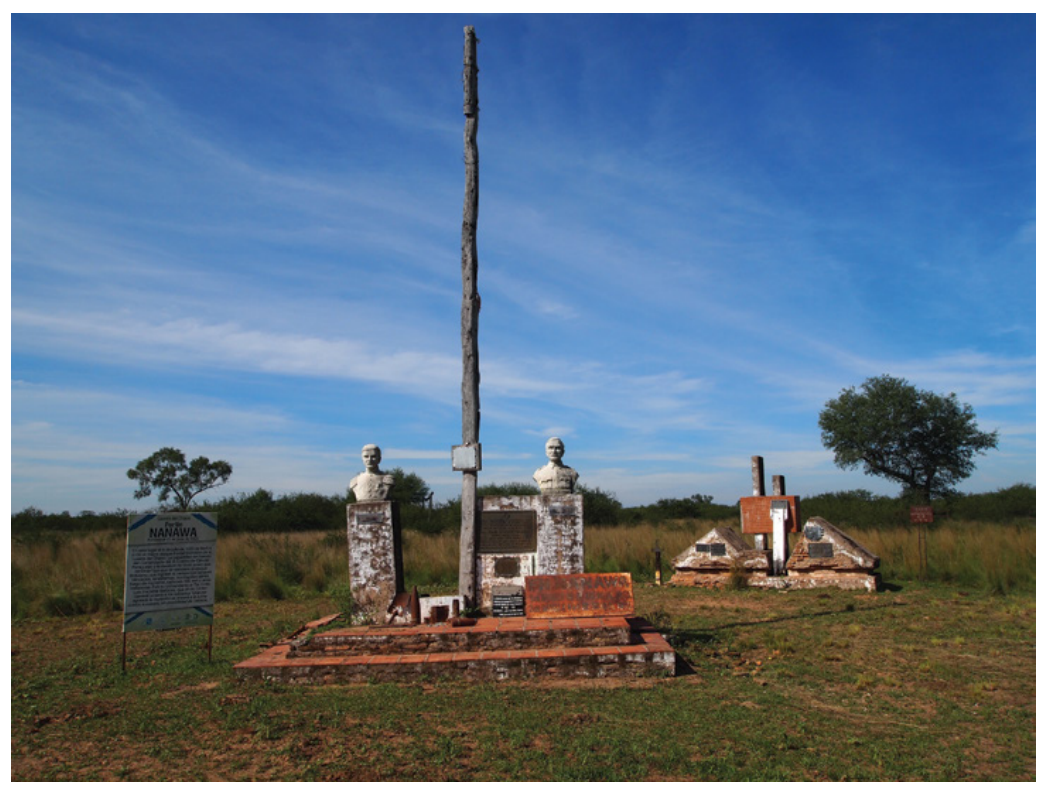

Figure 5.23 Neglected monolito inside Fortín Nanawa (Source: author). 
to the monolito and the small island of trees behind it and heads towards a cleared path leading into the bush. After about a kilometre the farmer stops. In a clearing, surrounded by high grass, lie the rusty remains of a tank. According to Alejandro de Quesada and Philip Jowett, Bolivia employed two Carden Lloyd MK VIB tankettes and three Vickers 6 ton MK E tanks in the Chaco War (two type A and one type B; Quesada with Jowett 2011, 34-5). ${ }^{5}$ Together with the flamethrowers, the tanks were weapons unknown to the Paraguayan soldier. The tanks' 'terrifying presence' and roaring noise, and the flames and smoke caused by the flamethrowers, created an 'infernal scene' that intimidated the Paraguayans, whose positions benefited from only minor anti-tank defences (Espínola 1960, 72-100).

Both sides promptly realised that despite their frightening appearance, tanks were useless in the Chaco. Although inadequate attack strategies administered by General Kundt and the drivers' inexperience played a decisive role in the tanks' failure (Espínola 1960, 100), the difficulty of the Chaco terrain and the extreme climate ultimately resulted in a Bolivian defeat as the crew was allegedly forced to leave the machine to avoid suffocation from heat (Quesada with Jowett 2011, 34). In his personal account of the Second Battle of Nanawa, Paraguayan General Jenaro Espínola notes that of the two tanks that approached the Paraguayan defences within $60 \mathrm{~m}$, only one escaped their angry fire. The other one was taken down first by Paraguayan artillery and then by a mine before it was further bombed by Bolivian forces to avoid its capture and reuse by the enemy. The Paraguayans managed to remove only the turret - the tank's 'symbol of power' - and put it on display in the military museum in Asunción (Espínola 1960, 72). ${ }^{6}$ 'The stopped tank, fatally wounded', writes Espínola, 'having been contained in its advance, stayed in that place forever' (Espínola 1960, 70).

Today, the remains of the tank are indeed still sitting where they were left more than 80 years ago. Surrounded by high grass and dense forest, and gleaming in the midday sun, the tank's metal frame looks out of place in the Chaco bush. However, it is this strangely uncomfortable presence that makes it such a powerful material marker not only of a failed military manoeuvre but also of the absurdity of the Chaco military campaign as a whole. In a similar example from Communist Ethiopia, González-Ruibal states that 'Astonishingly quick[ly], tanks become archaeological artefacts, monuments to the failures of modernity' (González-Ruibal 2006a, 181). But in their collective distribution, these tanks are also much more than just artefacts. They are part of a tangible record of industrialised warfare as Anthropocene hyperobject, their global archaeological distribution reflecting the thick, sticky, persistent and non-localised nature of modern conflict and its aftermath. 


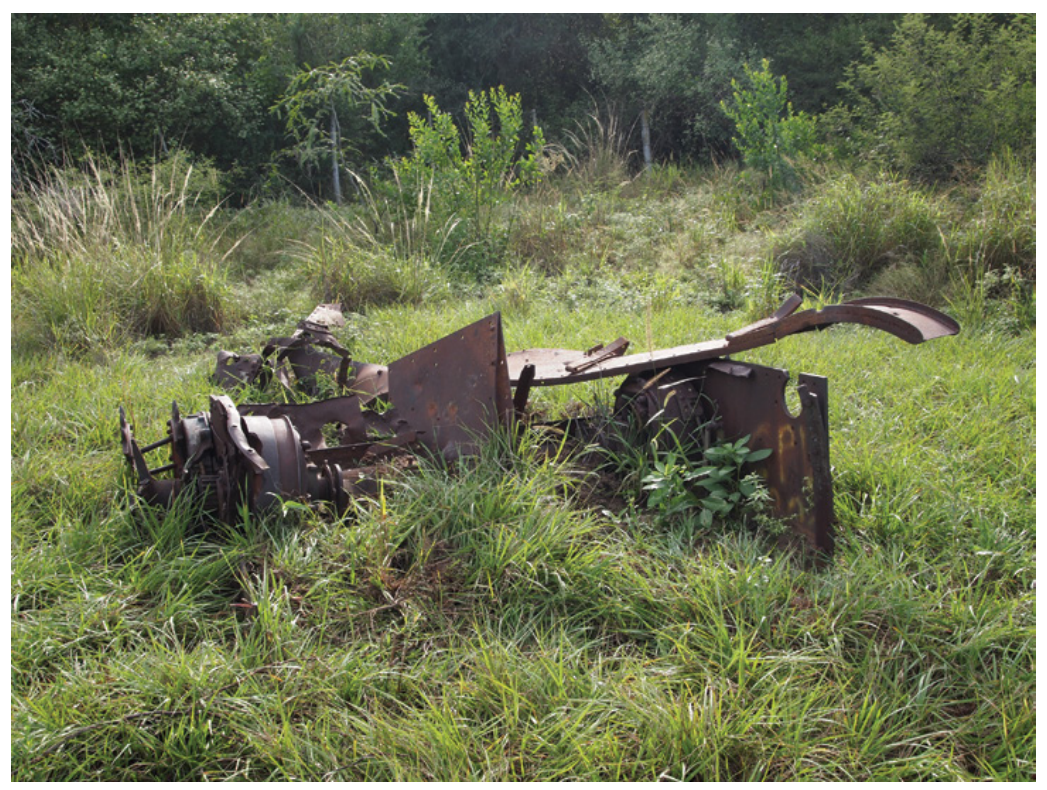

Figure 5.24 Remains of Bolivian tank inside Fortín Nanawa (Source: author).

A further kilometre past the tank appears another clearing with a large tuna cactus and an unassuming wooden signpost that reads 'Punta Mojoli' (also known as Isla Capitán Cristaldo). The simplicity of the board stands in stark contrast with the magnitude of horror that unfolded here in 1933 and which, supposedly, left men standing knee-deep in blood in the trenches (Paraguayan soldier of the RC1 Valois Rivarola military division in Pozo Colorado, pers. comm.). Situated around $2 \mathrm{~km}$ from the centre of the fortín, Punta Mojoli was named after Paraguayan Lieutenant Anibal Mojoli, who led a ferocious battle here against an advancing enemy. The site was later renamed after Captain Carlos Cristaldo, who was fatally wounded in the defence of the surrounding trenches (Espínola 1960, 21-2).

Over the years the landowners have deposited various kinds of scattered war debris - including bits of barbed wire, spent cartridges and mortar splinters - at the base of the signpost. 'For the rest', they repeat, 'we try to leave the trenches alone. You can still find all kinds of things in the forest. We don't touch them' (estancia owners, pers. comm.). Indeed, the forest surrounding the clearing is littered with war detritus - physical reminders of modernity gone awry. Pieces of shrapnel, part of a mortar, the shield of a scabbard, spent cartridges sticking out of the ground: 


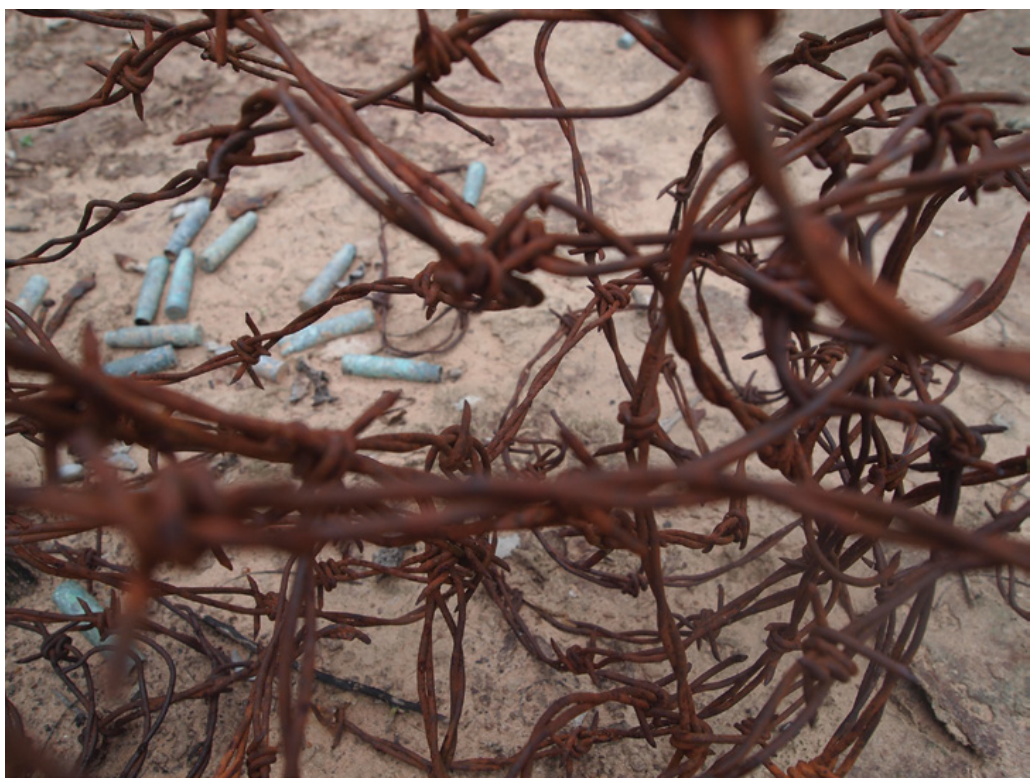

Figure 5.25 Remnants of modernity inside Fortín Nanawa (Source: author).

objects entangled with natural elements and human memories, shaping 'the afterlife of rubble' (Gordillo 2014). Rusty strands of barbed wire, a belt buckle and the crushed remains of what seems to have been a caramayola, buttons, isolated shoe soles and an empty medicine bottle and vial all hint at the thousands of personal tragedies that once unfolded inside the anonymity of this mechanised war.

Staging an armed conflict in a landscape that is covered in islands of impermeable scrubland presented the belligerent armies with both advantages and disadvantages. In the Chaco, forests offered material for the fortification of positions, gave protection and cover, and provided defensive obstacles and observation points. Yet they also hindered troop movement and management, and rendered artillery and infantry fire, as well as the use of tanks, ineffective in particularly dense parts of the bush (Belaieff 1934, 19-20; see also Winters et al. 2001b). The impact of the Chaco forest on warfare and soldiers was not purely tactical but also psychological. As Lisa Brady reminds us, 'war is not only fought on the ground' but 'also in the hearts and minds of those involved' (Brady 2005, 424). For the soldiers in the Chaco War, who were used to either the vast openness of the Andes or the lush fields of eastern Paraguay, the bush 
was a threatening labyrinth that spread a feeling of unease and entrapment on both sides. Céspedes writes that:

Everything is mysterious in the forest. There is a distressing presence and you never know whether it's close or far but it's there, tangled up in the underbrush and hidden in the very woods we were walking through ... Here we [the Bolivians and the Paraguayans] find ourselves in the same unit, without separation, locked in the same forest like two enemies in a dark room (Céspedes 1975, 56).

Today, Nanawa's forest emits an eerie air of abandonment. An overgrown Paraguayan trench winds its way through the underbrush, the riflemen's firing positions still clearly discernible at a regular interval by circular assemblages of spent cartridges and Mauser clips (cf. Prieto and Vila 2014, 333-9). How many lives did these bullets take and how many men were saved by tree trunks that took the deadly impact instead? Indeed, trees often revealed a ghastly sight in the Chaco. Crippled from the impact of bombs and heavy ammunition, their remaining branches heavy with human limbs and bodies (Farcau 1996, 134), they recalled the almost surreal sights of utter destruction from the First World War's Western Front, where they 'are no longer nature's trees, but artefactual objects - trunks without branches and leaves. Even more, there are forests of trunks - a testimony to previous forests, now destroyed, wounded and mutilated' (Beurier 2004, 115).

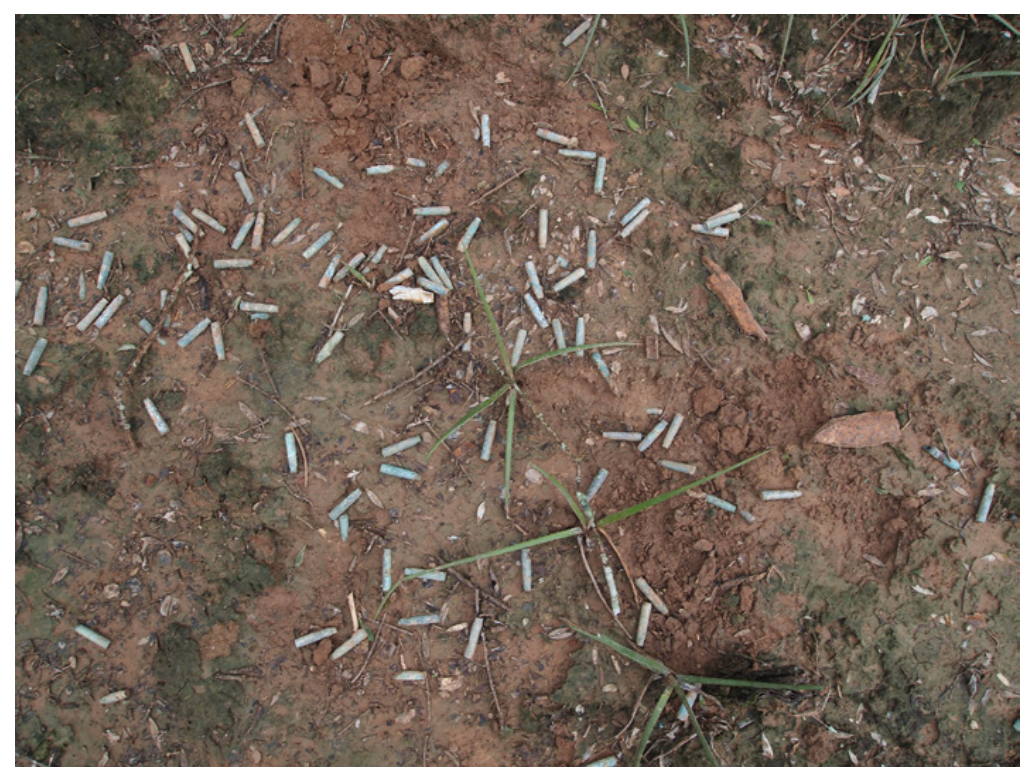

Figure 5.26 Spent bullet cases and mortar fragments on the surface marking one of the riflemen's firing positions (Source: author). 
Not far from the Paraguayan trench, a tree carries the physical scars of modern technology enforcing itself upon nature. Pierced into its trunk are two pieces of exploded artillery that shine bright against the monotonous brownish grey of the bark. Over the years the tree has grown around the metal, encasing the deadly pieces of supermodernity and becoming one with it. Beyond its material metaphor of precisely the entangled nature-cultures on which I focus here, it leaves us with questions of who fired the shell and who it was aimed at. If only trees could speak! In many ways they can, if we are attuned to their language. Trees are not mere bystanders but living entities that here form part of both the archaeological record and the persistent Anthropocene heritage of industrialised warfare. Chantal Summerfield has argued elsewhere that trees represent 'a unique kind of war heritage' (Summerfield 2012, 162). This hybrid tree-artillery shell bears physical witness to the ways in which war material is globally hyper-distributed and non-localised, fused into the very nature which this war was at least partially waged against.

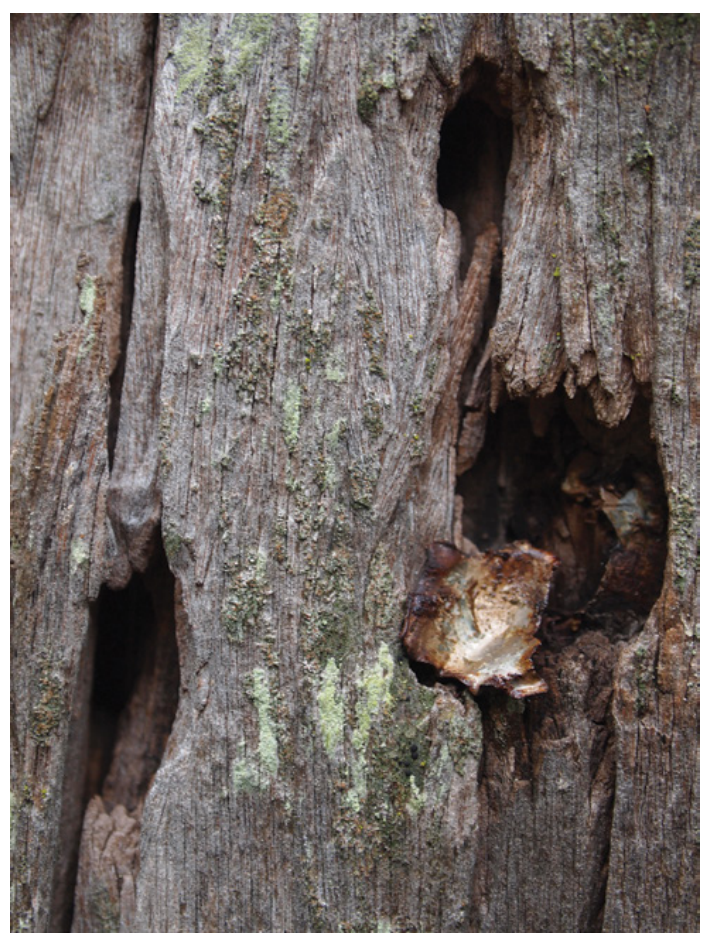

Figure 5.27 Metal splinter inside tree trunk (Source: author). 
In the Chaco, the scarred tree is both a witness and a memorial to the horrors of war. Yet, in contrast to human-made stone war memorials, which according to Olsen 'are the result of conscious inscribing practices, manifesting a "will to remember"' and whose 'very solidity and enduring nature ... have throughout history offered their competence as a memory-storing device to humans' (Olsen 2013, 125), the pierced tree in Nanawa can be considered an involuntary memorial (see Summerfield 2012). The scene further recalls the trenches in Ypres and the trees around them that were reduced to rotting trunks after the horrors of the First World War were unleashed upon them (Saunders 2014, 33). Yet while in Ypres visitors honour humanity's (and nature's) sacrifices by attaching remembrance poppies to the stumps, in Nanawa the mutilated trees stand forgotten deep inside the Chaco bush. One can only guess how many soldiers lie buried next to them in the immense anonymous grave of the Chaco - human bones entangled for eternity with tree roots and the material traces of supermodernity, an archaeological artefact of conflict as Anthropocene hyperobject.

The Chaco bush is eerily quiet at midday. There is a sense of time standing still. Yet as Barbara Bender says, 'landscapes, like time, never stand still' (Bender 2002, 103). Nature's clock keeps ticking, undisturbed by the human misery that once unfolded amid the foliage. The physical remnants of war appear ruined and abandoned. However, appearances are deceitful. Fortín Nanawa is not an empty place, nor is its material culture composed of inert relics of a detached past. On the contrary, the ruins and persistent heritage of the Chaco War 'collapse temporalities' (Merewether 1997, 25) and actively shape the present, which 'basically consists of a palimpsest of all durations of the past that have become recorded in matter' (Olivier 2001, 66).

In the years leading up to the war, both humans and nature were mobilised in an effort to militarise the region. Owing to the Chaco's isolated location, the lack of funds and a basic and unreliable road network, both armies relied heavily on local resources, and soldiers cut down thousands of trees to build trenches, bunkers, lookouts and camps. Today, the archaeologist interested in the physical remains of the war is faced with similar challenges. The sites are for the most part located in remote locations and access is often hampered by the Chaco's thick forest. This has resulted in the lack of documentation of Chaco War sites and their general neglect as national heritage sites. Approaching the Chaco War through the study of its material remains allows us to retrieve some of the lost information on the military structures. More importantly, by focusing on the ruins and rubbish of modernity, it enables us to capture those fleeting personal moments in matter. 
During my fieldwork I identified three main types of Chaco War sites within the physical boundaries of the Chaco region. Although fortines or military outposts are the predominant and defining sites of the Chaco War, a multitude of other sites connected to an aspect of the war exist. This chapter examined two examples, Puerto Casado and Km 145. Both serve as proof of the importance of the railway for the Paraguayan military during the war. However, Puerto Casado and the train line did not merely fulfil a practical purpose of transporting men and equipment into the heart of the bush but also acted as a gateway into an uncertain future. Once they arrived at $\mathrm{Km} \mathrm{145,} \mathrm{the} \mathrm{soldiers} \mathrm{could} \mathrm{not} \mathrm{escape} \mathrm{the}$ harsh realities of the war and the Chaco scrubland. Connected as they are by the ruined remains of the defunct train line and the soldiers' physical and psychological journey into the unknown, Puerto Casado and Km 145 could not differ more in their present-day state. The tannin factory and its train station, which once represented industrial progress, now lie in ruins and the town's past grandeur is but a memory. In contrast, and owing to the Mennonites' continuous desire to show their dominion over nature, Km 145's link to the horrors of war has been disguised by photographs of a successful Mennonite colonisation on the restored walls of the original train station building. The discursive reworking and 'heritagisation' of these persistent traces in the present speak to the ongoing ways in which objects, places and people collaborate in worlding processes in the Chaco.

Despite the Mennonites' best efforts at Km 145, nature has been slowly but surely reclaiming the remnants of modernity left in the landscape. In the process it shows no reverence for the physical remains of military outposts. Although human action caused the fortines to become ruins in the first place (through bombardment, abandonment, etc.), the continuous process of ruination is not dependent on human agency (Lucas 2013, 193). The collapsed bunkers of Toledo and the remains of the trenches at Boquerón, for instance, have become breeding grounds for numerous animals, and encourage the growth of a great variety of plants. These ruins thus represent a 'volatile mix of hybrid forces' that blur the boundaries between human and non-human elements (Lucas 2013, 196-7). Here the Chaco's role in collaborating with a range of human and non-human agents in the unmaking of these Anthropocene hyperobjects, even while it engages in the making of new worlds, is tangibly manifested.

Moreover, the 'ruinscapes' of the Chaco War are not the physical manifestations of a past grandeur, nor do they evoke romantic notions of nostalgia and melancholia (Yablon 2009, 21). On the contrary, they 
are scars in the landscape that conjure up feelings of despondency about the 'failures of modernity' (González-Ruibal 2006a, 2010) and the futility of this 'stupid war' (Céspedes 1975). They are the physical traces of the Chaco's militarisation - a process that history books generally recount as a mere logistical 'terrain and tactics' (Woodward 2005, 722) operation in which humans appropriate nature to fulfil their needs (O'Sullivan and Miller 1983; Winters et al. 2001a). This approach presents the interaction between humans and non-humans as something mechanical and casts nature in a static and submissive role. Taking a critical archaeological approach to the study of the Chaco's militarised landscapes and their afterlives instead allows us to unveil the fluid entanglements of people and things that make up the material as well as the emotional memories of the war within the present. The conflict landscapes of the Chaco War are thus 'not a record but a recording' (Bender 2002, 103) as the 'past is not passed but still has action' (Witmore 2007, 556; see also Olivier 2004, 2011). Not only is archaeological practice part of that action in the present but it also has the power to shape the future. These relations between material pasts, presents and futures form the subject of my final chapter.

\section{Notes}

1. For a detailed construction manual of Paraguayan fortifications in the Chaco, see Belaieff 1934.

2. The Mennonites named the station after the Norwegian-born Chaco pioneer and Mennonite sympathiser Fred Engen (Barreto 1985, 475).

3. Every year on 12 June Paraguayans celebrate Chaco Armistice Day, an event that typically includes a military procession through the capital and festivities in the Chaco. During my visit in 2013 Chaco Armistice Day was chosen as a suitable date for the official inauguration of a partially restored Fortín Isla Po'í. High-profile guests present were the Minister of Defence, the Minister of Culture, army officials, family members of both Marshal Estigarribia and war pilot Walter Gwynn, as well as the then President of the Republic, Don Luis Federico Franco Gómez. The remaining spectators were for the most part older Mennonites, Mennonite secondary school students, members of the Latino Paraguayan community and a small number of indigenous people. Interestingly, according to Hans Fast, the presence of indigenous families merely served the agenda of politicians eager to show that the indigenous community was included in national events (pers. comm.).

4. The Chaco War was the first Latin American conflict that saw the use of aircraft. The first aerial attack was carried out by the Bolivians against Fortín Isla Po'í on 12 June 1933. Paraguay responded by sending their own aircraft into the sky, resulting in the death of one of their pilots, Lieutenant Walter Gwynn (Hagedorn and Sapienza 1997, 76-7).

5. In his personal account, Paraguayan General Jenaro Espínola mentions the use of four tanks in Nanawa although he does not specify their make (Espínola 1960, 100).

6. According to Alejandro de Quesada and Philip Jowett the turret has since been handed back to Bolivia, where it is now on display alongside a further returned tank at the Colegio Militar del Ejercito Cnl Gualberto Villarroel in La Paz (Quesada with Jowett 2011, 35). 


\section{6}

\section{Anthropocene hyperobjects: Persistent heritages beyond the Chaco War}

On the first floor of the Círculo de Oficiales Retirados de las Fuerzas Armadas de la Nación (Circle of Retired National Military Forces Officials) in Asunción, hidden away from visitors, lies the Salón de Bronce (Bronze Hall), a high-ceilinged room which, as its name suggests, is covered in a variety of bronze objects, all related to the Chaco War. Items include a representation of the common Guaraní soldier-agriculturalist, a bronze bust of Marshal Estigarribia and a small bronze coffin of the soldado desconocido - the 'unknown soldier' - which is said to contain the ashes of an unidentified number of men who fell in combat. However, the most visually striking features of the hall are the bronze cast letters that cover the entirety of its walls. After the war, the Paraguayan military recovered 831 $\mathrm{kg}$ of empty bullet cases and shells from the battlefields (Gómez Silgueira 2012). The metal debris was melted down and used to create more than 200,000 letters making up the names of 8,500 Paraguayan military officials who fought in the conflict (Pusineri 2007, 77).

Although the Salón de Bronce was declared a national monument in 1974, the letter-casting process took three years and was finally completed in 1977 (Anonymous 2011). In an ironic turn, the bullets that claimed the lives of many of those military officials were now, although in a recycled and altered form, immortalising their victims in a peculiar twist on trench art. Like these bullets, many of the other material remains of the Chaco War form a persistent and ongoing material legacy of its battles, but have also been revisited, reworked and recycled to create new meanings and new material worlds in the present. 


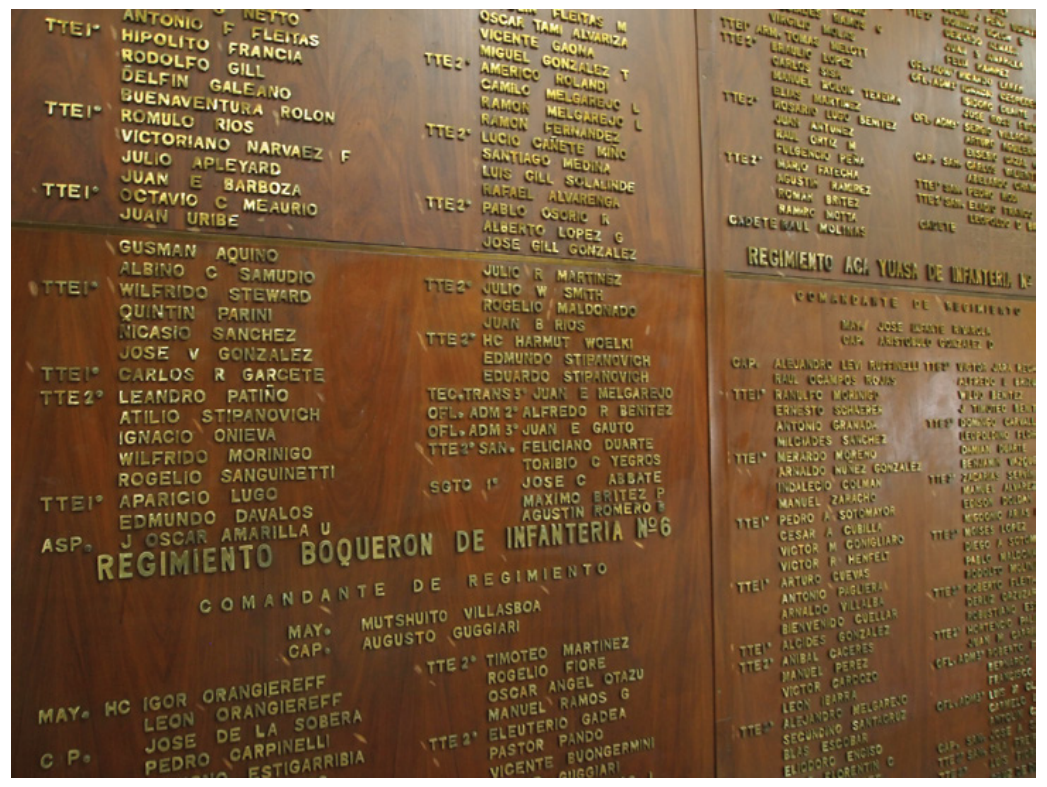

Figure 6.1 Detail from one of the walls in the Salón de Bronce (Source: author).

\section{Material memories: Pasts in the present}

Almost a century after the last bullet was fired, the Chaco and its war remain a significant part of contemporary national discourse and integral to the nation-building apparatus in Paraguay. Yet the current celebratory engagement with the predominantly heroic figure of the Paraguayan soldier-agriculturalist stands in stark contrast with veterans' written accounts of the war and the material evidence, which not only highlight the destructive forces at work during times of armed conflict but also remind us that the Chaco War was not fought by faceless military personnel but by sentient human beings from various cultural as well as non-military backgrounds. Nonetheless, since the end of the war, both countries have erected a large number of memorials dedicated primarily to the soldiers fallen in combat. Across the border, the bronze statue of an unknown dead soldier lying face down in a trench, still holding his rifle ready to defend his patria, has been erected in a street in Villamontes, Bolivia, in memory of the men who lost their lives in the Battle of Boquerón. In Paraguay, the heroic image of the brave and loyal soldier has been carved into bronze and stone across the country. Arguably the most famous and pompous of 
the Paraguayan war memorials is the Panteón de los Héroes (Pantheon to the Heroes) in the centre of downtown Asunción, originally designed as a chapel to the Virgin of Asunción in 1864. Work on the building came to a halt during the War of the Triple Alliance. It was only completed in 1936 - one year after the end of the Chaco War - and given its new and current role as a mausoleum that houses the human remains of a number of Paraguay's most famous leaders as well as those of Marshal Estigarribia and two unnamed soldiers from the Chaco War. Both Paraguay and Bolivia have also seen the establishment of a number of museums dedicated to an often celebratory military history of the war, including the Museo Militar inside the Ministerio de la Defensa Nacional in Asunción, the Museo Fortín Boquerón in the Chaco and the Museo Histórico Gral. Div. Enrique Duarte Alder in Paraguarí, and the Museo Histórico Militar Héroes del Chaco located in Villamontes, Bolivia.

Commemorative acts have not been limited to the erection of memorials and museums. In Paraguay two national holidays are now related to the Chaco War, with 29 September marking the Paraguayan victory at Boquerón, and Chaco Armistice Day observed on 12 June. On both occasions, the military and schools in Asunción and Colonia Fernheim

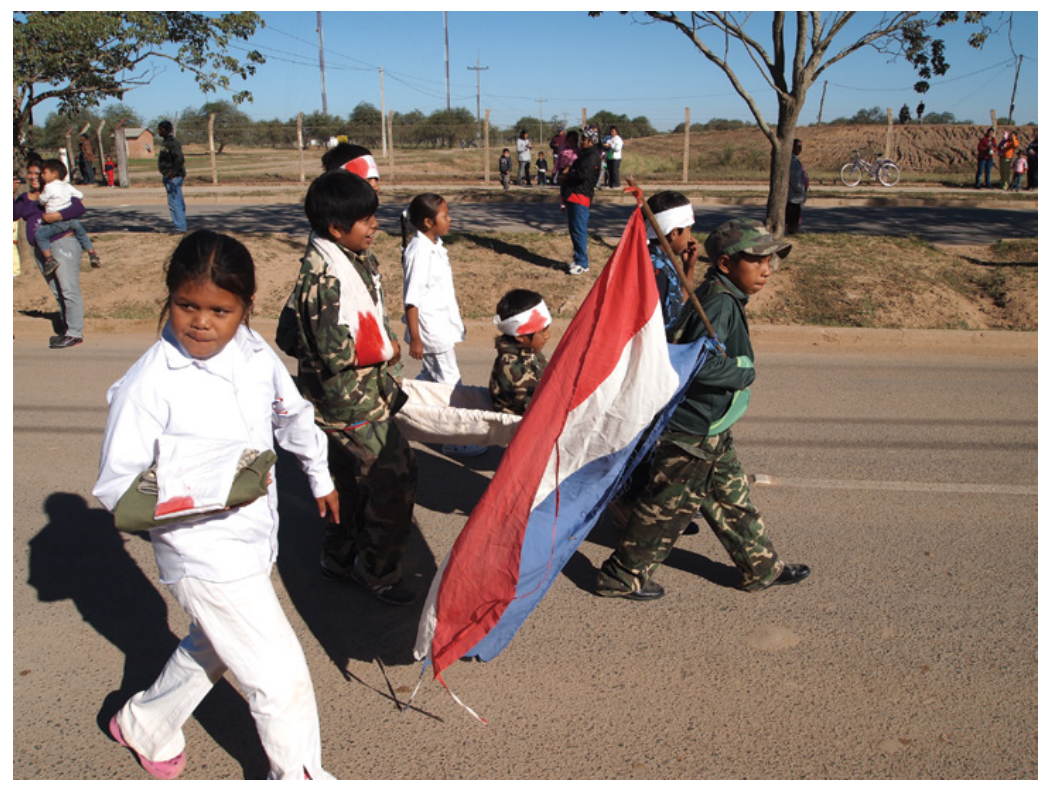

Figure 6.2 Children re-enacting scenes from the Chaco War during the Chaco Armistice Day parade in Filadelfia, Colonia Fernheim on 12 June 2011 (Source: author). 
organise parades that include military marches and children dressed as wounded soldiers and nurses from the Chaco War. Among the communities of Fernheim this is a much-anticipated and celebratory annual event with people from different ethnic backgrounds as well as military personnel lining the music-filled main street of Filadelfia and waving Paraguayan (and occasional Bolivian) flags at the passing procession.

In contrast to these colourful annual memorials to the dead, which suggest an active and official engagement with memorialisation of the Chaco War, the war cemeteries - which in other industrialised conflicts have formed the focus for intensive state-led memorialisation practices seem to be scarce and often hidden away in the depths of the bush. Erosion, agricultural and urban expansion, and the lack of preservation efforts have all contributed to the disappearance of countless war graves. Nonetheless, a small number of sites that once served as burial grounds for fallen soldiers have been restored by the local authorities in the Mennonite colonies. One example is Trébol cemetery, situated at the outskirts of Filadelfia in Colonia Fernheim, and others are the two Fortín Boquerón cemeteries, discussed in Chapter 5. Trébol cemetery, which is maintained by the colony and believed to hold the remains of Paraguayan soldiers who passed through Trébol on their way from the military headquarters in Isla Po'í to Fortín Toledo, has a manicured appearance. The Mennonites have erected neatly aligned rows of simple white wooden crosses as symbolic grave markers for the soldiers who lost their lives here.

An unknown number of cemeteries with original wooden crosses from the war have survived in the Chaco. However, as they are frequently located inside dense bush on private properties, their existence and location are often only known to ranch owners and their employees. One such example is Fortín Gondra, situated on farmland within Colonia Menno. Gondra served as a battlefield in 1933 and now houses a small privately run museum containing all kinds of war remains found in the surrounding area - from rifles to military cooking equipment and human skulls. A short walk from the tiny brick building inside the surrounding thicket lies a hidden cemetery. A small number of complete brown wooden crosses peek through the thorny underbrush with the broken remains of more crosses scattered on the ground. Interestingly, a number of candles have been deposited at the base of some of the crosses, suggesting that local people are still aware of the cemetery's existence despite its remote and concealed location. The candles also serve as evidence for people's continuous personal acts of commemoration for the fallen soldiers and the ways such material presences speak to ongoing private and collective memory practices. 


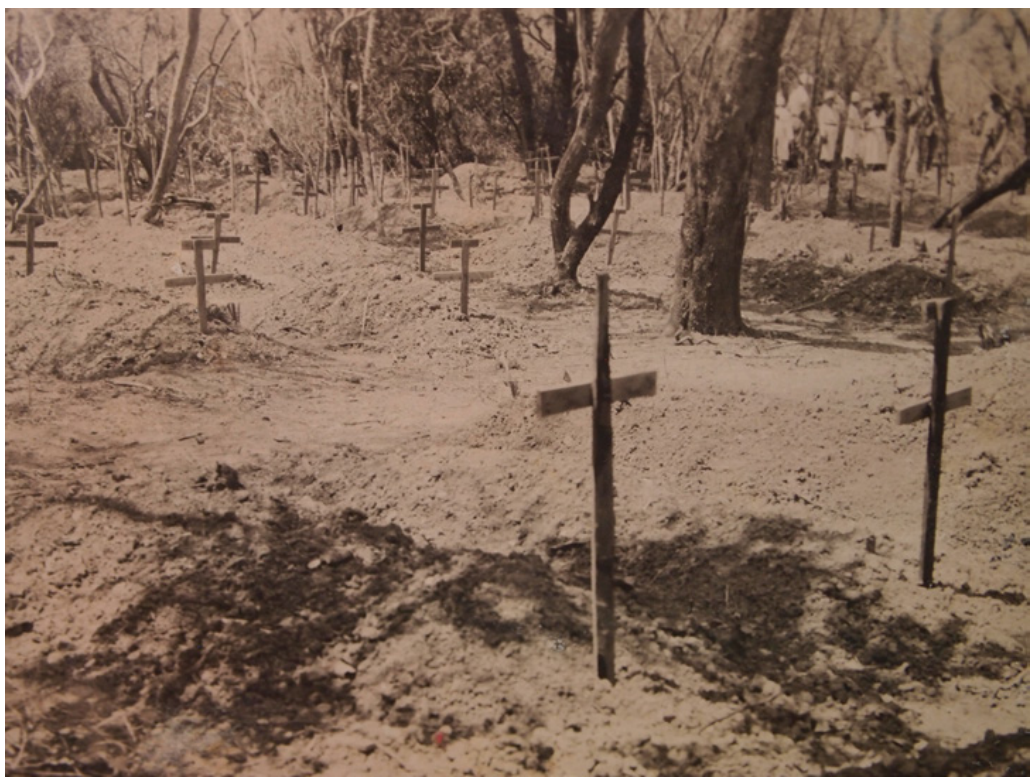

Figure 6.3 Military cemetery during the war. Location unknown (Courtesy of AIHMM).

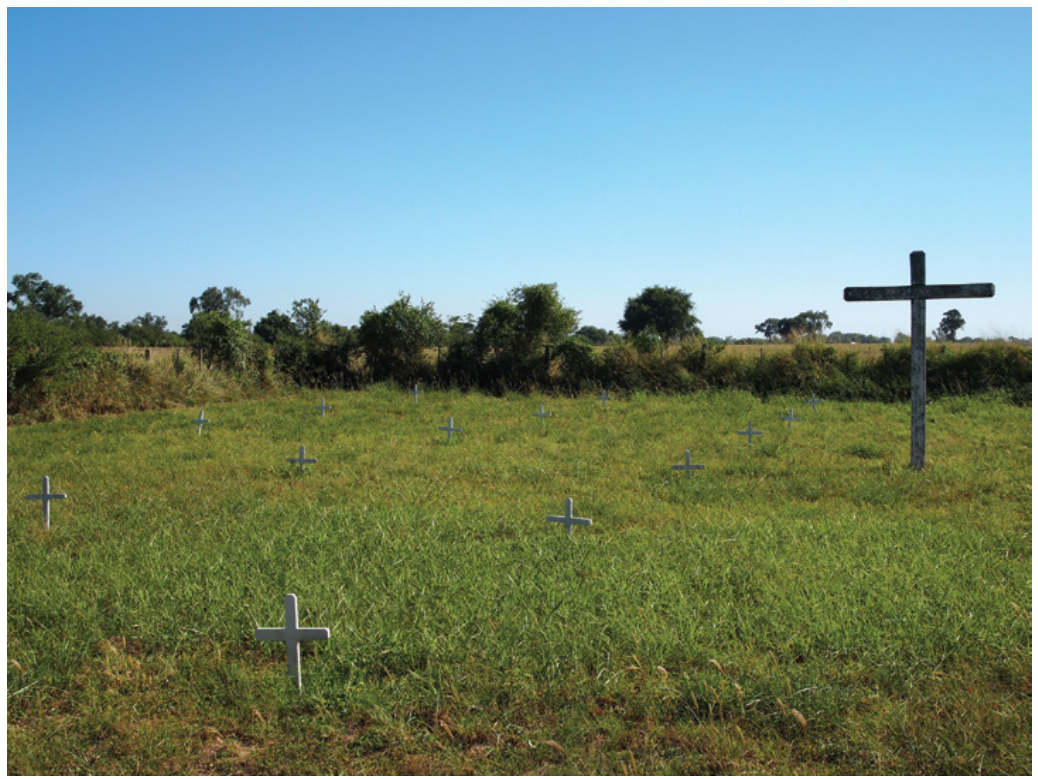

Figure 6.4 Trébol cemetery (Source: author). 


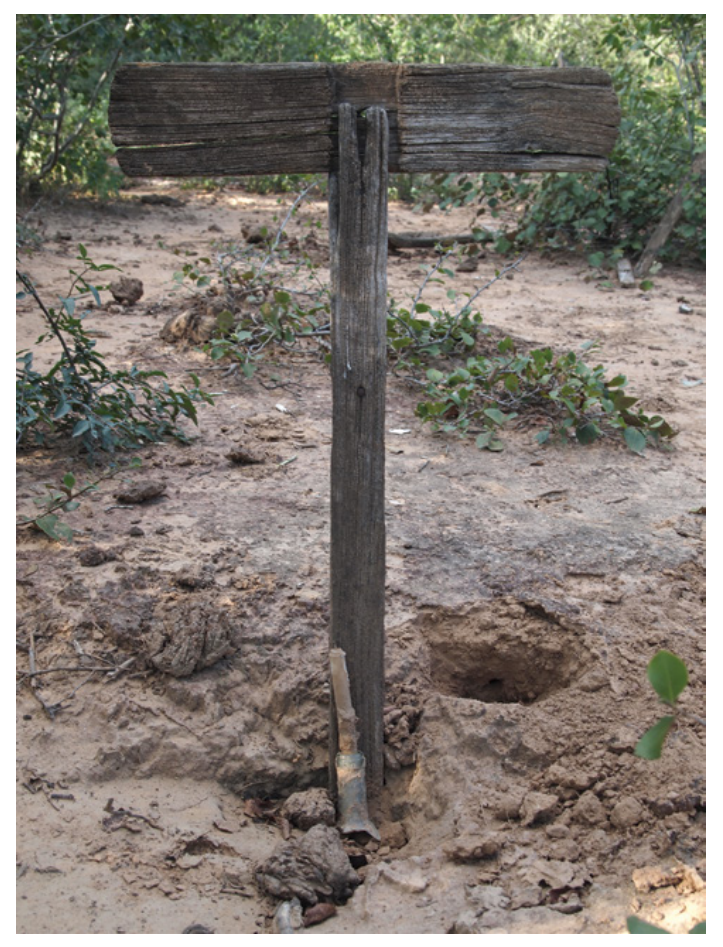

Figure 6.5 Remains of an original cross with a candle placed at its base, hidden in the bush at Fortín Gondra (Source: author).

Even more striking, perhaps, and located at a short distance from the cemetery, lies an alleged mass grave that is believed to be $100 \mathrm{~m}$ long and to hold the remains of 1,050 soldiers (Mennonite estancia owner, pers. comm.). An elevation in the ground and the remains of a large wooden cross and metal debris are indeed indicative of a human-made feature. Although the presence of a mass grave cannot be verified without intensive archaeological investigation of the site, it nonetheless seems to be embedded within present local beliefs and practices. These are exemplified by a small cardboard cross left at the base of the wooden cross and found during the site survey in 2011. Both the fact that it was the rainy season and the landowner's assurance that he did not place it there suggest that the cross was the product of recent commemorative activity. Arguably insignificant in design and material, the cardboard cross is testimony to people's ongoing awareness of and engagement with the site. Albeit seemingly primarily relevant on a local level, the war graves and their significance go far beyond the physical boundaries of the Chaco. 


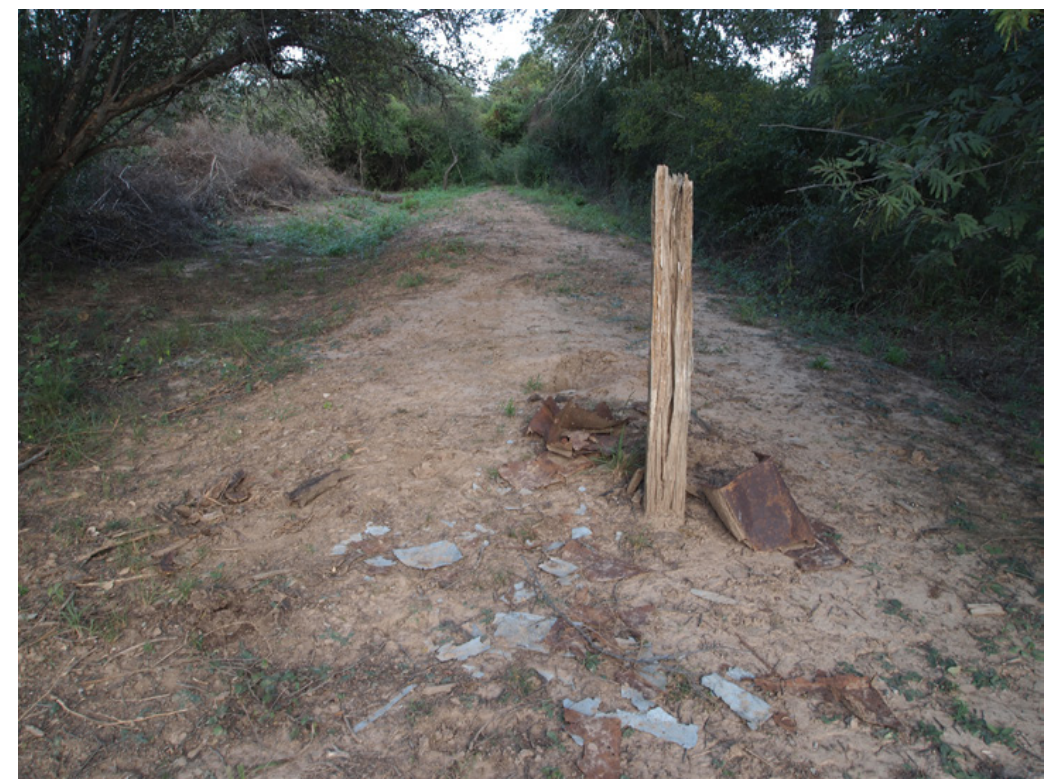

Figure 6.6a Suspected mass grave with remains of wooden cross and metal debris in Fortín Gondra (Source: author).

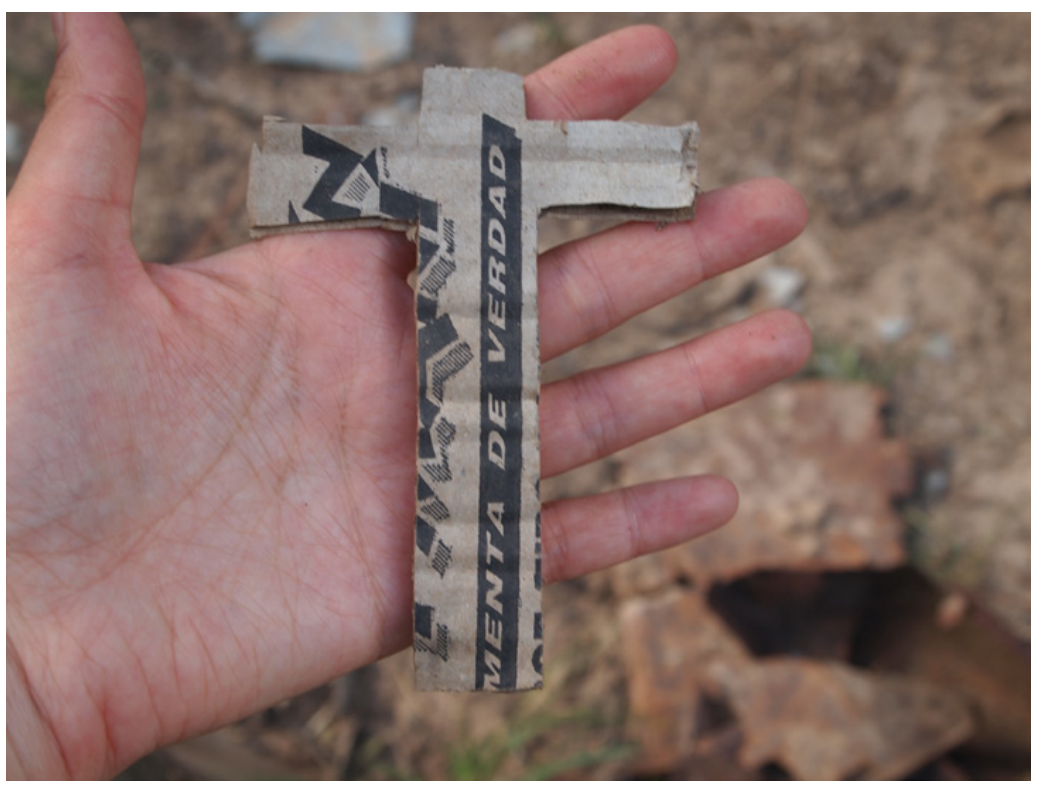

Figure 6.6b Cardboard cross found at the base of the wooden cross remains in 2011 (Source: author). 
Acting as final resting places of soldiers who died from bullets largely made in European and US factories, the cemeteries form a material record of entangled globalised networks across time and space and serve as a poignant example of conflict as both a massively distributed and persistent Anthropocene hyperobject.

Contemporary heritagisation practices represent another way in which the material remains of the war are recycled and repurposed in the present. Archaeology is not independent of the materials it produces, and the social and political uses which the pasts it creates are put to. This has been demonstrated through the decisive impact which the archaeological work recounted in Chapter 5 has had on the future of Fortín Nanawa in particular. After the release of information relating to the archaeological investigation of the site in 2013, Paraguay's National Ministry of Culture organised a press conference to disclose my immediate findings in front of a room filled with representatives of national newspapers, radio and television stations. Although interest focused on a potential live bomb that was discovered just outside the Paraguayan trench excavated, the press conference was the first ever attempt to open a national dialogue on the archaeology of Chaco War sites (Anonymous 2013a, Anonymous 2013b). Remarkably, the discussion moved beyond words and into concrete action on 9 August 2013 when, based on my preliminary work with the assistance of Miss Benítez from the Ministry of Culture, the Secretaría Nacional de Cultura's General Directorate of Cultural Heritage decided to:

Declare as protected archaeological site, in accordance with Law 946/82 on 'The Protection of Cultural Goods', the site of Fortin Nanawa, from the Chaco War (1932-1935), Department of Presidente Hayes, Paraguayan Chaco; comprising the area between the geographical coordinates $23^{\circ} 30^{\prime} 0^{\prime \prime}$ and $59^{\circ} 46^{\prime} 0^{\prime \prime}$ and its immediate surroundings in which are located trenches, campsite activity, metal material (war matériel) and soldiers' uniforms corresponding to battles that took place on the ground, and which are of great historical and cultural value (Resolución No. 30/2013).

The declaration has led directly to a renewed collective interest in the site, which reflects the role of recent heritagisation processes in the valorisation of the material remains of the Chaco War in contemporary nation-building practices. Following the media coverage of the excavation and the declaration as a protected archaeological site, Fortín Nanawa has undergone a major material transformation, which includes the erection of new war memorials, the reconstruction of a section of trenches and a 
bunker, and the addition of interpretative signage and a small museum that includes parts of a Bolivian aeroplane. Benítez de Casanova reports that this work has been led by military and departmental officials without the involvement of archaeologists or other heritage professionals.

On 24 November 2015 the Paraguayan Senate introduced Law No. 5528, creating 'the National Commission for the value enhancement and promotion/development of Chaco War historical sites, 1932-1935' to 'recognise the value of the trenches, forts, gullies, roads, battlefields, unmarked graves, promoting the historical, archaeological and tourist aspects' of Chaco War sites (article 2 of law no. 5528/2015). Not long after its initiation and in an effort to boost the tourism industry, the National Commission developed its 'Knowing the Ruta Chaco Boreal' tour, a multi-day guided visit to various Chaco War sites in the Central Chaco. This has opened the sites to new visitors, and has created the need for increased interpretive infrastructure, promoting renewed interest in the history of the war. Nonetheless, the interpretation of the sites rarely moves beyond nationalistic celebration, instead relying on familiar tropes of the heroic Paraguayan soldier battling both Bolivians and the Chaco landscape to claim victory on behalf of the homeland.

Heritagisation processes are not, however, permanent, and actively visited and maintained sites may also subsequently experience abandonment and neglect. In 2013, the Mennonite-owned cooperative Chortitzer Ldta helped fund and lead on the second restoration project of Fortín Isla Po'í, which was inaugurated in the presence of the then President of Paraguay, Federico Franco, as well as members of local indigenous, Mennonite and Latino communities. Reconstructed buildings from the first round of restorations had been painted and restored, a number of memorials had been added and the overgrown path to the even more overgrown cemetery had been weeded and made accessible. The cemetery's small wooden crosses had also been repainted and were once again visible amid freshly mowed shrubs. Hans, my Mennonite guide, seemed sceptical, though. Pointing at the sawn-off quebracho poles of what was once Estigarribia's commanding structure, he commented with a sneer that 'People have probably used them for a barbecue'. Having previously been restored and fallen into disrepair again, Fortín Isla Po'í, like all Chaco War sites, thus faces an uncertain future. The president of the Mennonite cooperative, however, seemed hopeful that 'Isla Po'í will be a place of friendships and not enmities; that the site remains restored and that it will become a place where different cultures meet' (comment made during a speech on 12 June 2013). 


\section{Conflict as hyperobject in and of the Anthropocene}

Through this account of the material culture and landscapes of the Chaco War, I have argued that twentieth-century industrialised warfare might be understood as a leitmotif for the Anthropocene, emblematic of the complex and often hostile extractive entanglements of people, things and places through which its parallel worlds are made, unmade and remade. As South America's first 'modern' conflict, which in many ways anticipated and prefigured later global conflicts, the Chaco War shows how the industrialised wars of the last century brought about significant changes in humanenvironmental transformations. I have suggested that twentieth-century industrialised warfare should be understood itself as a form of Anthropocene hyperobject. The material and discursive legacies of the Chaco War exemplify how modern industrialised warfare is massively distributed in time and space, viscous, inter-objective and non-localised. Here I explore each of these characteristics of conflict and its associated matériel in turn, drawing on my summary of Morton's (2013) definition of hyperobjects discussed in the introduction of this book to amplify this point.

\section{'Nonlocal' (massively distributed in time and space, sensed but not always able to be 'seen')}

Twentieth-century conflict is massively distributed: spatially because such wars are geographically widespread and fought across multiple fronts, and temporally because they are recursive and have complex afterlives, disappearing and reappearing and, as they do so, remaking presents and futures. In undertaking an archaeology of twentieth-century conflict, one could focus on one particular object or site but each of those will always refer to a different thing or place and expose the wider implications of industrialised conflict. A single spent bullet case lying in the Chaco scrub already encompasses all the social, political, economic, technological and ideological baggage of its time and place of manufacture while simultaneously representing a very specific human tragedy with the life it took in the bush. In this case the Chaco War was fought with leftover weapons and bullets produced in European and US factories for use in the First World War in entirely different political, social and environmental contexts as part of an emerging globalised military-industrial complex. These multiple, inter-objective references which spiral out from individual objects are not self-evident or able to be accounted for through a focus on local contexts but require a perspective that takes a much longer view of time and space. 
During the course of the Chaco conflict, the destructive power of industrialised warfare created a fusion of severed human limbs and broken things - the tragic and powerful consequence of a failed modernity. Like the mud in the trenches, conflict is viscous and difficult to escape. As a result, it is impossible to disentangle the different components of this Anthropocene hyperobject - things, people and time are all intrinsically linked and leave a sticky heritage.

A small abandoned house dating back to the early years of Colonia Menno stands forgotten at the edge of the village of Reinland. The owners have long since moved into a new-built house across from it. The house now lies in ruins and in spring, colourful flowers sprout from the cracks and crevices of its crumbled walls. On closer inspection, however,

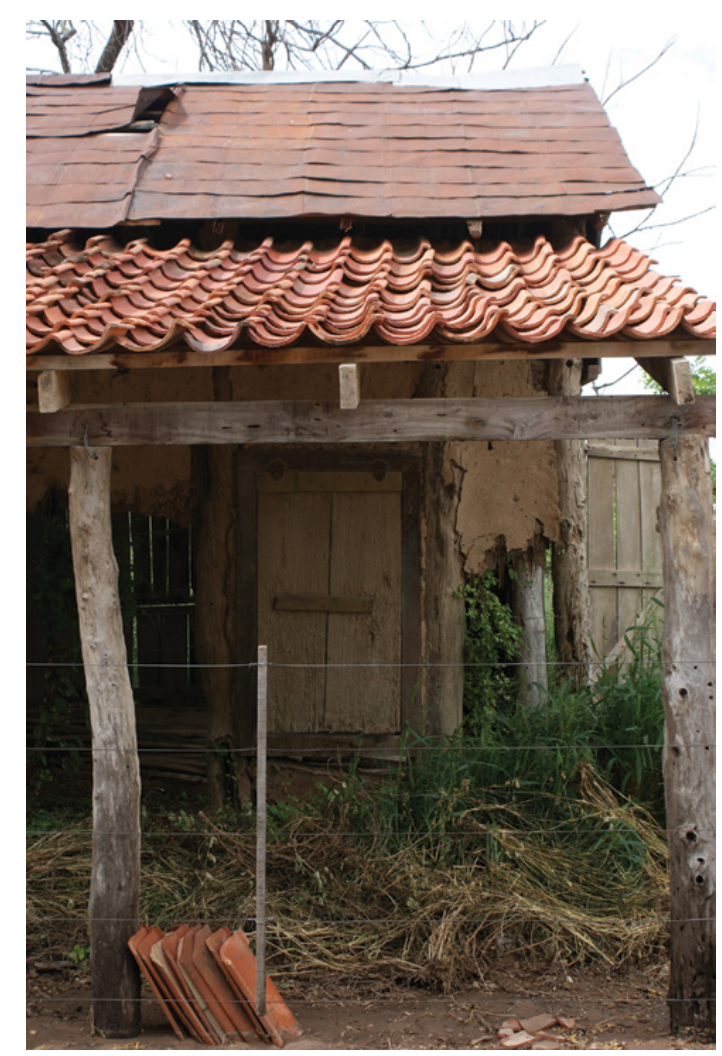

Figure 6.7 Mennonite house with sheet-metal roof made of flattened oil canisters from the war (Source: author). 
the picturesque scene reveals a troubling reality that has withstood the test of time. Otherwise built in traditional mud brick, the house has a rather unusual roof that has survived years of heavy rain and drought. My Mennonite guide asserts that the sheet metal covering - glinting in the midday sun - was made of flattened oil canisters from the war, found by the original house owners in the bush. In their attempt to build an existence in the Chaco, the farmers thus unknowingly transformed objects used to fuel conflict into a structure that represents protection and family life. More poignantly, perhaps, this hints at a larger picture of the Chaco War in which the global is materialised in the local.

This point is further illustrated by two objects found in local Mennonite museums. The first is a butter churn on display in the Koloniehaus museum in Filadelfia. Butter churns were used by the early colonists to convert cream into butter and would traditionally have consisted of a wooden container and staff. In this case, however, the maker substituted the wooden container with an old petroleum canister from the war, with the seashell logo of the Royal Dutch Shell oil and gas company embossed on it. Similarly, the Geschichtliches Archiv Kolonie Menno in Loma Plata preserves an old baking tray fashioned out of a flattened oil canister with the Shell emblem still faintly visible.

In his poem entitled 'Standard Oil Co.', Chilean-born Pablo Neruda condemns the US company's imperial exploitation of people and land in the Chaco for the personal profit of a select few:

Their obese emperors from New York are suave smiling assassins who buy silk, nylon, cigars, petty tyrants and dictators.

They buy countries, people, seas, police, county councils, distant regions where the poor hoard their corn

like misers their gold:

Standard Oil awakens them, clothes them in uniforms, designates which brother is the enemy. The Paraguayan fights its war, and the Bolivian wastes away in the jungle with its machine gun (Neruda 2000 [1950]: 176-7).

Although the Chaco War was fought between predominantly Aymara and Quechua miners and Guaraní mestizo farmhands in the distant, dense 


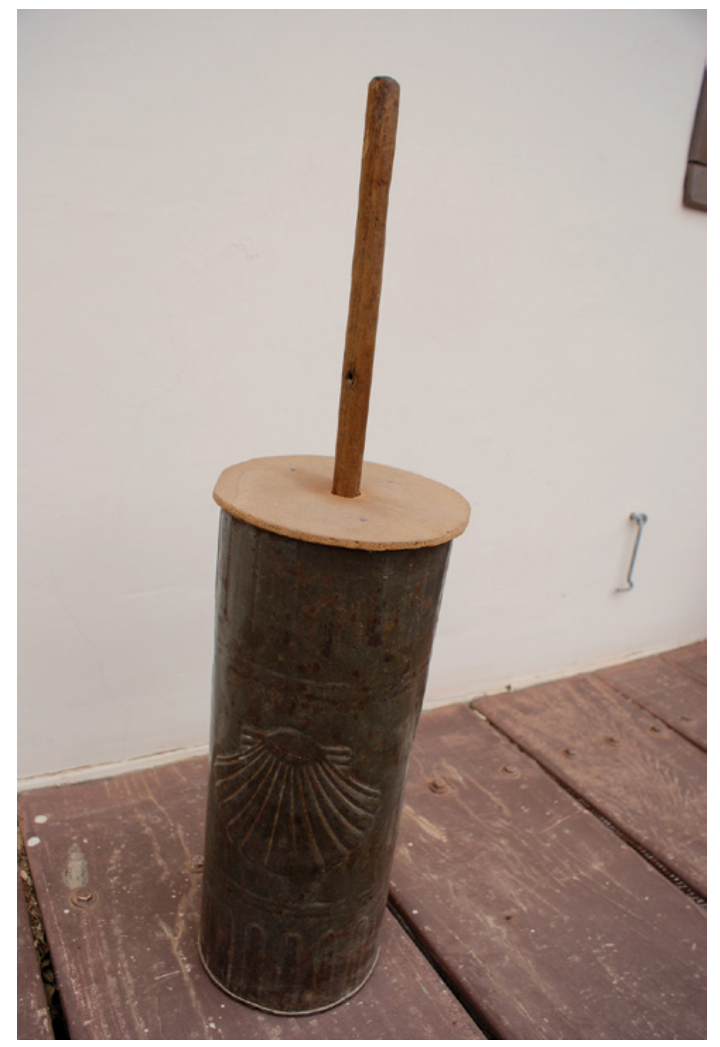

Figure 6.8 Butter churn with shell emblem on display in the Koloniehaus museum in Filadelfia (Source: author).

forest of South America, the implications of the armed conflict moved far beyond the physical boundaries of the Chaco scrubland. Fought with European and North American weaponry (Hughes 2005) and backed by powerful multinational corporations such as British Royal Dutch Shell and Standard Oil (Chiavenato 1989), the Chaco War was very much a global event that is reflected in local material culture. Similar to the American and Russian helmets found in post-conflict Ethiopia (González-Ruibal 2006a), the house roof, butter churn and baking tray become materialisations of globalisation, while simultaneously embodying the local, personal suffering and sacrifices of the soldiers, Mennonites and indigenous peoples of the Chaco. 


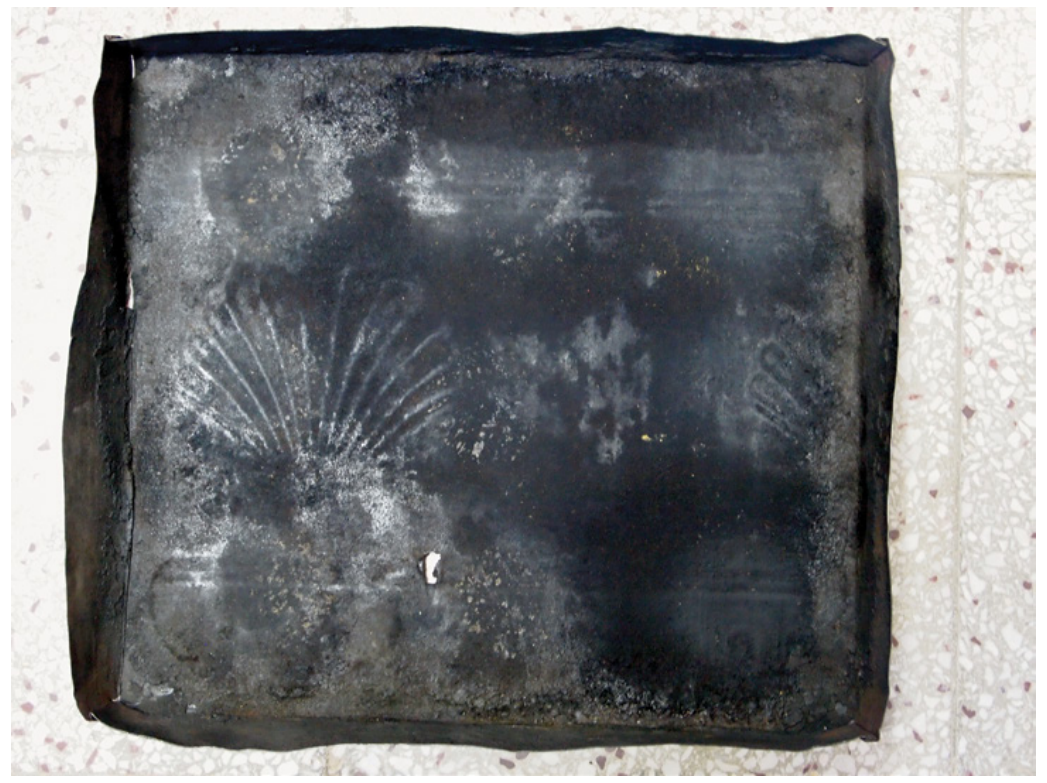

Figure 6.9 Baking tray with Shell emblem in the Geschichtliches Archiv Kolonie Menno in Loma Plata (Source: author).

\section{'Molten' and 'phased' (challenging conventional understandings of the relations between space and time)}

One of the ways in which conflict material culture challenges conventional relations between space and time is in the constant recycling of these materials, which act to fuse together past, present and future. For example, in my discussion of the Ayoreo objects produced using metal debris from the war in Chapter 4 I showed how these cannot simply be understood as the result of human autonomous creation but are ascribed to the action of forces that go beyond the human realm. As the Ayoreo do not associate the emergence of metal with the war, the objects made from it cannot be studied as materialisations of human experiences of conflict as they merge the experiences of the war with other experiences embedded in different times and places. I suggested that the metal objects created by the Ayoreo transcend the human realm as they originated independently of people's actions and outside the context of the Chaco War in a world where the concepts of time and space, subject and object, human and more-than-human are both complex and blurred. 
Similarly, whilst the wars of the twentieth century are generally characterised as a series of battles located in specific times and places with defined beginnings and endings, it is also possible - as Eric Hobsbawm showed in The Age of Extremes (1994) - to view the 'short twentieth century' as a constant, ongoing and inter-related set of global conflicts that have produced a sea of matériel that is continuously recycled for political and social goals in the present. Here the archaeological remains of the Chaco War and the various processes of heritagisation and nationbuilding they are involved in serve as examples of the ways in which such materials are not fixed in time and space but are continuously reworked to build new futures.

\section{'Inter-objective' (held together and formed out of relations between complex assemblages of objects, places and people)}

I have also shown how conflicts are formed out of complex assemblages of objects, places and people. In Chapter 3 I explored the inter-relations between the physical environment and the various human and non-human actors in the Chaco War. The strong sensorial experience of thirst bound the soldiers and the Chaco together, and access to water and the technology and skills to extract it was a decisive factor in the war. On the one hand people were fighting the Chaco bush but on the other hand they were dependent on its natural resources, including water sources, food and wood for building fortines and finding cover. The soldiers' and Mennonites' responses to the bush were prefigured by long histories of human-environmental entanglements in completely different contexts and these places also came to be bound up in this distant conflict. These inter-objective relations help to explain how even an arguably modest border dispute in a remote corner of South America can nonetheless have global effects.

I am aware that in my discussion of conflict legacies as hyperobject I have tended to focus on individual objects and sites rather than on the more substantial archaeological features that actually form the vast material and discursive stratigraphic 'submerged iceberg' of the hyperobject being described - the unfathomable number of mass graves containing countless human skeletons with their personal belongings, the locations of which have long been forgotten; the back-filled and overgrown trenches that remain undocumented; the earthworks associated with the forts; roads and trails that have since been reclaimed by the bush; and all the various objects contained below ground within those stratigraphic contexts. Hyperobjects are notoriously difficult to study because, as Morton notes, one can only ever really comprehend them partially, through 
their local manifestations. Nonetheless, an archaeological approach to the material culture and landscapes of the Chaco War and its afterlives exposes the many material realities of the Chaco as dynamic non-human (and sometimes more-than-human) actors that work with and through human actors in multiple worlds they shape together. As written records have primarily dealt with the military, political and logistical aspects of the war, this book has applied a set of qualitative research methods to study the objects, landscapes and people that have hitherto often been overlooked in historical accounts of the conflict, and to reveal the vast, obscured and uncanny aspects of conflict hyperobjects. I have tried to show how the description of these hyperobjects, in addition to focusing on surface materials, also needs to make reference to the much greater part which lies below the surface, and is buried and hidden from view - or 'withdrawn' as Graham Harman (2002, 1) would suggest. My research on different material-environmental-human engagements as distinctive worlding practices has allowed me to begin to explore the multiple parallel worlds that emerged during the Chaco War, and how their traces persist in the present as resources for the continued production and reproduction of multiple futures. It is these hidden depths of the hyperobject, which phase in and out of consciousness and experience (as for example when archaeologists themselves are reported to have uncovered buried materials), which best characterise their 'non-local' nature and their inter-objectivity in making, unmaking and remaking worlds. ${ }^{2}$

\section{A war of many worlds}

Even before the war, it could be argued that the Chaco had exerted its multiple worlding influences in a differentiated manner. On paper, Bolivia and Paraguay each saw it as an integral part of their respective patria. In practice, however, the Chaco was perceived to be alien and 'wild': an empty place waiting to be civilised through agricultural and military occupation. On the Paraguayan side, the Mennonites were called in, armed with ploughs, to help modernise and colonise the region. In the process, the indigenous communities of the Chaco were largely ignored. They were part of the 'wilderness' and could be tamed with rifle and Bible. Both nations were still licking their wounds from their failures in previous wars and were not ready to admit defeat again, even if it meant sending thousands of men to untimely deaths. Despite both states being unprepared for a major armed conflict in terms of military training, equipment and funds, war was declared by men in suits who only knew the Chaco from maps 
and were ignorant of the harsh reality of fighting a war in its hostile environments. Culturally and socially detached from the Chaco, both armies, as well as the Mennonites, struggled to survive in the scrubland. Armed with rifles and agricultural tools, they were powerless against the Chaco as they saw modern technology rendered useless by forces of nature. The soldiers and Mennonites perceived the bush as something alien, a threatening 'Other' that had to be fought like an enemy. These respective modes of existence contrast markedly with indigenous engagements with the Chaco. The latter thus represented a hybrid mix of human and nonhuman entities forming entangled yet parallel collectives, each aiming to negotiate their own role in and through the conflict. For the soldiers this was a painful experience characterised by powerful sensations of hunger and thirst. It was also a learning process in which they realised that by opening up to indigenous ways of understanding the Chaco, they could alleviate some of their suffering. In order to make life more bearable and to feel less alienated and out of place in the bush, they also maintained personal traditions such as the chewing of coca leaves in the case of the Bolivian soldier, and even adjusted customs such as the sharing of tereré in the case of the Paraguayan recruit. Nonetheless the soldiers, particularly the Bolivians, felt confused and out of place amid the deadly entangled fusion of industrial and natural forces which together forged their experience of the Chaco landscape.

In order to survive in this landscape, the soldiers depended on the support of the Mennonites, who wielded their ploughs and traded their crops in return for money and a chance to build a new world in the Chaco bush. Caught in the middle of these parallel worlding practices were the indigenous people, on whom modern industrialised conflict had crept up from behind. Fusing the traditional and industrial, the figure of the indigenous person holding in his hand a Mauser rifle becomes an emblematic symbol of the global impacts of modern warfare. But more than a symbol, we see how objects of violence and items crafted from the debris of modern failures become the raw materials for the making and unmaking of multiple worlds, each composed of specific constellations of things, persons and places in time. Archaeological and material culture-based approaches to conflict bring such issues to the fore. Modern, 'western' ontologies divide objects and subjects into two different spheres, in which the passive object comes to be seen as a blank canvas waiting to be bestowed with human meaning. In this sense, the soldiers' decorated shell cases could be interpreted as the materialisations of human feelings, hopes and desires. However, such an interpretation ignores the material forces always already at play in the world. 
Objects such as the house roof, baking tray and butter churn made by Mennonites from recycled war material become powerful reminders of the global nature of the Chaco War by transcending the artefacts' practical purpose, materialising conflicting worlds and realities that went beyond their makers' awareness. The idea that things act outside the human realm and even determine human existence annuls the western concept of inert object versus active subject, as explored in the recycled artefacts made by the Ayoreo. At the same time, it shows the futility of applying modern concepts such as trench art to non-modern material cultures. Such objects provide tangible windows into alternative worlding practices, and the existence of multiple parallel worlds.

In addition to the archaeology of the war itself, the book has also engaged with its varied material afterlives, simultaneously as 'heritage' and ruins of modernity in the Chaco landscape. While some sites are actively memorialised, others appear neglected and forgotten, to be engulfed by the bush. Their material decay is exacerbated by the lack of clearly defined heritage regulations and a general indifference to war heritage among the local population. Archaeological work at Fortín Nanawa showed the potential for such approaches to document the forgotten material memories of the past in the present and how such interventions themselves produce newly emergent realities. The subsequent declaration of Fortín Nanawa as a protected heritage site thus confirmed that an archaeological engagement with the material culture of the Chaco War does not merely add more words to the existing stories of the war but instead produces its own worlds and possible futures.

\section{Rethinking conflict archaeologies and conflict heritage studies}

Over the past 20 years, studies on the landscapes and material culture of twentieth- and twenty-first-century conflicts have been expanding both geographically and intellectually. Although research remains largely focused on archaeologies of the First and Second World Wars in Europe (and to a lesser extent the Spanish Civil War, the Cold War and archaeologies of dictatorships in Latin America), conflict archaeology and heritage studies have increasingly begun to turn their attention to other continents and conflicts and to include non-western experiences of armed violence and its aftermath (e.g. González-Ruibal 2014; 2006a). In engaging directly with the multiple parallel worlding practices of modern 
industrialised conflict, this book makes a significant contribution to the field of modern conflict archaeology in Latin America and beyond, and to the archaeological field as a whole.

Furthermore, this work challenges established ideas of the meaning and significance of the Chaco War itself. Adopting an archaeological approach towards the study of the conflict has enabled me to move beyond the military and diplomatic histories of the war to reveal the varied assemblages of actors - people, landscapes and objects - and their intrinsic connections during the years of armed violence up to the present day.

Having applied a material approach to a conflict as obscure as the Chaco War has also opened up the field of modern conflict archaeology to non-Eurocentric archaeologies in Latin America and beyond through the study of militarised indigenous and remote frontier landscapes. Furthermore, the examination of indigenous experiences of armed violence has opened a window into alternative worlds in which the landscapes and people are not necessarily viewed as distinct from one another. Amerindian indigenous material culture thus constitutes a challenge to the notion of trench art, and indeed recycling more generally, as objects have multiple, often non-anthropogenic origins and are brought into being in a range of different ways. By expanding the focus beyond the military realm to include minority groups such as the Mennonites and indigenous people, this book also provides an insight into marginalised communities and their experience of armed violence. Whereas previous work in Latin America has predominantly utilised a traditional battlefield approach to war sites, this study provides an alternative engagement with the wider landscapes and material cultures of modern conflicts.

While this book represents the first ever archaeological study of the physical remains of the Chaco War, it nonetheless has its limits. Within the cartographic boundaries of the Chaco countless fortines remain deep inside the bush, undocumented and unknown. Such sites are not limited to military outposts but include hospitals and camps. Future research might also broaden out to include not only landscapes but also seascapes and airscapes of war. An in-depth study of Chaco War cemeteries and mass graves would further enrich understandings of corporeality and the human body in conflict. Although excavations and exhumations of war dead, similar to those undertaken by forensic archaeologists working on sites of recent human tragedies elsewhere in the world, are a possibility in the Chaco, they raise ethical and regulatory concerns that need to be approached with integrity and sensitivity. A more detailed study of the military trench art collection in the United States would also allow a better understanding of who made these artefacts and why. ${ }^{3}$ Tracing the makers or their family members through the engraved names and dedications on 
the artillery shells would enable one to put a face to a shell and explore more of its hidden stories. There is also scope for further research on the Mennonite and indigenous role in the war. Although some aspects of these histories have previously been covered, there has been little focus on their engagements with material cultures and landscapes of conflict.

$$
* * *
$$

The practices, places and objects associated with modern conflicts encompass and co-create multiple pasts and futures, whilst they remain firmly and stubbornly embedded in their present(s). In exploring modern industrialised conflict as a hyperobject, I have also pointed to the role of such studies in understanding the emergence of the distinctive, often extractive and exploitative set of material-social-ecological-political relations that is both emblematic and constitutive of the Anthropocene. The archaeology, material culture and heritage of modern conflict expose the material realities of the Anthropocene as an epoch in which objects, people and landscapes have come to be entangled and connected both physically and conceptually across vast, almost unimaginable distances. If hyperobjects can be understood to represent the geological markers of the Anthropocene, we must add the rifle and the shell case to climate change, radionuclides and Styrofoam in its global museum.

\section{Notes}

1. It is worth noting that the contributions to and impact on indigenous and Mennonite communities by the war have been entirely neglected in official memorials and other state-led commemorative activities in Paraguay.

2. I thank one of my anonymous reviewers for their helpful comments regarding this vast 'stratigraphic underbelly' and for flagging Graham Harman's (2002) point about objects 'withdrawing', which I have referred to here.

3. At the time of writing the current whereabouts of the collection is unknown as its owner has sadly passed away. 


\section{References}

\section{Archival sources}

AIHMM: Archivo del Instituto de Historia y Museo Militar del Ministerio de Defensa Nacional (Institute for History and Ministry of Defence Military Museum Archive).

GAKF: Geschichtliches Archiv Kolonie Fernheim (Colony Fernheim Historical Archive; including correspondence with the villages and the periodical Mennoblatt, published monthly for the Mennonite community in Fernheim since 1930).

GAKM: Geschichtliches Archiv Kolonie Menno (Colony Menno Historical Archive).

\section{Secondary sources}

Abercrombie, Roland K. 1933. 'Peaceful Pawns in the Chaco Conflict', The Christian Century 50 (38): 1173-75.

Adeney Thomas, Julia. 2016. 'Coda: Who is the "We” Endangered by Climate Change?'. In Endangerment, Biodiversity and Culture, edited by Fernando Vidal and Nélia Dias, 241-60. London: Routledge.

Adorno Benítez, Félix. 1963. Relato de episodios de la guerra del Paraguay con Bolivia, 1932-1935. Asunción: El Arte.

Alberti, Benjamin, Severin Fowles, Martin Holbraad, Yvonne Marshall and Christopher Witmore. 2011. "Worlds Otherwise": Archaeology, Anthropology, and Ontological Difference', Current Anthropology 52 (6): 896-912.

Allen, Catherine J. 1988. The Hold Life Has: Coca and Cultural Identity in an Andean Community. Washington, DC: Smithsonian Institution Press.

Almada, Martín. 2010. Paraguay, la cárcel olvidada: El país exiliado. Asunción: Marben.

Anonymous. 1933. 'The Blond Men of the Chaco', Literary Digest, 1 April, 27.

Anonymous. 1980. Anécdotas de la Guerra del Chaco. Asunción: Hoy.

Anonymous. 2002. 'Construyen museo histórico en el Fortín Boquerón', ABC Color, 24 July. Accessed 26 February 2020. www.abc.com.py/edicion-impresa/interior/construyen-museohistorico-en-el-fortin-boqueron-655611.html.

Anonymous. 2006a. 'Empezó restauración del fortín Isla Poi, en Presidente Hayes', ABC Color, 8 June. Accessed 26 February 2020. www.abc.com.py/edicion-impresa/interior/empezorestauracion-del-fortin-isla-poi-en-presidente-hayes-909251.html.

Anonymous. 2006b. 'Miseria en Puerto Casado es la excusa para todos los robos', ABC Color, 24 August. Accessed 26 February 2020. www.abc.com.py/edicion-impresa/politica/miseria-enpuerto-casado-es-la-excusa-para-todos-los-robos-926224.html.

Anonymous. 2008. 'Fortín Isla Poi se encuentra en ruinas', ABC Color, 15 June. Accessed 26 February 2020. www.abc.com.py/edicion-impresa/interior/fortin-isla-poi-se-encuentra-enruinas-1075632.html.

Anonymous. 2011. 'Habilitan salón de bronce', Última Hora, 13 May. Accessed 5 June 2012. www. ultimahora.com/notas/428250-Habilitan-salon-de-bronce. 
Anonymous. 2013a. 'Encuentran bomba sin detonar en el Chaco', ABC Color, 24 June. Accessed 26 February 2020. www.abc.com.py/nacionales/encuentran-pequena-bomba-sin-detonar-en-elchaco-588109.html.

Anonymous. 2013b. 'Primera investigación arqueológica de zona bélica en el Chaco', ABC Color, 24 May. Accessed 24 May 2013. www.abc.com.py/nacionales/primera-investigacion-arqueologicade-zona-belica-en-el-chaco-576387.html.

Anonymous. 2015. 'Conceden 70.000 dólares para identificar restos de víctimas de la dictadura', Última Hora, 24 February. Accessed 24 September 2019. www.ultimahora.com/conceden70000-dolares-identificar-restos-victimas-la-dictadura-n875112.html.

Appadurai, Arjun, ed. 1988. The Social Life of Things: Commodities in Cultural Perspective. Cambridge: Cambridge University Press.

Augé, Marc. 1995. Non-Places: Introduction to an Anthropology of Supermodernity, translated by John Howe. London: Verso.

Balbi, Marco. 2009. 'Great War Archaeology on the Glaciers of the Alps'. In Contested Objects: Material Memories of the Great War, edited by Nicholas J. Saunders and Paul Cornish, 280-90. London: Routledge.

Barad, Karen. 2007. Meeting the Universe Halfway: Quantum Physics and the Entanglement of Matter and Meaning. Durham, NC: Duke University Press.

Barbrooke Grubb, Wilfred. 2011. An Unknown People in an Unknown Land: The Indians of the Paraguayan Chaco. Hamburg: Severus.

Barreto, Sindulfo. 1969. Por qué no pasaron: Nubes sobre el Chaco: Revelaciones diplomaticas y militares. Asunción: Talleres Gráficos de la Escuela Técnica Salesiana.

Barreto, Sindulfo. 1985. Nanawa: Sector de los Milagros. Asunción: Editora Liticolor.

BBC News Online. 2000. 'Uproar after Moonies Buy Town', 14 October. Accessed 2 April 2020. http://news.bbc.co.uk/1/hi/world/americas/970712.stm.

Bejarano, Ramón César. 1967. Boquerón: La batalla decisiva. 2nd ed. Asunción: Casa Editorial Toledo.

Belaieff, Juan. 1934. Fortifications de Campaña. Asunción: Talleres Gráficos La Rural.

Belaieff, Juan. 1941. 'Los indios del Chaco paraguayo y su tierra', Revista de la Sociedad Científica del Paraguay 5 (3): 1-48.

Bender, Barbara. 2002. 'Time and Landscape', Current Anthropology 43 (S4): S103-12.

Bender, Barbara. 2006. 'Place and Landscape'. In Handbook of Material Culture, edited by Chris Tilley, Webb Keane, Susanne Küchler, Mike Rowlands and Patricia Spyer, 303-14. London: SAGE Publications.

Benítez, Justo Pastor. 1976. Bajo el signo de Marte: Crónicas de la Guerra del Chaco. Asunción: Editorial Casa-Libro.

Benítez Alvarenga, Derlis. 1997. El tereré: Algo más que una bebida en Paraguay. Asunción: Editorial El Lector.

Benítez Alvarenga, Derlis. 2013. 'Tereré as a Social Bond'. In The Paraguay Reader: History, Culture, Politics, edited by Peter Lambert and Andrew Nickson, 426-33. Durham, NC: Duke University Press.

Bennett, Jane. 2010. Vibrant Matter: A Political Ecology of Things. Durham, NC: Duke University Press.

Bessire, Lucas. 2014. Behold the Black Caiman: A Chronicle of Ayoreo Life. Chicago: University of Chicago Press.

Beurier, Joëlle. 2004. 'Death and Material Culture: The Case of Pictures during the First World War'. In Matters of Conflict: Material Culture, Memory and the First World War, edited by Nicholas J. Saunders, 109-22. London: Routledge.

Blaser, Mario. 2009a. 'The Threat of the Yrmo: The Political Ontology of a Sustainable Hunting Program', American Anthropologist 111 (1): 10-20.

Blaser, Mario. 2009b. 'Political Ontology: Cultural Studies without "Cultures"?', Cultural Studies $23(5 / 6): 873-96$.

Blaser, Mario. 2010. Storytelling Globalization from the Chaco and Beyond. Durham, NC: Duke University Press.

Blaser, Mario and Marisol de la Cadena. 2018. 'Introduction: Pluriverse: Proposals for a World of Many Worlds'. In A World of Many Worlds, edited by Marisol de la Cadena and Mario Blaser, 1-22. Durham, NC: Duke University Press.

Bogost, Ian. 2012. Alien Phenomenology; or, What It's Like to Be a Thing. Minneapolis: University of Minnesota Press. 
Bolin, Inge. 2002. Rituals of Respect: The Secret of Survival in the High Peruvian Andes. Austin: University of Texas Press.

Bonneuil, Christophe and Jean-Baptiste Fressoz. 2016. The Shock of the Anthropocene: The Earth, History and Us, translated by David Fernbach. London: Verso.

Bórmida, Marcelo. 2005. 'Ergon y mito: Una hermenéutica de la cultura material de los Ayoreo del Chaco Boreal', Archivos 3 (1): 5-175.

Boschmann, Hans. 2012. 'Trébol - Eine historische Stätte in Fernheim', Jahrbuch für Geschichte und Kultur der Mennoniten in Paraguay 13: 101-26.

Boscov-Ellen, Dan. 2020. 'Whose Universalism? Dipesh Chakrabarty and the Anthropocene', Capitalism Nature Socialism 31 (1): 70-83.

Brady, Lisa M. 2005. 'The Wilderness of War: Nature and Strategy in the American Civil War', Environmental History 10 (3): 421-47.

Brady, Lisa M. 2012. War upon the Land: Military Strategy and the Transformation of Southern Landscapes during the Civil War. Athens: University of Georgia Press.

Brantz, Dorothee. 2009. 'Environments of Death: Trench Warfare on the Western Front, 1914-18'. In War and the Environment: Military Destruction in the Modern Age, edited by Charles E. Closmann, 68-91. College Station: Texas A\&M University Press.

Braunstein, José and Elmer S. Miller. 2001. 'Ethnohistorical Introduction'. In Peoples of the Gran Chaco, edited by Elmer S. Miller, 1-22. Westport, CT: Bergin and Garvey.

Bray, Arturo. 1981. Armas y letras: Memorias. Asunción: Ediciones NAPA.

Breithoff, Esther. 2012. 'The Many Faces of the Chaco War: Indigenous Modernity and Conflict Archaeology'. In Beyond the Dead Horizon: Studies in Modern Conflict Archaeology, edited by Nicholas J. Saunders, 146-58. Oxford: Oxbow Books.

Breithoff, Esther. 2013. 'Fortín Boquerón: A Conflict Landscape Past and Present', Cadernos do CEOM 26 (38): 65-83.

Breithoff, Esther. 2015. 'Conflict Landscapes of the Chaco War'. PhD thesis, University of Bristol.

Breithoff, Esther. 2016. 'Engraving Conflict: The Chaco War in a Shell Case'. In The Chaco War: Environment, Ethnicity, and Nationalism, edited by Bridget María Chesterton, 177-90. London: Bloomsbury Academic.

Breithoff, Esther. 2017. 'The "White Death": Thirst and Water in the Chaco War'. In Modern Conflict and the Senses, edited by Nicholas J. Saunders and Paul Cornish, 213-28. London: Routledge.

Breithoff, Esther and Rodney Harrison. 2020a. 'From Ark to Bank: Extinction, Proxies and Biocapitals in Ex-Situ Biodiversity Conservation Practices', International Journal of Heritage Studies 26 (1): 37-55.

Breithoff, Esther and Rodney Harrison. 2020b/in press. 'Making Futures in End Times: Nature Conservation in the Anthropocene'. In Deterritorialising the Future: Heritage in, of and after the Anthropocene, edited by R. Harrison and C. Sterling, 155-87. London: Open Humanities Press.

Brinckerhoff Jackson, John. 1980. The Necessity for Ruins and Other Topics. Amherst: University of Massachusetts Press.

Brönstrup, Rolf. 1966. Stacheldraht: Notizen und Mosaiken. Leer: G. Rautenberg.

Bryant, Levi 2011. The Democracy of Objects. Ann Arbor, MI: Open Humanities Press.

Bryant, Levi, Nick Srnicek and Graham Harman, eds. 2011. The Speculative Turn: Continental Materialism and Realism. Melbourne: re.press.

Buchli, Victor. 2002. 'Introduction'. In The Material Culture Reader, edited by Victor Buchli, 1-22. Oxford: Berg.

Buck, Alfred, Tom Sasaki, Jean Hewitt and Anne Macrae. 1968. 'Coca Chewing and Health: An Epidemiologic Study among Residents of a Peruvian Village', American Journal of Epidemiology 88 (2): 159-77.

Burchell, Mark. 2014. 'Skilful Movements: The Evolving Commando'. In Bodies in Conflict: Corporeality, Materiality and Transformation, edited by Paul Cornish and Nicholas J. Saunders, 208-18. London: Routledge.

Bustamante Rodríguez, Ladislao. 1987. Con las alas rotas. Asunción: Talleres de la Imprenta Militar. Butterly, John R. and Jack Shepherd. 2010. Hunger: The Biology and Politics of Starvation. Hanover, NH: Dartmouth College Press.

Capdevila, Luc. 2010. 'La Guerre du Chaco Tierra adentro: Déconstruire la représentation d'un conflit international'. In Les hommes transparents: Indiens et militaires dans la Guerre du Chaco (1932-1935), by Luc Capdevila, Isabelle Combès, Nicolas Richard and Pablo Barbosa, 15-34. Rennes: Presses universitaires de Rennes. 
Capdevila, Luc, Isabelle Combès and Nicolas Richard. 2008. 'Los indígenas en la Guerra del Chaco: Historia de una ausencia y antropología de un olvido'. In Mala guerra: Los indígenas en la Guerra del Chaco (1932-35), edited by Nicolas Richard, 13-66. Asunción: Museo del Barro, ServiLibro and CoLibris.

Capdevila, Luc, Isabelle Combès, Nicolas Richard and Pablo Barbosa. 2010. Les hommes transparents: Indiens et militaires dans la Guerre du Chaco (1932-1935). Rennes: Presses universitaires de Rennes.

Céspedes, Augusto. 1973. Sangre de mestizos: Relatos de la Guerra del Chaco. 3rd ed. La Paz: Librería Editorial Juventud.

Céspedes, Augusto. 1975. Crónicas heroicas de una guerra estúpida. La Paz: Librería Editorial Juventud.

Chakrabarty, Dipesh. 2009. 'The Climate of History: Four Theses', Critical Inquiry 35 (2): 197-222.

Chesterton, Bridget María. 2013. The Grandchildren of Solano López: Frontier and Nation in Paraguay, 1904-1936. Albuquerque: University of New Mexico Press.

Chesterton, Bridget María. 2014. 'Composing Gender and Class: Paraguayan Letter Writers during the Chaco War, 1932-1935', Journal of Women's History 26 (3): 59-80.

Chesterton, Bridget María, ed. 2016. The Chaco War: Environment, Ethnicity, and Nationalism. London: Bloomsbury.

Chesterton, Bridget María and Anatoly V. Isaenko. 2014. 'A White Russian in the Green Hell: Military Science, Ethnography, and Nation Building', Hispanic American Historical Review 94 (4): 615-48.

Chiavenato, Julio José. 1989. La Guerra del Chaco: Petróleo. Asunción: Carlos Schauman.

Classen, Constance, ed. 2005. The Book of Touch. Oxford: Berg

Conway, Janet and Jakeet Singh. 2011. 'Radical Democracy in Global Perspective: Notes from the Pluriverse', Third World Quarterly 32 (4): 689-706.

Coogan, Michael D., Marc Z. Brettler, Carol A. Newsom and Pheme Perkins, eds. 2007. The New Oxford Annotated Bible. 3rd ed. Oxford: Oxford University Press.

Coole, Diana and Samantha Frost, eds. 2010. New Materialisms: Ontology, Agency, and Politics. Durham, NC: Duke University Press.

Cooney, Jerry W. 2004. 'Economy and Manpower: Paraguay at War, 1864-69'. In I Die with My Country: Perspectives on the Paraguayan War, 1864-1870, edited by Hendrik Kraay and Thomas L. Whigham, 23-43. Lincoln: University of Nebraska Press.

Coote, Jeremy, Chris Morton and Julia Nicholson. 2000. 'From Found Forms to Formlessness'. In Transformations: The Art of Recycling, edited by Jeremy Coote, Chris Morton and Julia Nicholson, 15-28. Oxford: Pitt Rivers Museum.

Corcuera, Ruth and María Cristina Dasso. 2005. 'Présentación - Ergon y mito: Una hermenéutica de la cultura material de los Ayoreo del Chaco Boreal, by Marcelo Bórmida', Archivos 3 (1): 1-3.

Cosgrove, Denis E. 1998. Social Formation and Symbolic Landscape. Madison: University of Wisconsin Press.

Cote, Stephen. 2013. 'A War for Oil in the Chaco, 1932-1935', Environmental History 18 (4): 738-58.

Cote, Stephen. 2016. 'Bolivian Oil Nationalism and the Chaco War'. In The Chaco War: Environment, Ethnicity, and Nationalism, edited by Bridget María Chesterton, 157-76. London: Bloomsbury Academic.

Coutin, Cécile. 2012. 'Camouflage: L' Art de Tromper et de Disparaître'. In 1917, edited by Claire Garnier and Laurent Le Bon, 101-2. Metz: Centre Pompidou-Metz Editions.

Cronon, William. 1996. 'The Trouble with Wilderness; or, Getting Back to the Wrong Nature', Environmental History 1 (1): 7-28.

Dalla-Corte Caballero, Gabriela. 2012a. 'Fotografía, cine y novela en la Guerra del Chaco (19321935): El médico Carlos de Sanctis y el relato de La Sed (Hijo de Hombre) de Roa Bastos', Densidades 9: 181-204.

Dalla-Corte Caballero, Gabriela. 2012b. Empresas y tierras de Carlos Casado en el Chaco paraguayo: Historias, negocios y guerras (1860-1940). Asunción: Intercontinental Editora.

Das, Santanu. 2005. Touch and Intimacy in First World War Literature. Cambridge: Cambridge University Press.

Daston, Lorraine and Peter Galison. 2010. Objectivity. New York: Zone Books.

Dawdy, Shannon Lee. 2010. 'Clockpunk Anthropology and the Ruins of Modernity', Current Anthropology 51 (6): 761-93.

De Garine, Igor. 2001. 'For a Pluridisciplinary Approach to Drinking'. In Drinking: Anthropological Approaches, edited by Igor de Garine and Valeria de Garine, 1-10. New York: Berghahn Books. 
De Garine, Igor and Valerie de Garine, eds. 2001. Drinking: Anthropological Approaches. New York: Berghahn Books.

De la Cadena, Marisol and Mario Blaser, eds. 2018. A World of Many Worlds. Durham, NC: Duke University Press.

De La Pedraja, René. 2006. Wars of Latin America, 1899-1941. Jefferson, NC: McFarland and Company.

De Quesada, Alejandro, with Philip Jowett. 2011. The Chaco War, 1932-35: South America's Greatest Modern Conflict. Oxford: Osprey Publishing.

Descola, Philippe. 1986. La nature domestique: symbolisme et praxis dans l'écologie des Achuar. Paris: Maison des Sciences de l'Homme.

Descola, Philippe. 1996. In the Society of Nature: A Native Ecology in Amazonia, translated by Nora Scott. Cambridge: Cambridge University Press.

Descola, Philippe. 2005. 'Ecology as Cosmological Analysis'. In The Land Within: Indigenous Territory and the Perception of Environment, edited by Alexandre Surrallés and Pedro García Hierro, 22-35. Copenhagen: International Work Group for Indigenous Affairs.

DeSilvey, Caitlin. 2017. Curated Decay: Heritage beyond Saving. Minneapolis: University of Minnesota Press.

Dibley, Ben. 2012. “"The Shape of Things to Come”: Seven Theses on the Anthropocene and Attachment', Australian Humanities Review 52: 139-53.

Domínguez, A., S. Villagra, T. Palau, A. Mella and H. Valiente, eds. 1998. Derechos Humanos en Paraguay. Publisher Unknown.

Duguid, Julian. 1950 [1931]. Green Hell. London: Pan Books.

Edensor, Tim. 2005a. 'Waste Matter: The Debris of Industrial Ruins and the Disordering of the Material World', Journal of Material Culture 10 (3): 311-32.

Edensor, Tim. 2005b. Industrial Ruins: Space, Aesthetics and Materiality. Oxford: Berg.

Edgeworth, Matt, Jeffrey Benjamin, Bruce Clarke, Zoe Crossland, Ewa Domanska, Alice Claire Gorman, Paul Graves-Brown, Edward Cecil Harris, Mark James Hudson, Jason M. Kelly, Victor Joaquin Paz, Melisa Anabella Salerno, Christopher Witmore and Andrés Zarankin. 2014. 'Archaeology of the Anthropocene', Journal of Contemporary Archaeology 1 (1): 73-132.

Edgeworth, Matt, Erle C. Ellis, Philip Gibbard, Cath Neal and Michael Ellis. 2019. 'The Chronostratigraphic Method is Unsuitable for Determining the Start of the Anthropocene', Progress in Physical Geography: Earth and Environment 43 (3): 334-44.

Edgeworth, Matt, Dan Richter, Colin Waters, Peter Haff, Cath Neal and Simon James Price. 2015. 'Diachronous Beginnings of the Anthropocene: The Lower Bounding Surface of Anthropogenic Deposits', Anthropocene Review 2 (1): 33-58.

Ehrhardt, Kathleen L. 2005. European Metals in Native Hands: Rethinking Technological Change, 1640-1683. Tuscaloosa: University of Alabama Press.

Ellis, Erle C. 2018. Anthropocene: A Very Short Introduction. Oxford: Oxford University Press.

Ellis, Erle C., Jed O. Kaplan, Dorian Q. Fuller, Steve Vavrus, Kees Klein Goldewijk and Peter H. Verburg. 2013. 'Used Planet: A Global History', PNAS: Proceedings of the National Academy of Sciences of the United States of America 110 (20): 7978-85.

English, Adrian J. 2007. The Green Hell: A Concise History of the Chaco War between Bolivia and Paraguay, 1932-35. Stroud: Spellmount.

Ens, Adolf. 1994. Subjects or Citizens? The Mennonite Experience in Canada, 1870-1925. Ottawa: University of Ottawa Press.

Epp, Marlene. 2002. Women without Men: Mennonite Refugees of the Second World War. Toronto: University of Toronto Press.

Escobar, Arturo. 2010. 'Latin America at a Crossroads: Alternative Modernizations, Post-Liberalism, or Post-Development?', Cultural Studies 24 (1): 1-65.

Escobar, Arturo. 2012. 'Más allá del desarrollo: Postdesarrollo y transiciones hacia el pluriverso', Revista de Antropología Social 21: 23-62.

Escobar, Ticio. 2007. The Curse of Nemur: In Search of the Art, Myth, and Ritual of the Ishir, translated by Adriana Michele Campos Johnson. Pittsburgh: University of Pittsburgh Press.

Espínola, Jenaro. 1960. Nanawa, 4, 5 y 6 de julio de 1933: Una batalla en la campaña defensiva de la Guerra del Chaco. Asunción: La Colmena.

Estigarribia, José Félix. 1950. The Epic of the Chaco: Marshal Estigarribia's Memoirs of the Chaco War, 1932-1935, edited by Pablo Max Ynsfran. Austin: University of Texas Press.

Farcau, Bruce W. 1996. The Chaco War: Bolivia and Paraguay, 1932-1935. Westport, CT: Praeger. 
Fast, Hans. 2004. Yakaré Sur: Guía ecológico de la Cuenca Alta del Riacho. Loma Plata: Imprenta Friesen.

Faust, John B. 1929. 'The Mennonite Colony in Paraguay', Mennonite Quarterly Review 3 (3): 183-89.

Ferris, Neal. 2014. 'Being Iroquoian, Being Iroquois: A Thousand-Year Heritage of Becoming'. In Rethinking Colonial Pasts through Archaeology, edited by Neal Ferris, Rodney Harrison and Michael V. Wilcox, 371-96. Oxford: Oxford University Press.

Florentín, Heriberto. 1984. Lo que he visto en Boquerón: Apuntes para la historia de la Guerra del Chaco. 2nd ed. Asunción: Editorial El Foro.

Folch, Christine. 2010. 'Stimulating Consumption: Yerba Mate Myths, Markets, and Meanings from Conquest to Present', Comparative Studies in Society and History 52 (1): 6-36.

Friesen, Martin W. 1997. Neue Heimat in der Chacowildnis. Loma Plata: Druckerei Friesen.

Friesen, Martin W. 2004. Kanadische Mennoniten bezwingen eine Wildnis: 50 Jahre Kolonie MennoErste Mennonitische Ansiedlung in Südamerika. Loma Plata: Druckerei Friesen.

Funari, Pedro Paulo A. 2014. 'A Regional Perspective on Government, Archaeology, and Economic Development: The Americas', Public Archaeology 13 (1-3): 91-98.

Gagliano, Joseph A. 1994. Coca Prohibition in Peru: The Historical Debates. Tucson: University of Arizona Press.

Gaona, Silvio. 1964. Capellanes de la Guerra del Chaco (1932-1935). Asunción: EMASA.

Gómez-Perasso, José Antonio. 1978. Estudios arqueológicos en el Paraguay: Análisis interpretativo. Asunción: Editorial Arte Nuevo.

Gómez-Pompa, Arturo and Andrea Kaus. 1992. 'Taming the Wilderness Myth', BioScience 42 (4): 271-79.

Gómez Silgueira, Pedro. 2012. 'Nombres grabados en bronce, hechos rescatados en papel', $A B C$ Color, 6 February. Accessed 26 February 2020. www.abc.com.py/edicion-impresa/economia/ nombres-grabados-en-bronce-hechos-rescatados-en-papel-363474.html.

González-Ruibal, Alfredo. 2006a. 'The Dream of Reason: An Archaeology of the Failures of Modernity in Ethiopia', Journal of Social Archaeology 6 (2): 175-201.

González-Ruibal, Alfredo. 2006b. 'The Past is Tomorrow: Towards an Archaeology of the Vanishing Present', Norwegian Archaeological Review 39 (2): 110-25.

González-Ruibal, Alfredo. 2008. 'Time to Destroy: An Archaeology of Supermodernity', Current Anthropology 49 (2): 247-79.

González-Ruibal, Alfredo. 2010. 'Fascist Colonialism: The Archaeology of Italian Outposts in Western Ethiopia (1936-41)', International Journal of Historical Archaeology 14 (4): 547-74.

González-Ruibal, Alfredo. 2014. An Archaeology of Resistance: Materiality and Time in an African Borderland. Lanham and Plymouth: Rowman \& Littlefield.

González-Ruibal, Alfredo. 2018a. An Archaeology of the Contemporary Era: The Age of Destruction. Routledge.

González-Ruibal, Alfredo. 2018b. 'Beyond the Anthropocene: Defining the Age of Destruction', Norwegian Archaeological Review 51 (1-2):10-21.

González-Ruibal, Alfredo, Almudena Hernando and Gustavo Politis. 2011. 'Ontology of the Self and Material Culture: Arrow-Making among the Awá Hunter-Gatherers (Brazil)', Journal of Anthropological Archaeology 30 (1): 1-16.

González-Ruibal, Alfredo and Gabriel Moshenska, eds. 2015. Ethics and the Archaeology of Violence. New York: Springer.

González Vera, Roque. 2009. 'Nombre y apellido de quienes roban y también de quienes compran', ABC Color, 27 August. Accessed 26 February 2020. www.abc.com.py/edicion-impresa/ politica/nombre-y-apellido-de-quienes-roban-y-tambien-de-quienes-compran-14865.html.

Gootenberg, Paul. 2008. Andean Cocaine: The Making of a Global Drug. Chapel Hill: University of North Carolina Press.

Gordillo, Gastón R. 2004. Landscapes of Devils: Tensions of Place and Memory in the Argentinean Chaco. Durham, NC: Duke University Press.

Gordillo, Gastón R. 2014. Rubble: The Afterlife of Destruction. Durham, NC: Duke University Press.

Hagedorn, Dan and Antonio Luis Sapienza. 1997. Aircraft of the Chaco War, 1928-1935. Atglen, PA: Schiffer Publishing.

Haraway, Donna. 2003. The Companion Species Manifesto: Dogs, People, and Significant Otherness. Chicago: Prickly Paradigm Press.

Haraway, Donna. 2015. 'Anthropocene, Capitalocene, Plantationocene, Chthulucene: Making Kin', Environmental Humanities 6: 159-65. 
Haraway, Donna J. 2016. Staying with the Trouble: Making Kin in the Chthulucene. Durham, NC: Duke University Press.

Harder Horst, René. 2006. 'Indigenous Peoples, the Chaco War, and State Formation in a World History Context', World History Bulletin 22 (2): 14-18.

Harder Horst, René D. 2010. 'Crossfire, Cactus, and Racial Constructions: The Chaco War and Indigenous People in Paraguay'. In Military Struggle and Identity Formation in Latin America, edited by Nicola Foote and René D. Harder Horst, 286-306. Gainesville: University Press of Florida.

Harman, Graham. 2002. Tool-Being: Heidegger and the Metaphysics of Objects. Chicago: Open Court.

Harman, Graham. 2011. The Quadruple Object. Alresford: Zero Books.

Harrison, Rodney. 2002. 'Australia's Iron Age: Aboriginal Post-Contact Metal Artefacts from Old Lamboo Station, Southeast Kimberley, Western Australia', Australasian Historical Archaeology 20: 67-76.

Harrison, Rodney. 2006. 'An Artefact of Colonial Desire? Kimberley Points and the Technologies of Enchantment', Current Anthropology 47 (1): 63-88.

Harrison, Rodney. 2011. 'Surface Assemblages: Towards an Archaeology in and of the Present', Archaeological Dialogues 18 (2): 141-61.

Harrison, Rodney. 2013a. Heritage: Critical Approaches. London: Routledge.

Harrison, Rodney. 2013b. 'Heritage'. In The Oxford Handbook of the Archaeology of the Contemporary World, edited by Paul Graves-Brown, Rodney Harrison and Angela Piccini, 273-88. Oxford: Oxford University Press.

Harrison, Rodney. 2015. "Beyond "Natural" and "Cultural" Heritage: Toward an Ontological Politics of Heritage in the Age of Anthropocene', Heritage and Society 8 (1): 24-42.

Harrison, Rodney. 2018. 'On Heritage Ontologies: Rethinking the Material Worlds of Heritage', Anthropological Quarterly 91 (4): 1365-83.

Harrison, Rodney, Nadia Bartolini, Esther Breithoff, Caitlin DeSilvey, Cornelius Holtorf, Antony Lyons, Sharon Macdonald, Sarah May, Jennie Morgan and Sefryn Penrose. 2020. Heritage Futures: Comparative Approaches to Natural and Cultural Heritage Practices. London: UCL Press.

Harrison, Rodney and Esther Breithoff. 2017. 'Archaeologies of the Contemporary World', Annual Review of Anthropology 46: 203-21.

Hell, Julia and Andreas Schönle, eds. 2010. Ruins of Modernity. Durham, NC: Duke University Press.

Henare, Amiria, Martin Holbraad and Sari Wastell, eds. 2007. Thinking through Things: Theorising Artefacts Ethnographically. London: Routledge.

Hobsbawm, Eric. 1994. The Age of Extremes: The Short Twentieth Century, 1914-1991. New York: Vintage.

Hodder, Ian. 2012. Entangled: An Archaeology of the Relationships between Humans and Things. Chichester: Wiley-Blackwell.

Holbraad, Martin and Morten Axel Pedersen. 2017. The Ontological Turn: An Anthropological Exposition. Cambridge: Cambridge University Press.

Holbraad, Martin, Morten Axel Pedersen and Eduardo Viveiros de Castro. 2014. 'The Politics of Ontology: Anthropological Positions', Fieldsights, 13 January. Accessed 29 February 2020. https://culanth.org/fieldsights/the-politics-of-ontology-anthropological-positions.

Hornborg, Alf. 2017. 'Artifacts Have Consequences, Not Agency: Toward a Critical Theory of Global Environmental History', European Journal of Social Theory 20 (1): 95-110.

Howes, David. 2005a. Empire of the Senses: The Sensual Culture Reader. Oxford: Berg.

Howes, David, ed. 2005b. 'Embodiment, Culture, and Environment'. In The Book of Touch, edited by Constance Classen, 27-39. New York: Berg.

Howes, David. 2005c. 'Sensescapes'. In Empire of the Senses: The Sensual Culture Reader, edited by David Howes, 143-5. Oxford: Berg.

Hughes, Matthew. 2005. 'Logistics and the Chaco War: Bolivia versus Paraguay, 1932-1935', Journal of Military History 69 (2): 411-37.

Ingold, Tim. 1993. 'The Temporality of the Landscape', World Archaeology 25 (2): 152-74.

Ingold, Tim. 1995. 'Building, Dwelling, Living: How Animals and People Make Themselves at Home in the World'. In Shifting Contexts: Transformations in Anthropological Knowledge, edited by Marilyn Strathern, 57-80. London: Routledge.

Ingold, Tim. 1996. 'Hunting and Gathering as Ways of Perceiving the Environment'. In Redefining Nature: Ecology, Culture and Domestication, edited by Roy Ellen and Katsuyoshi Fukui, 117-55. Oxford: Berg.

Ingold, Tim. 2000. The Perception of the Environment: Essays in Livelihood, Dwelling and Skill. London: Routledge. 
Ingold, Tim. 2004. 'Culture on the Ground: The World Perceived through the Feet', Journal of Material Culture 9 (3): 315-40.

Ingold, Tim. 2011. Being Alive: Essays on Movement, Knowledge and Description. London: Routledge. Ingold, Tim. 2012. 'Toward an Ecology of Materials', Annual Review of Anthropology 41: 427-42.

Jünger, Ernst. 2004. Storm of Steel, translated by Michael Hofmann. London: Penguin.

Kalmar, Pierre, Édouard Joly and Maurice Gauthier. 2012. Lettres à Yvonne: Marraine de guerre à Clermont-Ferrand. Le Mont-Dore: Crébu Nigo.

Keller, Tait. 2009. 'The Mountains Roar: The Alps during the Great War', Environmental History 14 (2): $253-74$.

Kelly, John D. 2014. 'Introduction: The Ontological Turn in French Philosophical Anthropology', Hau: Journal of Ethnographic Theory 4 (1): 259-69.

Klassen, Burt. 2012. 'Puerto Casado - 16 Monate Wartezeit an der Tür zum Chacoinneren', Jahrbuch für Geschichte und Kultur der Mennoniten in Paraguay 13: 7-30.

Klassen, Paulhans. 2008. Die das Leid trugen. Asunción: Editora Litacolor.

Klassen, Paulhans. 2009. Der Himmel blüht. Asunción: Editora Litacolor.

Klassen, Paulhans. 2010. Relatos de mi querida patria. Asunción: Editora Litocolor.

Klassen, Peter P. 1993. Kaputi Mennonita: Eine freundliche Begegnung im Chacokrieg. Asunción: Imprenta Modelo.

Kobiałka, Dawid. 2019. 'Trench Art between Memory and Oblivion: A Report from Poland (and Syria)', Journal of Conflict Archaeology 14 (1): 4-24.

Kohn, Eduardo. 2015. 'Anthropology of Ontologies', Annual Review of Anthropology 44: 311-27.

Kraay, Hendrik and Thomas L. Whigham, eds. 2004. I Die with My Country: Perspectives on the Paraguayan War, 1864-1870. Lincoln: University of Nebraska Press.

Krell, Alan. 2002. The Devil's Rope: A Cultural History of Barbed Wire. London: Reaktion Books.

Krieg, Hans. 1934. Chaco-Indianer: Ein Bilderatlas. Stuttgart: Strecker und Schröder.

Kritsky, Gene and Ron Cherry. 2000. Insect Mythology. Lincoln, NE: iUniverse.

Kuletz, Valerie L. 1998. The Tainted Desert: Environmental Ruin in the American West. New York: Routledge.

Lambert, Peter and Andrew Nickson, eds. 2013. The Paraguay Reader: History, Culture, Politics. Durham, NC: Duke University Press.

Langer, Erick D. 2016. 'Indigenous Peoples and the Chaco War: Power and Acquiescence in Bolivia, Paraguay, and Argentina'. In The Chaco War: Environment, Ethnicity, and Nationalism, edited by Bridget María Chesterton, 113-34. London: Bloomsbury Academic.

Latour, Bruno. 1987. Science in Action: How to Follow Scientists and Engineers through Society. Cambridge, MA: Harvard University Press.

Latour, Bruno. 1993. We Have Never Been Modern, translated by Catherine Porter. Cambridge, MA: Harvard University Press.

Latour, Bruno. 2007. 'Can We Get Our Materialism Back, Please?', Isis 98 (1): 138-42.

Latour, Bruno. 2013. An Inquiry into Modes of Existence: An Anthropology of the Moderns, translated by Catherine Porter. Cambridge, MA: Harvard University Press.

Law, John. 2015. 'What's Wrong with a One-world World?', Distinktion: Scandinavian Journal of Social Theory, 16 (1): 126-39.

Leonard, Matthew. 2016. Beneath the Killing Fields: Exploring the Subterranean Landscapes of the Western Front. Barnsley: Pen and Sword Archaeology.

Leonard, Matthew. 2017. 'Assaulting the Senses: Life and Landscape beneath the Western Front'. In Modern Conflict and the Senses, edited by Nicholas J. Saunders and Paul Cornish, 43-60. London: Routledge.

Leonard, Matthew. 2019. 'A Sensorial No Man's Land: Corporeality and the Western Front during the First World War', The Senses and Society 14 (3): 257-70.

Leonard, Matthew and Esther Breithoff. 2020. 'Warfare and the Senses: Archaeologies of the Senses and Sensorial Archaeologies of Recent Conflict'. In The Routledge Handbook of Sensory Archaeology, edited by Robin Skeates and Jo Day, 281-92. London: Routledge.

Lewis, Simon L. and Mark A. Maslin. 2018. The Human Planet: How We Created the Anthropocene. London: Pelican Books.

Loomba, Ania. 2005. Colonialism/Postcolonialism. 2nd ed. London: Routledge.

Lucas, Gavin. 2004. 'Modern Disturbances: On the Ambiguities of Archaeology', Modernism/Modernity 11 (1): 109-20.

Lucas, Gavin. 2005. The Archaeology of Time. London: Routledge. 
Lucas, Gavin. 2006. 'Historical Archaeology and Time'. In The Cambridge Companion to Historical Archaeology, edited by Dan Hicks and Mary C. Beaudry, 34-47. Cambridge: Cambridge University Press.

Lucas, Gavin. 2010. 'Time and the Archaeological Archive', Rethinking History 14 (3): 343-59.

Lucas, Gavin. 2013. 'Ruins'. In The Oxford Handbook of the Archaeology of the Contemporary World, edited by Paul Graves-Brown, Rodney Harrison and Angela Piccini, 192-203. Oxford: Oxford University Press.

MacClancy, Jeremy. 2007. Expressing Identities in the Basque Arena. Oxford: James Currey.

Machuca, Vicente. 1962. Batalla de Toledo: Guerra del Chaco. Buenos Aires: Talleres Gráficos Abece. Macias, S. c. 1940. La Selva, la Metralla y la Sed. Publisher unknown.

Malm, Andreas. 2018. The Progress of This Storm: Nature and Society in a Warming World. London: Verso.

Manena, Alcides. 2012. 'Las vías del tren de Puerto Casado están por desaparecer', Última Hora, 5 August. Accessed 2 October 2019. www.ultimahora.com/las-vias-del-tren-puerto-casadoestan-desaparecer-n550109.html.

McAtackney, Laura. 2014. An Archaeology of the Troubles: The Dark Heritage of Long Kesh/Maze Prison. Oxford: Oxford University Press.

McNaspy, C.J. 1987. 'The Archaeology of the Paraguay Reductions (1609-1767)', World Archaeology 18 (3): 398-410.

McNeill, J.R. and Peter Engelke. 2014. The Great Acceleration: An Environmental History of the Anthropocene since 1945. Cambridge, MA: Harvard University Press.

Melgarejo, Juan E. 1969. Transmisiones en la Guerra del Chaco, Libro I. Asunción: Editorial El Gráfico.

Mendoza, Hugo. 2013. La Guerra del Chaco, 1932-1935. Asunción: El Lector.

Merewether, Charles. 1997. 'Traces of Loss'. In Irresistible Decay: Ruins Reclaimed, by Michael S. Roth, Claire Lyons and Charles Merewether, 25-78. Los Angeles: Getty Research Institute for the History of Art and the Humanities.

Meyer Aragón, Carlos. 1935. En ambos frentes: Memorias de un ex combatiente mutilado en la Guerra del Chaco. Asunción: La Colmena.

Miller, Elmer S., ed. 2001. Peoples of the Gran Chaco. Westport, CT: Bergin and Garvey.

Milwright, Marcus and Evanthia Baboula. 2014. 'Damascene "Trench Art": A Note on the Manufacture of Mamluk Revival Metalwork in Early 20th-Century Syria', Levant 46 (3): 382-98.

Moore, Jason. 2015. Capitalism in the Web of Life. New York: Verso.

Morales, Edmundo. 1989. Cocaine: White Gold Rush in Peru. Tucson: University of Arizona Press.

Morton, Timothy. 2013. Hyperobjects: Philosophy and Ecology after the End of the World. Minneapolis: University of Minnesota Press.

Moshenska, Gabriel. 2008a. 'Ethics and Ethical Critique in the Archaeology of Modern Conflict', Norwegian Archaeological Review 41 (2): 159-75.

Moshenska, Gabriel. 2008b. 'A Hard Rain: Children's Shrapnel Collections in the Second World War', Journal of Material Culture 13 (1): 107-25.

Moshenska, Gabriel. 2009. 'Resonant Materiality and Violent Remembering: Archaeology, Memory and Bombing', International Journal of Heritage Studies 15 (1): 44-56.

Moshenska, Gabriel. 2014. 'Children in Ruins: Bombsites as Playgrounds in Second World War Britain'. In Ruin Memories: Materialities, Aesthetics and the Archaeology of the Recent Past, edited by Bjørnar Olsen and Dóra Pétursdóttir, 230-49. London: Routledge.

Moshenska, Gabriel. 2019. Material Cultures of Childhood in Second World War Britain. London: Routledge.

Nash, June. 1979. We Eat the Mines and the Mines Eat Us: Dependency and Exploitation in Bolivian Tin Mines. New York: Columbia University Press.

Nash, Roderick Frazier. 2001. Wilderness and the American Mind. 4th ed. New Haven: Yale University Press.

Neruda, Pablo. 2000 [1950]. Canto General, translated by Jack Schmitt. Berkeley: University of California Press.

Netz, Reviel. 2004. Barbed Wire: An Ecology of Modernity. Middletown, CT: Wesleyan University Press.

Nobbs-Thiessen, Ben. 2016. 'Channeling Modernity: Nature, Patriotic Engineering, and the Chaco War'. In The Chaco War: Environment, Ethnicity, and Nationalism, edited by Bridget María Chesterton, 67-90. London: Bloomsbury Academic.

Nobbs-Thiessen, Ben. 2018. 'Reshaping the Chaco: Migrant Foodways, Place-making, and the Chaco War', Journal of Latin American Studies 50 (3): 579-611. 
Noelli, Francsico Silva. 2004. 'La distribución geográfica de las evidencias arqueológicas guaraní', Revista de Indias 64 (230): 17-34.

Oelschlaeger, Max. 1991. The Idea of Wilderness: From Prehistory to the Age of Ecology. New Haven: Yale University Press.

Olivier, Laurent. 2001. 'The Archaeology of the Contemporary Past'. In Archaeologies of the Contemporary Past, edited by Victor Buchli and Gavin Lucas, 175-88. London: Routledge.

Olivier, Laurent. 2004. 'The Past of the Present: Archaeological Memory and Time', Archaeological Dialogues 10 (2): 204-13.

Olivier, Laurent. 2011. The Dark Abyss of Time: Archaeology and Memory, translated by Arthur Greenspan. Lanham, MD: AltaMira Press.

Olivier, Laurent. 2013. 'Time'. In The Oxford Handbook of the Archaeology of the Contemporary World, edited by Paul Graves-Brown, Rodney Harrison and Angela Piccini, 167-77. Oxford: Oxford University Press.

Olmedo, Natalicio. 1959. Pitiantuta. Asunción: Talleres Gráficos del Estado Mayor General.

Olsen, Bjørnar. 2003. 'Material Culture after Text: Re-Membering Things', Norwegian Archaeological Review 36 (2): 87-104.

Olsen, Bjørnar. 2007. 'Keeping Things at Arm's Length: A Genealogy of Asymmetry', World Archaeology 39 (4): 579-88.

Olsen, Bjørnar. 2013. In Defense of Things: Archaeology and the Ontology of Objects. Lanham, MD: AltaMira Press.

Olsen, Bjørnar and Póra Pétursdóttir, eds. 2014. Ruin Memories: Materialities, Aesthetics and the Archaeology of the Recent Past. London: Routledge.

Olsen, Bjørnar and Dóra Pétursdóttir. 2016. 'Unruly Heritage: Tracing Legacies in the Anthropocene', Arkæologisk Forum 35: 38-45.

Olsen, Bjørnar, Michael Shanks, Timothy Webmoor and Christopher Witmore. 2012. Archaeology: The Discipline of Things. Berkeley: University of California Press.

Omura, Keiichi, Grant Jun Otsuki, Shiho Satsuka and Atsuro Morita, eds. 2019. The World Multiple: The Quotidian Politics of Knowing and Generating Entangled Worlds. London: Routledge.

O'Sullivan, Patrick and Jesse W. Miller. 1983. The Geography of Warfare. London: Croom Helm.

Pacheco Bellot, Gastón. 2000. 'Los patrulladores'. In Doce cuentos de la Guerra del Chaco, edited by Carlos Coello Villa and Helio Vera, 55-68. Santiago de Chile: LOM Ediciones.

Paniagua, Felino. 1994. Con los pies descalzos: Entre el polvo y la sed. Asunción: Ind. y Com.

Pearson, Chris. 2012a. Mobilizing Nature: The Environmental History of War and Militarization in Modern France. Manchester: Manchester University Press.

Pearson, Chris. 2012b. 'Researching Militarized Landscapes: A Literature Review on War and the Militarization of the Environment', Landscape Research 37 (1): 115-33.

Pearson, Chris, Peter Coates and Tim Cole, eds. 2010. Militarized Landscapes: From Gettysburg to Salisbury Plain. London: Continuum.

Pearson, Mike and Michael Shanks. 2001. Theatre/Archaeology. London: Routledge.

Pendle, George. 1967. Paraguay: A Riverside Nation. 3rd ed. London: Oxford University Press.

Pétursdóttir, Póra. 2013. 'Concrete Matters: Ruins of Modernity and the Things Called Heritage', Journal of Social Archaeology 13 (1): 31-53.

Pétursdóttir, Póra. 2016. 'For Love of Ruins'. In Elements of Architecture: Assembling Archaeology, Atmosphere, and the Performance of Building Spaces, edited by Mikkel Bille and Tim Flohr Sørensen, 365-86. London: Routledge.

Pétursdóttir, Póra. 2017. 'Climate Change? Archaeology and Anthropocene', Archaeological Dialogues 24 (2): 175-205.

Pétursdóttir, Dóra and Bjørnar Olsen. 2014. 'An Archaeology of Ruins'. In Ruin Memories: Materialities, Aesthetics and the Archaeology of the Recent Past, edited by Bjørnar Olsen and Dóra Pétursdóttir, 3-29. London: Routledge.

Pierpaoli Jr, Paul G. 2011. 'Indian Removal Act'. In The Encyclopedia of North American Indian Wars, 1607-1890: A Political, Social, and Military History, edited by Spencer Tucker, James R. Arnold and Roberta Wiener, 381-3. Santa Barbara: ABC-CLIO.

Pink, Sarah. 2009. Doing Sensory Ethnography. London: SAGE Publications.

Pinney, Christopher. 2005. 'Things Happen; or, From Which Moment Does That Object Come'. In Materiality, edited by Daniel Miller, 256-72. Durham, NC: Duke University Press.

Pollard, Tony. 2006. 'Seven Eventful Days in Paraguay: Reconnoitring the Archaeology of the War of the Triple Alliance'. In: Fields of Conflict: Battlefield Archaeology from the Roman Empire to the 
Korean War, edited by D. Scott, L. Babits and C. Haecker, 314-66. London: Praeger Security International.

Potthast, Barbara. 2004. 'Protagonists, Victims, and Heroes: Paraguayan Women during the "Great War"'. In I Die with My Country: Perspectives on the Paraguayan War, 1864-1870, edited by Hendrik Kraay and Thomas L. Whigham, 44-60. Lincoln: University of Nebraska Press.

Povinelli, Elizabeth A. 2012. 'The Will to Be Otherwise/The Effort of Endurance', South Atlantic Quarterly 111 (3): 453-75.

Prieto, Manuel and Xurxo M. Ayán Vila. 2014. “"Although the Loneliness is Great, Greater Yet is the Love of My Country": Archaeology of a Military Outpost on the Topaín Hillock (Antofagasta Region, Chile)', Journal of Contemporary Archaeology 1 (2): 323-50.

Pusineri, Adelina. 2007. 'Fuentes documentales, bibliotecas públicas y privadas en el Paraguay para el estudio de las dos guerras'. In Les Guerres du Paraguay aux XIXe et XXe siècles, edited by Nicolas Richard, Luc Capdevila and Capucine Boidin, 65-91. Paris: CoLibris.

Querejazu, Amaya. 2016. 'Encountering the Pluriverse: Looking for Alternatives in Other Worlds', Revista Brasileira de Política Internacional 59 (2), Article e007: 1-16. Accessed 23 February 2020. www.scielo.br/pdf/rbpi/v59n2/1983-3121-rbpi-59-02-e007.pdf.

Querejazu Calvo, Roberto. 1975. Masamaclay: Historia política, diplomática y militar de la Guerra del Chaco. La Paz: Editorial Los Amigos del Libro.

Quiring, Walter. 1934a. 'The Canadian Mennonite Immigration into the Paraguayan Chaco, 192627', Mennonite Quarterly Review 8 (1): 32-42.

Quiring, Walter. 1934b. 'The Colonization of the German Mennonites from Russia in the Paraguayan Chaco', Mennonite Quarterly Review 8 (2): 62-72.

Quiring, Walter. 2013. 'The Mennonites Arrive in the Chaco'. In The Paraguay Reader: History, Culture, Politics, edited by Peter Lambert and Andrew Nickson, 168-71. Durham, NC: Duke University Press.

Ratzlaff, Gerhard. 1998. Die Ruta Transchaco: Wie sie entstand. Asunción: Publisher Unknown.

Ratzlaff, Gerhard. 2009. Zwischen den Fronten: Mennoniten und andere evangelische Christen im Chacokrieg, 1932-1935. Asunción: Gerhard Ratzlaff.

Regehr, Walter. 1979. Die lebensräumliche Situation der Indianer im paraguayischen Chaco. Basel: Wepf.

Remarque, Erich Maria. 2005. All Quiet on the Western Front, translated by Brian Murdoch. London: Vintage.

Reno, Joshua. 2009. 'Your Trash is Someone's Treasure: The Politics of Value at a Michigan Landfill', Journal of Material Culture 14 (1): 29-46.

Renshaw, John. 2002. The Indians of the Paraguayan Chaco: Identity and Economy. Lincoln: University of Nebraska Press.

Richard, Nicolas, ed. 2008a. Mala guerra: Los indígenas en la Guerra del Chaco (1932-35). Asunción: Museo del Barro, ServiLibro and CoLibris.

Richard, Nicolas. 2008b. 'Presentación'. In Mala guerra: Los indígenas en la Guerra del Chaco (193235), edited by Nicolas Richard, 9-12. Asunción: Museo del Barro, ServiLibro and CoLibris.

Richard, Nicolas. 2008c. 'Los baqueanos de Belaieff: Actores y lógicas de mediación en el Alto Paraguay'. In Liderazgo: Representatividad y control social en el Gran Chaco, edited by José Braunstein and Norma C. Meichtry, 67-86. Corrientes: Editorial Universitaria de la Universidad Nacional del Nordeste.

Richard, Nicolas, Luc Capdevila and Capucine Boidin, eds. 2007. Les guerres du Paraguay aux XIXe et XXe siècles: actes du colloque international le Paraguay à l'ombre de ses guerres, acteurs, pouvoirs et representations. Paris: CoLibris.

Riester, Jürgen. 2008. 'Iyambae - Ser Libre: La Guerra del Chaco en la memoria indígena isoseña'. In Mala guerra: Los indígenas en la Guerra del Chaco (1932-35), edited by Nicolas Richard, 183-202. Asunción: Museo del Barro, ServiLibro and CoLibris.

Ríos, Angel F. 1950. La defensa del Chaco: Verdades y mentiras de una victoria. Buenos Aires: Editorial Ayacucho.

Rivera, Mario A., Arthur C. Aufderheide, Larry W. Cartmell, Constantino M. Torres and Odin Langsjoen. 2005. 'Antiquity of Coca-Leaf Chewing in the South Central Andes: A 3,000 Year Archaeological Record of Coca-Leaf Chewing from Northern Chile', Journal of Psychoactive Drugs 37 (4): 455-58.

Roa Bastos, Augusto. 2005 [1960]. Hijo de hombre. Buenos Aires: Editorial Losada.

Rose, Gillian. 1993. Feminism and Geography: The Limits of Geographical Knowledge. Cambridge: Polity Press. 
Roth, Michael S. 1997. 'Irresistible Decay: Ruins Reclaimed'. In Irresistible Decay: Ruins Reclaimed, by Michael S. Roth, Claire Lyons and Charles Merewether, 1-24. Los Angeles: Getty Research Institute for the History of Art and the Humanities.

Rout, Leslie B. 1970. Politics of the Chaco Peace Conference, 1935-1939. Austin: University of Texas Press.

Russell, Edmund. 2001. War and Nature: Fighting Humans and Insects with Chemicals from World War I to Silent Spring. Cambridge: Cambridge University Press.

Santella, Andrew. 2004. Navajo Code Talkers. Minneapolis: Compass Point Books.

Sarmiento, Emilio. 1978. Memorias de un soldado de la Guerra del Chaco. Buenos Aires: El Cid Editor.

Saunders, Nicholas J. 2000. 'Bodies of Metal, Shells of Memory: "Trench Art", and the Great War Re-Cycled', Journal of Material Culture 5 (1): 43-67.

Saunders, Nicholas J. 2001. 'Matter and Memory in the Landscapes of Conflict: The Western Front, 1914-1999'. In Contested Landscapes: Movement, Exile and Place, edited by Barbara Bender and Margot Winer, 37-53. Oxford: Berg.

Saunders, Nicholas J. 2002a. 'Memory and Conflict: Introduction'. In The Material Culture Reader, edited by Victor Buchli, 175-80. Oxford: Berg.

Saunders, Nicholas J. 2002b. 'The Ironic "Culture of Shells" in the Great War and Beyond'. In Matériel Culture: The Archaeology of Twentieth Century Conflict, edited by John Schofield, William Gray Johnson and Colleen M. Beck, 22-40. London: Routledge.

Saunders, Nicholas J. 2003. Trench Art: Materialities and Memories of War. New York: Berg.

Saunders, Nicholas J. 2013. 'Bodies in Trees: A Matter of Being in Great War Landscapes'. In Bodies in Conflict: Corporeality, Materiality and Transformation, edited by Paul Cornish and Nicholas J. Saunders, 22-38. London: Routledge.

Saunders, Nicholas J. and Paul Cornish. 2009. 'Introduction'. In Contested Objects: Material Memories of the Great War, edited by Nicholas J. Saunders and Paul Cornish, 1-10. London: Routledge.

Scheina, Robert L. 2003. Latin America's Wars, Volume 2: The Age of the Professional Soldier, 19002001. Washington, DC: Brassey's.

Schmidt, Max. 1932. 'Nuevos hallazgos prehistóricos del Paraguay', Revista de la Sociedad Científica del Paraguay 3 (3).

Schmidt, Max. 1934. 'Nuevos hallazgos prehistóricos del Paraguay: Continuación', Revista de la Sociedad Científica del Paraguay 3 (5).

Schneider, Dieter. 2007. 'Verein für Geschichte und Kultur der Mennoniten in Paraguay'. Accessed 2 October 2019. www.menonitica.org.

Schofield, John. 2005. Combat Archaeology: Material Culture and Modern Conflict. London: Duckworth.

Schuchard, Barbara. 2008. 'Etnias y Estados nacionales durante la Guerra del Chaco: Contribución al problema de la identidad indígena (el ejemplo de los isoceño-guaraníes)'. In Mala guerra: Los indígenas en la Guerra del Chaco (1932-35), edited by Nicolas Richard, 171-82. Asunción: Museo del Barro, ServiLibro and CoLibris.

Scott, Douglas, Lawrence Babits and Charles Haecker, eds. 2006. Fields of Conflict: Battlefield Archaeology from the Roman Empire to the Korean War. Washington, DC: Potomac Books.

Scranton, Roy. 2015. Learning to Die in the Anthropocene: Reflections on the End of a Civilization. San Francisco: City Lights Books.

Seiferheld, Alfredo M. 1983. Economía y petróleo durante la Guerra del Chaco. Asunción: El Lector.

Serres, Michel and Bruno Latour. 1995. Conversations on Science, Culture, and Time, translated by Roxanne Lapidus. Ann Arbor: University of Michigan Press.

Shanks, Michael. 2012. The Archaeological Imagination. Walnut Creek, CA: Left Coast Press.

Shanks, Michael, David Platt and William L. Rathje. 2004. 'The Perfume of Garbage: Modernity and the Archaeological', Modernism/modernity 11 (1): 61-83.

Shesko, Elizabeth. 2016. "Same as Here, Same as Everywhere”: Social Difference among Bolivian Prisoners in Paraguay'. In The Chaco War: Environment, Ethnicity, and Nationalism, edited by Bridget María Chesterton, 21-42. London: Bloomsbury Academic.

Shively Meier, Kathryn. 2010. 'Fighting in "Dante's Inferno": Changing Perceptions of Civil War Combat in the Spotsylvania Wilderness from 1863 to 1864'. In Militarized Landscapes: From Gettysburg to Salisbury Plain, edited by Chris Pearson, Peter Coates and Tim Cole, 39-56. London: Continuum. 
Shqiarat, Mansour, Zeyad Al-Salameen, Neil Faulkner and Nicholas J. Saunders. 2011. 'Fire and Water: Tradition and Modernity in the Archaeology of Steam Locomotion in a Desert War', Levant 43 (1): 98-113.

Silliman, Stephen W. 2014. 'Archaeologies of Indigenous Survivance and Residence: Navigating Colonial and Scholarly Dualities'. In Rethinking Colonial Pasts through Archaeology, edited by Neal Ferris, Rodney Harrison and Michael V. Wilcox, 57-75. Oxford: Oxford University Press.

Silva Lara, Amado. 1979. El infierno verde. Asunción: Ministerio de Educación y Culto.

Sluyter, Andrew. 2002. Colonialism and Landscape: Postcolonial Theory and Applications. Lanham, MD: Rowman and Littlefield.

Smith, Laurajane. 2006. Uses of Heritage. London: Routledge.

Smith, Mark M. 2015. The Smell of Battle, the Taste of Siege: A Sensory History of the Civil War. New York: Oxford University Press.

Solli, Brit, Mats Burström, Ewa Domanska, Matt Edgeworth, Alfredo González-Ruibal, Cornelius Holtorf, Gavin Lucas, Terje Oestigaard, Laurajane Smith and Christopher Witmore. 2011. 'Some Reflections on Heritage and Archaeology in the Anthropocene', Norwegian Archaeological Review 44 (1): 40-88.

Sosa, Estela Mary. 2010. El papel de las mujeres paraguayas en la Guerra del Chaco (1932-1935). Posadas: Universidad Nacional de Misiones.

Stahl, Wilmar. 2007. Culturas en interacción: Una antropología vivida en el Chaco paraguayo. Asunción: El Lector.

Steele, Caroline. 2008. 'Archaeology and the Forensic Investigation of Recent Mass Graves: Ethical Issues for a New Practice of Archaeology', Archaeologies: Journal of the World Archaeological Congress 4 (3): 414-28.

Steffen, Will, Reinhold Leinfelder, Jan Zalasiewicz, Colin N. Waters, Mark Williams, Colin Summerhayes, Anthony D. Barnosky, Alejandro Cearreta, Paul Crutzen, Matt Edgeworth, Erle C. Ellis, Ian J. Fairchild, Agnieszka Galuszka, Jacques Grinevald, Alan Haywood, Juliana Ivar do Sul, Catherine Jeandel, J.R. McNeill, Eric Odada, Naomi Oreskes, Andrew Revkin, Daniel deB. Richter, James Syvitski, Davor Vidas, Michael Wagreich, Scott L. Wing, Alexander P. Wolfe and H.J. Schellnhuber. 2016. 'Stratigraphic and Earth System Approaches to Defining the Anthropocene', Earth's Future 4 (8): 324-45.

Stoesz, Edgar and Muriel T. Stackley. 1999. Garden in the Wilderness: Mennonite Communities in the Paraguayan Chaco, 1927-1997. Winnipeg, MB: CMBC Publications.

Summerfield, Chantel. 2012. 'Trees as a Living Museum: Arborglyphs and Conflict on Salisbury Plain'. In Beyond the Dead Horizon: Studies in Modern Conflict Archaeology, edited by Nicholas J. Saunders, 159-71. Oxford: Oxbow Books.

Tilley, Christopher. 1994. A Phenomenology of Landscape: Places, Paths, and Monuments. Oxford: Berg.

Tilley, Christopher. 2002. 'Metaphor, Materiality and Interpretation: Introduction'. In The Material Culture Reader, edited by Victor Buchli, 23-26. Oxford: Berg.

Tilley, Christopher. 2006. 'Objectification'. In Handbook of Material Culture, edited by Chris Tilley, Webb Keane, Susanne Küchler, Mike Rowlands and Patricia Spyer, 60-73. London: SAGE Publications.

Tucker, Richard P. 2004. 'The World Wars and the Globalization of Timber Cutting'. In Natural Enemy, Natural Ally: Toward an Environmental History of Warfare, edited by Richard P. Tucker and Edmund Russell, 110-41. Corvallis: Oregon State University Press.

Tucker, Richard P. and Edmund Russell, eds. 2004. Natural Enemy, Natural Ally: Toward an Environmental History of Warfare. Corvallis: Oregon State University Press.

Turner, Victor. 1995. The Ritual Process: Structure and Anti-Structure. New York: Aldine de Gruyter.

Unruh, Ernesto and Hannes Kalisch. 2008. 'Salvación - ¿rendición? Los enlhet y la Guerra del Chaco'. In Mala guerra: Los indígenas en la Guerra del Chaco (1932-35), edited by Nicolas Richard, 99-124. Asunción: Museo del Barro, ServiLibro and CoLibris.

Unruh, Ernesto and Hannes Kalisch. 2014. Wie schön ist deine Stimme: Berichte der Enlhet in Paraguay zu ihrer Geschichte. Münster: Verlagshaus Monsenstein und Vannerdat.

Vargas, Luis Alberto. 2001. 'Thirst and Drinking as a Biocultural Process'. In Drinking: Anthropological Approaches, edited by Igor de Garine and Valeria de Garine, 11-21. New York: Berghahn Books.

Vera, Helio. 2000. 'Narrativa boliviana del Chaco'. In Doce cuentos de la Guerra del Chaco, edited by Carlos Coello Villa and Helio Vera, 11-36. Santiago de Chile: LOM Ediciones. 
Vera, Robustiano. 1930. 'Arqueología Guaraní: El hallazgo de urnas funerárias indígenas', Revista de la Sociedad Científica del Paraguay 2 (6): 274-80.

Vera, Robustiano. 1941. 'Arqueología guaranítica', Revista del Ateneo Paraguayo 1 (2).

Verón, Luis. 2010. La Guerra del Chaco, 1932-1935. Asunción: El Lector.

Viveiros de Castro, Eduardo Batalha. 1998. 'Cosmological Deixis and Amerindian Perspectivism', Journal of the Royal Anthropological Institute 4 (3): 469-88.

Viveiros de Castro, Eduardo Batalha. 2004a. 'Perspectival Anthropology and the Method of Controlled Equivocation', Tipití: Journal of the Society for the Anthropology of Lowland South America 2 (1): 3-22.

Viveiros de Castro, Eduardo Batalha. 2004b. 'Exchanging Perspectives: The Transformation of Objects into Subjects in Amerindian Ontologies', Common Knowledge 10 (3): 463-84.

Von Bremen, Volker. 2008. 'Impactos de la Guerra del Chaco en la territorialidad ayorea'. In Mala guerra: Los indígenas en la Guerra del Chaco (1932-35), edited by Nicolas Richard, 333-54. Asunción: Museo del Barro, ServiLibro and CoLibris.

Webmoor, Timothy and Christopher L. Witmore. 2008. 'Things Are Us! A Commentary on Human/ Things Relations under the Banner of a "Social" Archaeology', Norwegian Archaeological Review 41 (1): 53-70.

Whiston Spirn, Anne. 1998. The Language of Landscape. New Haven: Yale University Press.

White, John W. 1927. 'The Great Mennonite Migration to Paraguay', Bulletin of the Pan American Union 61: 432-42.

Winters, Harold A., Gerald E. Galloway, William J. Reynolds and David W. Rhyne. 2001a. Battling the Elements: Weather and Terrain in the Conduct of War. Baltimore: Johns Hopkins University Press.

Winters, Harold A., Gerald E. Galloway, William J. Reynolds and David W. Rhyne. 2001b. 'Forests and Jungles: The Wilderness and the Ia Drang Valley'. In Battling the Elements: Weather and Terrain in the Conduct of War, by Harold A. Winters, Gerald E. Galloway, William J. Reynolds and David W. Rhyne, 97-111. Baltimore: Johns Hopkins University Press.

Winterton, Melanie. 2012. 'Signs, Signals and Senses: The Soldier Body in the Trenches'. In Beyond the Dead Horizon: Studies in Modern Conflict Archaeology, edited by Nicholas J. Saunders, 229-41. Oxford: Oxbow Books.

Witmore, Christopher L. 2007. 'Symmetrical Archaeology: Excerpts of a Manifesto', World Archaeology 39 (4): 546-62.

Woodward, Rachel. 2004. Military Geographies. Malden, MA: Blackwell.

Woodward, Rachel. 2005. 'From Military Geography to Militarism's Geographies: Disciplinary Engagements with the Geographies of Militarism and Military Activities', Progress in Human Geography 29 (6): 718-40.

Yablon, Nick. 2009. Untimely Ruins: An Archaeology of American Urban Modernity, 1819-1919. Chicago: University of Chicago Press.

Ziegler, Philip. 2017. Between the Wars. London: MacLehose Press.

Zook, David H. 1960. The Conduct of the Chaco War. New Haven: Bookman Associates.

Zotti, Aníbal. 1974. Siempre vivos: Memorias de un ex-combatiente de la Guerra del Chaco. Asunción: Imprenta Militar de la Dirección de Publicaciones de las FF.AA. de la Nación. 


\section{Index}

afterlives 180

agency, forms of 1-2

Amazon region 19, 29

American Civil War 80

Amerindian myths 112

ancestral spirits 112

Anthropocene epoch 4-7, 23, 58, 116, 182;

beginning and end of 5

anthropology 32

Appadurai, Arjun 13

archaeology: definition of 1 ; as a discipline 11 ; of heritage and as heritage 24; surfacesurvey approach to 117

archaeological approach to war studies 25-6, $52,122,179,181$

archives 25-6, 92, 121-2

Argentina 31, 44, 56

Armistice Day celebrations 136

Armstrong-Vickers (company) 42

Asociación Cultural Arandú 11

assemblages 1-2, 23, 177, 181

Ayoreo mythology 113-16

Barad, Karen 4

barefoot soldiers 45-6, 79

battlefields, study of 13, 82, 121

'being in the world' 16

Belaieff, Juan 32-3, 49, 54, 63-4, 74, 119, 153

Bender, Barbara 20, 160, 162

Benítez, Justo Pastor 56, 140-1

Benítez Alvarenga, Derlis 63, 84

Benítez de Casanova, Ruth Alison 151, 171

Beurier, Joëlle 158

biblical connotations 18

birdsong 82

Blaser, Mario 2, 64, 87, 110

Boidin, Capucine 54

Bolivia 9, 31-4, 40-52, 56-7, 165, 178

Bolivian troops $41-4,47,56,59-63,68-71$, 74, 78-80, 85-7, 89-91, 95, 103-5, 117, 144-7, 151-5, 179

Bonneuil, Christophe 6

Boquerón, Battle of (1932) 43, 143, 147, 164

Bórmida, Marcelo 14, 25, 112

bottle tree 66-7, 76

Brady, Lisa 157

Brantz, Dorothee 21

Brinckerhoff Jackson, John 20

Buchli, Victor 77
Buenos Aires peace conference and treaty (1938) 9, 51

Bustamante Rodríguez, Ladislao 32, 63, 68, 79, 130

Canada 35-8

Capdevila, Luc 30, 45, 47, 54-7

caraguatá plant 64

Casado family and company $37-8,48,54$, 123-7, 131

cash crops 31

casualties of the Chaco War 9

Catholic Church 85

cemeteries and war graves 123, 128, 135, 138-9, 146-7, 166, 170-1

Céspedes, Augusto 62, 71, 78-82, 86, 88, 98, 146-7, 158, 162

Chaco region 8-9; geography, climate, flora and fauna 28-9, 32, 117; impact of warfare on 157-8; map of 8 ; origin of the name 59

Chaco War (1932-5) 1, 28, 45, 88, 125, 127, 151, 155; causes of 48; characteristics shared with the Western Front in the First World War 9; concise history of 47-52; continuing impact of 24; detritus from 156-9; heavy reliance on local resources 160 ; historiography of 52-6; legacies of 171-2, 180; main categories of site 123, 161; main individual sites 123-60; meaning and significance of 164,181 ; Mennonites' role in 39-41, 115; neglect of archaeological sites from 117, 122; physical and conceptual persistence of 120-1; studied through material remains 160

Chaves, F.C. 40

Chesterton, Bridget María 45, 54-5

Chortitzer Ldta 171

Christianity and the Christian life 3 , 90-3, 104

coca leaf 85-6, 179

code talking 33

Colonia Fernheim 38, 90-3, 166

Colonia Menno 38, 92, 109

Colonia Neuland 38, 111

colonialism 18, 34, 59-60; definition of 47

colonisation $36,91,161$

commemorative occasions 165-6 
conflict archaeologies and conflict heritage studies 180-2

conflict landscapes 3, 16-19, 27, 162; other than battlefields 26-7; visiting of 22

conscription 35

Cooney, Jerry W. 45

Coote, Jeremy 97, 127

Cristaldo, Carlos 156

critical archaeology 162

critical heritage studies 117

Cuártel de la Victoria 25

Dalla-Corte Caballero, Gabriela 54

'dark heritage' 1

Das, Santanu 20, 81

de la Cadena, Marisol 2

de la Pedraja 55

de Quesada, Alejandro 55, 155

death, 'white' and 'red' 70, 73, 88

dehydration 70-1, 81

Descola, Philippe 65

deserts, different views of 19

detentions under authoritarian regimes 12

Dirección de Reparación 12

disease 70, 91

documentation on archaeological sites, lack of

$$
121-2,160
$$

drought $60,73,76$

Duguid, Julian 29

‘dwelling perspective' (Ingold) 16, 64

Edensor, Tim 95, 142

'emptiness', myth of 18

Engen, Fred 36-7, 59-60

English, Adrian J. 29

environmental impacts 6

Ern, Nicolás 153

Escobar, Ticio 19, 25, 65

Espínola, Jenaro 155

Estigarribia, José Félix 10-11, 44, 50-3, 123-7, 135-7, 163, 165

exhumations 181

explorers 96

Farcau, Bruce 55, 140, 144, 153

Fast, Hans 132, 141, 143

'fieldcraft' 17

First World War 9, 20-1, 41, 44, 51, 63, 66, 70, $81,97,103-4,158,160$

Florentín, Heriberto 120-1

food shortages and sources 68-71

forest, mysteriousness of 158

Fortín Boquerón 118, 143-50

Fortín Gondra 166-9

Fortín Isla Po'í 118, 125, 130, 133-9, 171

Fortín Nanawa 24, 99, 118, 151-60, 170-1, 180

Fortín Toledo 118, 139-43

fortínes (in general) 118-21, 133-61

Franco, Federico 171

Fressoz, Jean-Baptiste 6

Friesen, Martin W. 41

galletas 69

Gaona, Silvio 54

la Generación del Chaco 53
Germany 38-9

global warming 6

Gondra, Manuel 36

González-Ruibal, Alfredo 95, 116, 122, 155, 161-2

Gordillo, Gastón 121, 156-7

Gwynn, Walter 135, 137

Hagedorn, Dan 54

Haraway, Donna 4

Harder-Horst, René 30

Harman, Graham 178

Harrison, Rodney 24-5, 127

heritage: making of 24; narrower and broader senses of 7; natural and cultivated 15

heritage studies 15

'heritagisation' 24, 101, 161, 171

Hernando, Almudena 116

Hobsbawm, Eric 177

homesickness 105

Howes, David 21, 78

Hughes, Matthew 55

human and non-human entities, study of 19 , $63,65,80,112,115,161,178-80$

human bodies, research on 16, 26

human impact on planetary systems 4

hunger $68-70$

hyperobjects $3-4,6-7,27,58,88,160-1$, $170-3,177-8,182$

indigenous beliefs and practices 3

indigenous groups 18-19, 23, 28, 30-4, 39, $47,59-60,64-5,74-6,96,179$

indigenous knowledge $32,58,179$

industrialised warfare $1,9,17,20-3,26-7$, $41,58,65,77-8,81-2,86-7,89,93-7$, 103-5, 145-6, 149-50, 155, 172-3, $180-2$

Ingold, Tim 16-19, 79-80

iron, sources of 114

Isaenko, Anatoly V. 54

Jowett, Philip 55, 155

Kamp areas 36-7

Klassen, Paulhans 54

Klassen, Peter P. 49, 54

Km 145 site 118, 125, 130-3, 161

Koloniehaus museum, Filadelfia 108, 174-5

Korean Moon sect 126

Kuletz, Valerie 19

Kundt, Hans 42-3, 50-1, 154-5

Lambert, Peter 55

landscape: definition of 16; engagement with 20,22 ; reshaping of $66,95,119$; see also conflict landscapes; militarisation

language 30-5

Latour, Bruno 13-14

Law, John 2

League of Nations 50

lifeworlds 2-3, 56-8, 61, 64, 116

Loomba, Ania 47

MacClancy, Jeremy 24

machetes 63-4 
Macias, Silvio 70

McRoberts, Samuel 36-8

marginalised communities 181

mass graves 12, 168, 177

material culture, engagement with $2-4,15$, $23-7,110,113,116,122,163$

Melgarejo, Juan E. 54

Mendoza, Hugo 53

Menno Simons 34

Mennonite settlers in the Chaco 9, 28, 34-41, 56, 58-60, 64-6, 76, 87, 89-96, 107, 110, $125,130,161,178-9$; role in the Chaco War 39-41, 115

Merewether, Charles 160

metal items/materials 95-6, 110-11, 115-16

Mexico 35

migration $31,35,76$

militarisation 16-17, 33, 42, 64-5, 91, 115, $120,160-2$

military-industrial complex 172

military outposts 48-50, 96, 107, 118, 130, 140, 154, 161; see also fortínes

mind/matter dualism 19, 112

missionary activity 96

Mojoli, Anibal 156

Morales, Edmundo 86

Morales, Evo 52

Morton, Chris 127

Morton, Timothy 3, 6, 172, 177

Moshenska, Gabriel 94, 122, 143

multinaturalism 2

museums 165

Nanawa, First and Second Battles of (1933) $50-1,153,155$

nationalism 103

nature 18-19; reclaiming the landscape 161 ; seen as hostile or alien 83, 87, 179; seen as something to be enjoyed 132; 'social' relations with 64

Neruda, Pablo 174

Nicholson, Julia 127

Nickson, Andrew 55

Nobbs-Thiessen, Ben 55

nostalgia 5

'note' system 92

nuclear technologies 5-6

objectification theory (Tilley) 13-15

Olivier, Laurent 160

Olsen, Bjørnar 1, 160

'one-world' concept 2-3

ontology 2, 15, 23, 66, 116, 179

palo santo tree 65

Paniagua, Felino 98, 101

Panteón de los Héroes 165

Paraguay 9, 31-42, 45-52, 56-7, 164-5, 178

Paraguayan troops 44-7, 56, 59, 62-3, 68, 71-4, 77-82, 85-7, 89-96, 99, 103-7, 117-19, 135, 140, 144-7, 150-5, 163, $166,171,179$

Pearson, Mike 21

pen friends 104

Peñaranda, General 51
Peru 42

Pinney, Christopher 14

Platt, David 115

'pluriverse' 2

Politis, Gustavo 116

Pollard, Tony 13

pozos indios 60

protection of heritage 122, 180

Puerto Casado 10, 37-8, 96, 118, 123-30, 161

qualitative research methods 23, 178

Querejazu Calvo, Roberto 42, 53-4

railway lines 119, 124-33, 161

Rathje, William L. 115

Ratzlaff, Gerhard 40, 54

recycling 89-90, 96-7, 110-11, 115, 163, $176-7,181$

Reinland 173

Reno, Joshua 96

Renshaw, John 76

Richard, Nicolas 54

Roa Bastos, Augusto 53, 70-2

romanticisation $18,65,103-7$

Romero, Genaro 40

Rose, Gillian 17

Roth, Michael 143

'ruinscapes' 161-2

Russell, Edmund 17

Russia 38-41

Salón de Bronce, Asunción 163-4

Sapienza, Antonio Luis 54

Sarmiento, Emilio 43, 82-3

Saunders, Nicholas 7, 96-7, 101, 105, 115

Scheina, Robert L. 55

Schofield, John 16

'scorched earth' policies 6

Second World War 33

Secretaría Nacional de Cultura 170

Seiferheld, Alfredo 53

'sensescapes' (Howes) 21

sensing the Chaco 78-87

sensorial experience and awareness 20, 22, 58, 78-9, 82-3, 88, 177

Serres, Michel 13

sexual abuse 33

Shanks, Michael 21, 115

Shell Oil 174-6

'shell sense' 20

Shively Meier, Kathryn 80

silver mining 61-2

Sluyter, Andrew 18

Smith, Mark M. 53

'social' relations 19, 64

soldiers: fraternisation between the two sides 145-7; receptivity of 20; see also Bolivian troops; Paraguayan troops

Sosa, Estela Mary 54

souvenirs of war 69

Soviet Union 41; see also Russia

Stahl, Wilmar 25, 64

Standard Oil (company) 48, 174-5 
Summerfield, Chantal 159

symmetrical archaeology 14-15

tank warfare 155-6

tereré 84-6, 179

'terrain and tactics' approach 17, 162

thirst 70-1, 74, 78-81,

$$
\text { 84, 87-8 }
$$

Tilley, Christopher 13-14, 20,

$$
\text { 61, } 63
$$

time, concept of 3

tombstones 145

trading activities 93-4, 115

Trans-Chaco Highway 10

Trébol cemetery 166-7

trees 65-6, 83, 120, 158-60

trench art 89, 96-107, 110-16

trench remains $143,147-8$,

$$
\text { 151-2 }
$$

trench warfare 21,89

Troxler, Heinrich 130

Tucker, Richard P. 17

unknown soldier, tomb

$$
\text { of the } 163
$$

Vera, Helio 78

Verón, Luis 53

veterans 28
Villamontes 164

Viveiros de Castro, Eduardo 2, 172

war memorials $123,128,135,143,150-1$, $154,160,164-5$

War of the Triple Alliance (1864-70) 13, 37, $45,48,50,105,124,165$

warfare: between indigenous populations 31 ; impact of 5-6

wasteland 87

water, scarcity of $49,72-81,84,87-8$

Wiebe, Heinz 147, 149

'wilderness' concept 18-19, 31-2, 48, 59, 119, 128,178

Witmore, Christopher 14-15

wood, types of 120

Woodward, Rachel 17, 64

world-making (and unmaking) 22-3, 64, 95, 116,179

worlding practices $2,4,25-6,116,178-81$

worldviews 3, 25

yerba mate 83-4

Ypres 160

yvy'á 76-7

Zook, David 50, 55, 71

Zotti, Anibal 68, 70, 76, 80-4, 105, 128-30 
'The war, as Breithoff eloquently proves, was much more than a conflict between nations: it was a war of worlds at the end of the world, a clash of divergent ontologies that has had myriad iterations ever since... Through her rich exploration of violence and its afterlife, Breithoff reinvents conflict archaeology and the study of negative heritage. This fascinating book will remain a landmark in those fields for many years.' - Alfredo Conzález-Ruibal, Spanish National Research Council (CSIC)

Conflict, Heritage and World-Making in the Chaco documents and interprets the physical remains and afterlives of the Chaco War (1932-35) - known as South America's first 'modern' armed conflict - in what is now present-day Paraguay. It focuses not only on archaeological remains as conventionally understood, but takes an ontological approach to heterogeneous assemblages of objects, texts, practices and landscapes shaped by industrial war and people's past and present engagements with them. These assemblages could be understood to constitute a 'dark heritage', the debris of a failed modernity. Yet it is clear that they are not simply dead memorials to this bloody war, but have been, and continue to be active in making, unmaking and remaking worlds - both for the participants and spectators of the war itself, as well as those who continue to occupy and live amongst the vast accretions of war matériel which persist in the present.

Framing the study as an exploration of modern, industrialised warfare as Anthropocene 'hyperobject' (Morton 2013), this book shows how the material culture and heritage of modern conflict fuse together objects, people and landscapes, connecting them physically and conceptually across vast, almost unimaginable distances and time periods. It makes a major contribution to key debates in anthropology, archaeology, environmental humanities, critical heritage and material culture studies on the significance of conflict in understanding the Anthropocene, and the roles played by its persistent heritages in assembling worlds.

Esther Breithoff is Lecturer in Contemporary Archaeology and Heritage in the Department of History, Classics and Archaeology at Birkbeck, University of London, and UKRI Future Leaders Fellow.

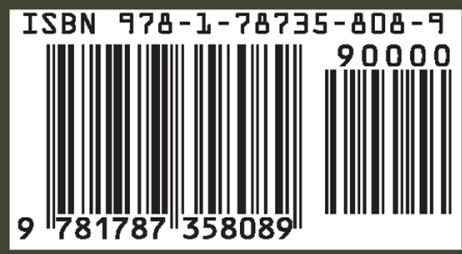

